ANA CAROLINA NICOLOSI DA ROCHA GRACIOSO

Avaliação da influência de emoções na tomada de decisão de sistemas computacionais 

ANA CAROLINA NICOLOSI DA ROCHA GRACIOSO

Avaliação da influência de emoções na tomada de decisão de sistemas computacionais

Tese apresentada à Escola Politécnica de São Paulo da Universidade de São Paulo, como parte dos requisitos para obtenção do título de Doutor em Ciências. 

ANA CAROLINA NICOLOSI DA ROCHA GRACIOSO

\section{Avaliação da influência de emoções na tomada de decisão de sistemas computacionais}

Tese apresentada à Escola Politécnica de São Paulo da Universidade de São Paulo, como parte dos requisitos para obtenção do título de Doutor em Ciências.

Área de Concentração: Engenharia de Sistemas Eletrônicos

Orientador: Prof. Livre-Docente Francisco Javier Ramirez Fernandez. 
Este exemplar foi revisado e corrigido em relação à versão original, sob responsabilidade única do autor e com a anuência de seu orientador.

São Paulo, 16 de maio de 2016.

Assinatura do autor:

Assinatura do orientador:

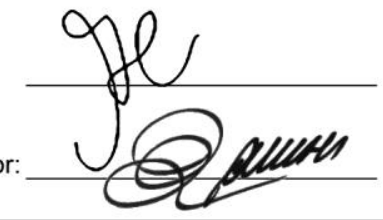

Catalogação-na-publicação

Gracioso, Ana Carolina Nicolosi da

Avaliação da influência de emoções na tomada de decisão de sistemas computacionais / A. C. N. Gracioso -- versão corr. -- São Paulo, 2016.

$225 \mathrm{p}$.

Tese (Doutorado) - Escola Politécnica da Universidade de São Paulo. Departamento de Engenharia de Sistemas Eletrônicos.

1.Computação Afetiva 2.Computação Assistiva 3.FACS 4.Reconhecimento de Emoções 5.Computação Aplicada I.Universidade de São Paulo. Escola Politécnica. Departamento de Engenharia de Sistemas Eletrônicos II.t. 
Dedico este trabalho ao Diogo, aluno do CEU de Osasco, portador de Paralisia Cerebral, e à Denise, paciente do Hospital das Clínicas de São Paulo, em estado de consciência mínima, que nos deixaram depois de inspirar esta pesquisa.

Obrigada aos dois pela oportunidade de conhecê-los e por tudo que me ensinaram. 



\section{AGRADECIMENTOS}

trabalho.

Primeiramente, e acima de tudo, agradeço a Deus por me capacitar na elaboração deste

Agradeço a minha família pelo apoio e pela compreensão durante os momentos em que estive ausente do convívio familiar. Em especial, agradeço ao meu marido Luciano Gracioso e ao meu filho Ariel da Rocha Gracioso. Sem o apoio de vocês, eu não teria conseguido.

Agradeço ao professor Francisco Javier Ramirez Fernandez pela orientação, ao professor Gerson Ballester pelas orientações referentes à parte neurológica deste trabalho, e ao professor Adilson Gonzaga por me socorrer nos momentos de maior desespero.

Agradeço ao aluno Doriedson Galdino pela implementação de parte do módulo afetivo no início do projeto, e aos alunos Cibele Ribeiro e David Rissardo pela elaboração da base de dados utilizada para os testes de emoções espontâneas. Aos alunos Anderson Diana, Daniella Sousa, Thiago Brandão e Vânia Angelotti por desenvolverem o sistema administrativo que gera as pranchas de comunicação, e à Terapeuta Ocupacional Aline Medina por suas preciosas contribuições na elaboração desta fase do trabalho.

Agradeço à empresa Inter-telco, em especial à sócia-proprietária Cláudia Botero, pelo apoio ao projeto. Obrigada Claudia por me receber não só na sua empresa, mas também em sua casa para a finalização da implementação de todos os códigos.

Agradeço à APAE de Presidente Prudente por permitir e por apoiar os testes realizados com deficientes. Obrigada à coordenadora Cristiane Godoy dos Santos, às professora e aos demais profissionais envolvidos. Obrigada aos pais dos alunos e, em especial, aos alunos.

Por fim, agradeço a todas as pessoas que participaram como voluntárias dos testes deste trabalho. 

O rosto é o retrato da alma.

(Marcus Tullius Cicero - 106A.C a 46A.C.) 



\section{RESUMO}

Este trabalho avalia a influência das emoções humanas expressas pela mímica da face na tomada de decisão de sistemas computacionais, com o objetivo de melhorar a experiência do usuário. Para isso, foram desenvolvidos três módulos: o primeiro trata-se de um sistema de computação assistiva - uma prancha de comunicação alternativa e ampliada em versão digital. O segundo módulo, aqui denominado Módulo Afetivo, trata-se de um sistema de computação afetiva que, por meio de Visão Computacional, capta a mímica da face do usuário e classifica seu estado emocional. Este segundo módulo foi implementado em duas etapas, as duas inspiradas no Sistema de Codificação de Ações Faciais (FACS), que identifica expressões faciais com base no sistema cognitivo humano. Na primeira etapa, o Módulo Afetivo realiza a inferência dos estados emocionais básicos: felicidade, surpresa, raiva, medo, tristeza, aversão e, ainda, o estado neutro. Segundo a maioria dos pesquisadores da área, as emoções básicas são inatas e universais, o que torna o módulo afetivo generalizável a qualquer população. Os testes realizados com o modelo proposto apresentaram resultados $10,9 \%$ acima dos resultados que usam metodologias semelhantes. Também foram realizadas análises de emoções espontâneas, e os resultados computacionais aproximam-se da taxa de acerto dos seres humanos. Na segunda etapa do desenvolvimento do Módulo Afetivo, o objetivo foi identificar expressões faciais que refletem a insatisfação ou a dificuldade de uma pessoa durante o uso de sistemas computacionais. Assim, o primeiro modelo do Módulo Afetivo foi ajustado para este fim. Por fim, foi desenvolvido um Módulo de Tomada de Decisão que recebe informações do Módulo Afetivo e faz intervenções no Sistema Computacional. Parâmetros como tamanho do ícone, arraste convertido em clique e velocidade de varredura são alterados em tempo real pelo Módulo de Tomada de Decisão no sistema computacional assistivo, de acordo com as informações geradas pelo Módulo Afetivo. Como o Módulo Afetivo não possui uma etapa de treinamento para inferência do estado emocional, foi proposto um algoritmo de face neutra para resolver o problema da inicialização com faces contendo emoções. Também foi proposto, neste trabalho, a divisão dos sinais faciais rápidos entre sinais de linha base (tique e outros ruídos na movimentação da face que não se tratam de sinais emocionais) e sinais emocionais. Os resultados dos Estudos de Caso realizados com os alunos da APAE de Presidente Prudente demonstraram que é possível melhorar a experiência do usuário, configurando um sistema computacional com informações emocionais expressas pela mímica da face.

Palavras-chave: Computação Afetiva. Computação Assistiva. FACS. Reconhecimento de Emoções. 



\begin{abstract}
The influence of human emotions expressed by facial mimics in decision-taking of computer systems is analyzed to improve user's experience. Three modules were developed: the first module comprises a system of assistive computation - a digital alternative and amplified communication board. The second module, called the Affective Module, is a system of affective computation which, through a Computational Vision, retrieves the user's facial mimic and classifies their emotional state. The second module was implemented in two stages derived from the Facial Action Codification System (FACS) which identifies facial expressions based on the human cognitive system. In the first stage, the Affective Module infers the basic emotional stages, namely, happiness, surprise, anger, fear, sadness, disgust, and the neutral state. According to most researchers, basic emotions are innate and universal. Thus, the affective module is common to any population. Tests undertaken with the suggested model provided results which were $10.9 \%$ above those that employ similar methodologies. Spontaneous emotions were also undertaken and computer results were close to human score rates. The second stage for the development of the Affective Module, facial expressions that reflect dissatisfaction or difficulties during the use of computer systems were identified. The first model of the Affective Module was adjusted to this end. A Decision-taking Module which receives information from the Affective Module and intervenes in the Computer System was developed. Parameters such as icon size, draw transformed into a click, and scanning speed are changed in real time by the Decision-taking Module in the assistive computer system, following information by the Affective Module. Since the Affective Module does not have a training stage to infer the emotional stage, a neutral face algorithm has been suggested to solve the problem of initialing with emotion-featuring faces. Current assay also suggests the distinction between quick facial signals among the base signs (a click or any other sound in the face movement which is not an emotional sign) and emotional signs. Results from Case Studies with APAE children in Presidente Prudente SP Brazil showed that user's experience may be improved through a computer system with emotional information expressed by facial mimics.
\end{abstract}

Keywords: Affective Computing. Assistive Computing. FACS. Emotion Recognition. 



\section{LISTA DE ILUSTRAÇÕES}

Figura do capítulo 1

Figura 1.1 - Módulos computacionais que compõem o modelo proposto nesta tese. 28

Figuras do capítulo 2

Figura 2.1 - Duchenne e um de seus pacientes. 36

Figura 2.2 - A. Frontal: músculo da atenção. B. Orbicular do olho (parte palpebral): músculo da reflexão. C e D. Pálpebra superior e pálpebra inferior: músculo do desprezo e complementar do choro. E. Orbicular do olho (parte inferior): músculo da benevolência e complementar da alegria. F. Zigomático menor: músculo do choro moderado e dor. G. Levantador do lábio superior: músculo do choro. $\mathrm{H}$. Levantador do ângulo da boca: músculo do "choramingo". I. Zigomático maior: músculo da alegria. L. Orbicular da boca. M. Depressor do ângulo da boca: músculo da tristeza e complementar da paixão agressiva. O. Corrugador do supercílio: músculo da angústia. P. Prócero: músculo da agressão. Q. Nasal: músculo da lascívia. R. Alar: músculo complementar da expressão de paixão. U. Bucinador: músculo da ironia. X. Depressor do lábio inferior: músculo complementar da ironia e da agressão. Y. Platisma: músculo do susto e complementar da raiva.

Figura 2.3 - Áreas faciais utilizadas no manual FACS.

Figura 2.4 - Músculos da região superior da face. (a) Anatomia muscular. (b) Ação muscular.

Figura 2.5 - Músculos da região inferior da face. (a) Anatomia muscular. (b) Ação muscular.

Figura 2.6 - Modelo bidimensional afetivo.

Figura 2.7 - Roda Emocional de Plutchik. (a) Modelo em três dimensões. (b) Modelo em duas dimensões.

Figuras do capítulo 3

Figura 3.1 - Avatar reproduzindo uma emoção do usuário. .51

Figura 3.2 - Utilização de simulcam por meio de controladores de movimentos

Figura 3.3 - Avatar animado em tempo real, a partir do software de monitoramento em tempo real.

Figura 3.4 - Exemplo do ambiente Second Life. .53

Figuras do capítulo 4

Figura 4.1 - Cartões de comunicação. 66

Figura 4.2 - Prancha de comunicação com símbolos, fotos ou figuras. 67

Figura 4.3 - Prancha de comunicação alfabética 
Figura 4.4 - História Carol for Christmas contada com o sistema de símbolos Rebus 69

Figura 4.5 - Símbolos Bliss Pictogramas. .......................................................................... 70

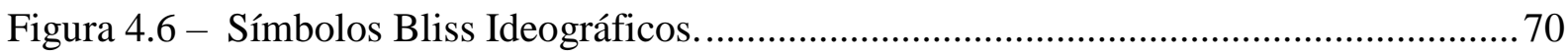

Figura 4.7 - Símbolos Bliss combinados para criar significados adicionais........................... 70

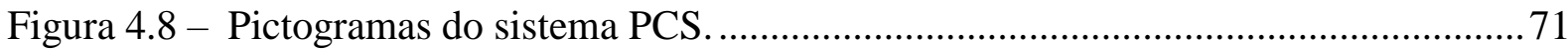

Figuras do capítulo 5

Figura 5.1- Exemplo para cálculos da imagem integral..................................................... 77

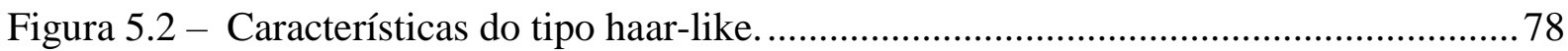

Figura 5.3 - Estrutura do detector em cascata proposto por Viola-Jones. ..............................79

Figura 5.4 - Fluxo óptico piramidal de Lucas-Kanade. ............................................................ 86

Figuras do capítulo 6

Figura 6.1- Mapa do site do sistema administrativo da prancha de comunicação................. 94

Figura 6.2 - Etapas de desenvolvimento do Módulo Afetivo para as duas versões................95

Figura 6.3 - Poses comuns de pessoas ao utilizar o computador. ......................................... 96

Figura 6.4 - (a) Pontos de referência retornados pela biblioteca clmtrackr. (b) Pontos de referência calculados a partir dos pontos retornados pela biblioteca que representam o modelo proposto neste trabalho...............................................99

Figura 6.5 - Range de direções consideradas para cada ponto............................................. 98

Figura 6.6 - Fluxograma do algoritmo de cálculo do vetor face neutra................................ 99

Figura 6.7 - Diversos tipos de aparência da boca durante a raiva....................................... 104

Figura 6.8 - (a) Imagem de face neutra marcada com pontos de referência. (b) Imagem com expressão de raiva marcada com pontos de referência. (c) Sobreposição das imagens 6.7 a e $6.7 \mathrm{~b}$ que permite identificar as direções de movimentação dos pontos de referência.

Tabela 6.5 - Pontos de referência e respectivas direções para as expressões faciais de insatisfação (I).

Figura 6.9 - Exemplo de sequência de imagens da base de dados $\mathrm{CK}+$. O primeiro quadro da segunda linha representa uma emoção com intensidade média, e o último quadro da última linha representa uma emoção com intensidade máxima. ..................114

Figura 6.10 - Imagens nas quais esperava-se a expressão de aversão. .................................116

Figura 6.11 - Prancha utilizada nos testes com usuários sem deficiência. ............................ 119

Figura 6.12 - Capa acrílica desenvolvida para os testes com alunos da APAE.....................122

Figuras do capítulo 7

Figura 7.1 - Resultados dos testes do modelo proposto usando a base de dados KDEF. ..... 132 
Figura 7.2 - Resultados dos testes do algoritmo da Sightcorp usando a base de dados KDEF.

Figura 7.3 - Comparação dos testes do modelo proposto versus algoritmo da Sightcorp com a BD KDEF....

Figura 7.4 - Resultados dos testes do modelo proposto usando a base de dados CK+

Figura 7.5 - Resultados dos testes do algoritmo da Sightcorp usando a base de dados CK+ ativação máxima.

Figura 7.6 - Resultados dos testes do algoritmo da Sightcorp usando a base de dados CK+ ativação média.

Figura 7.7 - Comparação dos testes do modelo proposto versus algoritmo da Sightcorp com a $\mathrm{BD} \mathrm{CK}+$

Figura 7.8 - Matriz de confusão dos testes realizados por Jeni et al. (2011) utilizando a base de dados $\mathrm{CK}+$ para treinamento e outra base de dados para teste.

Figura 7.9 - Representação da movimentação da sobrancelha. (a) Expressão neutra. (b) Expressão de surpresa. (c) Expressão de raiva. (d) Expressão de tristeza. ....... 140

Figura 7.10 - Gráfico com linha do tempo do Estudo de Caso 04....................................... 148

Figura 7.11 - Gráfico com linha do tempo do Estudo de Caso 05, primeiro teste................. 149

Figura 7.12 - Gráfico com linha do tempo do Estudo de Caso 05, segundo teste.................150

Figura 7.13 - Gráfico com linha do tempo do Estudo de Caso 07, primeiro teste..................151

Figura 7.14 - Gráfico com Linha do tempo do Estudo de Caso 07, segundo teste................ 152

Figura 7.15 - Gráfico com linha do tempo do Estudo de Caso 07, terceiro teste.................. 152

Figura 7.16 - Gráfico com linha do tempo do Estudo de Caso 08, primeiro teste................. 153

Figura 7.17 - Gráfico com linha do tempo do estudo de Caso 07, segundo teste.................. 154

Figura 7.18 - Gráfico com linha do tempo do Estudo de Caso 09, primeiro teste................. 155

Figura 7. 19 - Gráfico com linha do tempo do Estudo de Caso 09, segundo teste................155 



\section{LISTA DE TABELAS}

Tabelas do capítulo 1

Tabela 2.1 - Descrição das áreas faciais. 38

Tabela 2.2 - Modelo OCC simplificado

Tabela do capítulo 3

Tabela 3.1 - Comparação entre softwares que utilizam o FACS. (1) Método de Extração de Características Faciais. (2) Método de Classificação de Emoções. (3) Fornece API/SDK. (4) Emoções: (F) felicidade, (S) surpresa, (M) medo, (T) tristeza, (R) raiva, (A) aversão, (D) desprezo, (N) neutro. (5) Eficiência de classificação. (6) *1 (NVISO, 2015; SORCI et al., 2010) *2 (EMOTIENT, 2015; LITTLEWORT et al., 2006) 3* (AFFECTIVA, 2015a; AFFECTIVA, 2015b; MCDUFF et al., 2015) *4 (MOORE; ONG; BOWDEN, 2010; KAIROS; 2015) *5 JOHO et al., 2009; SEBE et al., 2006; SIGHTCORP, $2015 * 6$ (JENI et al., 2011;

REALEYESIT, 2015) *7 (NOLDUS, [201?] ; [EWINSKI; UYL; BUTLER, 2014) *8 (DE LA TORRE et al., 2015; INTRAFACE, 2015). * Somente uma API para aplicações on-line que roda diretamente no servidor da empresa. Não é possível baixar a API e integrar com soluções locais off-line.

Tabelas do capítulo 6

Tabela 6.1 - Pontos de referência e respectivas direções para as expressões faciais raiva (R), aversão (A), tristeza (T), medo (M), surpresa (S) e felicidade (F).

Tabela 6.2 - Pontos de referência e respectivas direções para as expressões faciais de valência negativa raiva $(\mathrm{R})$, aversão $(\mathrm{A})$, tristeza $(\mathrm{T})$ e medo $(\mathrm{M})$ (continua). 102

Tabela 6.2 - Pontos de referência e respectivas direções para as expressões faciais de valência negativa raiva (R), aversão (A), tristeza $(\mathrm{T})$ e medo $(\mathrm{M})$ (conclusão). 102

Tabela 6.3 - Pontos de referência e respectivas direções para as expressões faciais raiva (R), aversão (A), tristeza (T), medo (M), surpresa (S) e felicidade (F). Intersecções com fundo vermelho possuem peso 1, verde peso 2, amarelo peso 3 e azul peso 4 .

Tabela 6.4 - Exemplo do sistema de pontuação para inferência do estado emocional. 106

Tabela 6.5 - Pontos de referência e respectivas direções para as expressões faciais de insatisfação (I).

Tabela 6.6 - ...........Parâmetros de configuração inicial do módulo afetivo. P: parâmetro a ser alterado; Q: quantidade de insatisfações aceitáveis; T: janela de tempo; S: sentido da alteração e \% porcentagem da alteração.

Tabela 6.7 - Alunos voluntários da APAE.

Tabela 6.8 - Caracterização das pranchas utilizadas nos testes com os alunos. 121 
Tabelas do capítulo 7

Tabela 7.1 - Dados das situações descritas para as 48 sequências de vídeo cuja emoção inicial não era neutra.

Tabela 7.2 - Testes realizados na primeira edição da sequência dos vídeos dos estudos de caso 2,3 e 4 .

Tabela 7.3 - Categorização das emoções descritas pelos espectadores.

Tabela 7.4 - Matriz de confusão dos testes o modelo proposto versus a opinião dos espectadores.

Tabela 7.5 - Matriz de confusão dos testes o modelo proposto versus a opinião dos espectadores.

Tabela 7.6 - Detalhamento dos estados emocionais classificados na linha "outro" da Tabela 7.4 .

Tabela 7.7 - Matriz de confusão dos testes do modelo proposto versus a opinião dos espectadores para sequências de vídeos engraçados.

Tabela 7.8 - Matriz de confusão dos testes do modelo proposto versus a opinião dos espectadores para sequências de vídeos engraçados.

Tabela 7.9 - Classificação de Emoções de Valência Positiva, Neutra e Negativa.

Tabela 7.10 - Testes da classificação do modelo proposto versus relato do espectador considerando-se a valência das emoções segundo classificação da Tabela 7.9.143

Tabela 7.11 - Testes da classificação do modelo proposto versus relato do espectador considerando-se a valência das emoções segundo classificação da Tabela 7.9.143

Tabela 7.12 - Testes da classificação do modelo proposto versus relato do espectador considerando-se a valência das emoções incluindo surpresa como emoção de valência negativa.

Tabela 7.13 - Classificação de Emoções de Valência Positiva, Neutra e Negativa.

Tabela 7.14 - Testes da classificação do modelo proposto versus relato dos observadores considerando-se a valência das emoções segundo classificação da Tabela 7.13 .

Tabela 7.15 - Testes da classificação do modelo proposto versus relato dos observadores considerando-se a valência das emoções segundo classificação da Tabela 7.13.

Tabela 7.16 - Classificação de emoções de valência Positiva, Neutra e Negativa.

Tabela 7.17 - Testes da classificação relato do espectador versus relato dos observadores considerando-se a valência das emoções segundo classificação da Tabela 7.16 .

Tabela 7.18 - Testes da classificação do relato do espectador versus relato dos observadores considerando-se a valência das emoções segundo classificação da Tabela 7.16 .

Tabela 7.19 - Resumo dos estudos de caso realizados com pessoas sem deficiência. 148

Tabela 7.20 - Resumo dos estudos de caso realizados com pessoas com deficiência. 


\section{LISTA DE ABREVIATURAS E SIGLAS}

\begin{tabular}{|c|c|}
\hline AAM & Appearance Active Model \\
\hline $\mathrm{ACM}$ & Active Contour Models \\
\hline ADA & American with Disabilities Act \\
\hline APAE & Associação de Pais e Amigos dos Excepcionais \\
\hline API & Application Programming Interface \\
\hline ASM & Active Shape Models \\
\hline AU & Action Units \\
\hline $\mathrm{BD}$ & Base de Dados \\
\hline $\mathrm{CA}$ & Computação Afetiva \\
\hline CAA & Comunicação Alternativa e Ampliada \\
\hline $\mathrm{CK}+$ & Cohn-Kanade Dataset \\
\hline CLM & Constrained Local Models \\
\hline CSS & Cascading Style Sheets \\
\hline DCA & Discrete Choice Analysis \\
\hline $\mathrm{DCM}$ & Discrete Choice Models \\
\hline EAD & Educação a Distância \\
\hline EDU & Expression Descriptive Unit \\
\hline $\mathrm{EOH}$ & Edge Orientation Histograms \\
\hline EML & Emotion Markup Language \\
\hline EPFL & École Polytechnique Fédérale de Lausanne \\
\hline FACS & Facial Action Codign System \\
\hline FACSAID & Facial Action Coding System Affect Interpretation Dictionary \\
\hline $\mathrm{HCI}$ & Human-Computer Interaction \\
\hline HCII & Human-Computer Intelligent Interaction \\
\hline HOG & Histograms of Oriented Gradient \\
\hline HMM & Hidden Markov Models \\
\hline HTML & Hyper Text Markup Language \\
\hline IA & Inteligência Artificial \\
\hline IBGE & Instituto Brasileiro de Geografia e Estatística \\
\hline ISLA & Intelligent Systems Lab Amsterdam \\
\hline JPML & Join Path and Multi-label Learning \\
\hline KDEF & The Karolinska Directed Emotional Faces \\
\hline LBP & Local Binary Patterns \\
\hline LK & Algoritmo de Lucas-Kanade \\
\hline OCC & Ortony Clore and Collins \\
\hline PCS & Picture Communication Symbols \\
\hline PBVD & Piecewise Bézier Volume Deformation \\
\hline PCA & Principal Component Analysis \\
\hline PCS & Picture Communication Symbols \\
\hline PDM & Point Distribuition Model \\
\hline PHP & Hypertext Preprocessor \\
\hline
\end{tabular}




$\begin{array}{ll}\text { RB } & \text { Rede Bayesiana } \\ \text { RN } & \text { Redes Neurais } \\ \text { RNA } & \text { Rede Neural Artificial } \\ \text { ROI } & \text { Region of Interest } \\ \text { SDM } & \text { Supervised Descent Method } \\ \text { SDK } & \text { Software Development Kit } \\ \text { SGBD } & \text { Sistema Gerenciador de Banco de Dados } \\ \text { SIFT } & \text { Scale Invariant Feature Transform } \\ \text { STM } & \text { Selective Transfer Machine } \\ \text { SVM } & \text { Support Vector Machine } \\ \text { TTY } & \text { Teletype } \\ \text { UX } & \text { User eXperience. } \\ \text { WebGL } & \text { Web Graphics Library }\end{array}$




\section{SUMÁRIO}

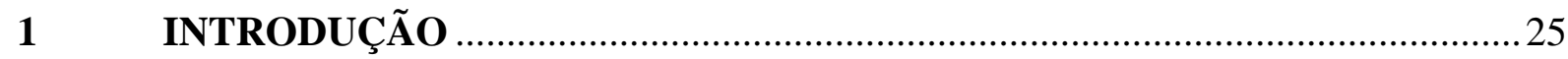

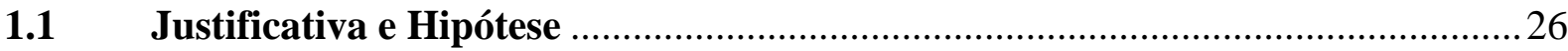

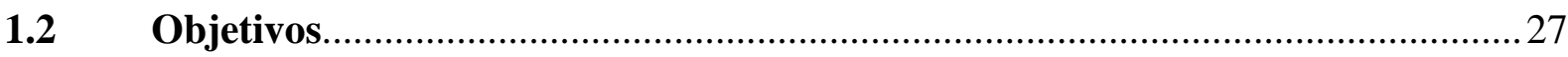

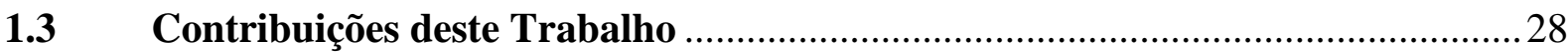

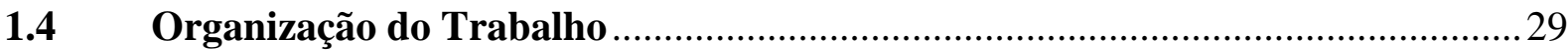

$2 \quad$ EMOÇÕES

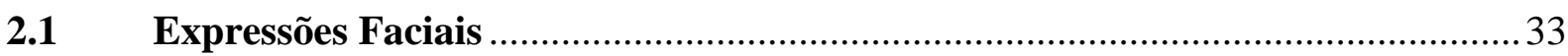

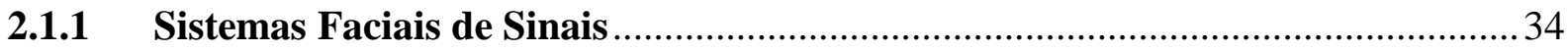

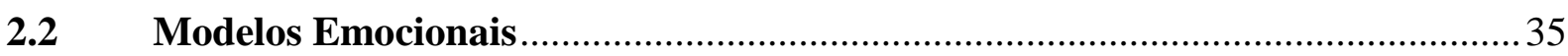

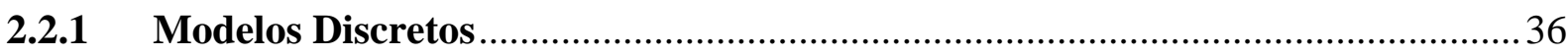

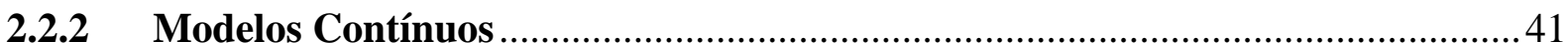

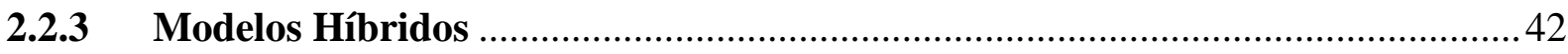

2.2.4 Modelos Baseados em Teorias de Avaliação ………………………………......... 43

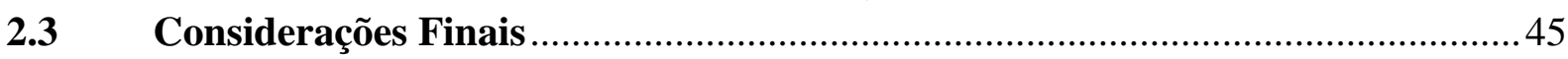

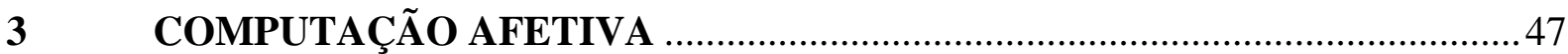

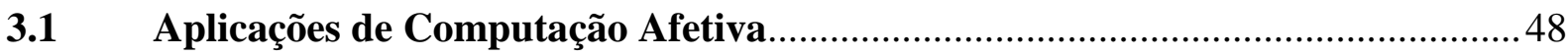

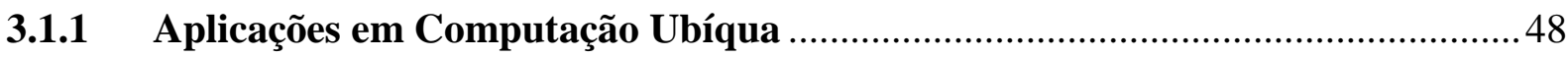

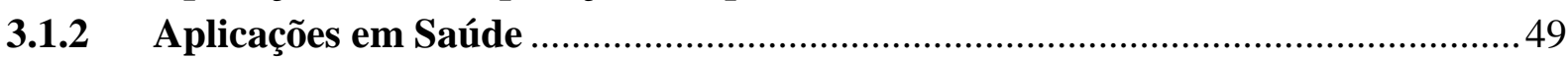

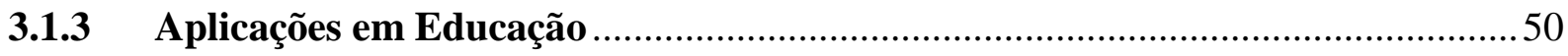

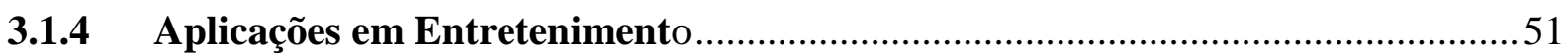

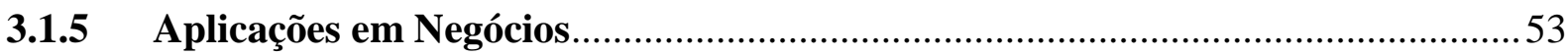

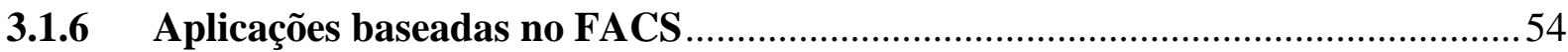

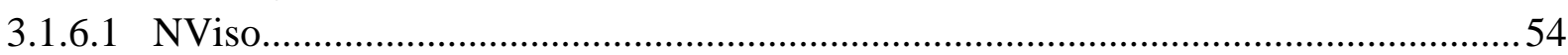

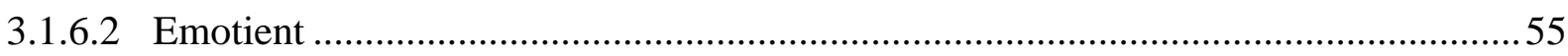

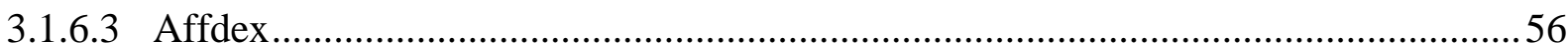

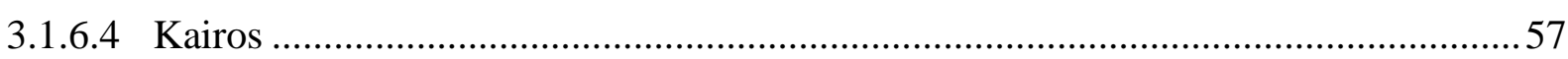

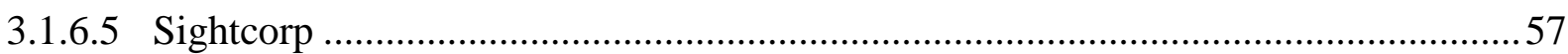

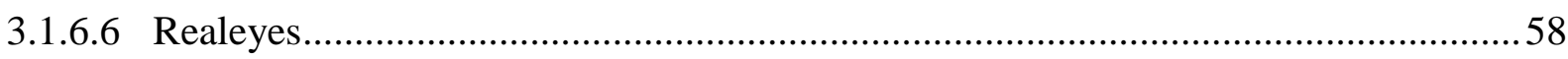

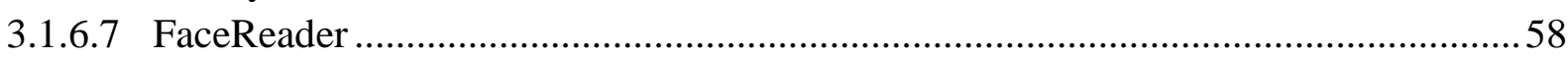

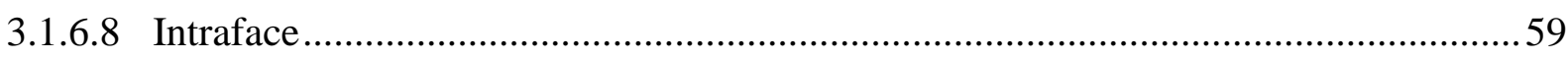

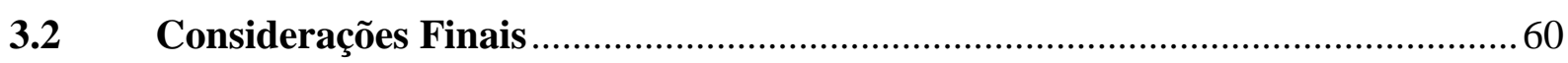

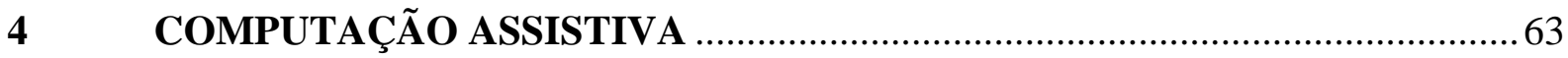

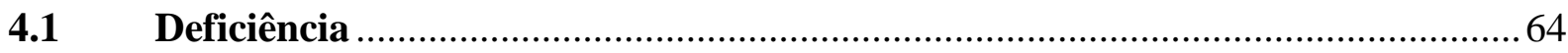

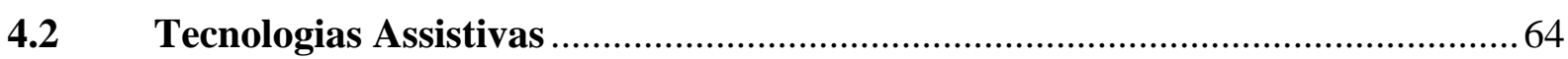

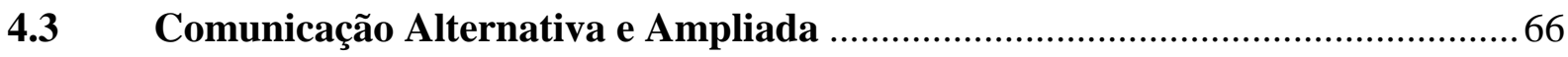

4.3.1 Comunicação Alternativa e Ampliada no Brasil ...................................................67

4.3.2 A Importância da CAA no Ambiente Familiar e Escolar ........................................6

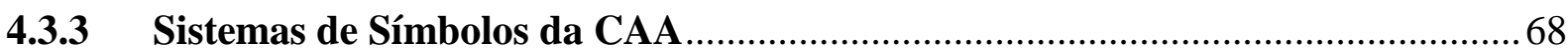




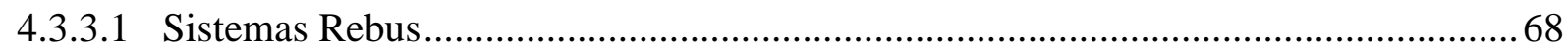

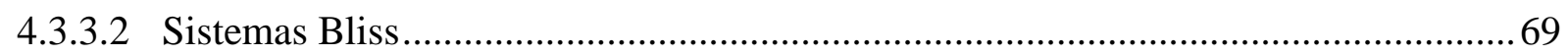

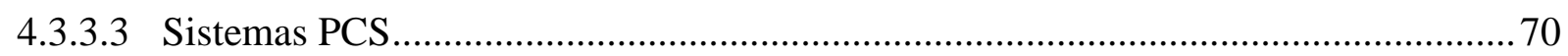

4.4 Softwares de Comunicação Alternativa e Ampliada........................................... 72

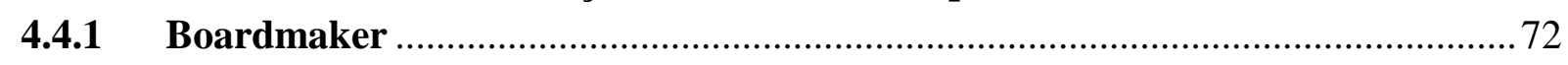

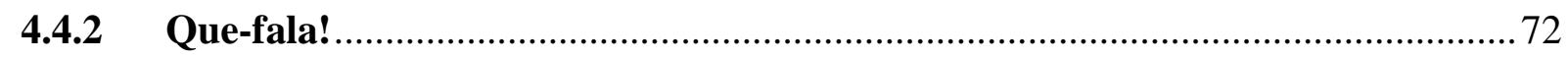

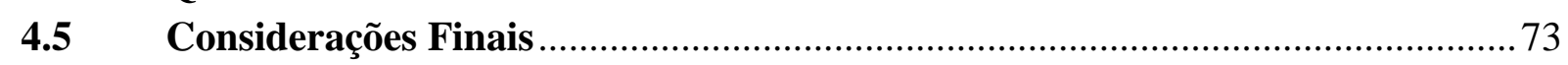

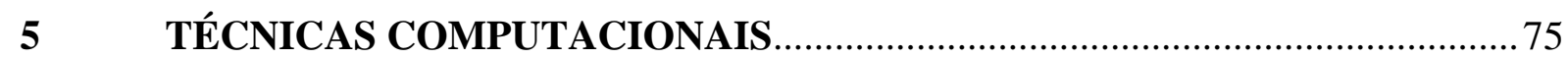

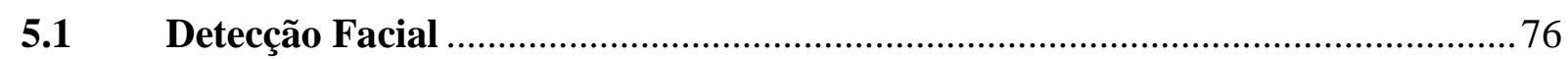

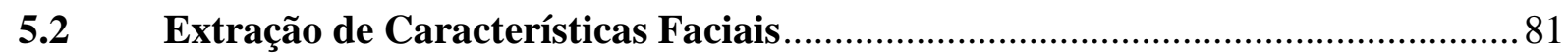

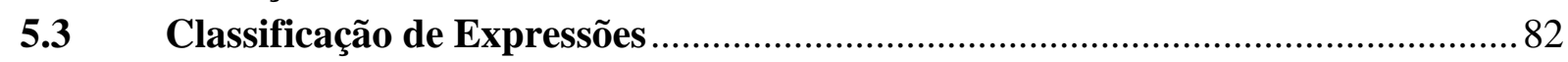

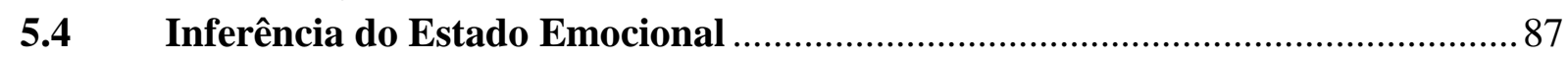

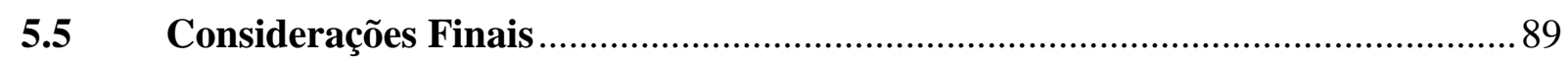

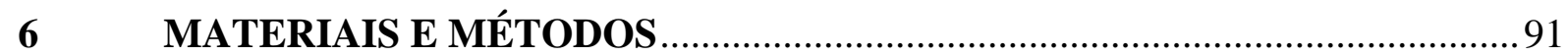

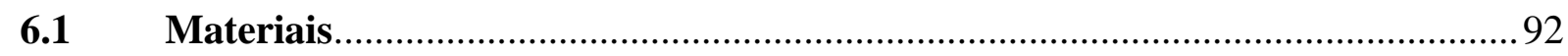

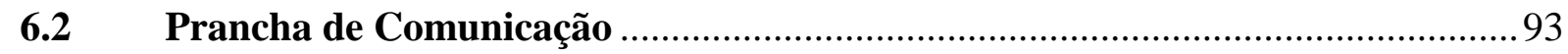

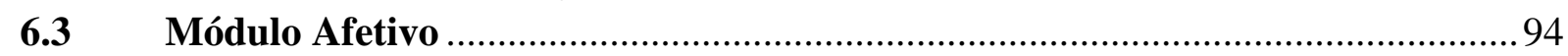

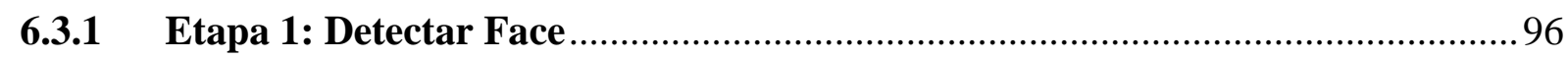

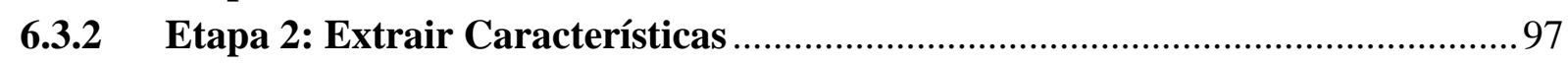

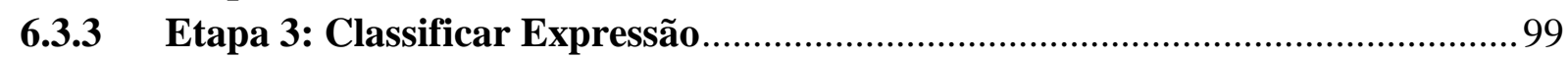

6.3.3.1 Classificar Expressões: Modelo 1 .......................................................................... 100

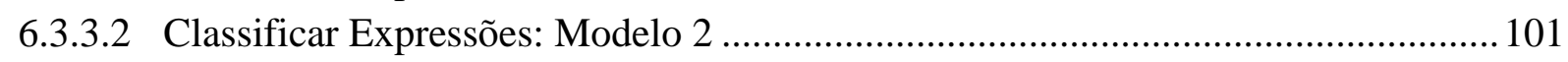

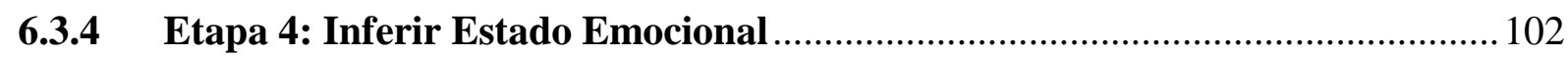

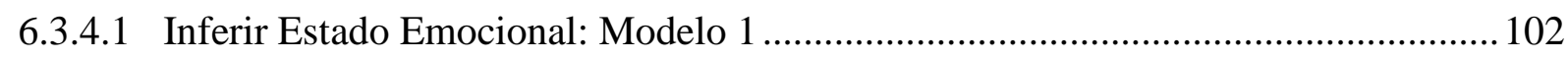

6.3.4.2 Inferir Estado Emocional: Modelo 2 …................................................................... 107

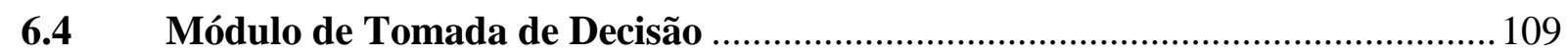

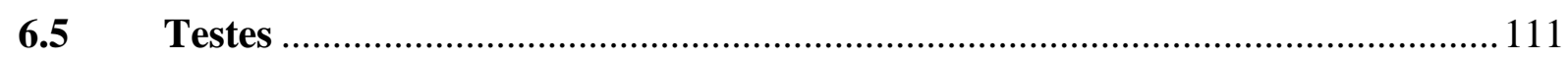

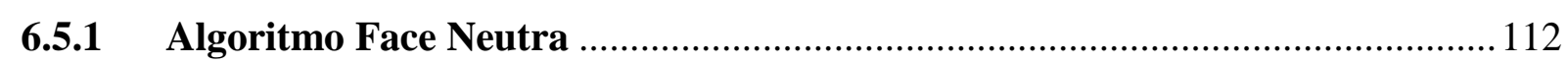

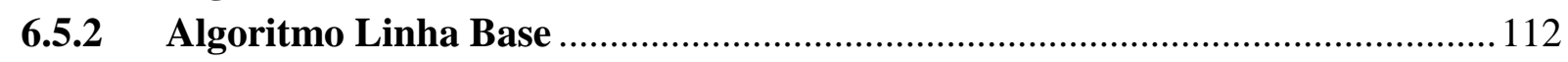

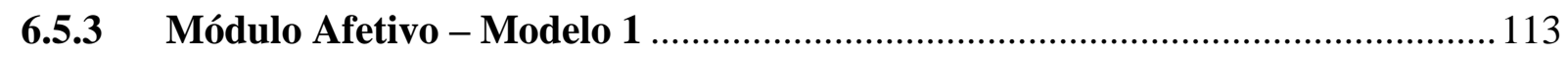

6.5.3.1 Emoções Simuladas........................................................................................... 113

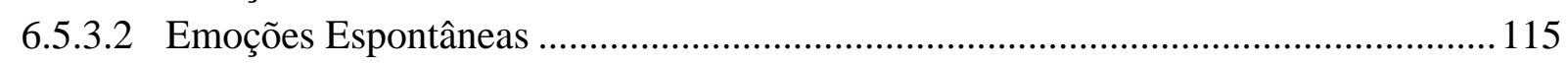

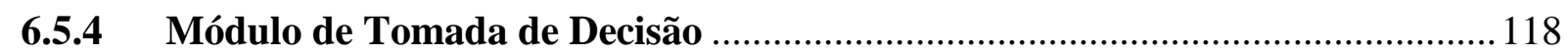

6.5.4.1 Testes com usuários (pessoas sem deficiências) ...................................................... 118

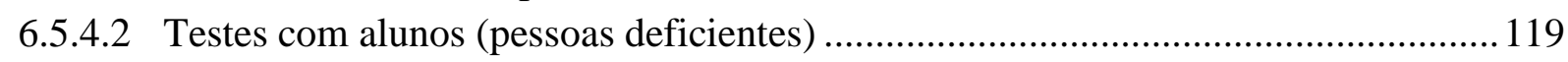

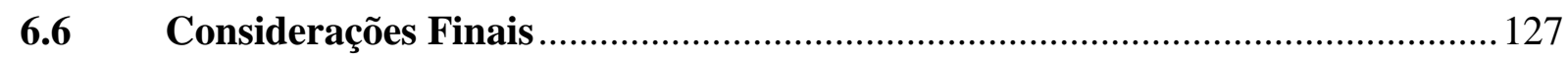

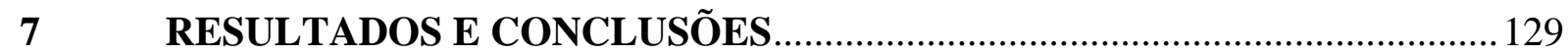

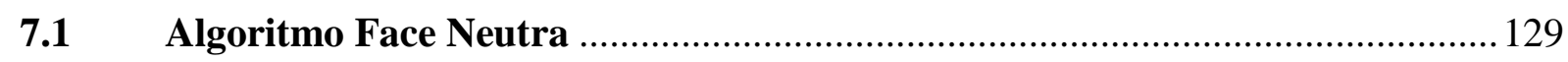

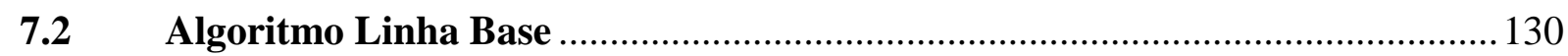

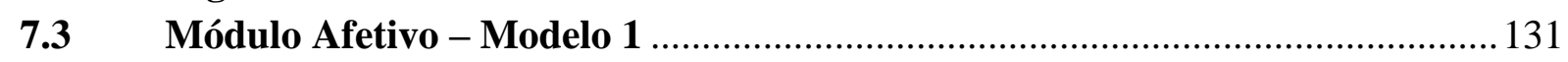

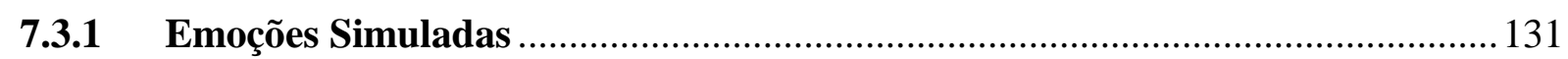




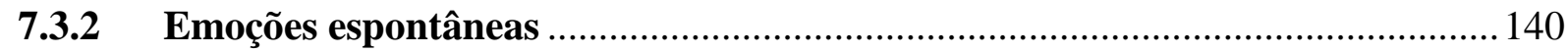

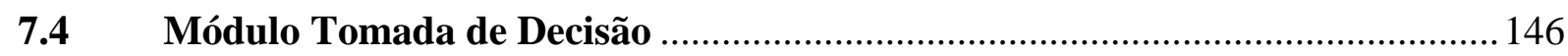

7.4.1 Testes com usuários (pessoas não deficientes) ………………………………....147

7.4.2 Testes com alunos (pessoas deficientes) ……………………………………........ 148

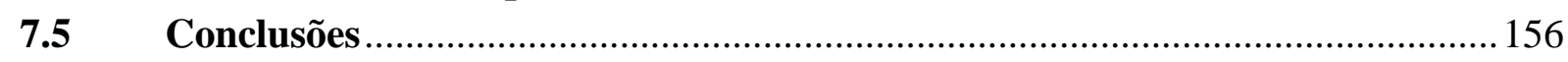

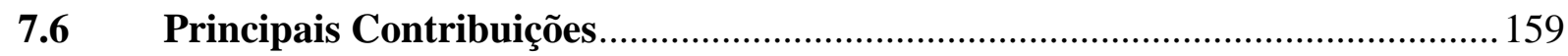

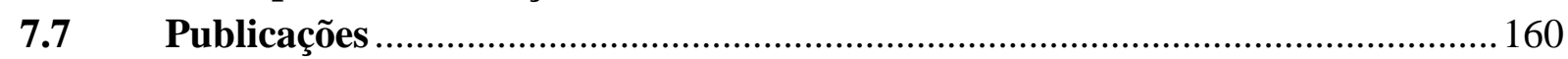

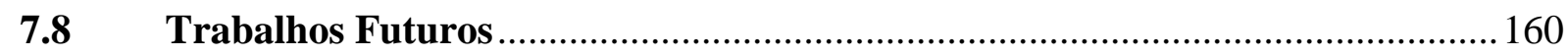

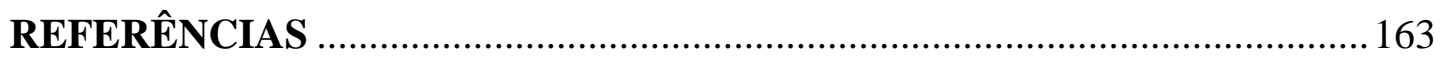

APÊNDICE A - Tabela de AUs..........................................................................179

ANEXO I - Wireframes e Detalhamento das Páginas da Prancha.....................189

ANEXO II - Termo de Autorização de Uso de Imagem ……………………........201

ANEXO III - Termo de Autorização Institucional.............................................203

ANEXO IV - Termo de Consentimento para Uso de Imagem e Voz...................205

ANEXO V - Pranchas de Comunicação ……………………………………….......207

ANEXO VI - Arquivos EML dos Estudos de Caso ……………………............221 



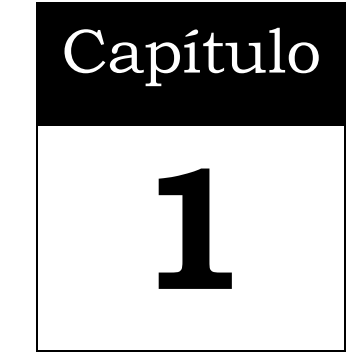

Introdução

A interação social humana se dá, predominantemente, por recursos perceptivos. Por meio da percepção de estímulos do meio externo, é possível processar, de forma mais integrada, as informações que norteiam os comportamentos e as ações das pessoas (SIMÕES; TIEDEMANN, 1985).

A face é o principal foco da comunicação, sendo considerada a região mais expressiva do corpo (GIMENEZ, 2006; OMOTE, 1992). Sua constituição física (dois olhos, um nariz, uma boca) proporciona uma percepção global que, primeiramente, é generalizada, mas, depois, pequenas diferenças proporcionam distinção entre os indivíduos (BRUCE; YOUNG, 1998). Além da função de distinguir indivíduos, também estão presentes na face outras características importantes para a identidade do sujeito, bem como para suas intenções, como o gênero, a idade e as emoções (BRUCE; YONG, 1998; MILLER, 2000), por exemplo.

As expressões faciais na espécie humana evoluíram para uma forma de comunicação não verbal, e muitos estudos têm sido realizados visando elucidar o complexo processamento dos sinais faciais, fruto dessas evoluções (GIMENEZ, 2006).

O estudo das expressões faciais tem levantado interesse desde a Grécia Antiga. Sociólogos e biólogos analisam expressões faciais e argumentam que o rosto é um órgão 
biológico da comunicação, muito importante na interação social humana, e que alguns sinais faciais são inatos e universais (KHAN, 2001).

Além da interação social entre humanos, uma nova forma de comunicação, impulsionada pela era tecnológica em que se insere a sociedade atual, tem se tornado cada vez mais comum: a interação entre humanos e máquinas. Assim como o reconhecimento das emoções foi fundamental no processo evolutivo humano, essa forma de comunicação pode evoluir e ser utilizada para realizar a Interação Humano-Computador (HCI - HumanComputer Interaction). Contudo, ainda é necessário alcançar interpretações mais efetivas. Dessa forma, o uso de informações não verbais apresenta-se como elemento de grande interesse para a evolução de sistemas de HCI.

\subsection{Justificativa e Hipótese}

Nos últimos anos, tem sido crescente o interesse em melhorar a interação entre seres humanos e computadores. Para obter-se uma Interação Humano-Computador Inteligente (HCII - Human-Computer Intelligent Interaction), é necessário que o computador seja capaz de trocar informações naturalmente com o usuário, simulando a comunicação entre humanos (SUN et al., 2004).

Nas interações humanas, a realimentação não verbal fornece importantes informações sobre o estado emocional do indivíduo. As emoções expressadas podem ser reconhecidas na voz, nos gestos e, principalmente, por meio das expressões faciais (EKMAN, 1989). Recentes descobertas da neurociência demonstram o papel fundamental da emoção na manutenção da saúde física e mental dos seres humanos (FRANTZIDIS et al., 2010). Com a tecnologia cada vez mais presente no cotidiano das pessoas, analisar os aspectos emocionais envolvidos na Interação Humano-Computador torna-se cada vez mais importante. Contudo, as atuais ferramentas computacionais existentes para áreas como educação, saúde, entretenimento, negócios, entre outras, apresentam limitações no reconhecimento das emoções humanas, o que empobrece tais interações (CASTELLANO et al., 2009).

A mímica da face é muito pesquisada em trabalhos sobre computação afetiva e bastante utilizada em softwares comerciais que se propõem a inferir o estado emocional dos seres humanos, por meio da análise da movimentação muscular facial. Porém, tais trabalhos não avaliam como as informações extraídas da mímica da face podem influenciar na tomada de decisão de sistemas computacionais, e qual a relevância dessa utilização para a experiência do usuário (UX - User eXperience). 
Observando-se os métodos atuais, não foram localizados artigos que tratam de estudos para avaliar a eficiência das técnicas computacionais de reconhecimento de emoções em pessoas deficientes. Segundo o Relatório Mundial sobre Deficiência, publicado pela Organização Mundial de Saúde em 2011, cerca de 15\% da população mundial possui algum tipo de deficiência. No Brasil, esse número é ainda maior: 23,92\%, segundo dados do último Censo Demográfico, realizado pelo Instituto Brasileiro de Geografia e Estatística (IBGE), em 2010 (IBGE, 2010; OMS, 2011).

Portanto, não se tem conhecimento na literatura científica de qualquer estudo que tenha avaliado como as emoções expressas pela mímica da face pode influenciar no processo de tomada de decisão de sistemas computacionais. Também, não foram localizadas publicações, até a presente data, sobre estudos dessa natureza que sejam aplicados a sistemas computacionais assistivos.

\subsection{Objetivos}

O objetivo precípuo deste trabalho é avaliar a influência das emoções na tomada de decisão de Sistemas Computacionais, demonstrando como a experiência de usuários deficientes pode ser melhorada, a partir do uso de informações afetivas em sistemas computacionais assistivos.

Além disso, este trabalho também objetiva:

Identificar as teorias que estudam a classificação de emoções por meio da análise da movimentação muscular facial.

Propor um modelo de inferência de emoções, baseado em conceitos psicológicos, capaz de identificar as emoções básicas de medo, raiva, felicidade, tristeza, surpresa e aversão, de acordo com a maneira como os seres humanos as interpretam.

Apresentar um modelo de classificação, também baseado em conceitos psicológicos e na maneira como os seres humanos interpretam as emoções, capaz de identificar a insatisfação ou não de pessoas deficientes durante a utilização de sistemas computacionais.

Descrever um sistema de tomada de decisão que tem como base dados de computação afetiva (emoções expressas pela mímica da face).

Implementar um aplicativo de comunicação alternativa e/ou ampliada para deficientes.

Gerar uma base de dados aberta, representativa de uma população, com imagens de vídeo que possam ser utilizadas em outras pesquisas na área de computação afetiva. 
Para isso, foram desenvolvidos os seguintes módulos computacionais ilustrados na Figura 1.1:

A. Prancha de Comunicação - trata-se da versão digital de uma prancha de comunicação alternativa e/ou ampliada para deficientes com dificuldade de comunicação pela fala. Neste estudo, a prancha faz o papel do Sistema Computacional, com o objetivo de melhorar a experiência do usuário.

B. Módulo Afetivo - programa que capta, em tempo real, imagens da webcam e classifica as emoções expressas pela face.

C. Módulo de Tomada de Decisão - programa que, com base nas informações recebidas do Módulo Afetivo, altera as configurações iniciais da Prancha de Comunicação, visando melhorar a experiência do usuário.

Figura 1.1 - Módulos computacionais que compõem o modelo proposto nesta tese.

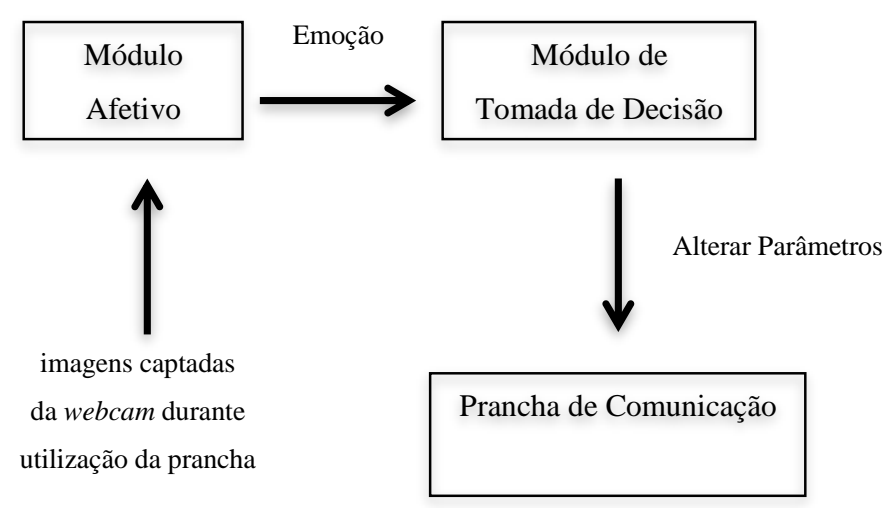

Fonte: Elaboração própria.

\subsection{Contribuições deste Trabalho}

Este trabalho traz as seguintes contribuições:

i. Nova frente de investigação sobre a experiência do usuário em sistemas computacionais dotados da capacidade de identificar emoções e, a partir delas, tomar decisões;

ii. Nova frente de investigação sobre computação afetiva voltada às pessoas deficientes;

iii. Modelagem do reconhecimento de emoções com base nos mecanismos utilizados pelos seres humanos; 
iv. Desenvolvimento de um modelo capaz de reconhecer a face neutra após algumas interações em tempo real, o que permite a utilização em aplicações reais, mesmo quando o algoritmo é iniciado diante de uma face não-neutra;

v. Desenvolvimento de um modelo que identifica emoções negativas e emoções positivas em tempo real, mesmo em pessoas com deficiência, as quais apresentam severos movimentos faciais repetitivos (tiques) que, usualmente, poderiam atrapalhar a classificação das emoções. Na modelagem proposta, esses movimentos, aqui denominados linha-base, são descartados após algumas interações.

vi. Criação de uma base pública de imagens de vídeos com dados em quantidade representativa para pesquisas na área de computação afetiva, com emoções expressas tanto de forma simulada quanto de forma espontânea;

vii. Disseminação da utilização do padrão EML (Emotion Markup Language) na representação de dados afetivos.

\subsection{Organização do Trabalho}

Este trabalho está dividido em 5 capítulos, incluindo a presente introdução, organizados da seguinte forma:

Capítulo 2 - Emoções. Nesse capítulo, são discutidos os conceitos psicológicos a respeito das emoções humanas relevantes para esta tese.

Capítulo 3 - Computação Afetiva. Nesse capítulo, são apresentados as definições sobre computação afetiva e os exemplos de aplicações nessa área de conhecimento.

Capítulo 4 - Computação Assistiva. São apresentadas definições sobre os temas tecnologia assistiva e deficiência relevantes ao estudo neste capítulo.

Capítulo 5 - Técnicas Computacionais. As técnicas computacionais e os trabalhos relevantes na área de reconhecimento de emoções que serviram de motivação para esta pesquisa são avaliados.

Capítulo 6 - Materiais e Métodos. A abordagem proposta, seu desenvolvimento e as implementações necessárias para avaliar a influência das emoções na tomada de decisão de sistemas computacionais são discutidos.

Capítulo 7 - Resultados e Conclusões. Os resultados obtidos, bem como a comparação com técnicas já conhecidas para a classificação de emoções, são apresentados. 


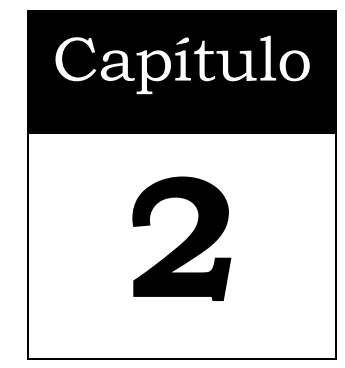

\section{Emoções}

A atividade humana é influenciada significativamente pelas emoções. Tudo que tem relevância na existência humana - a política, a religião, as artes, os esportes, a família, o nascimento, a morte - é marcado pela força do sentir (MARTINS, 2004).

O interesse pelo entendimento das emoções humanas é verificado na dita sabedoria popular desde os tempos mais antigos. Contudo, o estudo das emoções foi negligenciado por um bom tempo (OATLEY; JENKINS, 2002). Mesmo após a publicação de Charles Bell, em 1806, do trabalho Anatomia e fisiologia da expressão (BELL, 1865), que inclui uma descrição gráfica de todas as emoções e lança as fundações do tema enquanto ciência (DARWIN, 1872), durante muito tempo alguns autores sustentaram que a palavra "emoção" não possuía uma definição (SIVIERO, 2004), e a crença de que os sentimentos humanos estavam além do alcance da ciência foi bastante difundida (MARTINS, 2004).

Atualmente, existem várias linhas de pensamento acerca das emoções em abordagens que são complementares. Darwin, James e Freud formaram o primeiro grupo que estabeleceu a compreensão das emoções nas ciências biológicas e sociais. A abordagem biológica de Charles Darwin descreve que as emoções possuem funções na nossa sobrevivência e explicam as expressões emocionais na evolução humana. Para James (1884, p. 190-191), que descreveu 
a abordagem corporal, “[...] as mudanças corporais seguem diretamente a percepção do fato excitante[...] e do sentimento das mesmas mudanças à medida que ocorrem, É a emoção.”. Sigmund Freud, em sua abordagem psicoterapêutica, propôs três teorias: a teoria dos traumas emocionais, a teoria dos conflitos internos e a teoria da compulsão à repetição (OATLEY; JENKINS, 2002).

Ainda que considerados os fundadores do estudo das emoções, Darwin, James e Freud não foram os primeiros a pensar sobre o tema. Reflexões acerca das emoções podem ser encontradas em documentos mais antigos. Segundo a abordagem conceitual, a perspectiva de Aristóteles sobre esse tema consistia em considerar que as emoções estão ligadas à ação e derivam daquilo em que se acredita. A abordagem filosófica de René Descartes e Baruch de Spinoza ocupa-se em dar explicações para a natureza dos seres humanos, assim como um entendimento sobre as emoções. Descartes analisa as emoções em relação às suas bases neurofisiológicas, e apresenta seis emoções fundamentais - o espanto, o desejo, a alegria, o amor, o ódio e a tristeza -, examinando seus aspectos corporais, além de demonstrar como as seis emoções fundamentais se combinam para produzir emoções individuais distintas, como o orgulho, a esperança, o desdém, o medo, o ciúme, o remorso, a inveja, etc. (OATLEY; JENKINS, 2002).

Outro ponto de discussão relevante abordado na literatura é se as emoções humanas são inatas ou aprendidas durante os processos de interação social. A primeira vertente - de que as emoções são inatas - é defendida pelos teóricos evolucionários e serve de base para os estudos de diversos autores (EKMAN, 1994; NEESE, 1990; TOOBY; COSMIDES, 1990; TOMKINS, 2008). Em contraponto, apresenta-se uma abordagem sócio-construtivista (AVERILL, 1980; ORTONY; TURNER, 1990; RATNER, 1989), defendendo que a influência social molda a capacidade de resposta emocional, o que justificaria as distinções de expressões emocionais em diferentes culturas (FRAGOPANAGOS; TAYLOR, 2005; GRIFFITHS, 2002).

De fato, várias maneiras dos seres humanos se expressarem, se comunicarem, assim como as maneiras como interpretarem determinadas mímicas faciais (felicidade, aversão, surpresa, raiva, tristeza e medo) não são específicas da cultura, e sim inatas e universais, como documentado por Darwin (1872) e confirmado por diversos autores (KHAN, 2001).

Estudos apontam que recém-nascidos demonstram preferência em olhar fixamente para faces humanas, em detrimento de outros objetos, corroborando a ideia de que os mecanismos de identificação do padrão facial humano são inatos (BRUCE; YOUNG, 1998; GLEITMAN; REISBERG; GROSS, 2009). Segundo neuropsicólogos e neuroanatomistas, a 
capacidade humana de reconhecer e decodificar as expressões faciais de forma inata e intuitiva se deve à existência de vias neuronais dedicadas a essa tarefa (TOVEE, 1998). A complexidade do processamento dos sinais faciais e sua decodificação sugerem que tal processo seja de grande importância para a sobrevivência das espécies. De uma perspectiva evolutiva, um ser humano incapaz de reconhecer uma expressão facial de raiva e de respondêla apropriadamente pode ter sido eliminado do conjunto genético, cada vez mais cedo, do que aquele que conseguiu identificar a raiva e lutar ou fugir (DARWIN, 1861).

Matsumoto e Willingham (2006) analisaram as emoções expressas por atletas durante os Jogos Olímpicos e Paraolímpicos de 2004, e concluíram que as expressões de felicidade na vitória e de tristeza na derrota eram sempre as mesmas, considerando-se inclusive atletas cegos.

\subsection{Expressões Faciais}

O estudo para classificar as emoções por meio das expressões faciais pode fornecer informações sobre o estado afetivo do indivíduo, incluindo tanto emoções momentâneas, como a felicidade e o medo, quanto emoções mais duradouras, como o humor, a euforia e a irritabilidade. Informações sobre a atividade cognitiva (perplexidade, tédio e concentração), a personalidade (sociabilidade, hostilidade ou timidez), a veracidade (pistas de quando as informações sobre os planos ou ações fornecidas nas palavras são falsas) e a psicopatologia (depressão, mania, esquizofrenia e outros transtornos) também podem ser fornecidas pelo estudo da mímica da face (EKMAN et al., 1993).

Em pesquisa básica sobre o cérebro, as expressões faciais podem identificar quando processos mentais específicos estão ocorrendo. Contudo, tecnologias de imagem (por exemplo, Ressonância Magnética ou Tomografia por Emissão de Pósitrons) são muito onerosas e praticamente inviáveis para um monitoramento contínuo. Assim, o estudo das emoções por meio das expressões faciais apresenta-se como uma alternativa viável para pesquisas médicas aplicadas (EKMAN et al., 1993).

$\mathrm{Na}$ educação, as expressões faciais do professor podem influenciar no processo de aprendizagem dos alunos. Já as expressões faciais do aluno podem informar ao professor sobre a necessidade de ajustar a forma como é oferecido o conteúdo. Em contextos de justiça penal, expressões faciais desempenham um papel crucial em estabelecer ou não credibilidade. Nos negócios, as expressões faciais são importantes tanto nas negociações quanto nas decisões pessoais. Na medicina, as expressões faciais podem ser úteis em estudos do sistema 
nervoso autônomo e do estado psicológico do paciente. Nas relações internacionais, a análise de expressões faciais de líderes mundiais pode ser usada para avaliar a confiabilidade e a alteração do estado emocional. Na Interação Humano-Computador, expressões faciais podem fornecer uma maneira de comunicar informações básicas sobre as necessidades das pessoas e as demandas computacionais (EKMAN et al., 1993).

\subsubsection{Sistemas Faciais de Sinais}

Segundo Ekman (1978), o rosto transmite informações por meio de quatro classes de sinais. Os sinais faciais estáticos representam características relativamente permanentes da face, tais como a estrutura óssea e as massas de tecido mole, que contribuem para a aparência de um indivíduo. Os sinais faciais lentos ou brandos representam as mudanças na aparência da face que ocorrem gradualmente ao longo do tempo, tais como o surgimento de rugas permanentes e alterações na textura da pele. Os sinais faciais artificiais representam traços do rosto determinados artificialmente, como os óculos e os cosméticos. Já os sinais faciais rápidos ou imediatos representam mudanças na atividade física neuromuscular que levam a alterações visualmente detectáveis na aparência facial. Os sinais faciais rápidos são relevantes para estudos sobre as emoções e o estado cognitivo de um indivíduo, sendo que as outras três classes representam ruídos de fundo em tais estudos.

Os movimentos dos músculos faciais puxam a pele temporariamente, distorcendo a forma dos olhos, sobrancelhas e lábios, levando ao aparecimento de rugas, sulcos e protuberâncias em partes diferentes da pele. As alterações geradas pela atividade muscular facial geralmente são breves, durando alguns segundos. Essas alterações raramente ultrapassam o tempo de 5 segundos, ou são inferiores a 250 milissegundos, exceto em casos de crise ou patologias (EKMAN, 1978).

A terminologia mais útil para descrever ou medir ações faciais refere-se ao sistema de produção - a atividade de músculos específicos. Esses músculos podem ser designados pelos seus nomes latinos ou por um sistema numérico. Um nível de descrição alternativo envolve termos como sorrir, sorriso, olhar severo, etc. que são imprecisos, ignorando as diferenças entre uma variedade de diferentes ações musculares, o que gera inferências sobre o significado ou a mensagem que elas podem transmitir (EKMAN, 1978).

Um sistema de sinal facial deve medir os sinais faciais rápidos, baseados, principalmente, em ações musculares. Mas, isso não é necessariamente uma tarefa simples. Por exemplo, é possível construir, utilizando-se manuais de referência, uma tabela de direção 
na qual as sobrancelhas se movem durante a movimentação de diferentes músculos que ocorrem em diferentes emoções. Entretanto, nenhum marcador facial eficiente iria basear a marcação apenas nesse critério, porque muitas outras mudanças devem ser consideradas. Portanto, um sistema de medição com base em descrições de como certas características se modificam quando músculos particulares se movem seria impreciso. Pode-se construir um sistema de medição por meio de sinais faciais para os músculos específicos, entretanto essas medidas deveriam ser validadas como relevantes para a emoção, separadamente do trabalho que validou a relação de ações musculares à emoção. A melhor maneira de construir um sistema de medição computacional é entender as técnicas para medir comportamentos faciais, incluindo aquelas que os humanos usam em seu dia a dia (EKMAN, 1978).

\subsection{Modelos Emocionais}

Segundo Figueira (2011), a emoção é um impulso neural que move nosso organismo para a ação em um estado psicofisiológico. Dentre as diversas teorias propostas acerca das emoções humanas, as mais difundidas e apresentadas na literatura são as de James-Lange, propondo que um indivíduo, após perceber um estímulo que o afeta, sofre alterações fisiológicas (se alguém chora então está triste); e a de Cannon-Bard, defendendo que ao ser exposto a certo estímulo, esse mesmo estímulo conduz o indivíduo a um sentimento, por exemplo o medo, o qual, então, causa a reação física (se alguém está triste, então chora). James-Papers demonstra que a emoção não é uma função de centros cerebrais específicos, e sim um circuito com quatro estruturas básicas interconectadas. Paul MacLean, concordando com as descobertas de Papers, criou a denominação sistema límbico, acrescentando novas estruturas ao mesmo (DALGLEISH, 2004).

Assim como não existe uma teoria única sobre as emoções, a literatura sobre neurociência e ciência cognitiva também apresenta vários modelos que descrevem como o ser humano percebe as emoções, são os chamados Modelos Emocionais. Entre eles, podemos citar os modelos discretos, baseados em teorias cognitivas, e os modelos contínuos, baseados em teorias dimensionais. Os modelos discretos agrupam rótulos semelhantes sob uma mesma categoria emocional, enquanto os modelos contínuos também descrevem a relação entre as categorias (MARTINEZ; DU, 2012). Existem também os modelos híbridos, que definem um conjunto de emoções discretas e as mapeiam em um espaço dimensional contínuo (GOCKLEY; SIMMONS; FORLIZZI, 2006). 


\subsubsection{Modelos Discretos}

O modelo discreto proposto por Tomkins (2008) baseia-se no trabalho sobre a anatomia da face, publicado em 1862 por Duchenne, intitulado Mécanisme de la physionomie humaine, ou Analyse electro-physiologique de I'expression des passions. Duchenne apresenta um atlas que contém ilustrações do movimento muscular facial quando estimulados eletronicamente (Figura 2.1). A Figura 2.2 ilustra alguns músculos descritos no atlas, com suas respectivas emoções associadas (DUCHENNE, 1876; TOMKINS, 2008).

Figura 2.1 - Duchenne e um de seus pacientes.

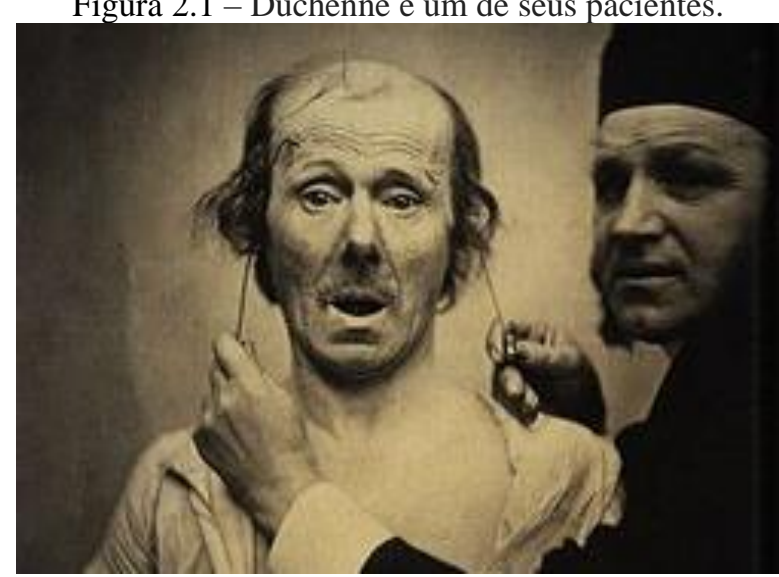

Fonte: Adaptado de Wikimedia Commons (2005).

Figura 2.2 - A. Frontal: músculo da atenção. B. Orbicular do olho (parte palpebral): músculo da reflexão. C e D. Pálpebra superior e pálpebra inferior: músculo do desprezo e complementar do choro. E. Orbicular do olho (parte inferior): músculo da benevolência e complementar da alegria. F. Zigomático menor: músculo do choro moderado e dor. G. Levantador do lábio superior: músculo do choro. H. Levantador do ângulo da boca: músculo do "choramingo". I. Zigomático maior: músculo da alegria. L. Orbicular da boca. M. Depressor do ângulo da boca: músculo da tristeza e complementar da paixão agressiva. O. Corrugador do supercílio: músculo da angústia. P. Prócero: músculo da agressão. Q. Nasal: músculo da lascívia. R. Alar: músculo complementar da expressão de paixão. U. Bucinador: músculo da ironia. X. Depressor do lábio inferior: músculo complementar da ironia e da agressão. Y. Platisma: músculo do susto e complementar da raiva.

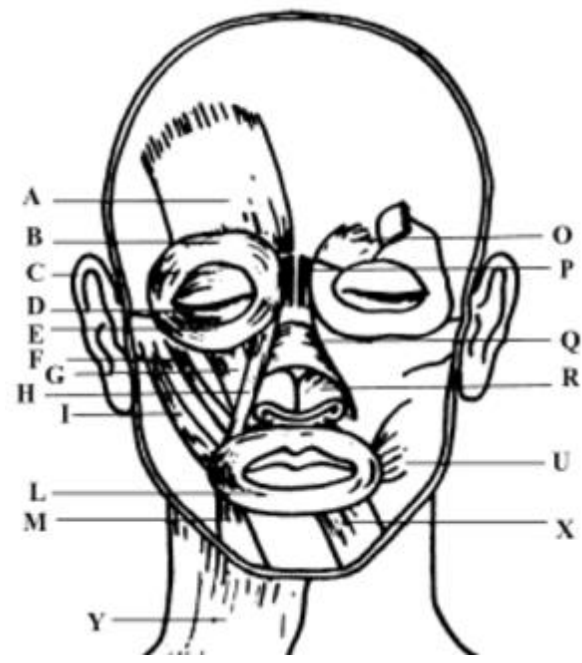

Fonte: Duchenne (1876) e Tomkins (2008). 
Tomkins (2008) conclui que há oito emoções básicas, inatas e universais: surpresasusto, aflição-angústia, raiva-ira, gozo-alegria, interesse-excitação, medo-terror, vergonhahumilhação e aversão (subdividida em dois tipos: aversão ao sabor e aversão ao cheiro), que geram experiências corporais distintas, refletidas, entre outros, na mímica da face. Segundo o autor, as emoções básicas podem ser agrupadas em: positivas: gozo-alegria e interesseexcitação; negativas: medo-terror, aflição-angústia, raiva-ira, vergonha-humilhação e aversão a sabores e cheiros; neutro: surpresa-susto (TOMKINS, 2008).

O gozo-alegria leva o ser humano ao outro, de maneira a formar ligações de vantagem mútua. Já o interesse-excitação impulsiona novas experiências, leva à compreensão do mundo e suas regras. As emoções negativas submetem a experiências ruins, cada uma de forma diferente, por isso elas são evitadas. Já a surpresa-susto assume uma posição neutra, deixando o ser humano atento ao próximo estímulo (TOMKINS, 2008).

A pesquisa de Tomkins inspirou e serviu de base para o modelo discreto mais difundido até hoje, o FACS (Facial Action Codign System) proposto por Ekman e Frisen (1978). O FACS é um sistema de codificação para as expressões faciais que determina como a contração muscular facial - isoladamente e em combinação com outros músculos - muda a aparência do rosto. Analisando-se diversas filmagens de expressões faciais, foram identificadas as mudanças específicas que ocorrem com contrações musculares, e definidas as formas de diferenciá-las. O objetivo dos estudos de Ekman e Frisen (1978) foi criar uma maneira de categorizar, por meio de índices, o comportamento facial humano. O Manual FACS foi publicado pela primeira vez em 1978 (EKMAN; FRIESEN, 1978; HAGER; EKMAN, 1983; HAGER, 2011).

A Figura 2.3 ilustra algumas características da face utilizadas no manual FACS, que são explicadas na Tabela 2.1 .

Figura 2.3 - Áreas faciais utilizadas no manual FACS.

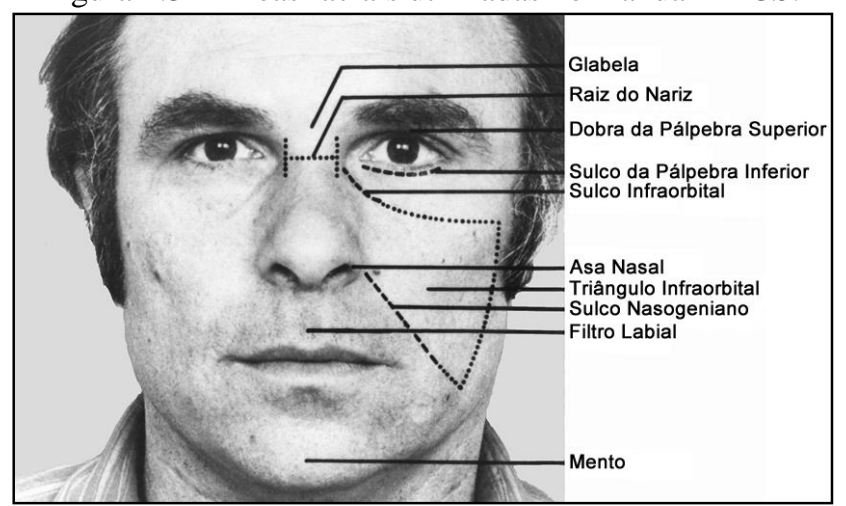

Fonte: Adaptado de Ekman e Friesen (1978). 
Tabela 2.1 - Descrição das áreas faciais.

\begin{tabular}{ll}
\hline \multicolumn{1}{c}{ Áreas Faciais } & \multicolumn{1}{c}{ Descrição } \\
\hline Glabela & Espaço compreendido entre as sobrancelhas. \\
\hline Raiz do Nariz & O início do nariz entre os olhos. \\
\hline Dobra da Pálpebra Superior & Localizada entre a sobrancelha e a pálpebra. \\
\hline Sulco da Pálpebra Inferior & Linha abaixo da pálpebra inferior. \\
\hline Sulco Infraorbital & Linha do canto interno do olho à lateral da bochecha. \\
\hline Asa Nasal & Parte externa da narina. \\
\hline Triângulo Infraorbital & Pele que cobre a bochecha. \\
\hline Sulco Nasogeniano & Linha da base da asa nasal até o canto da boca. \\
\hline Filtro Labial & Depressão acima do lábio superior. \\
\hline Mento & Pele que cobre o osso do queixo. \\
\hline
\end{tabular}

Fonte: Adaptado de Ekman e Friesen (1978).

No FACS, a movimentação muscular facial é descrita como um conjunto de Unidades de Ação (AU - Action Units), que representa a atividade muscular que produz alterações momentâneas na aparência facial.

As unidades de medida FACS são as AUs e não os músculos, pois os músculos faciais foram identificados e nomeados por anatomistas, e não por psicólogos comportamentais. Isso implica que, para algumas aparências, mais de um músculo foi combinado em uma única $A U$, porque as mudanças na aparência que eles produzem não podem ser distinguidas. Além disso, as mudanças na aparência produzidas por um músculo, por vezes, foram separadas em duas ou mais AUs para representar ações relativamente independentes de diferentes partes do músculo (HAGER; EKMAN, 1983; HAGER, 2011).

O FACS é composto por 46 AUs que se dividem em duas regiões faciais: superior, contendo olhos, sobrancelhas e testa (Figura 2.4); e inferior, onde são consideradas as bochechas, queixo, nariz e boca (Figura 2.5). Além das 46 AUs, no manual FACS estão descritos outros códigos que auxiliam e complementam essas ações, organizados em relação à movimentação da cabeça, movimentação dos olhos, visibilidade das características faciais e comportamentos. A lista com as AUs e suas respectivas descrições estão no Apêndice A deste trabalho.

O codificador FACS disseca uma expressão decompondo-a nas AUs específicas que produziram o movimento. Os índices para uma expressão facial consistem na lista de AUs que produziram o movimento. Os índices FACS são apenas descritivos e não oferecem implicações sobre o significado do comportamento. Para traduzir o índice em conceitos mais psicologicamente significativos, Ekman e Friesen desenvolveram um dicionário de interpretação da influência do FACS chamado FACSAID (Facial Action Coding System Affect Interpretation Dictionary) (HAGER, 2011). 
Figura 2.4 - Músculos da região superior da face. (a) Anatomia muscular. (b) Ação muscular.

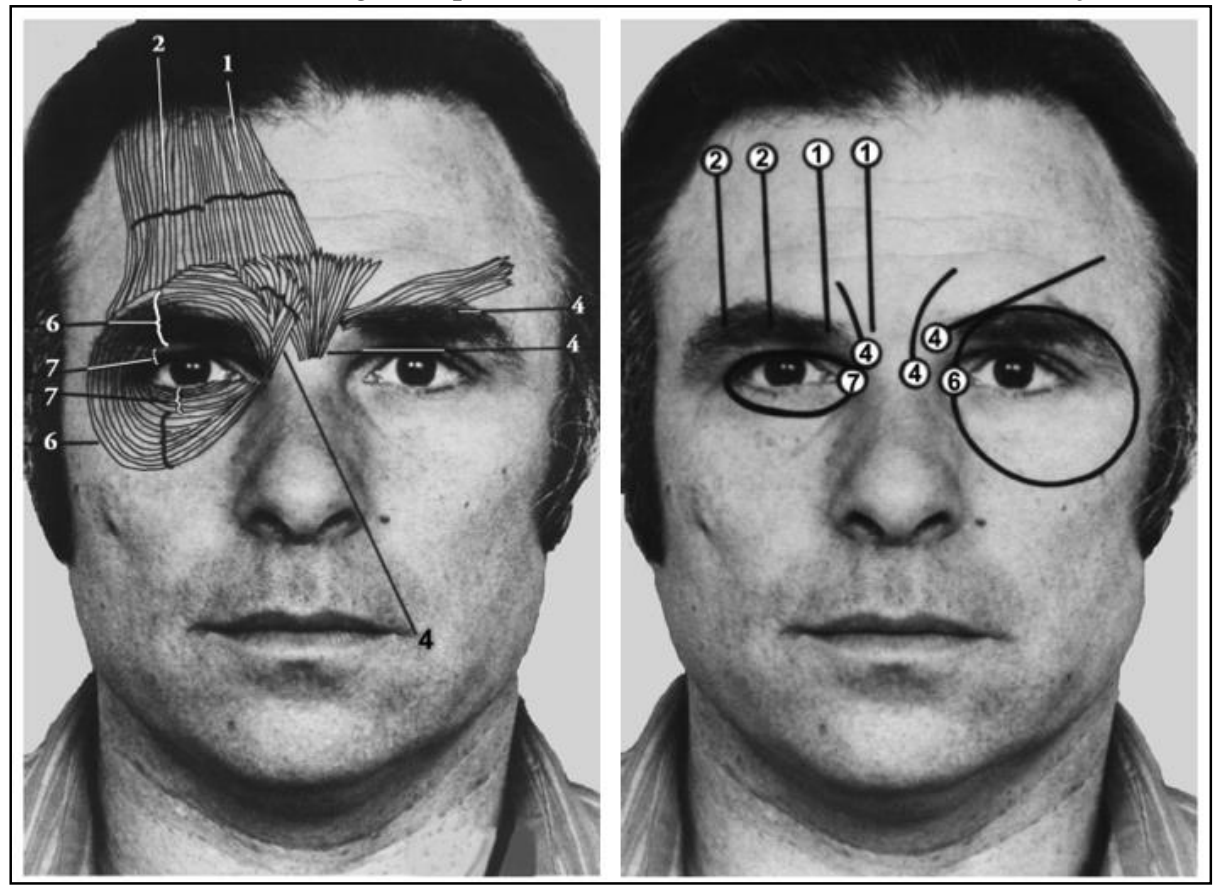

(a)

(b)

Fonte: Ekman e Friesen (1978).

Figura 2.5 - Músculos da região inferior da face. (a) Anatomia muscular. (b) Ação muscular.

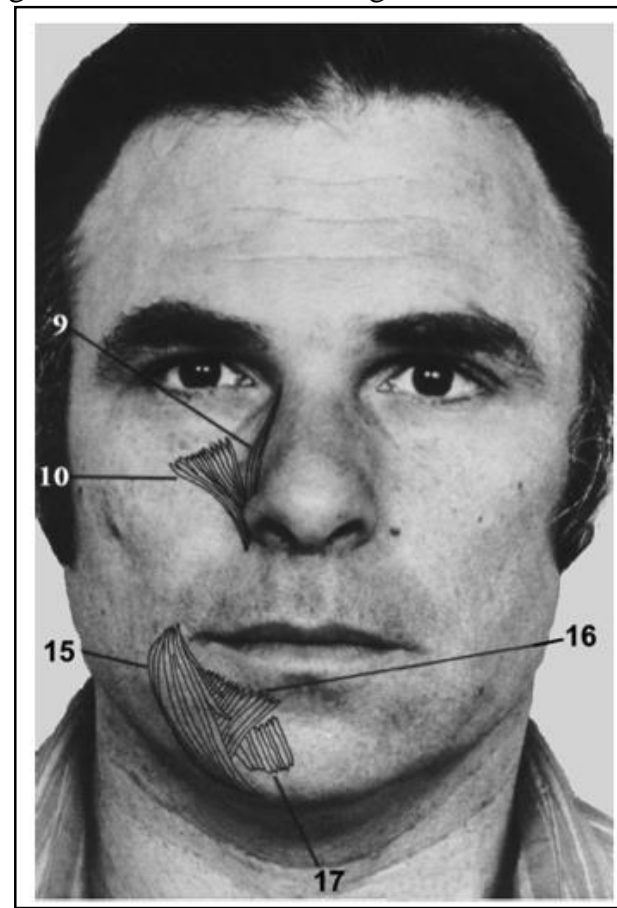

(a)

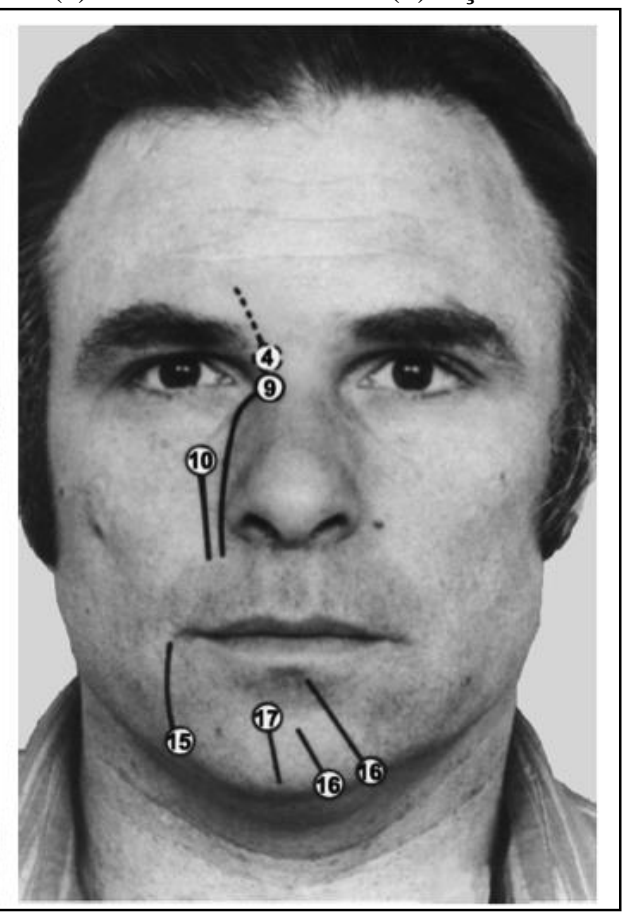

(b)

Fonte: Ekman e Friesen (1978). 
O FACSAID associa a análise das expressões faciais a uma perspectiva psicológica, afim de traduzir os índices FACS em categorias emocionais. No FACSAID, informações como os modelos de comportamentos faciais e os significados dessas expressões são armazenadas em um banco de dados relacional. A abordagem do FACSAID é diferente daquela de um sistema baseado em regras ou análise de um perito, na qual as interpretações são geradas de forma rígida, prevendo um único significado para cada expressão facial. O sistema é descrito como um dicionário, pois o usuário pode procurar significados para um determinado comportamento facial, ou analisar os comportamentos faciais que indicam uma emoção em particular, como, por exemplo, raiva ou felicidade.

O banco de dados FACSAID contém os índices FACS examinados por especialistas, que interpretaram o significado do comportamento facial representado pelos índices. As interpretações das expressões faciais são armazenadas no banco de dados para posterior recuperação por pesquisadores que queiram saber o que uma expressão facial (codificada como um índice FACS) significa. O banco de dados FACSAID contém vários tipos de dados: representações de expressões faciais em termos de FACS, representações de significados que podem ser anexados aos comportamentos faciais e outras informações sobre os comportamentos, como quem atribuiu o significado a uma expressão facial, quantas vezes o comportamento foi observado, representações pictóricas do comportamento, etc. (FACSAID, 2011).

Segundo Pantic e Rothkrantz (2000), o FACS possibilitou a automação da detecção e classificação das emoções, proporcionando aplicação do estudo das emoções nas ciências comportamentais, convergindo em uma série de métodos. A literatura traz diversos trabalhos que utilizam o FACS em aplicações computacionais de reconhecimento de emoções.

Essa e Pentland (1994) descrevem um sistema de visão computacional para observar a movimentação muscular de um rosto, usando sequências de vídeo como entrada. A observação visual (detecção) é conseguida por meio de um método de estimativa de fluxo óptico acoplado à geometria e a um modelo físico que descrevem a estrutura facial.

Bartlett et al. (1996) comparam três abordagens diferentes - análise espacial holística, baseada em componentes principais das imagens em tons de cinza; medida explícita de características locais da imagem, como rugas, por exemplo; e o modelo de correspondência com campos de fluxo de movimento - para classificar as expressões faciais em um banco de 1100 sequências de imagens de 24 indivíduos que executam mais de 150 expressões faciais (ou combinações) diferentes. 
Lien et al. (1998) utilizam técnicas de rastreamento de características faciais, análise de componentes principais e detecção de componentes de gradiente para classificar emoções com base no modelo FACS.

Uma comparação entre as técnicas de detecção automática de ações faciais em sequências de imagens com base no FACS foi realizada por Donato et al. (1999), incluindo a análise de movimento facial por meio de estimativa de fluxo óptico, análise espacial holística e análise discriminante linear.

Chuan et al. (2006) associaram sinais biológicos a sinais faciais (14 pontos na face e 12 distâncias entre esses pontos) para classificar as emoções amor, alegria, surpresa e medo.

Os métodos de aprendizagem de máquina AdaBoost, SVM (Support Vector Machines) e Análise Discriminante Linear foram usados por Littlewort et al. (2006) para classificar as expressões faciais neutro, raiva, aversão, medo, alegria, tristeza e surpresa de forma dinâmica em imagens de vídeos.

Wu, Bartlett e Movellan (2010) exploram filtros de energia de movimento Gabor biologicamente inspirados para criar uma representação das expressões faciais dinâmicas.

A principal vantagem dos modelos discretos, como os propostos por Tomkins e por Ekman, é que eles realizam a classificação das emoções utilizando o mesmo processo cognitivo que os seres humanos, apresentando-se muito intuitivos, correspondendo às experiências do cotidiano das pessoas. Porém, mesmo apresentando-se robustos para a classificação das emoções básicas, tais modelos não são capazes de descrever uma gama variada de emoções que ocorrem em ambientes reais de comunicação. Os modelos contínuos podem descrever uma variedade maior de emoções, uma vez que consideram a relação entre elas (ZENG et al., 2009).

\subsubsection{Modelos Contínuos}

O modelo contínuo de Russell (1980) apresenta uma ordenação circular para duas dimensões das emoções, definindo um modelo circumplex em que os descritores dos estados afetivos estão distribuídos ao longo de um perímetro circular. O modelo traz uma dimensão horizontal, onde estão descritos valência positiva versus valência negativa, e uma dimensão vertical, representando alta atividade versus baixa atividade. A excitação se opõe à letargia no eixo vertical, e o prazer se opõe ao desprazer no eixo horizontal. Outras quatro emoções não formam dimensões independentes, mas ajudam a definir os quadrantes do espaço. Por exemplo, o entusiasmo é a combinação de alta atividade e de valência positiva, sendo o seu 
oposto - baixa atividade e valência negativa - a depressão. De igual forma, o contentamento e a fúria são descritos nesse espaço bidimensional. Os estados afetivos, representados na Figura 2.6, ocupam os seguintes ângulos: prazer $=0^{\circ}$, entusiasmo $=45^{\circ}$, excitação $=90^{\circ}$, fúria $=$ $135^{\circ}$, desprazer $=180^{\circ}$, depressão $=225^{\circ}$, letargia $=270^{\circ}$ e contentamento $=315^{\circ}$.

Figura 2.6 - Modelo bidimensional afetivo.

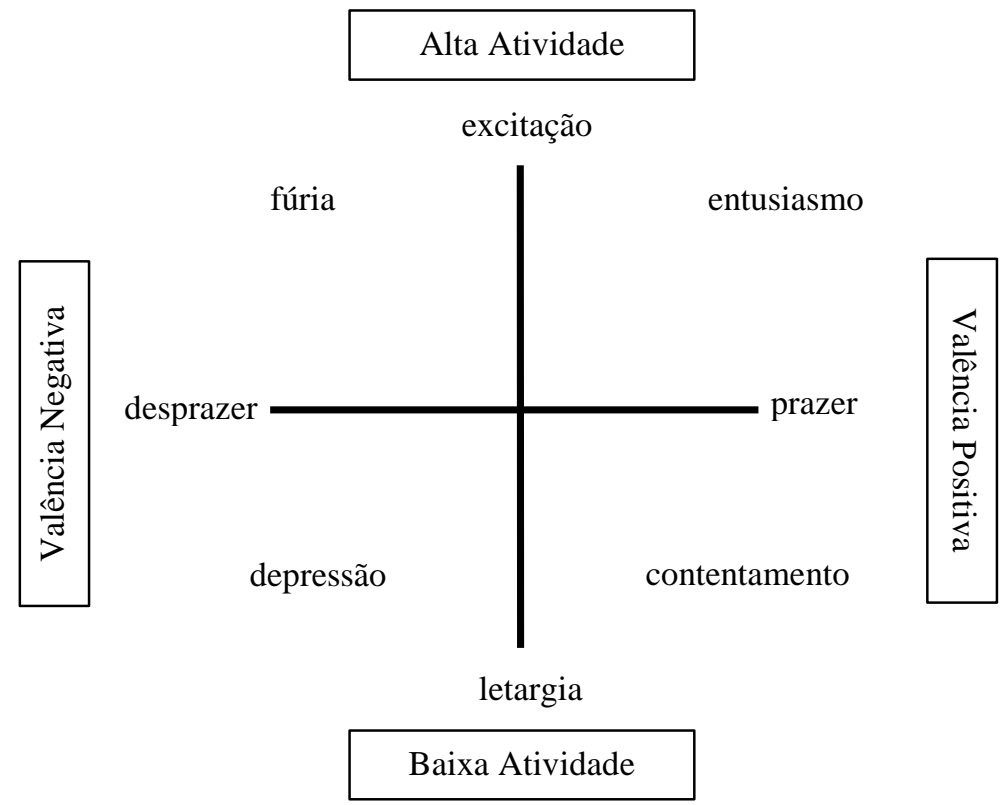

Fonte: Adaptado de Russel (1980).

O modelo pode ser aplicado a outras emoções. Considerando-se o espaço bidimensional atividade versus valência, é determinado o quadrante e ângulo da emoção. Em seu trabalho, Russell (1980) usa o modelo circumplex para classificar 28 emoções.

Em comparação aos modelos discretos, os modelos contínuos descrevem uma quantidade maior de emoções, pois consideram o relacionamento entre as mesmas. Porém, não mapeiam todas as emoções representadas pelas expressões faciais durante o processo de interação humano. Modelos híbridos, como a Roda Emocional de Plutchik (2001), trazem uma mistura das duas abordagens - discretas e contínuas - a fim de representar uma quantidade de emoções mais próxima àquelas identificadas nas interações humanas.

\subsubsection{Modelos Híbridos}

Plutchik (2001) define um conjunto de emoções discretas que são mapeadas em um espaço dimensional contínuo. Segundo o autor, as emoções básicas (ou primárias) alegria, confiança, medo, surpresa, tristeza, aversão, raiva e antecipação são biologicamente 
primitivas e evoluíram a fim de incrementar a aptidão reprodutiva animal. Todas as outras emoções são estados derivativos das emoções primárias. A teoria postula que existem estados emocionais secundários e terciários que variam de acordo com o grau de intensidade ou nível de excitamento (arousal). A Figura 2.7 apresenta o modelo circumplex tridimensional de Plutchik (2001), onde o ângulo no círculo representa uma emoção primária, e a dimensão vertical do cone representa a intensidade dessa emoção. As oito emoções primárias são descritas em setores do cone, organizados em quatro pares de emoções opostas: alegria versus tristeza, confiança versus aversão, medo versus raiva e surpresa versus antecipação. Emoções secundárias (não-prototípicas) são a mistura de emoções primárias. Otimismo, por exemplo, pode surgir da mistura dos sentimentos de interesse e serenidade.

Figura 2.7 - Roda Emocional de Plutchik. (a) Modelo em três dimensões. (b) Modelo em duas dimensões.

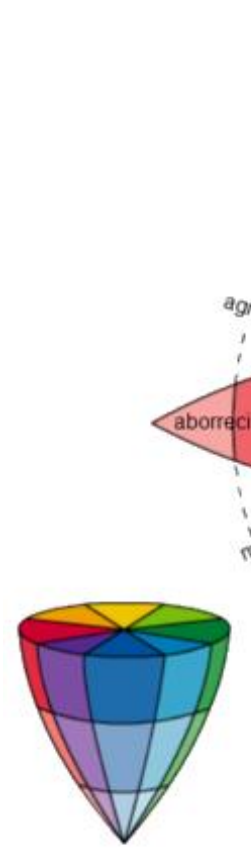

(a)

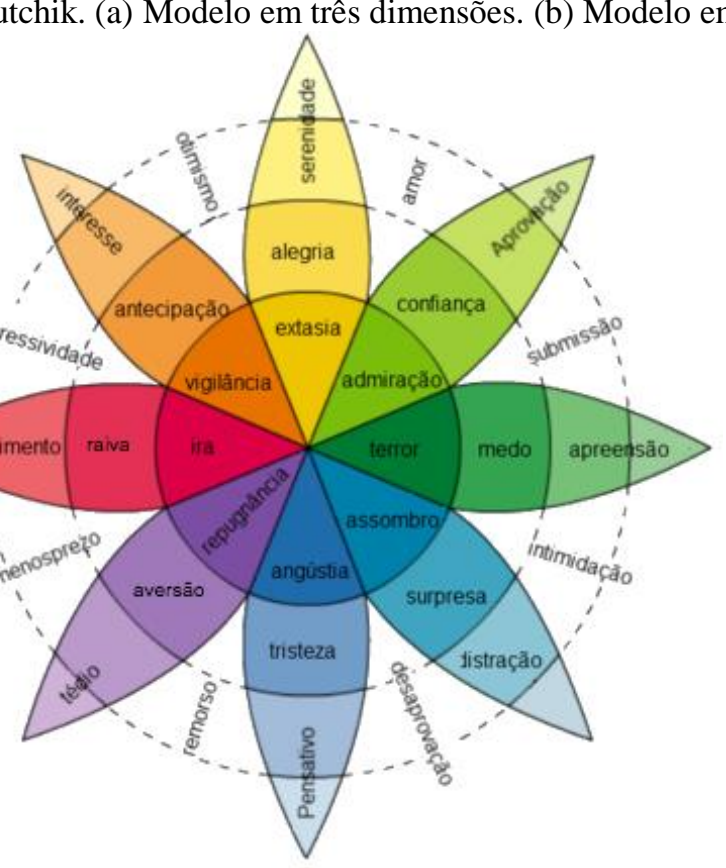

(b)

Fonte: Adaptado de Plutchik (2001).

\subsubsection{Modelos Baseados em Teorias de Avaliação}

O conceito de appraisal foi definido por Arnold (1960) que o caracteriza como processo por meio do qual a importância da situação para um indivíduo é determinante.

Segundo as teorias de avaliação, as emoções são processos dinâmicos (contínuos e recursivos) que consistem em eventos físicos e cognitivos. Appraisal apresenta a ideia de atração ou repulsa. Atração por algo que se avalia como sendo bom, e repulsa por algo que se 
julga ser mau. As emoções são geradas e diferenciadas em função da interpretação ou avaliação subjetiva de uma situação ou acontecimento.

Diversas teorias foram desenvolvidas acerca do tema, sendo a de Scherer (1984a; 1984b; 1987) uma das mais difundidas. Segundo o autor, as emoções são descritas como um processo global em que avaliações cognitivas de baixo nível, em particular o processamento de relevância, desencadeiam reações corporais, comportamentos e sentimentos subjetivos. O autor apresenta o Modelo de Processo Componente (CPM - Component Process Model) no qual as emoções são resultado de diversos componentes cognitivos e físiológicos. Segundo o modelo, cada componente é especializado para uma função particular (SCHERER, 1984a):

\section{Função:}

Avaliação do ambiente

Regulação do sistema

Preparação da ação

Comunicação da intenção

Reflexão e monitoramento

\section{Componente:}

Processamento de estímulo cognitivo

Processos fisiológicos

Tendências de motivação e comportamento

Expressão motora

Estado afetivo subjetivo

Ortony, Clore e Collins (1988) apresentaram uma categorização das emoções com base em objetivos e crenças. Em sua versão simplificada, o modelo OCC (Ortony, Clore e Coollins) são considera duas categorias de reações emocionais: positivas e negativas e, assim como no modelo original, as emoções são resultado de três tipos de avaliações (appraisals) subjetivas (ORTONY, 2001).

Tabela 2.2 - Modelo OCC simplificado

\begin{tabular}{|c|c|c|}
\hline Reações Emocionais & Positivas & Negativas \\
\hline Indiferenciadas & $\begin{array}{l}\text {... porque algo de bom aconteceu } \\
\text { (alegria) }\end{array}$ & $\begin{array}{l}\text {.. porque algo de mau aconteceu } \\
\text { (aflição) }\end{array}$ \\
\hline Baseadas em objetivos & $\begin{array}{l}\text {... pela possibilidade de algo bom } \\
\text { acontecer (esperança) }\end{array}$ & $\begin{array}{l}\text {... pela possibilidade de algo mau } \\
\text { acontecer (medo) }\end{array}$ \\
\hline \multirow{2}{*}{ Baseadas em Padrões } & $\begin{array}{l}\text {...por uma ação pessoal prezada pelo } \\
\text { próprio (orgulho) }\end{array}$ & $\begin{array}{l}\text {...por uma ação pessoal censurada pelo } \\
\text { próprio (remorso) }\end{array}$ \\
\hline & $\begin{array}{l}\text {..por uma ação de outro que é prezada } \\
\text { (gratidão) }\end{array}$ & $\begin{array}{l}\text {..por uma ação de outro que é censurada } \\
\text { (raiva) }\end{array}$ \\
\hline Baseadas no gosto & $\begin{array}{l}\text {..porque julga algo/alguém atraente } \\
\text { (gostar) }\end{array}$ & $\begin{array}{l}\text {..porque } \quad \text { julga } \\
\text { desagradável (detestar) }\end{array}$ \\
\hline
\end{tabular}




\subsection{Considerações Finais}

Diversas abordagens discutem e definem as emoções humanas na tentativa de melhor entender seu papel nas interações sociais. As teorias baseadas no modelo evolutivo de Darwin (1861) defendem que as emoções básicas são inatas e universais. Ekman e Oster (1979) apresentam resultados demonstrando que algumas expressões faciais são as mesmas, independentemente da cultura. Dessa forma, pessoas de culturas diferentes mostram as mesmas expressões ao experimentar a mesma emoção, exceto quando existem regras culturais específicas. Outros autores defendem justamente o contrário, ou seja, as emoções, mesmo as básicas, são aprendidas de acordo com influências socioculturais.

Assim como não existe um consenso acerca da natureza das emoções, diversos modelos emocionais são apresentados na literatura. Segundo Gockley, Simmons e Forlizzi (2006), o tipo do modelo não é um fator decisivo na simulação da emoção humana em máquinas, uma vez que o importante para a percepção humana é que a emoção demonstrada pela máquina seja como a humana, independentemente de o resultado ser fruto de um modelo semelhante ao processo cognitivo humano ou não. Já quando o que se deseja é identificar e processar computacionalmente emoções, os modelos discretos apresentam a vantagem de simular o processo cognitivo humano (EKMAN; ROSENBERG, 2005; ZENG et al., 2009).

Estudos em neurociência sugerem que regiões distintas no cérebro são utilizadas para reconhecer diferentes expressões, o que reforça a hipótese de que o modelo de reconhecimento de emoções usado pelos seres humanos é discreto (CALDER; LAWRENCE; YOUNG, 2001). Além disso, os seres humanos utilizam categorias para descrever as emoções básicas de seu cotidiano, o que facilita a associação da emoção a determinada expressão facial (ZENG et al., 2009).

A desvantagem da utilização dos modelos discretos em sistemas computacionais é que eles são eficientes apenas para determinar as emoções básicas. Emoções secundárias ou nãoprototípicas, advindas da combinação de emoções básicas, são melhor representadas por modelos contínuos ou híbridos. Os modelos emocionais mais recentes são advindos das propostas das teorias de avaliação e fogem ao escopo deste trabalho, pois se baseiam na avaliação de eventos para descrever respostas emocionais.

No que diz respeito ao conceito fundamental usado nas últimas décadas quanto à existência de seis emoções básicas, estudos recentes têm apresentado novos modelos, estendendo para 21 as emoções que seriam expressas (e reconhecidas) pelos seres humanos de forma universal, independentemente de fatores culturais. Tais pesquisas têm obtido êxito em 
sistemas de Visão Computacional que se propõem a classificar emoções em tempo real, usando características faciais (DU, TAO, MARTINEZ, 2014; MARTINEZ; DU, 2012; STAROSTENKO et al., 2015). 


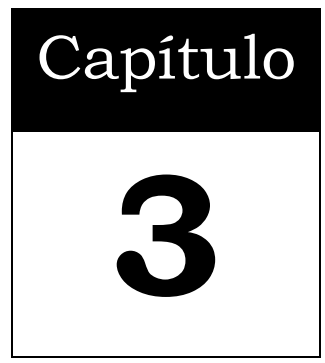

\section{Computação Afetiva}

Nas últimas décadas, estudiosos de diversas áreas, como psicologia, neurociência, engenharia e ciência da computação, têm voltado suas atenções para estudos sobre o reconhecimento da afetividade, por meio de modelos da emoção humana. Na ciência da computação, a Computação Afetiva (CA) é um ramo de estudo da Inteligência Artificial (IA) que investiga como desenvolver dispositivos e sistemas que podem reconhecer, interpretar e processar emoções humanas, como causar comportamento verossímil emocional artificialmente e como usar modelos de emoção em algoritmos para tomada de decisão em agentes artificiais.

Um dos pioneiros em pesquisas de IA - que mais tarde levaram ao surgimento da Computação Afetiva - foi Hebert Simon. No trabalho Motivational and Emotional Controls of Cognition, Simon (1967) demonstra como os controles motivacional e emocional sobre a cognição podem ser incorporados em um sistema de processamento de informação, contemplando duas características do pensamento humano: a associação do pensamento com as emoções e o fato de o pensamento humano ser utilizado em diversas tarefas ao mesmo tempo. Essas características, segundo o psicólogo Neisser (1963), não estavam presentes nos programas de computadores da época. A relevância dos estudos realizados por Simon só foi 
notada anos mais tarde, com o surgimento da área de pesquisa denominada Computação Afetiva.

A discussão sobre a utilização das emoções em sistemas computacionais já não era novidade na década de 90, mas o marco inicial para a fundamentação da CA, como área de pesquisa, foi outorgado pela publicação do artigo Affective Computing, de Rosalind Picard, em 1995. Em seu artigo, a autora apresenta e discute questões da CA, sugere modelos computacionais de reconhecimento de emoções humanas e apresenta novas aplicações para a aprendizagem assistida por computador, recuperação de informação perceptual, artes e entretenimento, saúde e Interação Humano-Computador (HCI - Human-Computer Interaction). Além disso, discute como a CA pode fornecer ferramentas importantes para o avanço das teorias da emoção e da cognição.

\subsection{Aplicações de Computação Afetiva}

Diversas áreas do conhecimento podem se beneficiar do uso da emoção em sistemas computacionais. Empresas já oferecem produtos e serviços para aplicações em saúde, marketing, expressão artística, biofeedback, call centers, jogos on-line, personalização de estilo de aprendizagem, comunicação não-verbal para as pessoas com deficiência na fala, robótica, melhoria da autoconsciência e realidade virtual, entre outros.

\subsubsection{Aplicações em Computação Ubíqua}

O advento da Internet das coisas, associado ao aumento da utilização de sistemas ubíquos e ambientes inteligentes, abre novas oportunidades de investigação de tecnologias centradas em humanos. Apresentar respostas compatíveis com o estado emocional dos usuários é um dos principais desafios de tais sistemas, a fim de alcançar interações mais verossímeis para a interação humana, melhorando a experiência do usuário (UX - User Experience).

Os autores Esmaeily e Hendessi (2014) propõem a combinação de modelos mentais e perfil afetivo para a comunicação social entre pessoas de grandes metrópoles, durante o tempo em que estão no trânsito. A ideia da utilização de uma rede social efêmera afetiva para cenários veiculares é introduzida, e os principais componentes da arquitetura de rede, perfil individual afetivo, exigências e restrições, privacidade do usuário, entre outros, são discutidos. 
Considerando o aumento da população idosa que vive de forma independente, o que pode levar ao isolamento social, os autores Sanchez et al. (2015) apresentam modelos preditivos para determinar o nível de solidão, dados os diferentes aspectos de saúde e sociais. Tais aspectos estão focados no comportamento do usuário e em atividades monitoradas usando smartphones.

A pesquisa de Kim, Cho e Park (2015) apresenta um porta-retratos digital projetado para ajudar os usuários a compartilhar experiências emocionais, por meio do reconhecimento e da transformação das respostas fisiológicas (fotopletismografia, temperatura e sinais de resposta galvânica da pele) em elementos visuais e auditivos personalizados sobre a fotografia. A ideia consiste em um sistema de reconhecimento de emoções, um servidor de compartilhamento de emoções e um porta-retratos emocional. Os resultados demonstram que a maioria dos participantes foi influenciada pela emoção do seu parceiro, apresentada nesse sistema.

O estudo desenvolvido por Starostenko et al. (2015) traz um ambiente inteligente de serviços $W e b$, desenvolvido para integrar e gerenciar diferentes aplicativos de reconhecimento de emoções, fornecendo informações sobre o estado afetivo do usuário em tempo real. Os autores também apresentam dois mecanismos de detecção de emoção baseados em características faciais, nos quais sistemas Fuzzy são usados para medição quantitativa e reconhecimento do nível de intensidade de expressões faciais básicas (primárias) e nãoprototípicas (secundárias, resultantes da combinação de emoções básicas).

Sanchez et al. (2015b) apresentam o Vikara, uma plataforma de software extensível que provê uma interface para que aplicativos possam interagir com ferramentas de interpretação de emoções. A plataforma também fornece componentes de gerenciamento, pelos quais é possível monitorar os estados afetivos dos usuários. As informações emocionais são extraídas por meio das técnicas: FACS com um sensor Kinect e interface de autorrelato para dispositivos móveis baseados em Android. Avaliação de usabilidade, UX, marketing, educação a distância e comunicação interpessoal são cenários possíveis de utilização da plataforma.

\subsubsection{Aplicações em Saúde}

$\mathrm{Na}$ área da saúde, pesquisas clínicas com recursos de Computação Afetiva podem ser úteis em estudos de uma grande gama de patologias, dentre elas vícios como alcoolismo e drogas, doença de Alzheimer, transtorno de ansiedade, autismo, déficit de atenção e 
hiperatividade, depressão, controle da dor, a doença de Parkinson, fobias, aconselhamento psiquiátrico, quadriplegia ou paraplegia, esquizofrenia e sociopatia, dentre outros (AFFECTIVA, 2015a).

Tendo em vista o aumento da utilização de serviços de saúde assistida por computador, para monitoramento e para assistência médica remotos, e a falta de aspectos afetivos médicopaciente envolvidos em tal prática, Chen et al. (2015) propõem uma nova arquitetura para interação afetiva baseada em computação vestível e computação em nuvem que inclui três componentes: coleta colaborativa de dados, por meio de múltiplos sensores de dispositivos portáteis; modelos de previsão e análise aprimorada de sentimentos, com base em informações de múltiplos espaços (espaço cibernético, físico e social); interações afetivas controláveis, baseadas em recursos de cognição para sincronização entre sensores e controladores.

\subsubsection{Aplicações em Educação}

A aprendizagem é uma experiência emocional por excelência. Em todas as interações de ensino e aprendizagem, a identificação de componentes relacionados aos sentimentos permite uma interação mais estreita entre o educador e seu público. Um episódio de aprendizagem pode começar com curiosidade e fascínio, mas, quando a dificuldade aumenta, pode-se experimentar a frustração, a confusão ou a ansiedade, sentimentos que tendem a prejudicar a aprendizagem. O bom professor detecta esses sinais importantes, e responde a eles (PICARD, 1995; VYGOTSKY, 1962).

A utilização de técnicas de CA em sistemas educacionais, em especial nos sistemas de Educação a Distância (EaD), torna possível verificar, por exemplo, se o aluno está indo bem com a execução de determinada atividade. O sistema, tendo certeza do interesse dos alunos, pode propor exercícios mais difíceis e, ao detectar a frustração dos usuários e muitos erros, pode dar-lhes sugestões de atividades mais animadoras. Observando as emoções do aluno, o sistema educacional computacional pode responder de forma semelhante à presença de um professor humano, dando-lhe uma orientação personalizada (BAKER et al., 2008).

Conati (2002) apresenta um modelo probabilístico para monitorar as emoções e o engajamento do usuário durante a utilização de jogos educativos. As informações emocionais são extraídas por meio de eventos, e o modelo Ortony Clore and Collins (OCC) (ORTONY; CLORE; COLLINS, 1998), baseado nas teorias de avaliação, é utilizado. 


\subsubsection{Aplicações em Entretenimento}

O cinema sempre foi um ambiente inspirador para novas tecnologias. Várias empresas de games têm utilizado recursos de IA para criar uma ponte entre o mundo real e o mundo virtual. Um dos focos atuais dos desenvolvedores de games é criar jogos capazes de reconhecer o estado emocional do usuário e reagir de acordo com essas informações.

$\mathrm{Na}$ Universidade de Abertay Dundee são desenvolvidas diversas pesquisas para reproduzir experiências de interatividade em jogos digitais. Um dos projetos, liderados pelo Dr. Leslie Ball, tem como objetivo reduzir o gap entre a Inteligência Humano-Humano e a Inteligência Humano-Computador, adicionando informações não verbais nos processos de HCI melhorando a UX. Os estudos focam na autenticidade de avatares, em especial na sua capacidade de exibir emoções autênticas para o jogador. Segundo Ball (apud ABERTAY, 2010, não paginado, tradução nossa),

[...] em essência, se imaginarmos as técnicas que estão sendo utilizadas com grande sucesso em jogos multi-player na Internet tais como World of Warcraft, os jogadores de todo o mundo poderiam comunicar-se uns com os outros, como avatares, a partir de suas salas de estar, em diferentes lugares do mundo, utilizando apenas expressões faciais. Embora a realidade deste exemplo sendo postas em prática esteja distante é completamente factível.

A Figura 3.1 mostra um avatar reproduzindo uma emoção do usuário (ABERTAY, 2010).

Figura 3.1 - Avatar reproduzindo uma emoção do usuário.

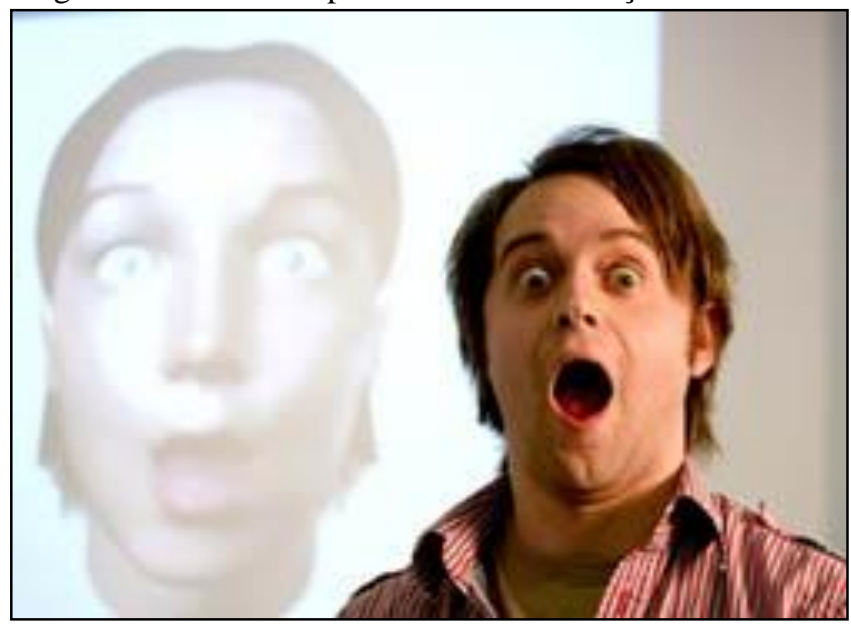

Fonte: ABERTAY (2010).

Outro projeto da mesma universidade, inspirado no filme Avatar, de James Cameron, utiliza câmeras virtuais e um controle semelhante ao do Nintendo Wii (Figura 3.2a) para o 
usuário interagir com o ambiente do jogo. Uma técnica de filmagem chamada simulcam foi desenvolvida para adicionar um maior realismo. Nela, a imagem gravada é processada em tempo real antes de ser exibida na tela do monitor (ABERTAY, 2010). Mais recentemente, a pesquisa também foi utilizada no filme Planeta dos Macacos: o Confronto, de Matt Reeves. A técnica associa o poder de uma câmera virtual a controladores de movimento acessíveis, projetados para jogos de PC (Figura 3.2b) (ABERTAY, 2014).

Figura 3.2 - Utilização de simulcam por meio de controladores de movimentos.

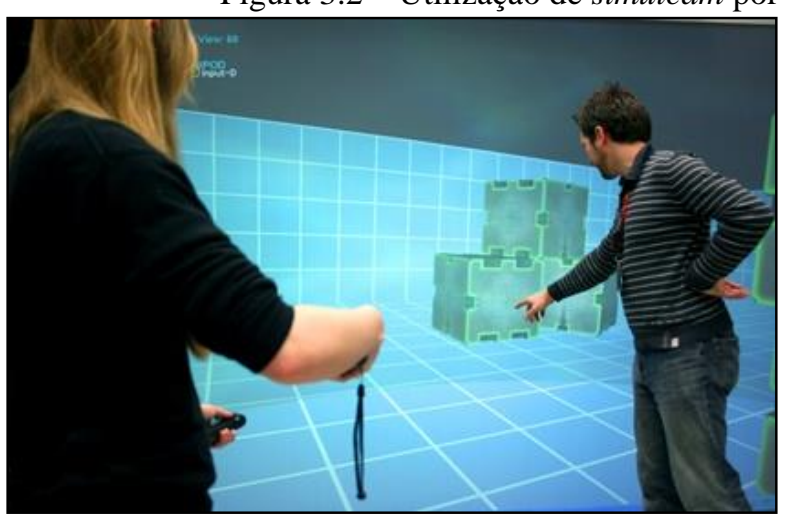

(a)

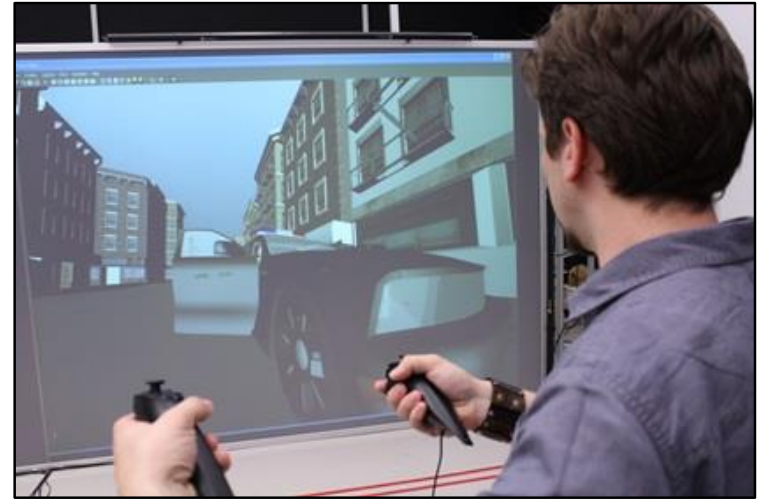

(b)

Fonte: ABERTAY $(2010,2014)$.

A ferramenta faceshift, desenvolvida pelos pesquisadores da École Polytechnique Fédérale de Lausanne (EPFL), liderados pelo Dr. Mark Pauly, captura a mímica da face em tempo real e reproduz as emoções expressas pelo usuário em avatares de forma realística. A Figura 3.3 ilustra ofaceshift em funcionamento (ICHIM; BOUAZIZ; PAULY, 2015):

Figura 3.3 - Avatar animado em tempo real, a partir do software de monitoramento em tempo real.
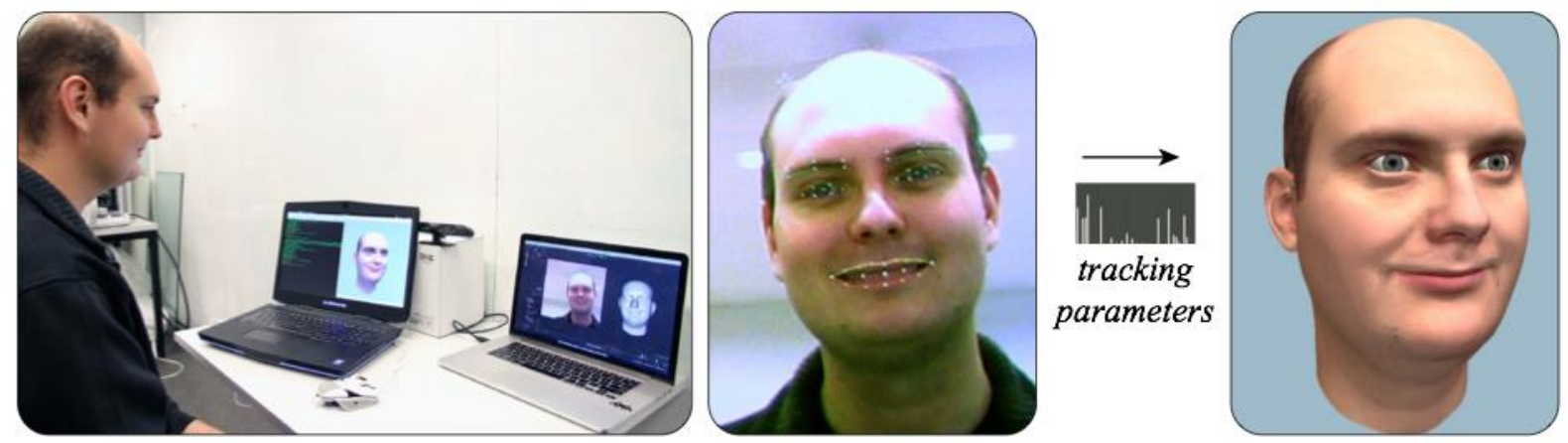

Fonte: Ichim, Bouaziz e Pauly (2015).

A Sightcorp é uma empresa oriunda das atividades de pesquisa do Laboratório ISLA (Intelligent Systems Lab Amsterdam), da Universidade de Amsterdam, que fornece soluções de Visão Computacional. Uma das ferramentas oferecidas pela empresa é o software eMotion, 
que realiza o reconhecimento das emoções do usuário por meio de imagens capturadas via webcam. O eMotion integra-se ao Second Life (SECONDLIFE, 2011), um ambiente virtual tridimensional que simula a vida real e social do ser humano, permitindo animar a expressão facial do avatar em tempo real por meio do mapeamento das expressões faciais do usuário. A Figura 3.4 mostra uma tela do software Second Life na qual os avatares interagem, reproduzindo as expressões faciais do usuário, utilizando o software eMotion. O eMotion foi o primeiro software a ser oferecido pela empresa, na época denominada Visual Recognition (SIGHTCORP, 2015; VISUAL RECOGNITION, 2011).

Figura 3.4 - Exemplo do ambiente Second Life.

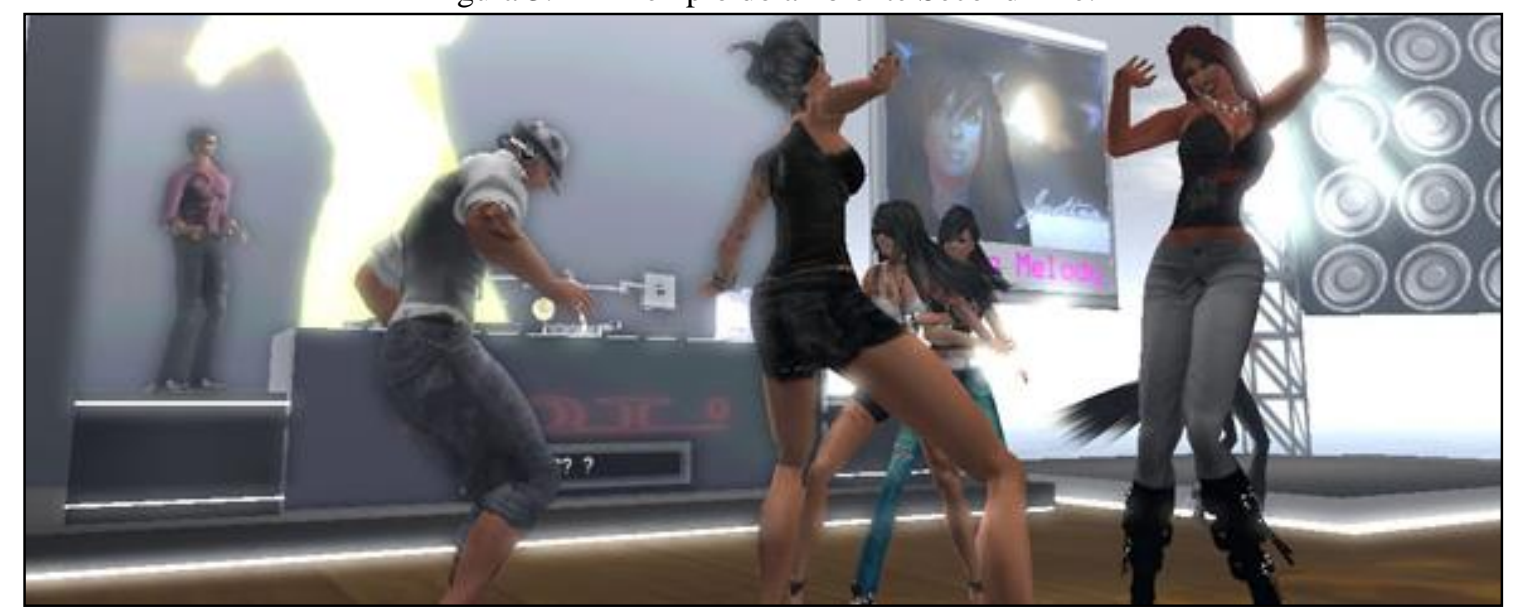

Fonte: SECONDLIFE (2011).

\subsubsection{Aplicações em Negócios}

No mundo corporativo, as empresas podem se valer de sistemas de Computação Afetiva para seus negócios, obtendo informações estratégicas a respeito de produtos, serviços, funcionários e clientes. Sistemas de CA ajudam, por exemplo, a entender se o consumidor gostou de um produto ou serviço, auxiliando em testes de usabilidade, questões relativas ao design, às promoções de vendas, ao atendimento, etc. Uma empresa de telemarketing, por exemplo, pode avaliar o nível de stress de atendentes, usar essas informações para melhorar o ambiente de trabalho e prestar um serviço melhor a seus clientes.

A empresa Sightcorp, além do eMotion, oferece soluções para identificar expressões faciais e reconhecimento de emoções, idade, gênero, etnia e reconhecimento facial, entre outros, para análise de vídeos em ambientes reais (capaz de processar várias faces simultaneamente) ou em ambientes controlados (analisando uma face por vez). Suas aplicações vão desde pesquisa de mercado, varejo, publicidade, sinalização digital e 
narrowcasting, até jogos, vigilância e monitoramento, automação residencial e UX (SIGHTCORP, 2015).

As empresas Affectiva, nViso, Emotient, Kairos, Noldus e VicareVision também oferecem soluções de CA para business, desenvolvendo projetos relacionados à medicina e ao uso comercial de pesquisas de marketing, entre outras (AFFECTIVA, 2015a; EMOTIENT, 2015; NVISO, 2015; KAIROS, 2015).

\subsubsection{Aplicações baseadas no FACS}

Diversas universidades têm pesquisado aplicações basedas no FACS. A maioria dessas pesquisas tornam-se produtos comerciais para áreas como saúde, entretenimento, marketing e educação. A seguir, são apresentadas algumas dessas aplicações.

\subsubsection{NViso}

Os trabalhos realizados nos últimos anos pelo Instituto Federal de Tecnologia da Suíça (Swiss Federal Institute of Technology), liderados pelo Dr. Sorci, levaram à implementação computacional do FACS (NVISO, 2015; SORCI et al., 2008; YUCE, SORCI, THIRAN, 2013). A empresa nViso oferece um serviço de análise das emoções humanas expressas pela mímica da face, com objetivo de avaliar o impacto emocional de mensagens, produtos e marcas com base nos resultados das pesquisas do Dr. Sorci.

Para utilizar o software não é necessário a instalação de nenhum programa. Inicialmente, é enviado ao computador do usuário um vídeo contendo um comercial de TV ou mensagem promocional, por exemplo. Usando o navegador Web e a Webcam, as imagens da face do usuário são capturadas, segundo a segundo, e encaminhadas ao servidor Web para serem processadas. O software também oferece uma versão off-line e fornece APIs para utilização em dispositivos móveis.

O algoritmo implementado é baseado no FACS, o qual analisa a movimentação de 43 músculos da face - por meio de 143 pontos de referência (landmarks), capturados com Modelos de Aparência Ativa (AAM - Active Appearence Models) (COOTES; EDWARDS; TAYLOR, 2001) -, possibilitando a classificação das emoções básicas. Sistemas de aprendizagem de máquina - modelos de escolha discreta (DCM - Discrete Choice Models) são utilizados para classificar emoções subjacentes, resultantes da combinação das emoções básicas (NVISO, 2015; SORCI et al., 2010). 
Um dos problemas em se trabalhar com imagens estáticas, realizando a captura segundo a segundo, é que muitas vezes a expressão da emoção pode durar uma fração de segundo (EKMAN, 1978). Isso pode levar a perda de dados relevantes para a análise e a classificação das emoções.

Na documentação do software apresentada e publicada na Australian Market \& Social Research Society, em 2011, o autor faz uma comparação de técnicas de detecção de emoções por Imagem de Ressonância Magnética Funcional, Eletroencefalografia, Eye-Tracking, BioSensores de suor, frequência cardíaca e respiração, Codificação Facial com análise humana e a técnica proposta que corresponde à Codificação Facial realizada por sistemas computacionais. Porém, tal comparação é realizada apenas sob a perspectiva da escalabilidade do sistema. Outras publicações do autor apresentam resultados sobre a eficiência em identificar a movimentação dos pontos que representam as unidades de ação do FACS, e também dados sobre a eficiência de generalização do modelo proposto (SORCI et al., 2008; YUCE, SORCI, THIRAN, 2013).

\subsubsection{Emotient}

Outra implementação computacional do FACS é o Emotient, que se propõe a fazer a análise de expressões faciais para aplicações nas áreas de publicidade, psicologia, neurociência, HCI, diagnóstico médico, economia comportamental, educação e jogos, entre outras. Resultado das pesquisas desenvolvidas por Movellan, Bartlett, Fasel, Littlewort e Susskind, no Institute for Neural Computation, da Universidade da Califórnia em San Diego, o software fornece informações sobre a atenção do usuário (verificando se a posição da face é frontal), envolvimento emocional (se a face está neutra ou não) e emoções básicas (qual emoção está sendo demonstrada), com um índice de acerto de 95\% segundo informação do site, e 93\% segundo publicação dos autores (EMOTIENT, 2015; LITTLEWORT et al., 2006).

Além da utilização on-line mantida em nuvem, também é possível a aquisição do módulo off-line para aplicações que integram análise de expressões faciais com outras técnicas, como Ressonância Magnética, Eletroencefalografia, Eye-Tracking, Bio-Sensores, etc.

Dado um vídeo, a cada frame é extraída a imagem da face para detecção do rosto, usando o algoritmo de Viola-Jones (VIOLA; JONES, 2001). O reconhecimento das emoções básicas de raiva, aversão, medo, felicidade, tristeza e surpresa, além de neutro, é feito por meio de uma combinação do algoritmo de aprendizagem de máquina AdaBoost (Adaptive Boosting) (VAPNIK, 1998) e do algoritmo Máquina de Vetores de Suporte (SVM - Support 
Vector Machine) (CAMPBELL, 2002), aplicados às características extraídas das imagens das faces com filtros de Gabor. Esta combinação é chamada pelo autor de AdaSVM's (BARTLETT et al., 2004; LITTLEWORT et al., 2004; LITTLEWORT et al., 2006).

Além do reconhecimento das emoções básicas com base no FACS, os autores propõem a utilização de métodos de aprendizagem de máquina para que o software aprenda e classifique outras emoções (BARTLETT et al., 2006a; BARTLETT et al., 2008; BARTLETT et al., 2010).

\subsubsection{Affdex}

Originada das pesquisas acadêmicas de Rana el Kaliouby, a empresa Affectiva também oferece soluções de computação afetiva baseadas no FACS. O Affdex, por exemplo, é um software em nuvem que identifica as emoções e a intensidade da atenção do usuário, mediante estímulos visuais. Os insights emocionais são transportados para uma visualização que permite uma análise momento a momento ou cumulativa, possibilitando a avaliação do impacto emocional ao estímulo visual apresentado. Além do Affdex, a empresa também oferece o serviço de análise de imagens de vídeo capturadas por meio de sensores como câmaras de monitoramento, por exemplo. Os dados são enviados para processamento via um painel de controle, e os resultados das emoções básicas identificadas (raiva, tristeza, aversão, felicidade, surpresa, medo e desprezo) são disponibilizados em forma de relatórios. APIs e SDKs das soluções permitem a integração com aplicativos em diversas plataformas, e o módulo off-line possibilita integrar o reconhecimento de emoções pela mímica da face com outras técnicas, como Eletroencefalografia, Eye-Tracking e Bio-Sensores (AFFECTIVA, 2015a).

Em todos os casos, o software realiza a detecção da face e a seleção de 22 pontos de referência com o Nevenvision facial feature tracker $^{1}$ (GOOGLE, 2010). Os pontos de referência são utilizados para segmentar a face em regiões de interesse (ROI - region of interest): olhos com sobrancelhas, nariz e boca. A extração de características é feita nas ROIs com histogramas de gradiente orientados (HOG - histograms of oriented gradients) (DALAL; TRIGGS, 2005), e o algoritmo SVM (CAMPBELL, 2002) é utilizado como classificador das emoções (MCDUFF et al., 2015).

\footnotetext{
${ }^{1}$ Licenciado pela Google inc.
} 


\subsubsection{Kairos}

Em abril de 2015, a empresa Kairos, que até então oferecia apenas produtos de software de reconhecimento facial, adquiriu a start-up IMRSV (antiga Immersive Labs), fundada pelo pesquisador Stephen Moore da University of Surrey, Reino Unido. Após a aquisição, a Kairos passou a oferecer novos serviços de análise de emoções. Sua nova API de Visão Computacional é capaz de identificar, por meio de características faciais, o gênero, a idade, o nível de atenção, as expressões faciais e as emoções. A solução visa atender testes de mídia, testes de usabilidade e pesquisas médicas, entre outros (KAIROS, 2015).

A implementação de detecção de emoções da Kairos tem como base o FACS. A extração de características faciais é realizada por meio de recursos baseados na aparência da face, considerando contornos extraídos com o algoritmo detector de bordas de Canny (CANNY, 1986). Informações temporais são construídas com uma variação do algoritmo AdaBoost, denominada TemporalBoost (SMITH; LOBO; SHAH, 2005), que possui potencial para desenvolver classificadores fracos, utilizando quadros anteriores ao quadro corrente na avaliação. O algoritmo de SVM (CAMPBELL, 2002) é utilizado para uma classificação final reduzida de erros. Segundo informações do site, o índice de precisão de classificação das emoções felicidade, surpresa, medo, tristeza, raiva e aversão chega a 95\%, mas os dados publicados por Moore, Ong e Bowden (2010) apresentam uma média de $86 \%$ de precisão de classificação.

\subsubsection{Sightcorp}

Outra empresa que utiliza o FACS em suas soluções de detecção de emoções é a Sightcorp (SIGHTCORP, 2015). As soluções de reconhecimento de emoções realizam a detecção da face por meio de uma técnica de rastreamento denominada Piecewise Bézier Volume Deformation (PBVD) (COHEN et al., 2003). A detecção é iniciada utilizando-se uma malha genérica, que é ajustada à face detectada no vídeo (TAO; HUANG, 1998). A movimentação de regiões específicas da face como sobrancelha, olhos e boca é rastreada pela deformação da malha, gerando um vetor de características de movimento, fornecido como entrada para uma estrutura de Rede Bayesiana (RB), que faz a classificação da emoção (JOHO et al., 2009; SEBE et al., 2006). 


\subsubsection{Realeyes}

Originalmente fundada na Universidade de Oxford, a empresa Realeyes usa as seis emoções básicas propostas por Ekman como cerne de sua plataforma automatizada de codificação facial. Impulsionada pelos avanços tecnológicos da computação em nuvem e pela popularidade de webcams, a empresa - conduzida por Maja Pantic e Jeffrey Cohn - oferece uma plataforma on-line para análise de emoções (REALEYESIT, 2015).

Para detecção e extração de características faciais, o software utiliza Modelos Locais Restritos (CLM - Constrained Local Models) (CRISTINACCE; COOTES, 2006). Dada uma face, após estimar a localização correta dos pontos de referência por meio de CLM, algoritmos de SVM (CAMPBELL, 2002) são utilizados para estimar as AUs e classificar as emoções (JENI et al., 2011). Segundo vídeo do site da Realeyes, a precisão em classificar as emoções básicas propostas por Ekman chega a 95\% (REALEYESIT, 2015).

\subsubsection{FaceReader}

Tendo as Universidades de Wageningen e de Twente como principais colaboradoras de pesquisa, a empresa Noldus, fundada por Lucas Noldus, fornece soluções de CA aplicáveis a áreas como investigação do comportamento do consumidor, estudos de usabilidade, psicologia, pesquisa educacional e pesquisa de mercado (NOLDUS, 2014).

A solução de software Observer ${ }^{\circledR}$ XT, fornecida pela Noldus, apresenta um sistema de coleta, análise e gestão de dados comportamentais (NOLDUS, [201?]b). Já a ferramenta FaceReader ${ }^{\mathrm{TM}}$, uma marca comercial da empresa VicarVision, analisa automaticamente as expressões faciais básicas propostas por Ekman, com base no FACS, além de fornecer informações sobre a direção do olhar, orientação cabeça e sobre as características como gênero e idade dos usuários (NOLDUS, [201?]a; VICARVISION, 2015).

O FaceReader realiza 3 etapas para classificação das emoções: 1- Localização da face: inicialmente, a face é detectada por meio do algoritmo de Viola-Jones (VIOLA; JONES, 2001), e a posição dos olhos é utilizada para calcular possível rotação da face. 2- Modelagem: em seguida é criada uma modelagem 3D da face, usando uma abordagem algorítmica baseada em Modelos de Aparência Ativa (AAM - Appearance Active Model) (COOTES; EDWARDS; TAYLOR, 2001), descrevendo 500 pontos-chave nas ROI do rosto, incluindo sobrancelhas, olhos e boca. A textura da face é descrita pelo emaranhamento desses pontos, que podem conter informações sobre enrugamento da pele e mudanças de iluminação. $\mathrm{O}$ 
AAM identifica variações em um conjunto de imagens e descreve as principais fontes de variação encontradas. $\mathrm{O}$ modelo se assemelha com a face original, e novas faces podem ser descritas pelo desvio médio usando o vetor de aparências. 3- Classificação: uma rede neural artificial (RNA), treinada com mais de 10 mil imagens analisadas por peritos, é utilizada na classificação das emoções (NOLDUS, [201?]a; KUILENBURG; WIERING; UYL, 2005; LEWINSKI; UYL; BUTLER, 2014).

\subsubsection{Intraface}

Além dos sistemas comerciais apresentados, todos com licenças comerciais e proprietárias, existe também o Intraface fornecido em forma de software livre. O Intraface surgiu dos esforços de pesquisa no desenvolvimento de algoritmos para análise de imagem facial das Universidades de Carnegie Mellon e de Pittsburgh. Em 2008, as equipes de pesquisadores começaram a integrar seus algoritmos, cinco anos mais tarde foi lançado o IntraFace (INTRAFACE, 2015). O sistema oferece as funcionalidades de detecção da face, estimativa de pose da face, detecção de atributos como gênero, idade, etnia e cor do cabelo, classificação da expressão e transferência de expressão facial.

Os autores utilizam método SDM (Supervised Descent Method), baseado no método de Newton, para a detecção de características faciais (XIONG; DE LA TORRE, 2013), e o algoritmo de treinamento Selective Transfer Machine (STM), que considera características específicas de cada usuário, personalizando classificadores genéricos no treinamento do classificador das AUs (CHU; DE LA TORRE; COHN, 2013; DE LA TORRE et al., 2015). Atualmente, os pesquisadores têm trabalhado em formas de identificar mais precisamente as AUs, propondo o algoritmo Join Path and Multi-label Learning (JPML) (ZHAO et al., 2015).

A Tabela 3.1 apresenta um comparativo entre as aplicações baseadas em FACSs, em relação às técnicas computacionais utilizadas, evidenciando quais delas oferecem APIs e SDKs, emoções reconhecidas e eficiência de classificação. 
Tabela 3.1 - Comparação entre softwares que utilizam o FACS. (1) Método de Extração de Características

Faciais. (2) Método de Classificação de Emoções. (3) Fornece API/SDK. (4) Emoções: (F) felicidade, (S) surpresa, (M) medo, (T) tristeza, (R) raiva, (A) aversão, (D) desprezo, (N) neutro. (5) Eficiência de classificação.

(6) *1 (NVISO, 2015; SORCI et al., 2010) *2 (EMOTIENT, 2015; LITTLEWORT et al., 2006) 3*

(AFFECTIVA, 2015a; AFFECTIVA, 2015b; MCDUFF et al., 2015) *4 (MOORE; ONG; BOWDEN, 2010;

KAIROS; 2015) *5 JOHO et al., 2009; SEBE et al., 2006; SIGHTCORP, $2015 * 6$ (JENI et al., 2011; REALEYESIT, 2015)*7 (NOLDUS, [201?]a ; LEWINSKI; UYL; BUTLER, 2014) *8 (DE LA TORRE et al.,

2015; INTRAFACE, 2015). * Somente uma API para aplicações on-line que roda diretamente no servidor da empresa. Não é possível baixar a API e integrar com soluções locais off-line.

\begin{tabular}{|c|c|c|c|c|c|c|}
\hline \multicolumn{7}{|c|}{ Comparação entre Softwares que Utilizam FACS } \\
\hline & (1) & (2) & (3) & (4) & (5) & $(6)$ \\
\hline nViso & AAM & DCM & API & $\mathrm{F} / \mathrm{S} / \mathrm{M} / \mathrm{T} / \mathrm{R} / \mathrm{A} / \mathrm{N}$ & $76 \%$ & $* 1$ \\
\hline Emotient & Gabor & AdaSVM's & API & $\mathrm{F} / \mathrm{S} / \mathrm{M} / \mathrm{T} / \mathrm{R} / \mathrm{A} / \mathrm{D} / \mathrm{N}$ & $93 \%$ & $* 2$ \\
\hline Affdex & HOG & SVM & API/SDK & $\mathrm{F} / \mathrm{S} / \mathrm{M} / \mathrm{T} / \mathrm{R} / \mathrm{A} / \mathrm{D}$ & $80 \% \sim 90 \%$ & $* 3$ \\
\hline Kairos & $\begin{array}{c}\text { Canny } \\
\text { Temp.Boost }\end{array}$ & SVM & API & $\mathrm{F} / \mathrm{S} / \mathrm{M} / \mathrm{T} / \mathrm{R} / \mathrm{A} / \mathrm{N}$ & $86 \%$ & $* 4$ \\
\hline Sightcorp & PBVD & RB & API/SDK & $\mathrm{F} / \mathrm{S} / \mathrm{M} / \mathrm{T} / \mathrm{R} / \mathrm{A} / \mathrm{N}$ & $93 \%$ & $* 5$ \\
\hline RealEyes & CLM & SVM & API* & $\mathrm{F} / \mathrm{S} / \mathrm{M} / \mathrm{T} / \mathrm{R} / \mathrm{A} / \mathrm{D}$ & $95 \%$ & $* 6$ \\
\hline FaceReader & AAM & RNA & API & $\mathrm{F} / \mathrm{S} / \mathrm{M} / \mathrm{T} / \mathrm{R} / \mathrm{A} / \mathrm{N}$ & $88 \%$ & $* 7$ \\
\hline Intraface & SDM & STM & API & $\mathrm{F} / \mathrm{S} / \mathrm{M} / \mathrm{T} / \mathrm{R} / \mathrm{A} / \mathrm{D}$ & $96 \%$ & $* 8$ \\
\hline
\end{tabular}

Fonte: Elaboração própria.

\subsection{Considerações Finais}

Nos primórdios da computação pessoal, a inexistência de formas de expressar emoções na HCI levou as empresas desenvolvedoras de softwares a adaptarem o conceito do mascote associado a uma marca e criarem seus mascotes virtuais. As expressões faciais dos mascotes complementavam os textos, remetendo o usuário a algo familiar à interação entre humanos durante o processo de HCI. Essa foi a primeira forma de adicionar componentes emocionais a sistemas computacionais.

Com o avanço da tecnologia e a diminuição dos custos de hardware, os produtos computacionais tornaram-se cada dia mais populares e presentes no cotidiano dos seres humanos. Assim, a construção de máquinas com comportamentos verossímeis aos humanos deixou de ser apenas tema de filmes de ficção científica e passou a integrar as pesquisas científicas e acadêmicas. Empresas começaram a desenvolver agentes virtuais e físicos capazes de interagir com os usuários, simulando emoções pela fala e expressões faciais. Pesquisas também foram desenvolvidas com base em teorias advindas da psicologia, com o objetivo de dotar o computador da capacidade de reconhecer as emoções humanas, visando melhorar a experiência do usuário nos processos de HCI.

O Sistema de Codificação de Ação Facial tem sido utilizado por pesquisadores que implementam, por meio de técnicas de processamento de imagens, o sistema proposto por Ekman e Frisen (1978) para realizar a classificação das emoções, analisando-se a 
movimentação dos músculos da face. O FACS está consolidado não só em pesquisas acadêmicas, mas também em implementações comerciais para aplicações nas mais diversas áreas, tais como entretenimento, saúde, automação e vigilância, entre outras. A área de pesquisas de marketing é a que concentra a maior parte das aplicações comerciais que utilizam FACS.

Questões como iluminação, inclinação da face, resolução da imagem e ruídos como óculos e maquiagem não fazem parte do escopo deste trabalho, porém, os trabalhos realizados nos últimos anos apresentam as mais diversas soluções computacionais para estas questões, o que torna a implementação do sistema em um ambiente real (natural) viável.

Um outro ponto importante, e que os algoritmos atuais ainda não conseguem lidar de forma robusta, é que, ao utilizar um computador, o usuário pode estar falando, comendo ou fumando, por exemplo. Tais ações modificam o comportamento muscular facial. Lidar com essas questões ainda se apresenta um desafio para a execução de sistemas computacionais de detecção das emoções em ambientes reais de forma automatizada. O software nViso, por exemplo, utiliza uma exibição resumida de imagens empilhadas de fácil visualização, para que tais ruídos possam ser eliminados. Porém, a seleção dos trechos com ruído é feita por seres humanos (NVISO, 2015). Contudo, assim como o ser humano tem a capacidade de processar de forma paralela a mímica da face, expressa durante a emoção e a movimentação facial gerada por ações como comer, falar, etc., é possível criar um modelo computacional capaz de processar separadamente tais informações.

Um forte indício dessa possibilidade é a forma de resolução proposta neste trabalho para o problema encontrado na modelagem das emoções de pessoas deficientes, com as quais um ruído - o tique - teve que ser filtrado para que as emoções pudessem ser classificadas com maior precisão.

De fato, os seres humanos apresentam tiques em maior ou menor intensidade. $\mathrm{Na}$ maioria das pessoas isso quase nem é notado, e pelos resultados apresentados nas pesquisas sobre FACS, relatadas neste capítulo, que sequer consideram tal assunto, pode-se supor que os tiques não são relevantes (não atrapalham) para a classificação das emoções básicas. $\mathrm{O}$ mesmo já não se pode afirmar quando o objeto de estudo é classificar micro expressões. Nesse caso, um rápido e pequeno movimento do rosto, dado por um tique, pode ser confundido facilmente com uma micro expressão. Outra questão a ser analisada é se o tique é constante na pessoa ou se só é apresentado quando a pessoa é submetida a determinadas situações, ou seja, o tique pode refletir uma alteração no estado emocional do indivíduo. 
O fato é que mesmo para classificar emoções básicas em pessoas deficientes os modelos descritos na literatura pesquisada não foram eficientes, uma vez que o tique em pessoas deficientes é bastante acentuado e impediu a classificação correta das emoções. Dessa forma, pode-se afirmar que os sistemas de Computação Afetiva atuais, que utilizam a classificação das emoções por meio da mímica da face, não estão preparados para uso por pessoas com deficiência. Assim, uma nova abordagem é proposta, classificando a emoção apenas depois de filtrar os tiques dos usuários. A abordagem é descrita em detalhes no capítulo Materiais e Métodos. 


\section{Capítulo}

\section{Computação Assistiva}

Desde a história primitiva até poucas décadas atrás, a exclusão de pessoas, seja por motivos sociais, culturais, psicológicos, físicos ou outros, ocorre sistematicamente.

Atualmente, a discussão do tema nos meios de comunicação, nas leis, além de maior facilidade de acesso à informação têm dado destaque ao assunto inclusão. Em meio a este cenário, surge o conceito de tecnologia assistiva.

A tecnologia assistiva pode ser definida como "uma ampla gama de equipamentos, serviços, estratégias e práticas concebidas e aplicadas para diminuir os problemas encontrados pelos indivíduos com deficiências" (COOK; HUSSEY, 2008, p. 3).

$\mathrm{O}$ avanço da informática associado à diminuição dos custos de hardware torna a ciência da computação um dos ramos de conhecimento de grande difusão de tecnologias assistivas, denominado computação assistiva. 


\subsection{Deficiência}

A deficiência faz parte da condição humana. Seja por incapacidades natas, inatas, temporárias, permanentes ou advindas da idade, de alguma forma, ao longo da vida, o ser humano experimenta dificuldades em algum tipo de funcionalidade (OMS, 2011).

Estima-se que cerca de $15 \%$ da população mundial (aproximadamente um bilhão de pessoas) vivam com alguma forma de deficiência. Dessas, segundo a World Health Survey, 110 milhões possuem dificuldades funcionais muito significativas. Já a Global Burden of Disease estima que existem 190 milhões de pessoas com deficiências graves, tais como a tetraplegia, a depressão grave ou a cegueira. A Global Burden of Disease mensura que 95 milhões de crianças entre 0 a 14 anos são deficientes, das quais 13 milhões possuem deficiências graves (OMS, 2011).

O aumento da expectativa de vida associado ao aumento de condições crônicas de saúde - tais como diabetes e pressão alta, abuso de drogas, dietas e doenças mentais modernas, tais como stress e síndromes - tendem a aumentar a cada ano o número de pessoas deficientes.

Segundo dados do Portal Brasil (2015), no Brasil existem 24,5 milhões de pessoas com alguma deficiência, das quais 4,3 milhões possuem limitações severas.

As deficiências podem ter origem genética, surgir no período pré-natal ou em decorrência do parto. Podem, ainda, ser consequência de perturbações psiquiátricas, desnutrição, abusos de drogas, doenças transmissíveis ou crônicas, traumas e lesões. Existem ainda as deficiências por acidentes, que podem causar deficiências temporárias ou permanentes (PORTAL BRASIL, 2015).

\subsection{Tecnologias Assistivas}

O termo Tecnologia Assistiva (Assistive Technology) surgiu em 1988, na criação de uma legislação americana conhecida como Public Law 100-407. A tecnologia assistiva é composta por recursos que são produtos ou sistemas produzidos para aumentar, manter ou melhorar as capacidades funcionais das pessoas deficientes, e por serviços que auxiliam a seleção, a compra ou o uso de recursos. Um recurso pode variar de uma simples bengala a um complexo sistema computacional. Já um serviço é prestado à pessoa com deficiência visando selecionar, obter ou usar um instrumento de tecnologia assistiva (BERSCHE; TONOLLI, 2006). 
Sartoretto e Bersch (2014a) apresentam uma categorização das tecnologias assistivas segundo a ADA (American with Disabilities Act):

Auxílio para a vida diária: materiais e produtos que auxiliam o cotidiano das pessoas deficientes como, por exemplo, comer, cozinhar, vestir-se, entre outros.

Sistemas de Controle de Ambiente: dispositivos eletrônicos que permitem aos deficientes controlar remotamente aparelhos eletroeletrônicos.

Projeto Arquitetônico Acessível: adaptações estruturais que removem as barreiras físicas, possibilitando a locomoção de deficientes. Exemplo: rampas de acesso e elevadores.

Órtese e prótese: utilização de membros artificiais em partes do corpo faltantes ou com funcionamento comprometido.

Adaptações em Veículos: acessórios e adaptações que possibilitam a condução do veículo, elevadores para cadeiras de rodas, camionetas modificadas e outros veículos automotores usados no transporte de deficientes.

Adequação Postural: adaptações que proporcionam distribuição adequada da pressão na superfície da pele, além de maior estabilidade e postura adequada por meio do suporte e posicionamento de tronco, cabeça e membros.

Auxiliadores de Mobilidade: equipamento utilizado na locomoção do deficiente como cadeira de rodas, andadores, etc.

Auxiliadores para Deficiências Visuais: produtos específicos para pessoas cegas, com baixa visão ou com daltonismo. Exemplos: lupas, sintetizadores de voz, braile, sistemas de cores, contrastes e tamanhos adaptáveis em sistemas computacionais.

Auxiliadores para Deficientes Auditivos: produtos específicos para surdos ou pessoas com déficit auditivo. Exemplos: equipamentos infravermelho, aparelhos para surdez, telefones com teclado - teletipo (TTY) e sistemas com alerta táctil-visual, entre outros.

Acessibilidade Computacional: recursos de hardware e software que permitem às pessoas deficientes usarem o computador. Entre tais recursos, encontram-se os sintetizadores de voz, teclados em braile, software de reconhecimento de voz e sistemas de visão computacional que permitem operar o mouse por meio do movimento dos olhos.

Comunicação Alternativa e Ampliada: recursos que possibilitam a comunicação expressiva e receptiva de deficientes da fala. Como exemplo, pode-se citar as pranchas de comunicação com os símbolos PCS (Picture Communication Symbols) ou Bliss, além de vocalizadores e softwares dedicados para este fim. 


\subsection{Comunicação Alternativa e Ampliada}

A Comunicação Alternativa e Ampliada (CAA) é responsável por oferecer às pessoas com dificuldade de comunicação uma nova forma de interação com o meio externo, de maneira diferente da comunicação oral ou escrita, sendo esses meios: gestos, sons, expressões faciais e corporais, permitindo-as expressar, socialmente, suas vontades, desejos e opiniões (SARTORETTO; BERSCH, 2014b).

Também chamada de comunicação suplementar, a CAA pode auxiliar pessoas de qualquer idade que possuam distúrbios de comunicação, como paralisia cerebral, autismo, traumatismo crânio-encefálico, etc., no processo de interação dos indivíduos (JUNQUEIRA, 2007). Dentre os recursos oferecidos pela CAA estão os sintetizadores de voz e de língua de sinais. As pranchas de comunicação, cartões de comunicação ou pranchas de alfabetização também figuram entre os recursos que visam promover a CAA (SARTORETTO; BERSCH, 2014b).

As Figuras 4.1 a 4.3 apresentam exemplos de sistemas de CAA por símbolos.

Figura 4.1 - Cartões de comunicação.

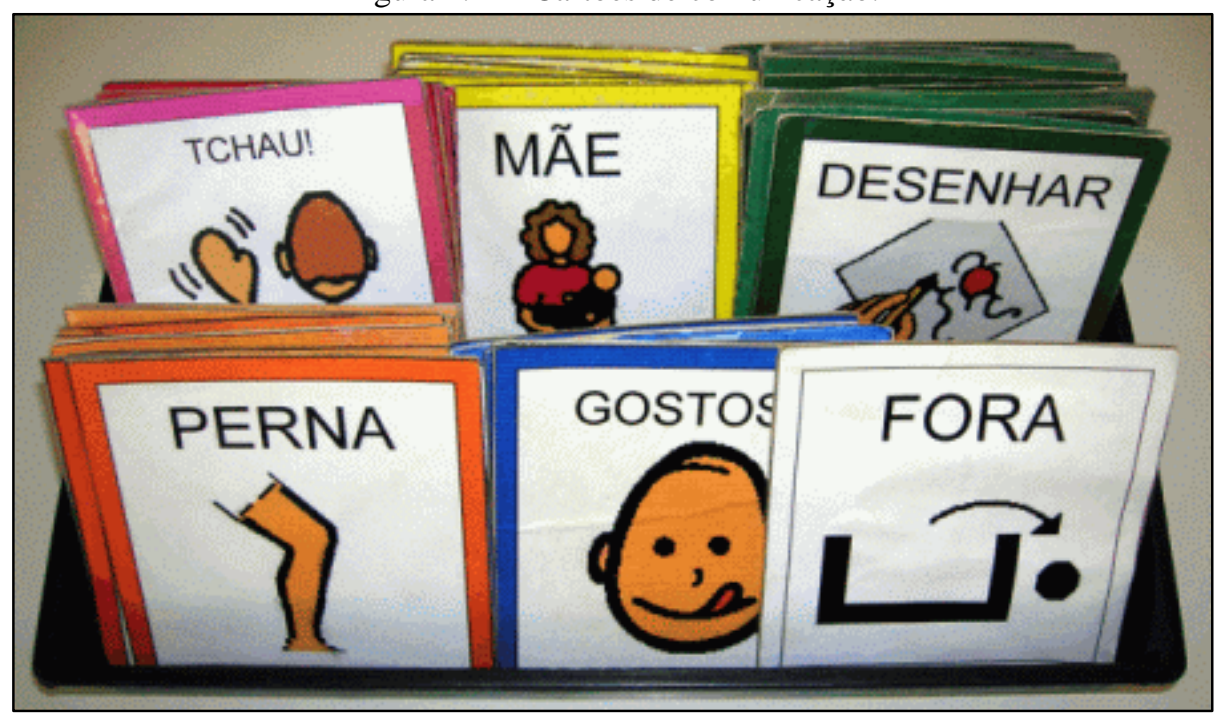

Fonte: Sartoretto e Bersch (2014b). 
Figura 4.2 - Prancha de comunicação com símbolos, fotos ou figuras.

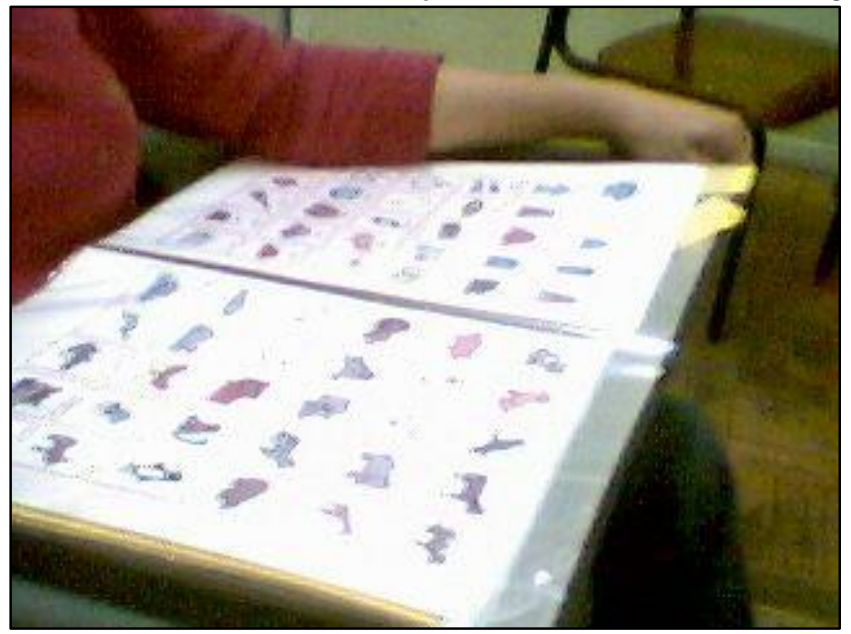

Fonte: Sartoretto e Bersch (2014b).

Figura 4.3 - Prancha de comunicação alfabética.

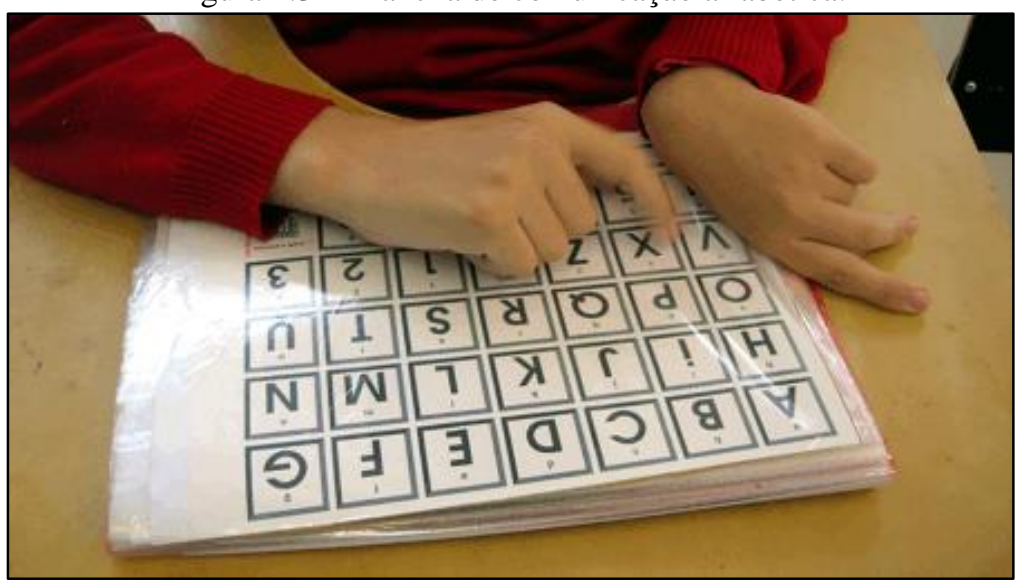

Fonte: Sartoretto e Bersch (2014b).

\subsubsection{Comunicação Alternativa e Ampliada no Brasil}

No Brasil, a CAA foi trazida por uma escola especial de um centro de habilitação de São Paulo, que atendia pessoas com paralisia cerebral sem déficits cognitivos, no ano de 1978 (NUNES, 2007). A partir de então, diversos estudos e pesquisas foram desenvolvidos voltados à área educacional e familiar.

O Laboratório de Tecnologia e Comunicação Alternativa, conhecido como LATECA, da Universidade Estadual do Rio de Janeiro (UERJ), é o pioneiro em pesquisas sobre educação especial no Brasil. Desde 1995, oferece disciplinas sobre o tema para programas de graduação e pós-graduação (LATECA, 2015). 


\subsubsection{A Importância da CAA no Ambiente Familiar e Escolar}

Alencar (2002) demonstrou em seus estudos que a interação entre alunos, professores e outros departamentos de uma escola para deficientes do Rio de Janeiro melhorou após o início do uso da CAA por meio de um sistema pictográfico.

Lacerda (2000) observou durante sua pesquisa o uso doméstico de uma prancha de comunicação por um adolescente com paralisia cerebral. Constatada a impaciência da mãe na utilização da prancha, por ela acreditar que compreendia os gestos e expressões do seu filho, realizou-se sua orientação e conscientização sobre a importância do uso da prancha para o adolescente. Então, a mãe percebeu a dificuldade que o filho tinha em construir frases e passou a motivá-lo para usar, com frequência, a prancha de comunicação, trazendo uma melhora no nível de cognição desse adolescente.

Em ambos os casos, é notável que a comunicação das pessoas deficientes melhorou com o uso de meios de CAA.

\subsubsection{Sistemas de Símbolos da CAA}

A prancha de comunicação está introduzida no sistema de símbolos gráficos da CAA que utiliza um conjunto de imagens gráficas para expressar as necessidades do usuário deficiente. Os sistemas de símbolos mais conhecidos são: Rebus, BlyssSimbolics (Sistema Bliss) e PCS (Picture Communication Symbols).

\subsubsection{Sistemas Rebus}

O Sistema Rebus, da Widgit, possui milhares de símbolos com representações gráficas de conceitos, ideias e palavras. Os símbolos possuem uma estrutura esquemática e fazem uso de indicadores gramaticais, como setas para indicar o modo verbal, categorias, preposições e negativos (RUS, 2015). A Figura 4.4 apresenta um exemplo do sistema de símbolos contando a história Carol for Christmas. 
Figura 4.4 - História Carol for Christmas contada com o sistema de símbolos Rebus.
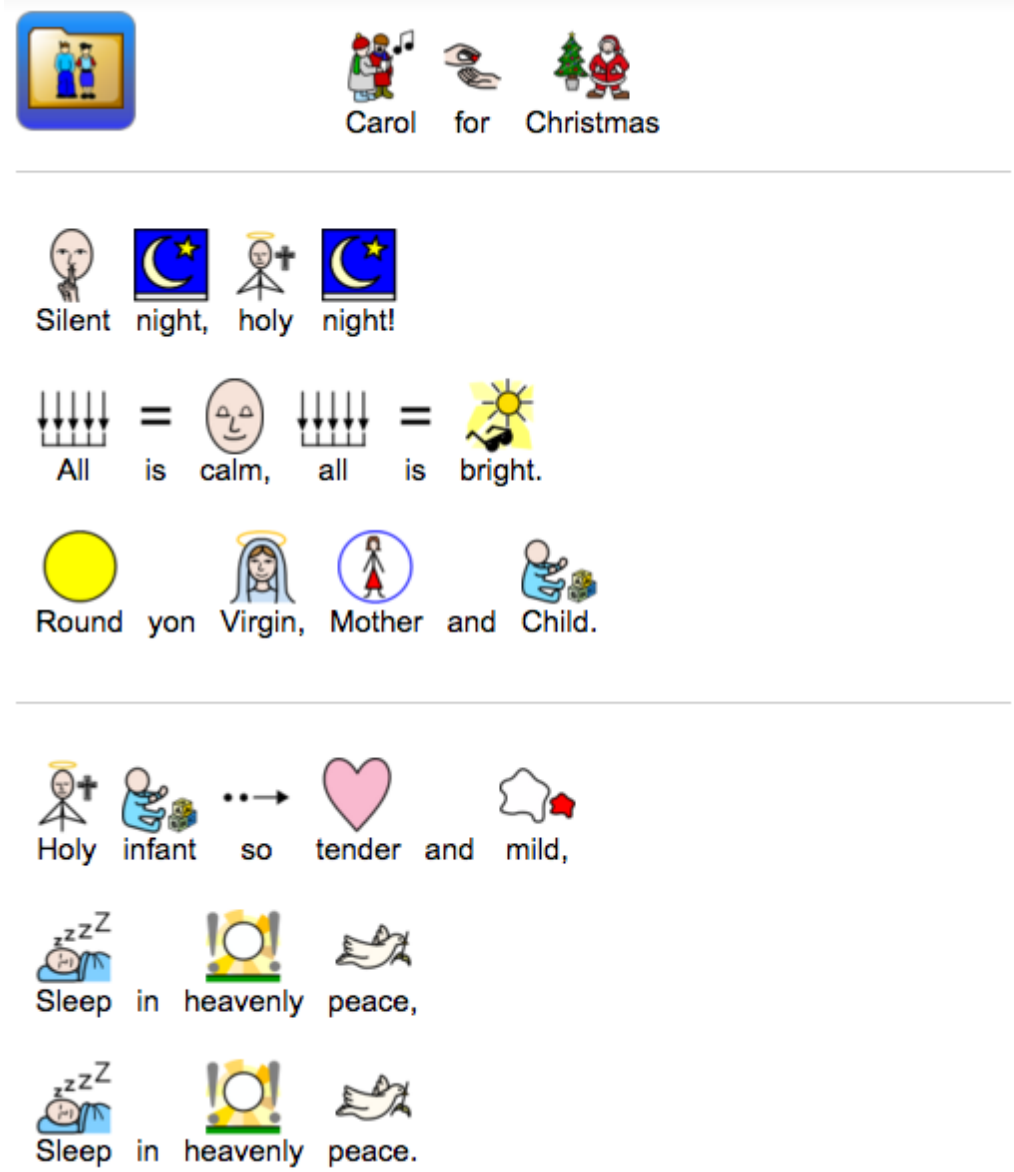

Fonte: SYMBOLWORLD (2015).

\subsubsection{Sistemas Bliss}

O sistema de comunicação por símbolos Bliss foi originalmente desenvolvido por Charles K. Bliss com o objetivo de criar uma comunicação internacional. Em 1971, foi utilizado pela primeira vez para a comunicação de crianças deficientes (LUNDALV, 2015).

A linguagem Blissymbolics é atualmente composta por mais de 5.000 símbolos gráficos. Cada símbolo ou palavra-Bliss é composto por um ou mais BLISS-caractere, que podem ser combinados de diversas formas para criar novos símbolos (LUNDALV, 2015).

As formas simples possibilitam acesso fácil e rápido, já as utilizações mais complexas permitem expressar diversas sentenças e expressões gramaticais. Assim, o sistema Bliss atende pessoas com capacidades intelectuais variadas.

Alguns símbolos são pictogramas, ou seja, parecem-se com as coisas que eles representam (Figura 4.5). Outros são sugestivos aos conceitos que representam e denominamse ideográficos (Figura 4.6). Os demais são símbolos arbitrários, reconhecidos por 
convenções internacionais. Os símbolos podem ainda ser combinados para criar significados adicionais, como ilustra a Figura 4.7.

Figura 4.5 - Símbolos Bliss Pictogramas.

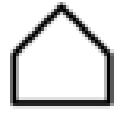

casa

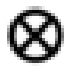

roda

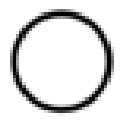

sol

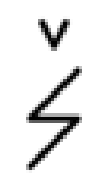

elétrico

Fonte: Lundalv (2015).

Figura 4.6 - Símbolos Bliss Ideográficos.
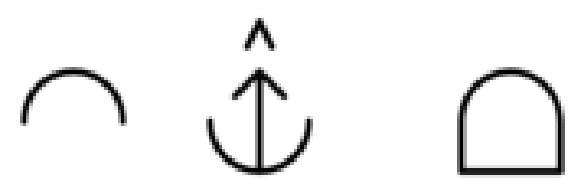

mente dar conhecimento

Fonte: Lundalv (2015).

Figura 4.7 - Símbolos Bliss combinados para criar significados adicionais.

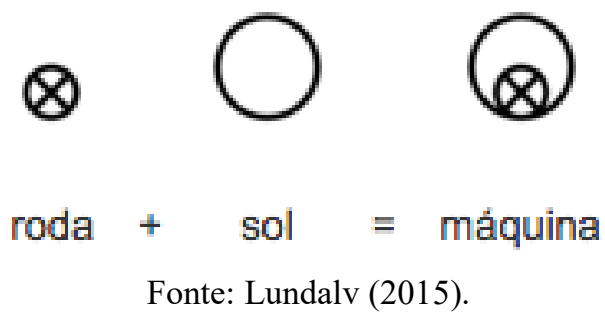

\subsubsection{Sistemas PCS}

O PCS (Picture Communication Symbols), desenvolvido no ano de 1980 por Roxanna Mayer Johnson, possui os mesmos conceitos dos demais sistemas de comunicação alternativa e ampliada. O sistema conta com aproximadamente 8.000 símbolos e uma extensa variedade de vocábulos. Porém, é mais compreensível em relação aos outros sistemas pictográficos, uma vez que suas imagens são mais simples (SARTORETTO; BERSCH, 2014b). 
O PCS possui uma tradução para o português brasileiro, e seus símbolos incorporam características culturais do país, tornando o sistema mais utilizado para elaboração de pranchas de comunicação no Brasil (SCHIRMER et al., 2007).

Além de apresentar símbolos de fácil entendimento, outra característica do PCS é a subdivisão dos símbolos feitas de acordo com as categorias das imagens. Em cada categoria, o pictograma é representado por uma cor de fundo diferente (SCHIRMER et al., 2007; VERZONI, 2011):

Social (rosa): palavras de contexto social;

Pessoas (amarelo): palavras que se referem a pronomes pessoais;

Verbos (verde): palavras que se referem a ações;

Substantivos (alaranjado): palavras que se referem a características;

Descritivos (azul): adjetivos e advérbios;

Miscelânea (branco): artigos, conjunções, preposições, conceitos de tempo, cores, o alfabeto, números e outras palavras abstratas.

A Figura 4.8 ilustra pictogramas de um sistema PCS.

Figura 4.8 - Pictogramas do sistema PCS.

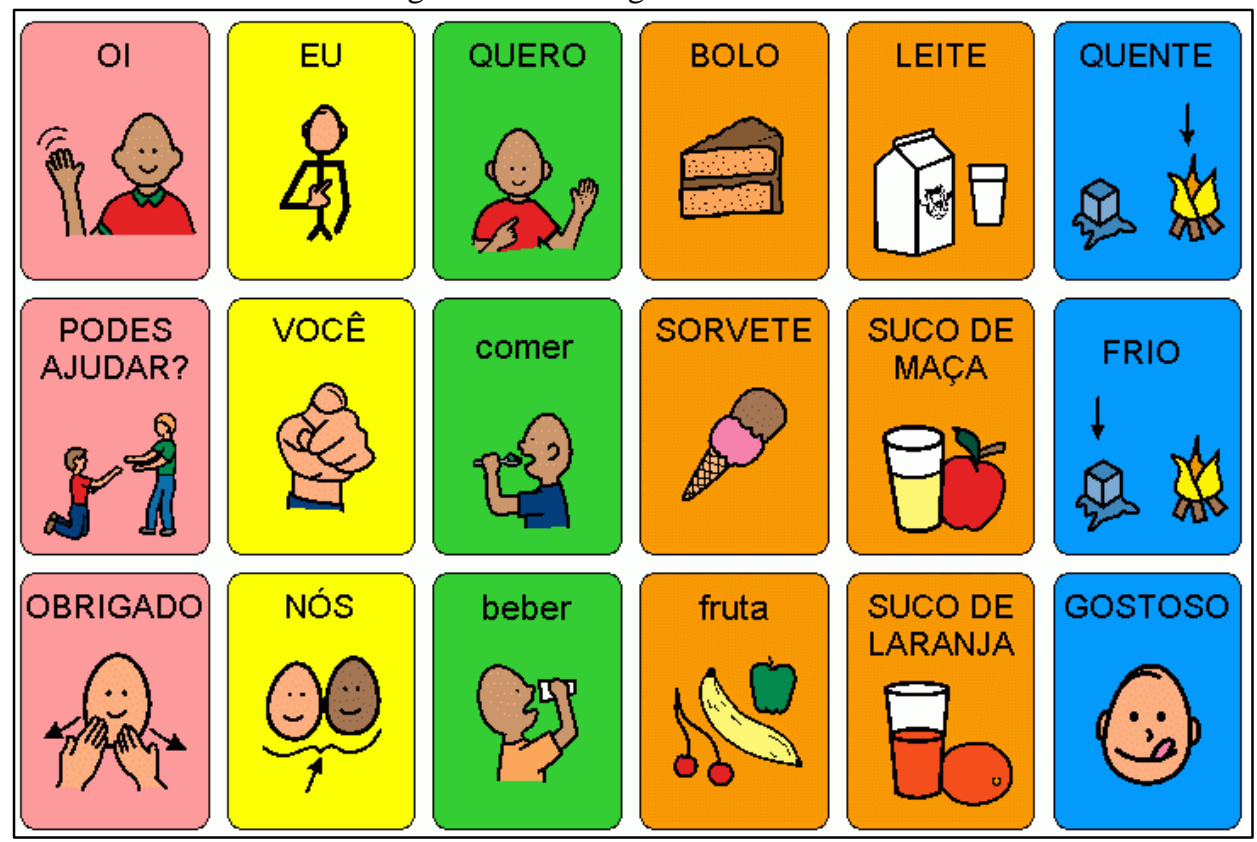

Fonte: Sartoretto e Bersch (2014b).

Uma característica importante do sistema PCS é que os símbolos podem ser modificados e personalizados de acordo com a deficiência do usuário (SCHIRMER et al., 2007). 


\subsection{Softwares de Comunicação Alternativa e Ampliada}

A seguir, serão apresentados dois softwares de comunicação alternativa e ampliada que permitem criar pranchas de comunicação em versão digital.

Versões digitais de pranchas de comunicação possibilitam o acoplamento de outros softwares como sintetizadores de voz e eye tracker, por exemplo, que auxiliam a utilização da prancha por usuários com deficiências mais severas.

Em pranchas digitais há também a possibilidade de implementar um sistema de varredura para usuários que não possuem movimento motor fino suficiente para a seleção de um símbolo. O software, neste caso, é programado para focar símbolo por símbolo, e o acionamento (via toque na tela, mouse, teclado, etc.) é feito pelo usuário no momento em que o símbolo está em foque. Além disso, parâmetros como velocidade do sistema de varredura, lateralidade da varredura (vertical/horizontal) e tamanho do símbolo são facilmente configuráveis.

\subsubsection{Boardmaker}

O Boardmaker é um software que, originalmente, foi desenvolvido para facilitar a criação de pranchas de comunicação para posterior impressão. A versão atual permite sua utilização em dispositivos como computadores e tablets.

Atualmente, o software é comercializado em três versões. O Boardmaker ${ }^{\circledR}$ clássico que permite criar pranchas de comunicação com símbolos PCS ou imagens personalizadas; o Boardmaker® Plus que, além das funcionalidades da versão clássica, oferece recursos de som, animação e vídeo para atividades em dispositivos eletrônicos; e o Boardmaker ${ }^{\circledR}$ Estúdio que traz uma ferramenta de edição de símbolos. Os valores variam de acordo com a versão, base de dados PCS, quantidade de licenças e tipos de dispositivo. Uma versão básica do Boardmaker® Plus, por exemplo, custa $\$ 399,00$. Já a mesma versão com controle eye tracker sai por $\$ 1.169,00$ (JOHNSON, 2015).

\subsubsection{Que-fala!}

O Que Fala! trata-se de um software que permite criar pranchas de comunicação tanto para impressão quanto para utilização em tablets e smartphones. O software de exibição e operação da prancha é gratuito e possui um sintetizador de voz que facilita a comunicação 
entre o deficiente e outras pessoas. No entanto, é necessário adquirir um dos pacotes disponíveis para a edição e a integração de conteúdo personalizado para cada paciente. Os valores das mensalidades dos pacotes variam de $\mathrm{R} \$ 65,00$ a $\mathrm{R} \$ 1.000,00$, de acordo com o tempo de aquisição (QUE FALA, 2013).

\subsection{Considerações Finais}

O aumento da população deficiente e o avanço tecnológico têm levado ao desenvolvimento de sistemas computacionais assistivos que objetivam melhorar o cotidiano de pessoas com necessidades especiais.

Os sistemas atuais de comunicação alternativa e ampliada voltados à comunicação, que possibilitam o uso da tecnologia aliada aos sistemas de símbolos, apresentam um custo alto para a maioria da população.

Assim, nesta pesquisa, a avaliação da influência das emoções humanas em sistemas computacionais foi realizada em testes com pranchas de comunicação em versão digital. No desenvolvimento da área administrativa da prancha, utilizou-se softwares livres e a distribuição do sistema é feita sob licença livre. 


\section{Capítulo}

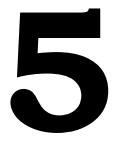

\section{Técnicas Computacionais}

O reconhecimento de expressões faciais pode ser feito sob imagens estáticas ou considerando informações de uma sequência de imagens. Pesquisas demonstram que sequências de imagens fornecem informações mais precisas do que imagens individuais (BASSILI, 1979).

As técnicas computacionais utilizadas na maioria dos sistemas de reconhecimento automatizado de emoções expressas pela face envolvem três etapas: detecção facial, extração de características faciais e inferência do estado emocional do indivíduo (SORCI et al., 2010).

No caso de imagens estáticas, o processo de extração de características é referido como a detecção da face e suas características. Em sequências de imagens, esse processo é designado por rastreamento da face e suas características. Neste ponto, uma distinção deve ser feita entre as características faciais e as características do modelo da face. As características faciais mais proeminentes são sobrancelhas, olhos, nariz, boca e queixo. Já as características do modelo da face são as características usadas para descrever um modelo da mesma. A face pode ser representada de diversas maneiras: como uma unidade integral (representação holística), como um conjunto de características (representação analítica), ou como uma combinação de ambas, gerando uma representação híbrida. A representação escolhida para a 
face e o tipo de imagem de entrada (estática ou sequencial) determinam a escolha do mecanismo de extração de características faciais. O passo final é definir um conjunto de categorias nas quais se deseja usar as expressões detectadas para inferência do estado emocional (PANTIC; ROTHKRANTZ, 2000).

\subsection{Detecção Facial}

O cérebro humano possui a capacidade de reconhecer uma face mesmo em condições desfavoráveis, como baixa iluminação, a uma grande distância, em posições não frontais, com rosto rotacionado, com a presença de óculos, de barba, de chapéu ou de outros objetos que encobrem parcialmente a face. Os trabalhos apresentados nessa área objetivam uma detecção cada vez mais próxima às condições apresentadas em ambientes não controlados.

Diversas pesquisas foram desenvolvidas com o objetivo de detectar a face em imagens, no entretanto, o primeiro estudo a apresentar resultados satisfatórios com alta taxa de acerto em baixo tempo computacional foi o apresentado por Viola e Jones (VIOLA; JONES, 2001). O trabalho desses autores traz três contribuições importantes: uma cascata de classificadores por meio de características haar-like, um classificador boosted que combina classificadores lineares para alcançar alta precisão com baixo tempo de processamento, e o conceito de imagem integral (PAISITKRIANGKRAI; SHEN; ZHANG, 2010). Esse trabalho foi tão importante que se tornou o ponto de partida para diversos outros estudos (MENA; MAYORAL; DÍAZ-LÓPEZ, 2015; ZAFEIRIOU; ZHANG; ZHANG, 2015) e apresenta-se como um dos métodos mais consolidados para detecção da face (SORCI et al., 2010).

Lienhart e Maydt (2002) propuseram um novo conjunto de características haar-like rotacionadas, apresentando resultados mais eficientes para detecção da face e menor índice de falso-positivo. Mais tarde, Li e Zhang (2004) propuseram a utilização da Wavelet de Haar para separar os retângulos haar-like a uma distância à parte. Mita, Kaneko e Hori (2005) propõem juntar características haar-like, que se baseiam na coocorrência de múltiplas características haar-like simples. Huang et al. (2007) utilizam características granulares esparsas que representam a soma de intensidades de pixel em um quadrado, em vez de usar retângulos. Além disso, eles também propõem um algoritmo de aprendizagem fraco eficiente, por meio de um método de busca heurística (PAISITKRIANGKRAI; SHEN; ZHANG, 2010).

O método de Viola e Jones baseia-se na aparência do objeto para aprender características a partir de um conjunto de imagens de treinamento (VIOLA; JONES; SNOW, 2003). Esse processo ocorre sobre imagens estáticas, podendo ser estendido para aplicações 
em tempo real. O método é realizado em três módulos: a criação da imagem integral, o algoritmo Adaboost (FREUND; SCHAPIRE, 1997) para classificação utilizando características haar-like (LIENHART; MAYDT, 2002), e a criação de uma estrutura em árvore chamada de cascata de classificadores.

Viola e Jones (2001) apresentam o conceito de imagem integral que computa, de forma eficiente, a presença ou não de uma característica haar-like para cada posição e escala da janela de observação em que se quer detectar um objeto. Para isso, é feita a soma dos valores dos pixels presentes acima e à esquerda de um pixel específico da imagem. Esse processo está representado na Figura 5.1, onde o ponto 1 contém a soma dos pixels da área do retângulo $\mathrm{A}$. O ponto 2 corresponde à soma dos pixels da área dos retângulos $\mathrm{A}$ e $\mathrm{B}$. Já o ponto 3 é a soma dos pixels das áreas dos retângulos $\mathrm{A}$ e $\mathrm{C}$, e o ponto 4 a soma dos pixels das áreas dos retângulos A, B, C e D. A soma dos pixels na área do retângulo D é dada por: $4+1$ - $(2+3)$ (VIOLA; JONES, 2001).

Figura 5.1- Exemplo para cálculos da imagem integral.

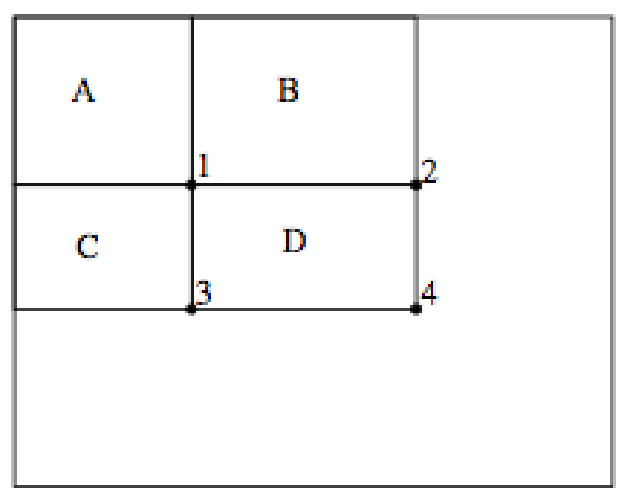

Fonte: Adaptado de Viola e Jones (2001).

A presença ou não de uma característica haar-like em uma posição da imagem é determinada pela convolução na imagem do objeto, baseada numa decisão binária a partir de um limiar. Se a diferença estiver acima do limiar, então pode ser verificada a existência da característica. 
Figura 5.2 - Características do tipo haar-like.

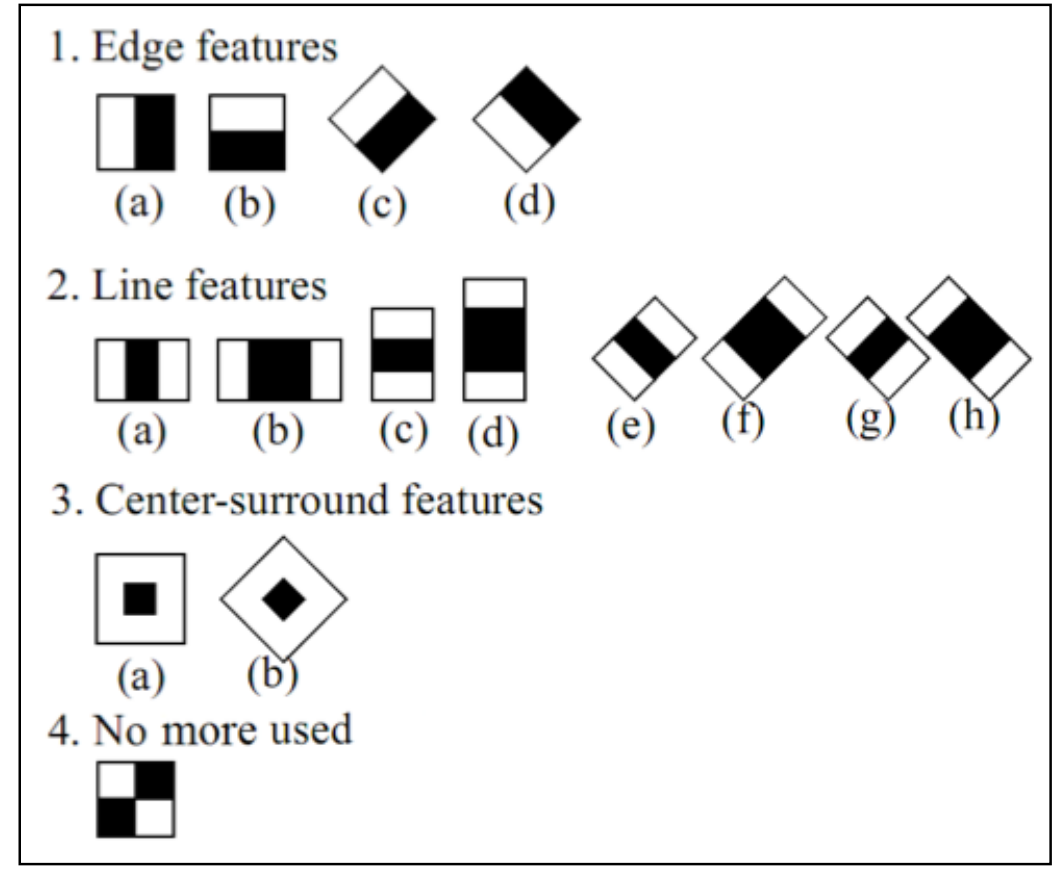

Fonte: Adaptado de Lienhart e Maydt (2002).

Em Viola e Jones (2001) são definidos quatro tipos de características para uso (Figura 5.2, subfiguras 1a, 1b, 2a e 4). No trabalho de Lienhrt e Maydt (2002), essas características foram ampliadas (Figura 5.2, subfiguras 1c, 1d, 2b, 2c, 2d, 2e, 2f, 2g, 2h, 3a e 3b) e retirada uma (Figura 5.2, subfigura 4), que foi substituída por uma combinação (Figura 5.2, subfiguras $2 \mathrm{~g}$ e $2 \mathrm{e})$.

O método Viola-Jones constrói um classificador por meio do algoritmo AdaBoost para definir quais características serão utilizadas e a quais os valores de limiar estarão sujeitas. Assim, é possível formar um bom classificador com a combinação de um número pequeno de características. O principal desafio é definir quais características são mais adequadas. Para isso, o algoritmo realiza a escolha de uma característica para treinar cada classificador, a fim de que ele consiga separar, da melhor maneira possível, amostras positivas e negativas. $\mathrm{O}$ AdaBost constrói um classificador eficiente a partir de um classificador fraco, baseado em decisões binárias pela convolução de máscaras na imagem do objeto. $\mathrm{O}$ algoritmo gera um conjunto de características considerando todas as escalas e enquadramentos possíveis (VIOLA; JONES, 2001).

Por meio de múltiplas chamadas a um classificador fraco, separadas em etapas, o AdaBoost seleciona as características que melhor representam o objeto, esse é o processo de treinamento do classificador. Isso é feito atribuindo-se um peso para indicar a importância de alguns exemplos no conjunto de dados para a classificação. A cada etapa, o peso para cada 
exemplo classificado de forma incorreta é incrementado, fazendo o classificador focar mais esses exemplos. Assim, ao final do processo, os exemplos classificados incorretamente têm seus pesos aumentados, e os exemplos classificados de forma correta têm seus pesos diminuídos. Ao testar uma nova distribuição de pesos, o algoritmo seleciona um classificador que melhor identifica os exemplos que o classificador anterior errava. Cada classificador forte obtido é submetido a uma estrutura de cascata de rejeição (Figura 5.3), ordenada do classificador menos complexo ao mais complexo, onde a complexidade é medida pela quantidade de características. Para a construção da cascata, devem ser considerados a taxa de detecção mínima aceitável, a taxa máxima de falsos positivos aceitável para cada etapa, um conjunto de amostras positivas e negativas, e os valores de falsos positivos para todos estágios da cascata.

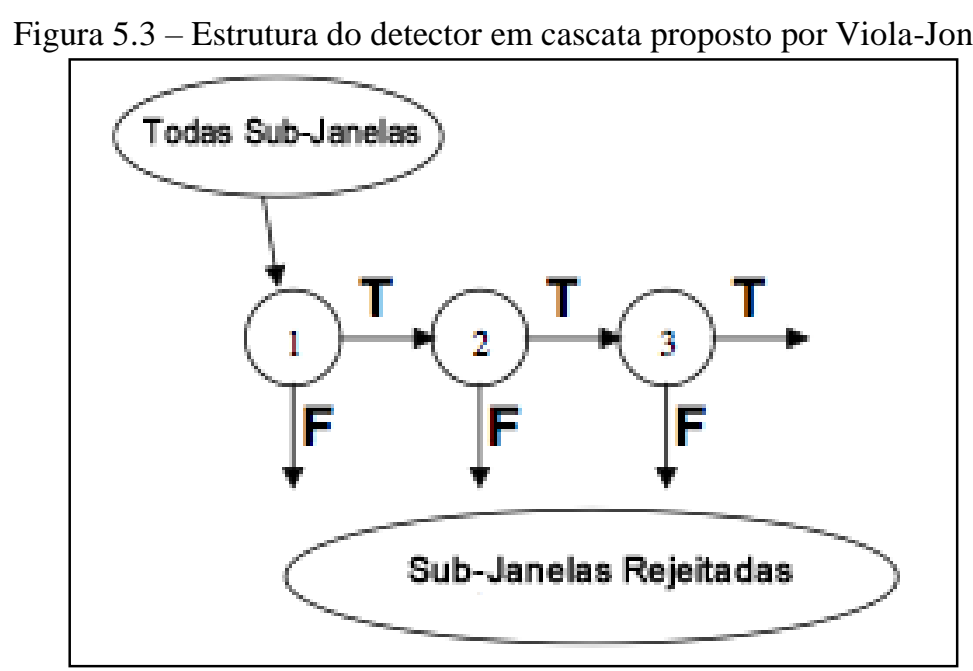

Fonte: Adaptado de Viola e Jones (2001).

O funcionamento do classificador ocorre com a passagem de todas as subjanelas de uma imagem por diversos classificadores. Quando é obtido um resultado positivo, a janela segue para o classificador seguinte, e assim sucessivamente até que seja rejeitada ou chegue no final da cascata. Quando uma janela é rejeitada significa que, segundo o classificador, ali não há uma face.

Uma das características observadas nesse processo é que o número de subjanelas negativas é bem maior do que as subjanelas que são positivas em uma imagem. Assim, o classificador rejeitando as subjanelas negativas, logo nas primeiras etapas, diminui o custo computacional, já que os classificadores mais complexos se encontram no final da cascata. Apenas subjanelas positivas passam por toda árvore. A cada etapa, os classificadores se 
tornam mais custosos, pois eles são treinados usando os exemplos que passaram por todas as etapas anteriores.

Enquanto AdaBoost usa características binárias, outros trabalhos (HUANG et al., 2007; LI et al., 2002; LI; ZHANG, 2004; MITA; KANEKO; HORI, 2005) propõem uma alternativa que utiliza características com valores entre 0 e 1 , buscando melhorias em relação ao algoritmo de aprendizado AdaBoost (MENA; MAYORAL; DÍAZ-LÓPEZ, 2015).

Porém, características do tipo haar-like não foram as únicas que obtiveram êxito na classificação de faces. Levi e Weiss (2004) propuseram o uso de histogramas de orientação de bordas (EOH -Edge Orientation Histograms) para detectar objetos a partir de um banco de treinamento pequeno, melhorando o desempenho em comparação aos sistemas já existentes, sendo capaz de identificar faces frontais e de perfil em tempo real. Dalal e Triggs (2005) utilizaram recursos baseados em histograma de gradiente orientado (HOG - Histograms of Oriented Gradient) para detectar características humanas. Ojala, Pietikaeinen e Maeenpaea (2002) propõem a utilização de padrões locais binários (LBP - Local Binary Patterns) para classificação baseada em textura. Embora esses descritores tenham obtido bons resultados na detecção da face, quando comparados com descritores haar-like eles têm uma complexidade muito maior e demandam mais processamento computacional (PAISITKRIANGKRAI; SHEN; ZHANG, 2010).

Existem, ainda, técnicas de detecção facial baseadas na geometria da face, como por exemplo a abordagem Eigenface, apresentada por Gunduz e Krim (2003), que se baseia em projetar o espaço de imagens em um espaço de características com dimensões reduzidas, fazendo uso da análise de componentes principais (TURK; PENTLAND, 1991); técnicas morfológicas que extraem faces em imagens com base em cores (SAWANGSRI; PATANAVIJIT; JITAPUNKUL, 2007; TORRES; REUTTER; LORENTE, 1999); técnicas baseadas na detecção de bordas, como a proposta por Rakesh, Chaudhuri e Murthy (2004). Entretanto, todas essas técnicas apresentam problemas na detecção de faces em ambientes não controlados (KARMAKAR; MURTHY, 2015).

Alguns autores também propõem a detecção de face por meio de Modelos de Forma Ativa (ASM - Active Shape Models) (COOTES et al., 1995), ou Modelos de Contorno Ativo (ACM - Active Contour Models) (YOKOYAMA; WU; YACHIDA, 1996), porém, tais técnicas apresentam tempo de processamento elevado, além de problemas na detecção da face em certas condições de inicialização (KARMAKAR; MURTHY, 2015).

Mais recentemente, Modelos de Aparência Ativa (AAM - Appearance Active Model) (COOTES; EDWARDS; TAYLOR, 2001) e Modelos Locais Restritos (CLM - Constrained 
Local Models) (CRISTINACCE; COOTES, 2006) também foram propostos na detecção da face (MCDUFF et al., 2015).

\subsection{Extração de Características Faciais}

Após detectar a face, é necessário extrair dela as características utilizadas na inferência das emoções. Dois métodos são mais comumente utilizados para extração de características faciais: métodos baseados em geometria e métodos baseados em aparência. Características geométricas exploram forma e localização de informações de componentes faciais. Recursos baseados na aparência capturam as mudanças da face (incluindo rugas, saliências e sulcos) por meio de filtros aplicados à imagem da face ou sub-regiões do rosto, chamadas de regiões de interesse (ROI - region of interest). Características geométricas são sensíveis ao ruído e normalmente requerem ambientes controlados para uma detecção confiável de características faciais. Já recursos baseados na aparência são menos dependentes de inicialização, são menos suscetíveis a erros de rastreamento e podem codificar mudanças na textura da pele que são importantes para o reconhecimento da expressão facial (MOORE; ONG; BOWDEN, 2010; SORCI et al., 2010).

Técnicas de extração de características faciais com base na geometria da face são apresentadas por Valstar e Pantic $(2006,2007)$ e Pantic e Patras (2006) que detectam e rastreiam um conjunto de pontos de referência (landmarks) ao redor da boca, do nariz, da sobrancelha e do queixo, por meio de características GentleBoost construídas a partir de recursos Wavelet de Gabor. Hu et al. (2004) também se baseiam na geometria da face e considera uma máscara com 58 pontos de referência com base em uma representação ASM da forma da face. Bartlett et al. (2005), Bartlett et al. (2006b) e Ye, Zhan e Song (2004) são exemplos de métodos baseados em aparência, utilizando Wavelets de Gabor na construção de templates para expressões faciais em múltiplas resoluções e diferentes orientações. A abordagem de Chang, Hu e Turk (2004), também baseada em aparência, trabalha com subespaços múltiplos de alinhamentos da aparência da face. Anderson e McOwan (2006) extraem características da face para posterior classificação das expressões faciais por meio de fluxo óptico. Zhang e Ji (2005) apresentam uma abordagem híbrida que detecta 26 pontos de referência torno das ROI (olhos, nariz e boca), inicializando a busca por meio de estatísticas antropométricas.

Outas duas técnicas bastante utilizadas na extração de características faciais são padrões binários locais (LBP - local binary patterns) (CHOI; PLATANIOTIS; RO, 2010; HADID, 
2008) e histogramas de gradiente orientados (HOG - histograms of oriented gradients) (DALAL; TRIGGS, 2005; MCDUFF et al., 2015).

Saragih, Lucey e Cohn (2011) apresentam uma abordagem de otimização de ajustes de modelos deformáveis, na qual dado um modelo global, que representa os pontos de interesse em uma imagem, os pontos de referência (landmarks) ajustam-se ao objeto de interesse por meio de detectores locais que, ao contrário das abordagens holísticas, consideram os pontos separadamente. A abordagem não paramétrica proposta baseia-se na busca de deslocamento pela média de Fukunaga e Hostetler (1975), porém diferenciando-se ao não considerar os pontos de forma simultânea e, também, não impondo uma média global prévia sobre os pontos de articulação.

Inicialmente, o algoritmo calcula os conjuntos candidatos à localização para cada ponto de referência, realizando buscas em regiões retangulares, e então é feita uma estimativa não paramétrica dos mapas de resposta. Após a estimativa, o modelo linearizado é encontrado, e os vetores de deslocamento são calculados pela média cujos pontos seguem a direção do aumento máximo da função de densidade local. Por fim, os parâmetros do vetor $P$ são atualizados. O vetor $P$ é baseado no modelo de distribuição de pontos (PDM - Point Distribuition Model) (COOTES; TAYLOR, 1992). Por meio da busca dos parâmetros do vetor $P$, o erro de desalinhamento (diferença entre o ponto alvo na imagem e os pontos de referência) é minimizado. O algoritmo que realiza o ajuste é denominado Regularized landmark mean-shift (SARAGIH; LUCEY; COHN, 2011).

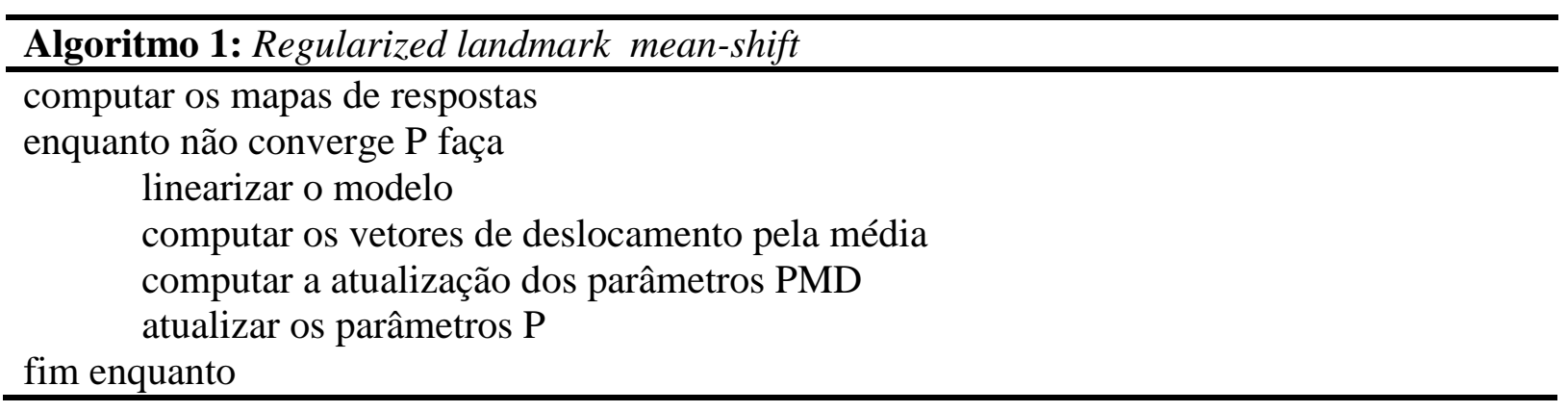

\subsection{Classificação de Expressões}

Após identificar a face e realizar a extração de características da mesma, a etapa seguinte consiste em determinar uma regra para a classificação das características obtidas, a fim de identificar a expressão detectada. Os métodos de reconhecimento de expressão podem 
ser divididos entre métodos baseados em imagens estáticas e métodos baseados em sequências de imagens (SORCI et al., 2010).

Vários métodos baseados em imagens estáticas utilizam Redes Neurais (RN) para classificar a expressão (PADGETT; COTTRELL, 1998; TIAN; KANADE; COHN, 2001, TIAN; KANADE; COHN, 2002; ZHANG et al., 1998). A diferença entre eles são os dados de entrada. Cohen et al. (2003) introduziram e testaram diferentes classificadores bayesianos, comparando-os com a RN proposta por Padgett e Cottrell (1998). Abboud e Davoine (2004) utilizaram coeficientes de aparência em espaços de análise discriminante linear para identificar o cluster de expressão mais próximo. Antonini et al. (2006) introduziram o uso de análise de escolha discreta (DCA - Discrete Choice Analysis) para classificar expressões faciais estáticas, descrevendo as mesmas em termos de um conjunto de características híbridas que consistem em um conjunto de medidas de alto nível, derivadas de um modelo de aparência ativa (AAM), e redefinem a classificação da expressão facial como um processo de escolha discreta. Pantic e Rothkrantz (2000) exploram um modelo de rosto combinando uma vista frontal e uma vista de perfil para extrair características faciais, a fim de reduzir as ambiguidades da geometria da face. Os dados faciais extraídos são convertidos para um conjunto de descritores de regra baseada em FACS. A classificação de expressões faciais é realizada comparando a descrição AU-codificada de expressão observada versus os descritores de regra de seis expressões faciais (SORCI et al., 2010).

Os métodos de reconhecimento baseados em sequências de imagens usam informações temporais para detecção das expressões. Essa e Pentland (1997) apresentaram um sistema capaz de estimar movimento facial utilizando fluxo óptico. Um modelo físico da face é aplicado para a modelagem de atuação do músculo facial. A classificação da expressão facial é feita por meio da invariância entre o template de energia, aprendido a partir das vistas ideais de movimento 2D, e a energia de movimento observada na imagem. Cohen et al. (2003) propõem uma utilização multinível dos modelos ocultos de Markov (HMM - Hidden Markov Models), aplicados a espaços temporais para o reconhecimento de expressões faciais dinâmicas. Changbo et al. (2004) propuseram um método de classificação de expressão probabilístico, integrando rastreamento de expressão e reconhecimento em um sistema cooperativo. Tian, Kanade e Cohn (2001) apresentam uma abordagem de análise automática de expressões faciais com base em características faciais permanentes (sobrancelhas, olhos, boca) e características faciais transitórias (aprofundamento dos sulcos faciais) para sequências de imagens frontais. Valstar e Pantic $(2006,2007)$ combinam algoritmo de SVM com o HMM na classificação das expressões faciais. Koelstra e Pantic (2008) propõem uma abordagem 
baseada na aparência para reconhecimento de AUs e segmentos temporais em sequências de imagens frontais. Um registro não-rígido com base em deformações de forma livre é usado para extrair campos de movimentos faciais e obter histogramas descritores de movimento. Uma combinação de conjunto de aprendizagem e HMMs permite detectar a presença de uma AU e seu segmento temporal numa sequência de vídeo (SORCI et al., 2010).

Moore, Ong e Bowden (2010) apresentam uma abordagem para reconhecimento de expressões faciais em sequências de vídeo. Contornos são utilizados para descrever regiões mais salientes da face. $\mathrm{O}$ algoritmo Temporalboost é usado para construir classificadores que permitem a utilização de informação temporal no reconhecimento de expressões faciais. Classificadores fracos são formados pela montagem de fragmentos de borda com dezenas de chanfro, o algoritmo SVM é utilizado para a classificação final. De la Torre et al. (2015) e Jeni et al. (2011) também utilizam algoritmos de SVM para classificação final das expressões faciais.

Chu, De la Torre e Cohn (2013) propõem personalizar um classificador genérico de forma não supervisionada que considere características individuais - como sobrancelha espessa versus sobrancelha fina, face com marcas profundas de expressão versus face sem marcas de expressão, por exemplo - por meio de um método transdutivo, denominado pelo autor de Selective Transfer Machine (STM).

Diversos autores, como, por exemplo, Abdat, Maaoui e Pruski (2011), Bansal, Chaudhary e Roy (2013), Maaoui, Abdat e Pruski (2014), e Pu et al. (2015), utilizam o algoritmo de Lucas-Kanade (LUCAS; KANADE, 1981; BOUGUET, 2000) em seus estudos sobre classificação automática de expressão facial. Em todos os casos, após detectar a face e inserir pontos de referência nas ROI, as expressões faciais são classificadas por meio da medição da movimentação dos pontos de referência com o algoritmo de Lucas-Kanade (LK).

O método diferencial proposto por Lucas e Kanade (1981) para cálculo do fluxo óptico parte do princípio de que o fluxo é aproximadamente constante em uma vizinhança de pixels e em um intervalo pequeno de tempo (ZHANG; GAO; BAKOS, 2014). Desta forma, o método dos mínimos quadrados é aplicado na resolução das equações básicas para os pixels em determinada vizinhança. Dado um vetor $\left(V_{x}, V_{y}\right)$, a seguinte condição deve ser satisfeita (KALYAN et al., 2011, p. 21): 


$$
\begin{gathered}
I_{x}\left(q_{1}\right) V_{x}+I_{y}\left(q_{1}\right) V_{y}=-I_{t}\left(q_{1}\right) \\
I_{x}\left(q_{2}\right) V_{x}+I_{y}\left(q_{2}\right) V_{y}=-I_{t}\left(q_{2}\right) \\
\vdots \\
I_{x}\left(q_{n}\right) V_{x}+I_{y}\left(q_{n}\right) V_{y}=-I_{t}\left(q_{n}\right)
\end{gathered}
$$

Onde $q_{1}, q_{2}, \ldots, q_{n}$ são pixels dentro de uma janela centrada em um ponto $P$, e $I_{x}\left(q_{i}\right), I_{y}\left(q_{i}\right), I_{t}\left(q_{i}\right)$ são derivadas parciais da imagem $I$ em relação à posição $x, y$ e o tempo $t$, calculados no ponto $q_{i}$ e no tempo corrente.

Transcrevendo a equação em forma de matriz tem-se $A_{v}=b$, onde

$$
A=\left[\begin{array}{cc}
I_{x}\left(q_{1}\right) & I_{y}\left(q_{1}\right) \\
I_{x}\left(q_{2}\right) & I_{y}\left(q_{2}\right) \\
\vdots & \vdots \\
I_{x}\left(q_{n}\right) & I_{y}\left(q_{n}\right)
\end{array}\right], v=\left[\begin{array}{l}
V_{x} \\
V_{y}
\end{array}\right], \text { e } b=\left[\begin{array}{c}
-I_{t}\left(q_{1}\right) \\
-I_{t}\left(q_{2}\right) \\
\vdots \\
-I_{t}\left(q_{n}\right)
\end{array}\right]
$$

Aplicando-se o método dos mínimos quadrados tem-se:

$$
A^{T} A_{v}=A^{T} b \quad \text { ou } \quad v=\frac{A^{T} b}{A^{T} A}
$$

Onde $A^{T}$ é a matriz transposta, ou seja, computa:

$$
\begin{gathered}
{\left[\begin{array}{l}
V_{x} \\
V_{y}
\end{array}\right]=\left[\begin{array}{cc}
\sum_{i} I_{x}\left(q_{i}\right)^{2} & \sum_{i} I_{x}\left(q_{i}\right) I_{y}\left(q_{i}\right) \\
\sum_{i} I_{x}\left(q_{i}\right) I_{y}\left(q_{i}\right) & \sum_{i} I_{x}\left(q_{i}\right)^{2}
\end{array}\right]^{-1}} \\
{\left[\begin{array}{l}
-\sum_{i} I_{x}\left(q_{i}\right) I_{t}\left(q_{i}\right) \\
-\sum_{i} I_{y}\left(q_{i}\right) I_{t}\left(q_{i}\right)
\end{array}\right]}
\end{gathered}
$$

A solução plana dos mínimos quadrados dá a mesma importância para todos os $n$ pixels $q_{i}$ da janela. Porém, uma solução melhor é dar um peso maior aos pixels mais próximos ao ponto central $P$ :

$$
A^{T} W A_{v}=A^{T} W b \quad \text { ou } \quad v=\frac{A^{T} W b}{A^{T} W A}
$$


Onde $W$ é uma matriz diagonal $n \times n$ contendo os pesos $W_{i i}=w_{i}$ a serem assinalados na equação do pixel $q_{i}$ por meio de:

$$
\begin{gathered}
{\left[\begin{array}{l}
V_{x} \\
V_{y}
\end{array}\right]=\left[\begin{array}{cc}
\sum_{i} w_{i} I_{x}\left(q_{i}\right)^{2} & \sum_{i} w_{i} I_{x}\left(q_{i}\right) I_{y}\left(q_{i}\right) \\
\sum_{i} w_{i} I_{x}\left(q_{i}\right) I_{y}\left(q_{i}\right) & \sum_{i} w_{i} I_{x}\left(q_{i}\right)^{2}
\end{array}\right]^{-1}} \\
{\left[\begin{array}{l}
-\sum_{i} w_{i} I_{x}\left(q_{i}\right) I_{t}\left(q_{i}\right) \\
-\sum_{i} w_{i} I_{y}\left(q_{i}\right) I_{t}\left(q_{i}\right)
\end{array}\right]}
\end{gathered}
$$

O peso $w_{i}$ pode ser ajustado como uma função Gaussiana da distância entre $q_{i}$ e $P$.

A versão LK Piramidal consiste em criar uma pirâmide Gaussiana da imagem. O topo da pirâmide contém as imagens com menos detalhes e a base a imagem com todos os pixels, com maior riqueza de detalhes. O fluxo óptico é calculado para os pontos da imagem do topo da pirâmide, e os resultados do cálculo servem de base para os cálculos do nível seguinte (Figura 5.4). Assim, movimentos maiores são computados por janelas locais, tornando o método mais robusto e eficiente, uma vez que não satisfaz à condição inicial do método de que o pixel rastreado e seus vizinhos pertencem à mesma superfície fechada (BRADSKI; KAEHLER, 2008).

Figura 5.4 - Fluxo óptico piramidal de Lucas-Kanade.

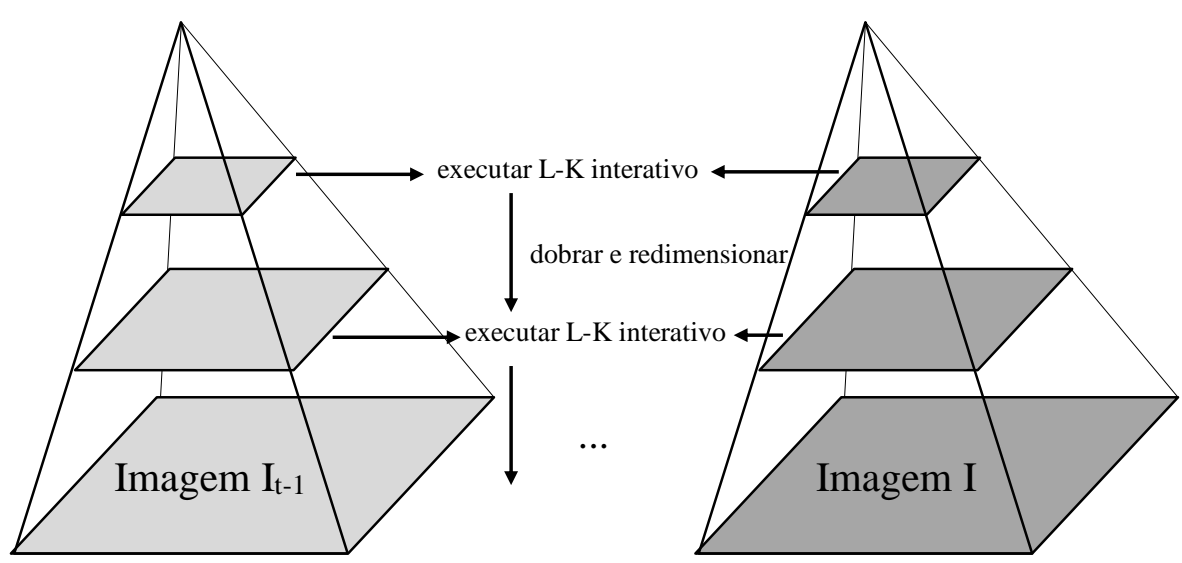

Pirâmide Gaussiana da Imagem It-1

Pirâmide Gaussiana da Imagem I Fonte: Adaptado de Bradski e Kaehler (2008). 


\subsection{Inferência do Estado Emocional}

Após classificar as expressões do usuário, o último passo para um sistema de computação afetiva é inferir o estado emocional.

Os autores Jeni et al. (2011), McDuff et al. (2015), Moore, Ong e Bowden (2010) utilizam o algoritmo de SVM para inferência do estado emocional. Jeni et al (2011) estudam o desempenho do SVM multi-classe na classificação das emoções raiva, desprezo, aversão, medo, felicidade, tristeza e surpresa sob um conjunto de dados utilizando o método CLM para extração de características. McDuff et al. (2015) investigam a relação entre expressões faciais e a eficácia de anúncios em pesquisas de marketing, afirmando que ao modelar tal relação o gosto pelo anúncio pode ser previsto com precisão. Os resultados apresentados demonstram um sistema fiável e generalizável para prever a eficácia do anúncio, automaticamente, a partir de respostas faciais, sem a necessidade de obter respostas de autorrelato dos telespectadores. Além disso, pode-se obter insights sobre a estrutura de anúncios eficazes. Após extrair características faciais por meio de 22 pontos de leitura capturados com o Nevenvision, um algoritmo personalizado da Affectiva classifica o levantar das sobrancelhas, sorriso, expressão de aversão e expressões de valência positiva e negativa por meio de um algoritmo de SVM. Moore, Ong e Bowden (2010) realizam a extração de características por meio da extração de contornos da face, utilizam o algoritmo Temporalboost para construir um classificador que considera informações temporais e fazem a classificação final das emoções felicidade, surpresa, medo, raiva e aversão utilizando uma SVM.

Littlewort et al. (2006) apresentam um sistema de inferência dos estados emocionais tristeza, raiva, felicidade, medo, aversão, surpresa e neutro no qual características faciais extraídas com filtros de Gabor são selecionadas pelo algoritmo AdaBoost e, em seguida, o SVM é treinado sobre as mesmas. O algoritmo SVM, treinado sobre os recursos selecionados por AdaBoost, é denominado pelos autores de AdaSVM.

Sorci et al. (2010) propõem a classificação do estado emocional com o uso de um modelo de escolha discreta (DCM - Discrete Choice Model) para preencher a lacuna existente nos sistemas de detecção de emoções expressas pela mímica da face, no que se refere à falta de uma base única e confiável de classificação de emoções para treinamento de sistemas afetivos e também para a comparação com resultados obtidos computacionalmente. Os autores propõem a utilização de três conjuntos de dados interpretativos para rotular uma emoção: um conjunto de características FACS, unidades de expressões descritivas (EDU Expression Descriptive Unit) - que trazem uma representação de aspectos de configuração 
das características provenientes de recursos individuais da face como boca, nariz, etc. -, e um vetor de aparência que fornece uma descrição do rosto como uma entidade global.

Sebe et al. (2006) propõem um sistema de detecção de emoções por meio de características faciais e da fala, capaz de identificar os estados emocionais neutro, felicidade, surpresa, raiva, aversão, medo, tristeza, frustração, confusão, interesse e tédio. O sistema de reconhecimento de expressão facial utiliza um modelo de face baseado em PBVD (Piecewise Bezier Volume Deformation) no qual um modelo genérico da face é deformado para se ajustar a características faciais detectadas. Deformações em ROI da malha são medidas e armazenadas em um vetor de movimento que representam não só a ativação de uma $\mathrm{AU}$, mas também sua direção e intensidade. A inferência do estado emocional é realizada por meio de uma Rede Bayesiana (RB) que, segundo os autores, consegue lidar com a fusão dos dados de vídeo e áudio de forma adequada. Joho et al. (2009) apresentam uma abordagem para sumarização de vídeo afetivo com base nas expressões faciais de telespectadores. Assim como Sebe et al. (2006), utilizam as informações armazenadas nos vetores de movimentos gerados a partir do método PBVD e também propõem uma estrutura de RB para classificar o estado emocional. A diferença entre as abordagens é que a segunda, além de não considerar sinais vocais, em vez de utilizar a RB para calcular a probabilidade de uma emoção dada a ocorrência de uma AU, considera a relação entre as AUs utilizando a rede para tentar minimizar o erro, por meio de um método de classificação semissupervisionado.

Lewinski, Uyl e Butler (2014) avaliam a implementação computacional do FACS da empresa Noldus, o FaceReader versão 6.0. Inicialmente, é criado um modelo genérico da face por meio do AAM. Depois, são gerados vetores de aparência, também com a utilização do AAM, e a inferência do estado emocional é realizada por meio de um Rede Neural.

De la Torre et al. (2015) apresentam os resultados obtidos com testes do Intraface. Inicialmente, pontos de referência faciais são extraídos utilizando o método SDM (Supervised Descent Method). Após a normalização da imagem, características HOG (histograms of oriented gradients) são extraídas de cada marco e armazenadas em um vetor de características. Finalmente, um classificador SVM é aprendido para cada um dos atributos. A classificação dos estados emocionais é realizada com uma abordagem de aprendizagem transdutiva, denominada STM (Selective Transfer Machine). O Algoritmo STM aprende um classificador enquanto repondera as amostras mais relevantes para os testes. 


\subsection{Considerações Finais}

As técnicas de extração de características faciais baseadas em filtros de Gabor tendem a apresentar uma melhor precisão no reconhecimento da expressão facial. Técnicas de aparência ativa e modelos geométricos, em geral, apresentam-se mais eficientes para detectar alterações faciais dimensionais sob grande variação. Técnicas de análise de componentes principais proporcionam uma melhor discriminação entre característica de emoções semelhantes. Abordagens baseadas em fluxo óptico e textura são boas em representar parâmetros de ação faciais temporais independentes. Modelos ocultos de Markov, redes Bayesiana e os modelos baseados em SIFT (Scale Invariant Feature Transform) oferecem maior resiliência para variações de escala, rotação e ruídos nas imagens (STAROSTENKO et al., 2015).

No desenvolvimento do módulo afetivo deste trabalho, optou-se por realizar a detecção da face nas sequências de vídeo com o algoritmo de Viola e Jones. Após a detecção da face, foram inseridos pontos de referência na face, seguindo a abordagem apresentada por Saragih, Lucey e Cohn (2011). A classificação das emoções foi realizada por uma estrutura de decisão baseada no FACS, com informações extraídas por meio a análise do fluxo óptico da movimentação dos pontos de referência. 


\section{Capítulo}

\section{6}

Materiais e Métodos

Este capítulo descreve os materiais e métodos utilizados nesta pesquisa.

Para avaliar a influência da emoção na tomada de decisão de sistemas computacionais, foram desenvolvidos três módulos: prancha de comunicação; módulo afetivo; módulo de tomada de decisão. A descrição resumida de cada um apresenta-se no início desta tese, e a descrição detalhada será apresentada no presente capítulo. Objetivando uma maior compreensão dos stakeholders envolvidos nas fases de implementação e testes dos três módulos, utilizou-se a seguinte convenção de nomes:

Espectador: pessoa cujas imagens faciais foram capturadas para testes. As imagens faciais dos espectadores foram capturadas em forma de vídeo e deram origem a uma base de dados emocionais com 96 sequências de vídeos, de aproximadamente 3 minutos cada.

Observador: pessoa que assistiu aos vídeos que compõem a base de dados e classificou as emoções neles identificadas.

Usuário: pessoa não deficiente que participou dos testes com a prancha de comunicação. 
Aluno: pessoa matriculada na APAE (Associação de Pais e Amigos dos Excepcionais) de Presidente Prudente que apresenta algum tipo de deficiência e participou dos testes com a prancha de comunicação.

\subsection{Materiais}

Todos os códigos e todos os testes desta pesquisa foram desenvolvidos em um notebook cedido pela Intel Semicondutores do Brasil, na forma de empréstimo em comodato de equipamento, conforme especificações a seguir: BIOS/FW: BIOS 91.3and ME 8.1.0.1220; EC/KSC: EC v3.11; Sensor Hub Firmware: 171755; Chassis: Clamshell form fator; Power Supply: 100-240V AC Adapter; Battery: ATL 594793 47Whrs; Baseboard or Board Set: FAB2-1; Chipset: Mobile Intel ${ }^{\circledR}$ UM77 Express Chipset codenamed Panther Point; Processor: Intel ${ }^{\circledR}$ CoreTM i7-3667U processor (4M Cache, $2.00 \mathrm{GHZ}$ ) codenamed Ivy Bridge 2C ULV 17W; Memory: 4GB DDR3L 1333MHz soldered down; Display and Touch Screen: CPT/Young lighting* UX31 (CLAB133UA02 CG) 13.3" LCD eDP panel with Cando + Atmel* touch screen; Storage Drive: 180GB SSD-Intel® 520 series; Features - Sensor Hub: Accelerometer, Magnetometer, Gyro meter, Ambient Light Sensor; GPS: Fastrax*GPS IT430; TPM: ST Micro*ST33ZP24AR28P-VRC; NFC: SEMCO* module and Cirque* track pad; WLAN: Jackson Peak 2802.11 b/g/n (Wi-Fi)/802.15.1(BT); Audio: Integrated sound card, built in microphone, $3 \mathrm{~W}$ stereo speaker (1.5W x 2); Camera: 1.3MP HD webcam; IO Ports: Multi-touch pad, keyboard, stereo speakers, USB 3.0, SD Micro*, mini HDMI, $3.5 \mathrm{~mm}$ headphone and microfone combo jack; Pre-Installed OS: Microsoft Windows* 8 Release Preview (64 bit); Documentation: DCL, Safety Warning, Wireless Safety, CE, Software Tools COA Card; Accessory Kit: AC adapter/power cord, documentation, 16GB Kingston* DT101G2 flash drive w! Intel Beta 2 drivers for Microsoft Windows* 8 Release Preview (64 bit).

A prancha de comunicação, o módulo afetivo e o módulo de tomada de decisão foram implementados sob Open Web Platform, com as linguagens de marcação HTML (Hyper Text Markup Language), de apresentação CSS (Cascading Style Sheets), e de programação PHP (Hypertext Preprocessor) e ECMAScript, sendo que a PHP foi utilizada como linguagem server-side e o ECMAScript como linguagem client-side. O SGBD (Sistema Gerenciador de Banco de Dados) MySQL foi utilizado para armazenar as informações administrativas da prancha de comunicação, e a linguagem de marcação EML (Emotion Markup Language) para armazenar os dados do módulo afetivo. A interface SpeechSynthesis da API Web Speech foi 
utilizada na prancha de comunicação como sintetizador de voz e a recomendação Touch Events para configurar a sensibilidade do toque (ECMASCRIPT, 2015; MYSQL, 2015; PHP, 2015; W3C, 2015a, 2015b, 2015c, 2015d).

$\mathrm{Na}$ implementação do módulo afetivo, foram utilizadas as bibliotecas clmtrackr (OYGARD, 2014) e jsfeat (ZATEPYAKIN, 2014).

Os softwares AMcap, Camtasia Studio 8 e Windows Live Movie Maker, e a extensão Screencastify do navegador Google Chrome foram utilizados para a captação e edição de vídeos (MICROSOFT, 2015; SCREENCASTIFY, 2015).

O navegador Web Google Chrome foi utilizado em todos os testes (CHROME, 2013).

\subsection{Prancha de Comunicação}

Uma vez que o objetivo principal deste estudo é avaliar a influência das emoções humanas na tomada de decisão de sistemas computacionais e que se optou pela utilização de softwares específicos para deficientes, foi desenvolvido um sistema administrativo capaz de gerar de forma automatizada pranchas digitais de comunicação alternativa e ampliada para deficientes com dificuldade de fala. O sistema PCS é utilizado na prancha devido à sua flexibilidade de combinação dos símbolos, de acordo com a necessidade de cada usuário. Além disso, é possível adicionar símbolos personalizados. O levantamento de requisitos do software foi feito com o auxílio de profissionais de Terapia Ocupacional, Psicólogos e Fisioterapeutas.

O sistema administrativo permite ao profissional que atende pessoas com deficiência cadastrar seus pacientes e gerar pranchas personalizadas para os mesmos. Essas pranchas podem ser copiadas localmente para dispositivos como computadores, tablets e smartphones, entre outros, necessitando apenas do navegador web para funcionar. A Figura 6.1 ilustra a estrutura do mapa do site do sistema administrativo implementado.

Nas telas "criar prancha" e "editar prancha" são configurados parâmetros como tamanho do símbolo, que na versão digital é denominado ícone, lateralidade e velocidade de varredura.

O tamanho do ícone representa a porcentagem que o mesmo será apresentado na tela em relação ao tamanho da imagem original. Já a lateralidade pode assumir os valores vertical, horizontal e nenhuma. O valor nenhuma significa que o sistema de varredura não estará habilitado. A velocidade de varredura representa o tempo que cada ícone ficará focado, caso o mecanismo de varredura esteja habilitado. 
Durante a utilização da prancha com os módulos afetivo e de tomada de decisão atuando, o módulo afetivo identifica dificuldades de utilização, e o módulo de tomada de decisão altera os parâmetros descritos no parágrafo anterior, objetivando melhorar a experiência do usuário.

Figura 6.1- Mapa do site do sistema administrativo da prancha de comunicação.

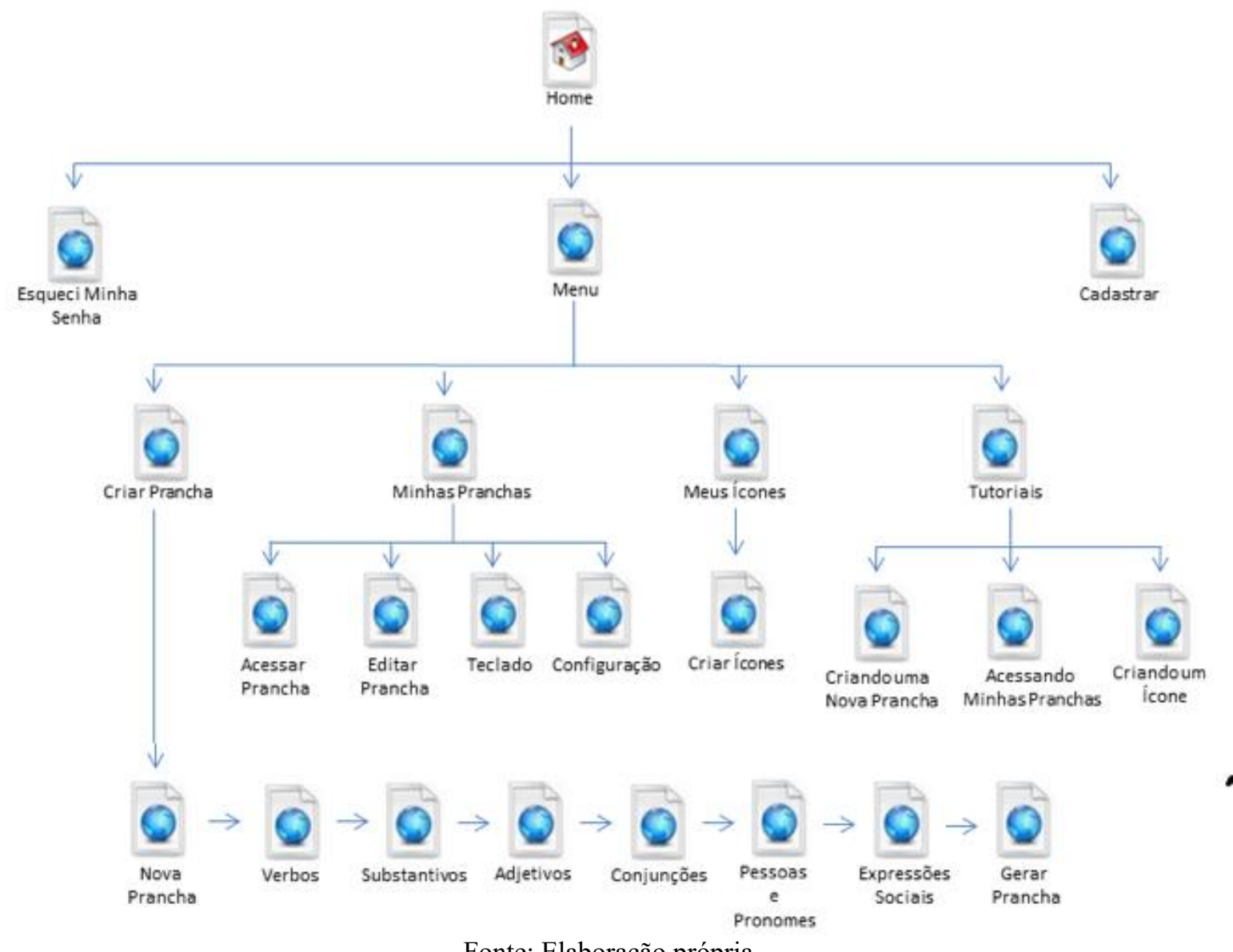

Fonte: Elaboração própria.

Os wireframes e o detalhamento das páginas do mapa do site (Figura 6.1) estão descritos no ANEXO I deste trabalho. O sistema administrativo que gera as pranchas pode ser solicitado para download, por meio do formulário: http://goo.gl/forms/u8am0QFS51.

\subsection{Módulo Afetivo}

Segundo Ekman (1978), a melhor maneira de construir um sistema de medição computacional das ações faciais é entender as técnicas usadas pelos seres humanos em tal processo. O FACS representa as ações faciais por meio dos mesmos processos cognitivos humanos, aproximando-se da experiência do cotidiano das pessoas. Isso o torna muito robusto 
para classificação das emoções básicas (ZENG et al., 2009). Assim, o módulo afetivo implementado neste estudo é baseado no FACS.

O módulo afetivo foi desenvolvido em duas versões: Versão 1: classificar emoções e Versão 2: detectar insatisfação. O objetivo da primeira versão é classificar as emoções raiva, medo, surpresa, tristeza, felicidade e aversão, além do estado emocional neutro. A segunda versão objetiva identificar emoções de valência negativa associadas à dificuldade de utilização de um sistema computacional que, no caso, trata-se de uma prancha de comunicação digital para pessoas deficientes.

As etapas computacionais de detecção da face, extração de características, classificação da expressão facial e inferência do estado emocional foram implementadas nas duas versões do módulo afetivo, sendo que as duas primeiras etapas (detecção da face e extração de características) foram implementas da mesma forma. Já os modelos propostos para as duas últimas etapas (classificação da expressão facial e inferência do estado emocional) são distintos entre as versões. A Figura 6.2 ilustra as versões e etapas do desenvolvimento do Módulo Afetivo.

Figura 6.2 - Etapas de desenvolvimento do Módulo Afetivo para as duas versões.

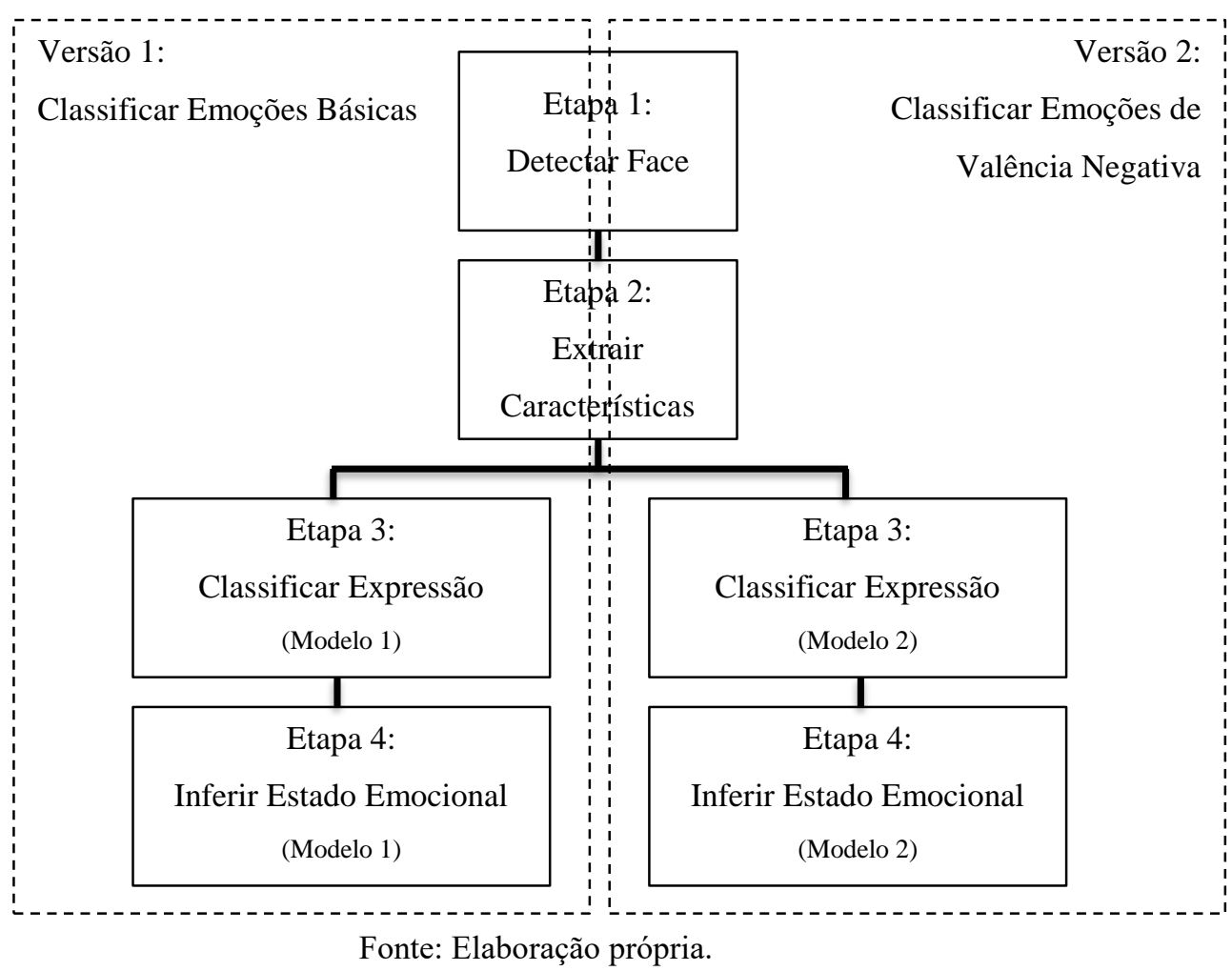




\subsubsection{Etapa 1: Detectar Face}

Dado um streaming de vídeo ou um vídeo pré-gravado, a detecção da face é realizada utilizando-se o algoritmo de Viola e Jones (2001) para aplicações em tempo real com características haar-like descritas em Lienhart e Maydt (2002). O módulo HAAR Cascades object detector da biblioteca jsfeat foi utilizado nesta etapa. A implementação apresentou-se eficiente na detecção da face em poses e situações normalmente vivenciadas pelos usuários de computadores (Figura 6.3). Uma versão de demonstração on-line do algoritmo pode ser acessada em: http://inspirit.github.io/jsfeat/sample_haar_face.html.

Figura 6.3 - Poses comuns de pessoas ao utilizar o computador.

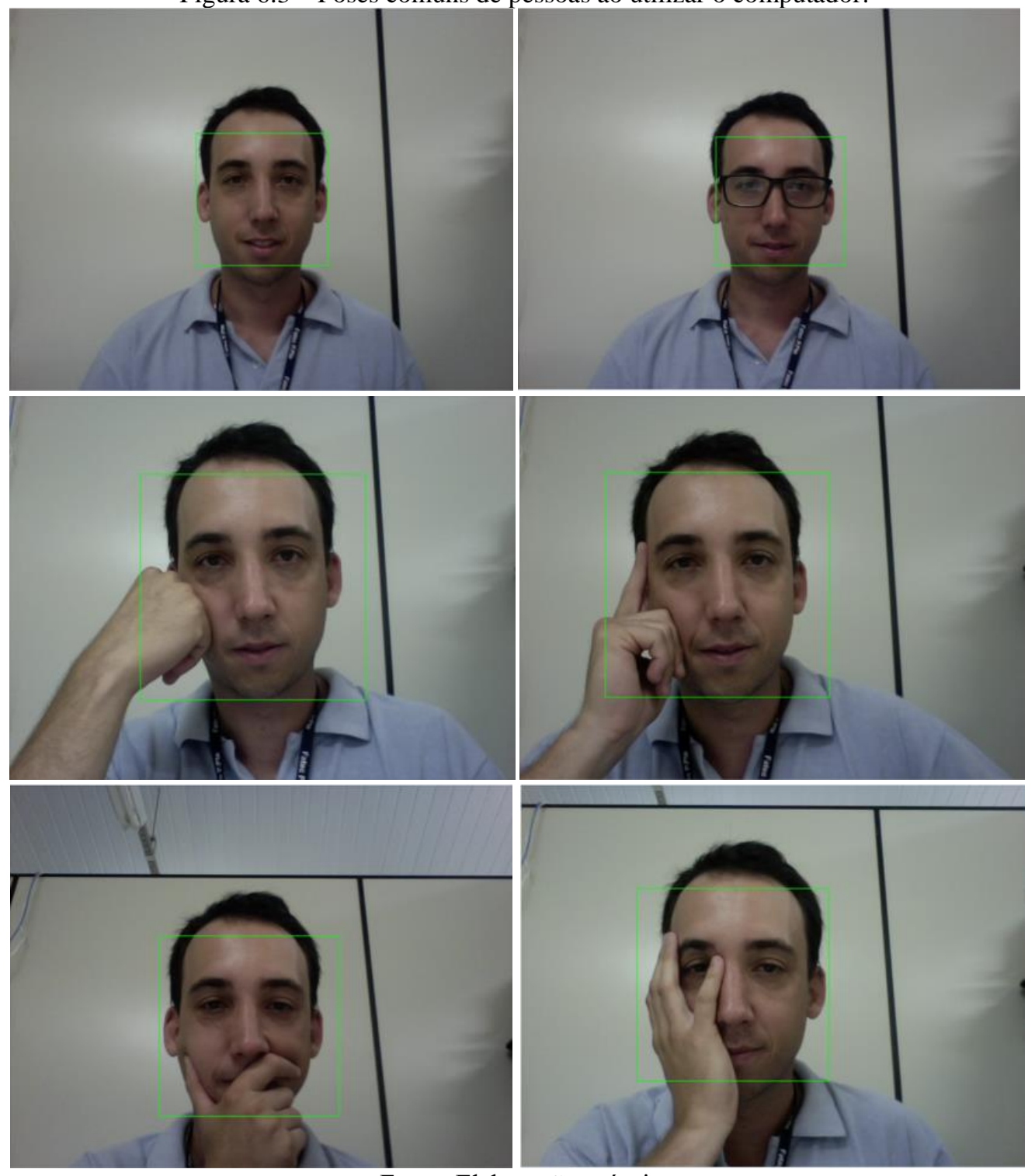

Fonte: Elaboração própria. 


\subsubsection{Etapa 2: Extrair Características}

Após a detecção da face, são detectados 20 pontos de referência utilizados posteriormente na etapa de classificar a expressão. O input dos pontos de referência é feito de forma automática com a utilização da biblioteca clmtrackr. Dada a localização da face, 70 pontos são ajustados à mesma por meio de Modelos Locais Restritos (CLM - Constrained Local Models). A partir dos 70 pontos retornados pela biblioteca (Figura 6.4a), é criado um vetor de características com a posições dos 20 pontos de referência propostos neste trabalho (Figura 6.4b).

Figura 6.4 - (a) Pontos de referência retornados pela biblioteca clmtrackr. (b) Pontos de referência calculados a partir dos pontos retornados pela biblioteca que representam o modelo proposto neste trabalho.

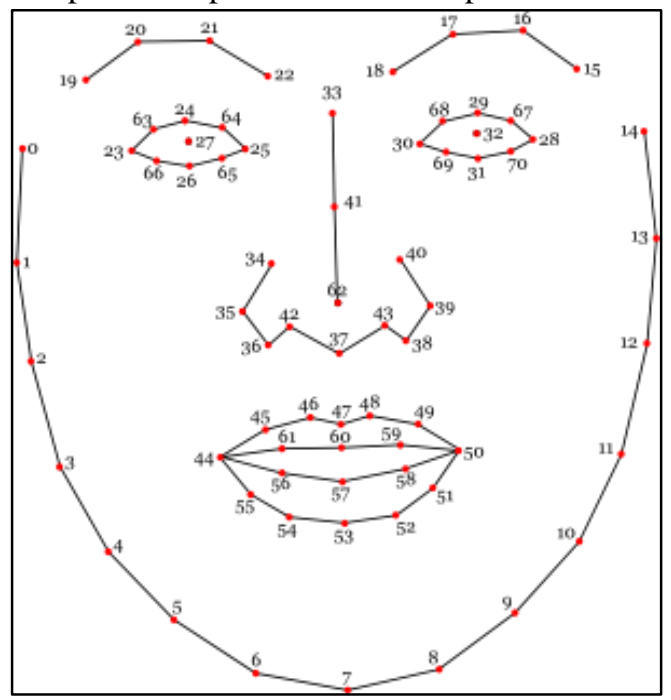

(a)

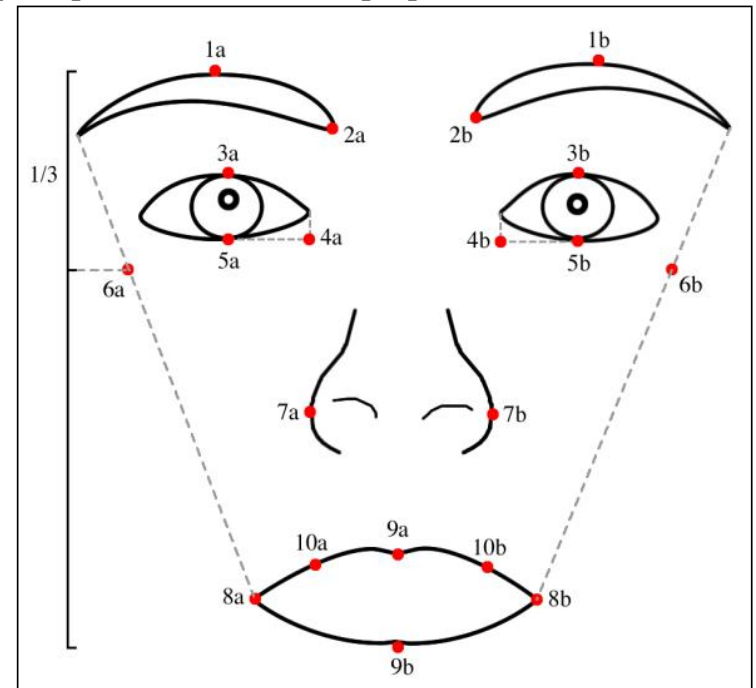

(b)

Fonte: (a) Oygard (2014); (b) Elaboração própria.

Dado um elemento (imagem ou vídeo) contendo uma face, o algoritmo clmtrackr inicia o ajuste do modelo facial, retornando as posições de cada um dos 70 pontos descritos na Figura 6.3(a). O Algoritmo de ajuste é implementado segundo descrito em Saragih, Lucey e Cohn (2011). Os modelos são treinados em dados anotados a partir da base de dados MUCT (MILBORROW; MORKEL; NICOLLS, 2010). Ao ajustar o modelo, o algoritmo calcula a probabilidade de os pontos de referência estarem na posição correta. Essas probabilidades podem ser calculadas de três formas diferentes: "crú", baseado em regressão SVM dos fragmentos em escala de cinza; "Sobel”, que se baseia em regressão SVM dos gradientes de Sobel; e "LBP”, baseado na regressão SVM de padrões binários locais. Neste trabalho, o tipo 
"crú" foi escolhido por ser a forma mais rápida de calcular as respostas, uma vez que não realiza nenhum pré-processamento nos fragmentos.

A biblioteca também oferece vários modelos de dados treinados, todos sobre o mesmo conjunto de dados. A diferença entre eles é o tipo do classificador, o número de componentes e como os componentes são extraídos. Neste trabalho, optou-se pela utilização do SVM como classificador com 20 componentes extraídos com PCA. Esta é a recomendação do desenvolvedor para navegadores com suporte à webGL ${ }^{2}$.

Alguns exemplos de aplicações que utilizam a biblioteca clmtrackr podem ser encontrados em: https://github.com/auduno/clmtrackr\#examples.

A partir dos 20 pontos de referência propostos neste trabalho (Figura 6.3b), são criados vetores de movimento para cada ponto que contém informações sobre a direção de movimentação do ponto (Figura 6.5).

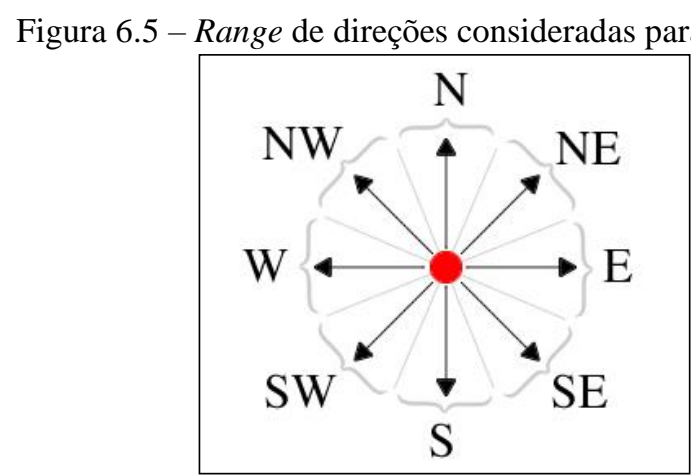

Fonte: Elaboração própria.

A análise da movimentação dos pontos é feita por meio do fluxo óptico, utilizando a função Lukas Kanade optical flow, da biblioteca jsfeat (ZATEPYAKIN, 2014), que calcula um fluxo óptico para um conjunto de recursos, utilizando o método de Lucas Kanade piramidal de forma interativa, segundo descrito em Lucas e Kanade (1981) e Bouguet (2000).

Uma demonstração on-line do algoritmo está disponível para teste em: http://inspirit.github.io/jsfeat/sample_oflow_lk.html.

\footnotetext{
${ }^{2}$ WebGL (Web Graphics Library) é uma API em JavaScript, disponível a partir do novo elemento canvas da HTML5, que oferece suporte para renderização de gráficos 2D e gráficos 3D.
} 


\subsubsection{Etapa 3: Classificar Expressão}

Para identificar as expressões faciais, são analisadas as movimentações dos 20 pontos de referência da Figura 6.4b, segundo o range de direções apresentados na Figura 6.5, tomando como base um vetor de face neutra que, na primeira interação, é composto pelas características do vetor da face atual.

Ocorre que, durante a classificação de expressões espontâneas, algumas vezes o sistema pode ser inicializado enquanto o usuário não está com a face neutra. Para resolver esse problema, o algoritmo recalcula o vetor da face neutra a cada interação, conforme ilustra o Fluxograma da Figura 6.6. Considerando que uma expressão facial dura em média 0.5 segundo, mesmo que o vetor da face neutra seja inicializado com valores de uma face não neutra, após algumas interações o vetor da face neutra estará ajustado.

Figura 6.6 - Fluxograma do algoritmo de cálculo do vetor face neutra.

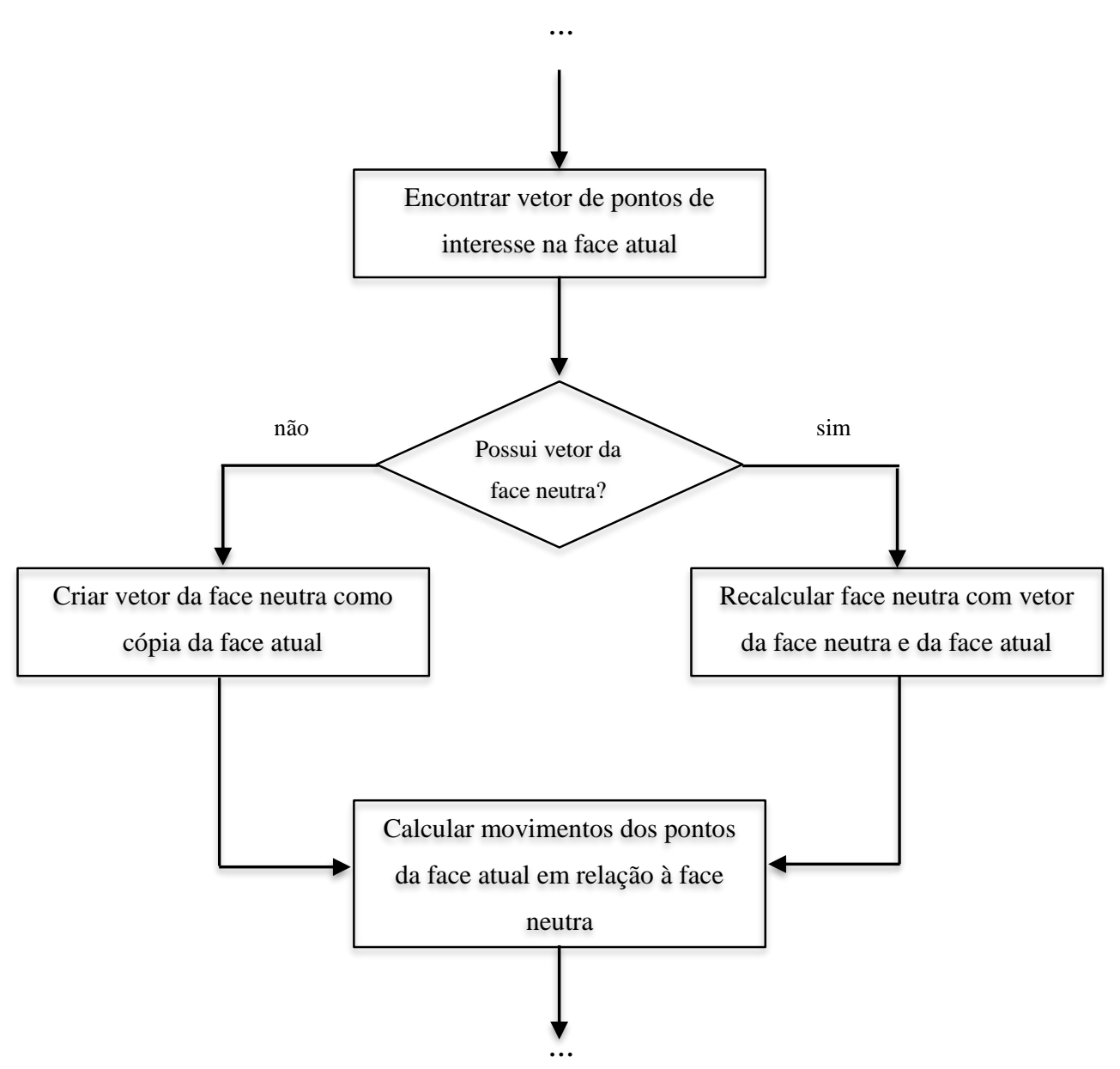

Fonte: Elaboração própria. 


\subsubsection{Classificar Expressões: Modelo 1}

A etapa de classificar da expressão facial da versão 1 do módulo afetivo tem o objetivo de identificar as movimentações musculares faciais presentes nas expressões de raiva, aversão, tristeza, medo, surpresa e felicidade, a partir de uma face neutra. Ou seja, a partir do modelo da face neutra, pretende-se identificar a movimentação com respectiva direção dos pontos de referência.

A Tabela 6.1 descreve uma representação para as expressões faciais na qual as linhas representam os pontos de referência da Figura $6.4 \mathrm{~b}$, e as colunas representam as direções descritas na Figura 6.5. A intersecção entre linhas e colunas representa a movimentação de um ponto de referência em determinada direção, dada uma expressão facial. Cada expressão facial é representada na tabela por uma letra, sendo raiva (R), aversão (A), tristeza (T), medo $(\mathrm{M})$, surpresa $(\mathrm{S})$ e felicidade $(\mathrm{F})$.

Tabela 6.1 - Pontos de referência e respectivas direções para as expressões faciais raiva (R), aversão (A), tristeza $(\mathrm{T})$, medo $(\mathrm{M})$, surpresa $(\mathrm{S})$ e felicidade $(\mathrm{F})$.

\begin{tabular}{|c|c|c|c|c|c|c|c|c|c|c|}
\hline pts & $\mathbf{N}$ & NE & $\mathbf{E}$ & $\mathbf{S}$ & & $\mathbf{S}$ & SI & & $\mathbf{W}$ & NW \\
\hline $1 \mathrm{a}$ & M & & & $\mathrm{R}$ & A & A & & & & \\
\hline $1 b$ & M & & & & & A & $\mathrm{R}$ & A & & \\
\hline $2 a$ & M & $\mathrm{T} \quad \mathrm{M}$ & & $\mathrm{R}$ & A & A & & & & \\
\hline $2 b$ & $\begin{array}{l:l}\mathrm{S} & \mathrm{M}\end{array}$ & & & & & A & $\mathrm{R}$ & A & & $\mathrm{T} \quad \mathrm{M}$ \\
\hline $3 a$ & $\mathrm{R} M \mathrm{~S}$ & & & & & R $\quad \mathrm{T}$ & & & & \\
\hline $3 b$ & $\mathrm{R} M \mathrm{~S}$ & & & & & $\mathrm{R} \quad \mathrm{T}$ & & & & \\
\hline $4 a$ & R A & $\mathrm{R} \quad \mathrm{A}$ & & & & & & & & \\
\hline $4 b$ & R $\mathrm{A}$ & & & & & & & & & $\mathrm{R} \quad \mathrm{A}$ \\
\hline $5 a$ & $\mathrm{R} A \mathrm{~T} \quad \mathrm{~F}$ & & & & & & & & & \\
\hline $5 b$ & $\mathrm{R} A \mathrm{~T} F$ & & & & & & & & & \\
\hline $6 a$ & & $\mathrm{R} A \mathrm{~F}$ & & & & & & & & \\
\hline $6 b$ & & & & & & & & & & $\mathrm{R} A \mathrm{~F}$ \\
\hline $7 a$ & A & & & & & & & & $\mathrm{R}$ & R A \\
\hline $7 b$ & A & R $\quad A$ & $\mathrm{R}$ & & & & & & & \\
\hline $8 \mathrm{a}$ & A & & $\mathrm{R}$ & $s$ & & A & A $\mathrm{T}$ & $\mathrm{M}$ & M & $\mathrm{F}$ \\
\hline $8 \mathrm{~b}$ & A & $\mathrm{F}$ & M & A 7 & $\mathrm{M}$ & A & $S$ & & $\mathrm{R}$ & \\
\hline $9 a$ & $\mathrm{R} A \mathrm{~F}$ & & & & & R A & & & & \\
\hline $9 \mathrm{~b}$ & $\mathrm{R}$ A $\mathrm{M}$ & & & & & $\mathrm{R} A \mathrm{~S} F$ & & & & \\
\hline $10 \mathrm{a}$ & A & & & & & & $\mathrm{T}$ & & $\mathrm{T}$ & $\mathrm{R} \quad \mathrm{F}$ \\
\hline $10 b$ & R A & $\mathrm{R}$ & $\mathrm{T}$ & $\mathrm{T}$ & & & & & & \\
\hline
\end{tabular}

Fonte: Elaboração própria. 


\subsubsection{Classificar Expressões: Modelo 2}

Segundo Tomkins (2008), as emoções básicas podem ser agrupadas em positivas, negativas ou neutras. A etapa de classificar as expressões faciais da segunda versão do módulo afetivo baseia-se nos estudos de Tomkins e objetiva identificar as movimentações musculares faciais presentes nas expressões de emoções com valência negativa. As expressões com valência negativa representam, neste estudo, dificuldades demonstradas pela mímica da face por usuários e alunos, durante a utilização de um sistema computacional assistivo que, no caso, trata-se de uma prancha de comunicação em versão digital.

A Tabela 6.2 descreve uma representação adaptada dos estudos de Tomkins para as expressões faciais. As linhas representam os pontos de referência da Figura $6.4 \mathrm{~b}$, e as colunas representam as direções descritas na Figura 6.5. A intersecção entre linhas e colunas representa a movimentação de um ponto de referência em determinada direção, dada uma expressão facial de valência negativa. Considerou-se raiva, aversão, tristeza e medo como emoções de valência negativa, surpresa como valência neutra, e felicidade como valência positiva. Assim, eliminando-se as emoções de valência positiva e neutra da Tabela 6.1, tem-se as emoções de valência negativa representadas na Tabela 6.2 . 
Tabela 6.2 - Pontos de referência e respectivas direções para as expressões faciais de valência negativa raiva (R), aversão (A), tristeza (T) e medo (M).

\begin{tabular}{|c|c|c|c|c|c|c|c|c|}
\hline pts & $\mathbf{N}$ & NE & $\mathbf{E}$ & SE & $\mathbf{S}$ & SW & $\mathbf{W}$ & NW \\
\hline 1a & M & & & $\mathrm{R} \quad \mathrm{A}$ & A & & & \\
\hline $1 b$ & M & & & & A & $\mathrm{R} \quad \mathrm{A}$ & & \\
\hline $2 \mathrm{a}$ & M & $\mathrm{M}$ & & $\mathrm{R} \quad \mathrm{A}$ & A & & & \\
\hline $2 \mathrm{~b}$ & M & & & & A & R A & & $\mathrm{T}$ \\
\hline $3 \mathrm{a}$ & $\mathrm{R} \quad \mathrm{M}$ & & & & $\begin{array}{ll}\mathrm{R} & \mathrm{T} \\
\end{array}$ & & & \\
\hline $3 b$ & R $\quad \mathrm{M}$ & & & & $\begin{array}{ll}\mathrm{R} & \mathrm{T} \\
\end{array}$ & & & \\
\hline $4 \mathrm{a}$ & $\mathrm{R} \quad \mathrm{A}$ & $\mathrm{R} \quad \mathrm{A}$ & & & & & & \\
\hline $4 b$ & R $\quad \mathrm{A}$ & & & & & & & R $\quad \mathrm{A}$ \\
\hline $5 \mathrm{a}$ & $\mathrm{R} \quad \mathrm{A} \quad \mathrm{T}$ & & & & & & & \\
\hline $5 b$ & $\mathrm{R} \quad \mathrm{A} \quad \mathrm{T}$ & & & & & & & \\
\hline $6 \mathrm{a}$ & & $\mathrm{R} \quad \mathrm{A}$ & & & & & & \\
\hline $6 \mathrm{~b}$ & & & & & & & & R A \\
\hline $7 \mathrm{a}$ & A & & & & & & $\mathrm{R}$ & R A \\
\hline $7 b$ & A & R A & $\mathrm{R}$ & & & & & \\
\hline $8 \mathrm{a}$ & A & & $\mathrm{R}$ & & A & A $\quad \mathrm{T} \quad \mathrm{M}$ & M & \\
\hline $8 b$ & A & & M & $\mathrm{A} \quad \mathrm{T} \quad \mathrm{M}$ & A & & $\mathrm{R}$ & \\
\hline $9 \mathrm{a}$ & $\mathrm{R} \quad \mathrm{A}$ & & & & $\mathrm{R} \quad \mathrm{A}$ & & & \\
\hline $9 \mathrm{~b}$ & $\mathrm{R} A \mathrm{M}$ & & & & $\mathrm{R} \quad \mathrm{A}$ & & & \\
\hline $10 \mathrm{a}$ & $\mathrm{R} \quad \mathrm{A}$ & & & & & $\mathrm{T}$ & $\mathrm{T}$ & $\mathrm{R}$ \\
\hline $10 b$ & R $A$ & $\mathrm{R}$ & $\mathrm{T}$ & $\mathrm{T}$ & & & & \\
\hline
\end{tabular}

\subsubsection{Etapa 4: Inferir Estado Emocional}

A etapa final do módulo afetivo é realizar a inferência do estado emocional. Neste trabalho, não se faz uso de treinamento de classificadores para categorização do estado emocional. A inferência do estado emocional é realizada por meio de estruturas de decisão elaboradas com informações de especialistas.

\subsubsection{Inferir Estado Emocional: Modelo 1}

Após identificar as movimentações faciais presentes nas expressões de raiva, aversão, tristeza, medo, surpresa e felicidade, foi modelada uma estrutura de decisão com sistema de pontuação, objetivando eliminar ambiguidades na classificação das emoções.

No sistema de pontuação proposto, o peso é dado por $p x$ onde: 


$$
p=\left[\begin{array}{c}
2 \\
1 \\
0.5 \\
0
\end{array}\right]
$$

A pontuação final é obtida com a soma dos pontos. A emoção com maior pontuação é inferida pelo sistema. Como visto, a movimentação dos pontos de referência, classificados com peso 4 , não influencia na soma total da pontuação, mas pode ser requisitada por uma função de desempate.

O sistema de pontuação está representado na Tabela 6.3 na qual a cor vermelho representa peso 1 , a cor verde peso 2, a cor amarelo peso 3 , e a cor azul peso 4 .

Tabela 6.3 - Pontos de referência e respectivas direções para as expressões faciais raiva (R), aversão (A), tristeza (T), medo (M), surpresa (S) e felicidade (F). Intersecções com fundo vermelho possuem peso 1, verde peso 2, amarelo peso 3 e azul peso 4 .

\begin{tabular}{|c|c|c|c|c|c|c|c|c|c|}
\hline pts & & $\mathbf{N}$ & NE & $\mathbf{E}$ & $\mathbf{S E}$ & $\mathbf{S}$ & SW & W & NW \\
\hline $1 \mathrm{a}$ & & $\mathrm{M}$ & & & $\begin{array}{l:l}\mathrm{R} & \mathrm{A}\end{array}$ & A & & & \\
\hline $1 \mathrm{~b}$ & S & $\mathrm{M}$ & & & & A & \begin{tabular}{l|l}
$\mathrm{R}$ & $\mathrm{A}$
\end{tabular} & & \\
\hline $2 \mathrm{a}$ & S & $\mathrm{M}$ & T N & & \begin{tabular}{l|l}
$\mathrm{R}$ & $\mathrm{A}$
\end{tabular} & A & & & \\
\hline $2 \mathrm{~b}$ & S & $\mathrm{M}$ & & & & A & \begin{tabular}{l|l}
$\mathrm{R}$ & $\mathrm{A}$
\end{tabular} & & T N \\
\hline $3 \mathrm{a}$ & $\mathrm{R}$ & $\mathrm{MS}$ & & & & $\begin{array}{ll}\mathrm{R} & \mathrm{T}\end{array}$ & & & \\
\hline $3 b$ & $\mathrm{R}$ & $\mathrm{MS}$ & & & & $\begin{array}{ll}\mathrm{R} & \mathrm{T} \\
\end{array}$ & & & \\
\hline $4 \mathrm{a}$ & $\mathrm{R}$ & A & $\mathrm{R}$ & & & & & & \\
\hline $4 \mathrm{~b}$ & $\mathrm{R}$ & A & & & & & & & $\mathrm{R}$ \\
\hline $5 \mathrm{a}$ & R A & $\mathrm{T} \mathrm{F}$ & & & & & & & \\
\hline $5 b$ & & $\mathrm{~T} \mathrm{~F}$ & & & & & & & \\
\hline $6 a$ & & & $\mathrm{R} A$ & & & & & & \\
\hline $6 \mathrm{~b}$ & & & & & & & & & R A \\
\hline $7 \mathrm{a}$ & & A & & & & & & $\mathrm{R}$ & R A \\
\hline $7 b$ & & A & $\mathrm{R}$ & $\mathrm{R}$ & & & & & \\
\hline $8 \mathrm{a}$ & & A & & $\mathrm{R}$ & S & A & $\mathrm{A} \quad \mathrm{T} \quad \mathrm{M}$ & M & $\mathrm{F}$ \\
\hline $8 \mathrm{~b}$ & & $A$ & $\mathrm{~F}$ & M & \begin{tabular}{l|ll}
$\mathrm{A}$ & $\mathrm{T}$ & $\mathrm{M}$ \\
\end{tabular} & $\mathrm{A}$ & S & $\mathrm{R}$ & \\
\hline $9 \mathrm{a}$ & $\mathrm{R}$ & A $F$ & & & & R A & & & \\
\hline $9 \mathrm{~b}$ & $\mathrm{R}$ & A $M$ & & & & R A S F & & & \\
\hline $10 \mathrm{a}$ & $\mathrm{R}$ & A & & & & & $\mathrm{T}$ & $\mathrm{T}$ & \\
\hline $10 \mathrm{~b}$ & $\mathrm{R}$ & A & $\mathrm{R}$ & $\mathrm{T}$ & $\mathrm{T}$ & & & & \\
\hline
\end{tabular}

Fonte: Elaboração própria.

Inferência da Raiva: Para inferência do estado emocional raiva, foram considerados os pontos de referência e direções segundo descrito abaixo: 
Peso 1: $1 \mathrm{a} \rightarrow \mathrm{SE} ; 1 \mathrm{~b} \rightarrow \mathrm{SW} ; 2 \mathrm{a} \rightarrow \mathrm{SE} ; 2 \mathrm{~b} \rightarrow \mathrm{SW}$; Peso 2: $4 \mathrm{a} \rightarrow \mathrm{N}$ ou $4 \mathrm{a} \rightarrow \mathrm{NE} ; 4 \mathrm{~b} \rightarrow \mathrm{N}$ ou $4 \mathrm{~b} \rightarrow \mathrm{NW} ; 5 \mathrm{a} \rightarrow \mathrm{N} ; 5 \mathrm{~b} \rightarrow \mathrm{N} ; 7 \mathrm{a} \rightarrow \mathrm{W}$ ou $7 \mathrm{a} \rightarrow \mathrm{NW} ; 7 \mathrm{~b} \rightarrow \mathrm{E}$ ou $7 \mathrm{~b} \rightarrow \mathrm{NE}$; Peso 3: $3 \mathrm{a} \rightarrow \mathrm{N}$ ou $3 \mathrm{a} \rightarrow \mathrm{S}$; $3 b \rightarrow N$ ou $3 b \rightarrow S ; 6 a \rightarrow N E ; 6 b \rightarrow N W ;$ Peso 4: $8 a \rightarrow E ; 8 b \rightarrow W ; 9 a \rightarrow N$ ou $9 a \rightarrow S ; 9 b \rightarrow N$ ou $9 \mathrm{~b} \rightarrow \mathrm{S} ; 10 \mathrm{a} \rightarrow \mathrm{N}$ ou $10 \mathrm{a} \rightarrow \mathrm{NW} ; 10 \mathrm{~b} \rightarrow \mathrm{N}$ ou $10 \mathrm{~b} \rightarrow \mathrm{NE}$.

A movimentação da boca não foi utilizada na classificação da raiva, pois durante a expressão de raiva ela pode executar vários movimentos diferentes, inclusive opostos, como, por exemplo, o ponto de referência 9a que pode se mover na direção $\mathrm{N}$ ou na direção S. Além disso, essa movimentação pode ser confundida com a expressão de outras emoções, como ilustra a Figura 6.6. Em (a), tem-se uma boca de face neutra, em (d) a boca pode ser confundida com a boca da expressão tristeza, em (f) e (g) com felicidade.

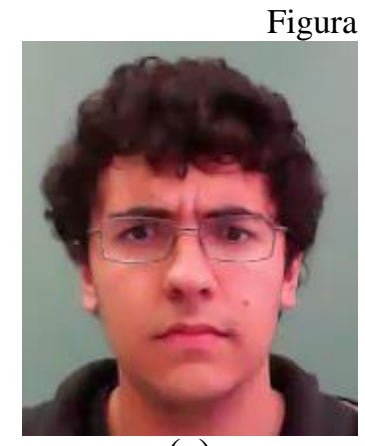

(a)

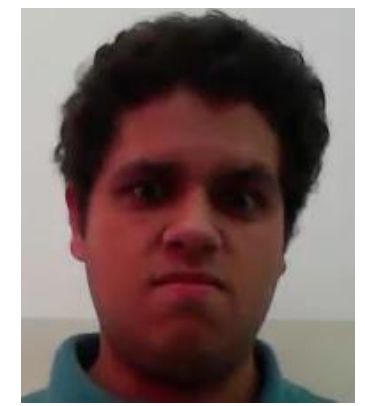

(e)

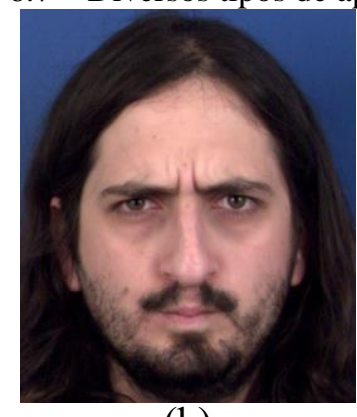

(b)

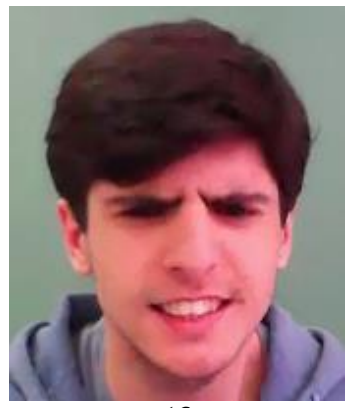

(f)

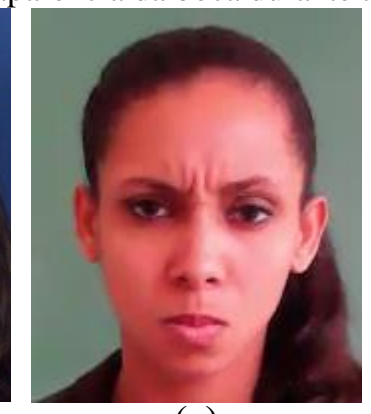

(c)

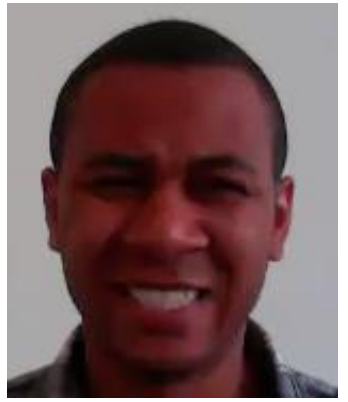

$(\mathrm{g})$

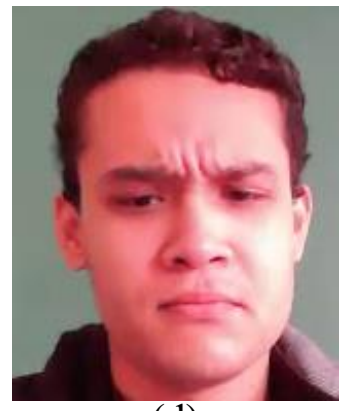

(d)

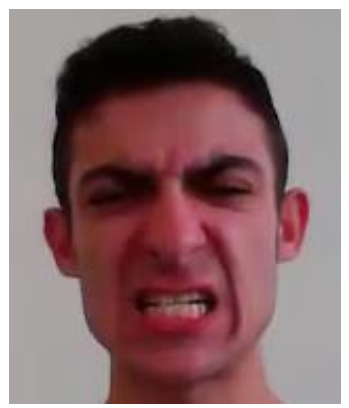

(h)

Fonte: Elaboração própria.

Inferência da Aversão: Para inferência do estado emocional aversão, foram considerados os pontos de referência e direções segundo descrito abaixo:

Peso 1: $1 \mathrm{a} \rightarrow \mathrm{S} ; 1 \mathrm{~b} \rightarrow \mathrm{S} ; 2 \mathrm{a} \rightarrow \mathrm{S} ; 2 \mathrm{~b} \rightarrow \mathrm{S} ; 4 \mathrm{a} \rightarrow \mathrm{N}$ ou $4 \mathrm{a} \rightarrow \mathrm{NE} ; 4 \mathrm{~b} \rightarrow \mathrm{N}$ ou $4 \mathrm{~b} \rightarrow \mathrm{NW} ; 7 \mathrm{a} \rightarrow \mathrm{N}$; $7 \mathrm{~b} \rightarrow \mathrm{N}$; Peso 2: $1 \mathrm{a} \rightarrow \mathrm{SE} ; 1 \mathrm{~b} \rightarrow \mathrm{SW} ; 2 \mathrm{a} \rightarrow \mathrm{SE} ; 2 \mathrm{~b} \rightarrow \mathrm{SW} ; 5 \mathrm{a} \rightarrow \mathrm{N} ; 5 \mathrm{~b} \rightarrow \mathrm{N} ; 6 \mathrm{a} \rightarrow \mathrm{NE} ; 6 \mathrm{~b} \rightarrow \mathrm{NW}$; $7 \mathrm{a} \rightarrow \mathrm{NW} ; 7 \mathrm{~b} \rightarrow \mathrm{NE} ; 10 \mathrm{a} \rightarrow \mathrm{N} ; 10 \mathrm{~b} \rightarrow \mathrm{N} ;$ Peso $3: 8 \mathrm{a} \rightarrow \mathrm{N}$ ou $8 \mathrm{a} \rightarrow \mathrm{S}$ ou $8 \mathrm{a} \rightarrow \mathrm{SW} ; 8 \mathrm{~b} \rightarrow \mathrm{N}$ ou $8 \mathrm{~b} \rightarrow \mathrm{SE}$ ou $8 \mathrm{~b} \rightarrow \mathrm{S} ; 9 \mathrm{a} \rightarrow \mathrm{N}$ ou $9 \mathrm{a} \rightarrow \mathrm{S} ; 9 \mathrm{~b} \rightarrow \mathrm{N}$ ou $9 \mathrm{~b} \rightarrow \mathrm{S}$. 
Inferência da Tristeza: Para inferência do estado emocional tristeza, foram considerados os pontos de referência e direções segundo descrito abaixo:

Peso 1: $8 \mathrm{a} \rightarrow \mathrm{SW} ; 8 \mathrm{~b} \rightarrow \mathrm{SE} ; 10 \mathrm{a} \rightarrow \mathrm{SW}$ ou $10 \mathrm{a} \rightarrow \mathrm{W} ; 10 \mathrm{~b} \rightarrow \mathrm{E}$ ou $10 \mathrm{~b} \rightarrow \mathrm{SE} ;$ Peso 2: $2 \mathrm{a} \rightarrow \mathrm{NE} ; 2 \mathrm{~b} \rightarrow \mathrm{NW}$; Peso 3: $3 \mathrm{a} \rightarrow \mathrm{S} ; 3 \mathrm{~b} \rightarrow \mathrm{S} ; 5 \mathrm{a} \rightarrow \mathrm{N} ; 5 \mathrm{~b} \rightarrow \mathrm{N}$.

Inferência da Medo: Para inferência do estado emocional medo, foram considerados os pontos de referência e direções segundo descrito abaixo:

Peso 1: $2 \mathrm{a} \rightarrow \mathrm{NE} ; 2 \mathrm{~b} \rightarrow \mathrm{NW} ; 3 \mathrm{a} \rightarrow \mathrm{N} ; 3 \mathrm{~b} \rightarrow \mathrm{N} ; 8 \mathrm{a} \rightarrow \mathrm{W} ; 8 \mathrm{~b} \rightarrow \mathrm{E}$; Peso 2: $1 \mathrm{a} \rightarrow \mathrm{N} ; 1 \mathrm{~b} \rightarrow \mathrm{N}$; $2 \mathrm{a} \rightarrow \mathrm{N} ; 2 \mathrm{~b} \rightarrow \mathrm{N} ; 8 \mathrm{a} \rightarrow \mathrm{SW} ; 8 \mathrm{~b} \rightarrow \mathrm{SE} ; 9 \mathrm{~b} \rightarrow \mathrm{N}$.

Inferência da Surpresa: Para inferência do estado emocional surpresa, foram considerados os pontos de referência e direções segundo descrito abaixo:

Peso 1: $1 \mathrm{a} \rightarrow \mathrm{N} ; 1 \mathrm{~b} \rightarrow \mathrm{N} ; 2 \mathrm{a} \rightarrow \mathrm{N} ; 2 \mathrm{~b} \rightarrow \mathrm{N} ; 8 \mathrm{a} \rightarrow \mathrm{SE} ; 8 \mathrm{~b} \rightarrow \mathrm{SW} ; 9 \mathrm{~b} \rightarrow \mathrm{S} ;$ Peso 3: $3 \mathrm{a} \rightarrow \mathrm{N}$; $3 b \rightarrow N$.

Inferência da Felicidade: Para inferência do estado emocional felicidade, foram considerados os pontos de referência e direções segundo descrito abaixo:

Peso 1: $8 \mathrm{a} \rightarrow \mathrm{NW} ; 8 \mathrm{~b} \rightarrow \mathrm{NE} ; 9 \mathrm{a} \rightarrow \mathrm{N} ; 9 \mathrm{~b} \rightarrow \mathrm{S} ; 10 \mathrm{a} \rightarrow \mathrm{NW} ; 10 \mathrm{~b} \rightarrow \mathrm{NE}$; Peso 3: $5 \mathrm{a} \rightarrow \mathrm{N}$; $5 b \rightarrow \mathrm{N} ; 6 \mathrm{a} \rightarrow \mathrm{NE} ; 6 \mathrm{~b} \rightarrow \mathrm{NW}$.

Tomando como exemplo a expressão da movimentação dos pontos de referência da Figura 6.8a em direção aos pontos de referência da Figura 6.8b, sobrepondo-se as duas imagens (Figura 6.8c) observa-se as direções descritas na primeira coluna da tabela 6.4 para cada ponto de referência. Aplicando-se o sistema de pontuação, o estado emocional é classificado como raiva pelo módulo afetivo. 
Tabela 6.4 - Exemplo do sistema de pontuação para inferência do estado emocional.

\begin{tabular}{|c|c|c|c|c|c|c|}
\hline & Raiva & Aversão & Tristeza & Medo & Surpresa & Felicidade \\
\hline $1 \mathrm{a} \rightarrow \mathrm{SE}$ & 2 & 1 & & & & \\
\hline $1 \mathrm{~b} \rightarrow \mathrm{SW}$ & 2 & 1 & & & & \\
\hline $2 \mathrm{a} \rightarrow \mathrm{SE}$ & 2 & 1 & & & & \\
\hline $2 \mathrm{~b} \rightarrow \mathrm{SW}$ & 2 & 1 & & & & \\
\hline $3 a \rightarrow S$ & 0.5 & & 0.5 & & & \\
\hline $3 b \rightarrow S$ & 0.5 & & 0.5 & & & \\
\hline \multicolumn{7}{|l|}{$4 a \rightarrow n / d$} \\
\hline \multicolumn{7}{|l|}{$4 b \rightarrow n / d$} \\
\hline $5 \mathrm{a} \rightarrow \mathrm{N}$ & 1 & 1 & 0.5 & & & 0.5 \\
\hline $5 \mathrm{~b} \rightarrow \mathrm{N}$ & 1 & 1 & 0.5 & & & 0.5 \\
\hline $6 \mathrm{a} \rightarrow \mathrm{NE}$ & 0.5 & 1 & & & & 0.5 \\
\hline $6 \mathrm{~b} \rightarrow \mathrm{NW}$ & 0.5 & 1 & & & & 0.5 \\
\hline $7 \mathrm{a} \rightarrow \mathrm{NW}$ & 1 & 1 & & & & \\
\hline $7 \mathrm{~b} \rightarrow \mathrm{NE}$ & 1 & 1 & & & & \\
\hline \multicolumn{7}{|l|}{$8 \mathrm{a} \rightarrow \mathrm{n} / \mathrm{d}$} \\
\hline \multicolumn{7}{|l|}{$8 \mathrm{~b} \rightarrow \mathrm{n} / \mathrm{d}$} \\
\hline \multicolumn{7}{|l|}{$9 \mathrm{a} \rightarrow \mathrm{n} / \mathrm{d}$} \\
\hline $9 b \rightarrow S$ & & 1 & & & 2 & 2 \\
\hline $10 \mathrm{a} \rightarrow \mathrm{N}$ & & 1 & & & & \\
\hline $10 \mathrm{~b} \rightarrow \mathrm{N}$ & & 1 & & & & \\
\hline Total & 14 & 13 & 2 & $\mathbf{0}$ & 2 & 4 \\
\hline
\end{tabular}


Figura 6.8 - (a) Imagem de face neutra marcada com pontos de referência. (b) Imagem com expressão de raiva marcada com pontos de referência. (c) Sobreposição das imagens 6.7a e 6.7b que permite identificar as direções de movimentação dos pontos de referência.

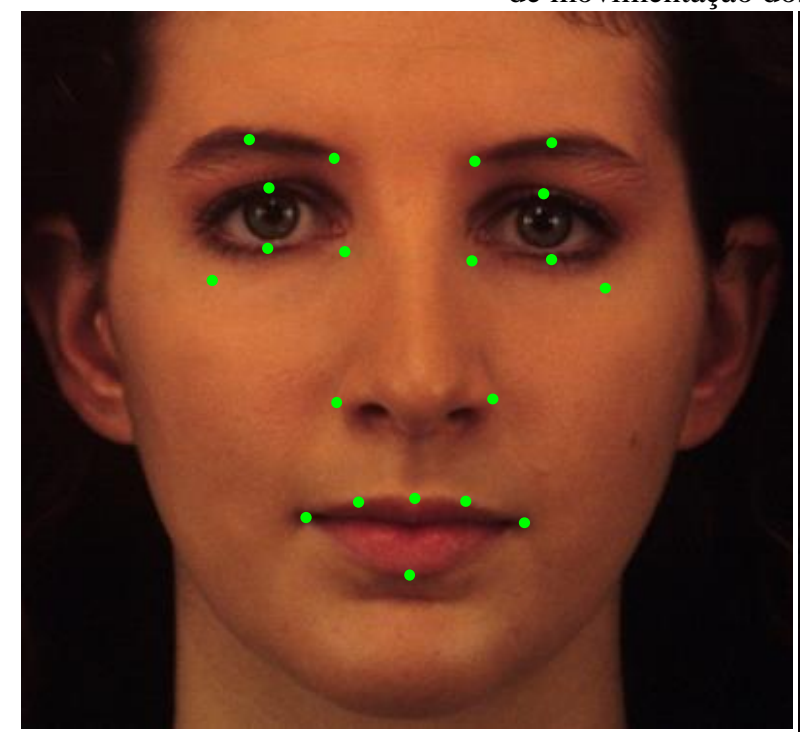

(a)

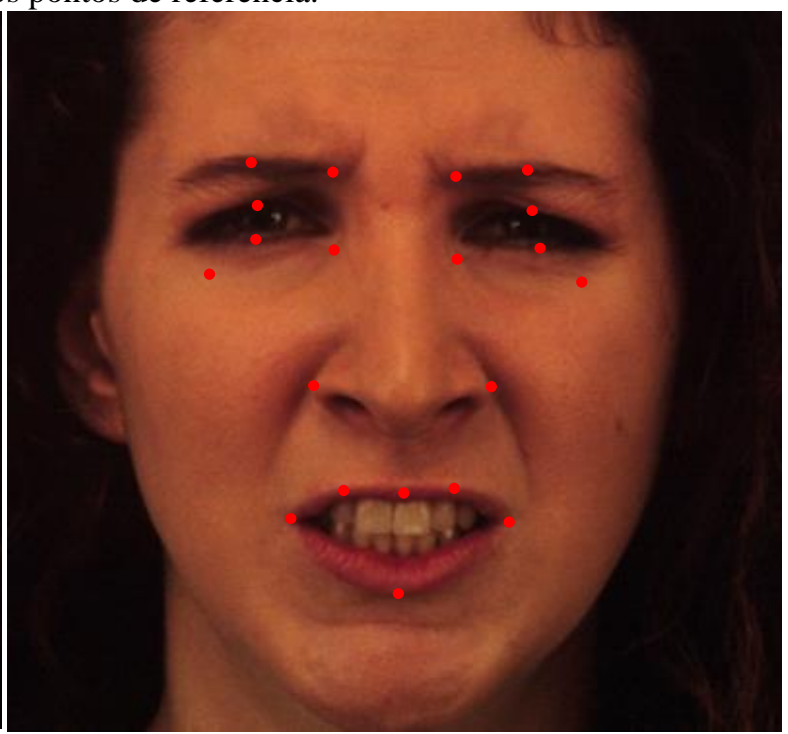

(b)

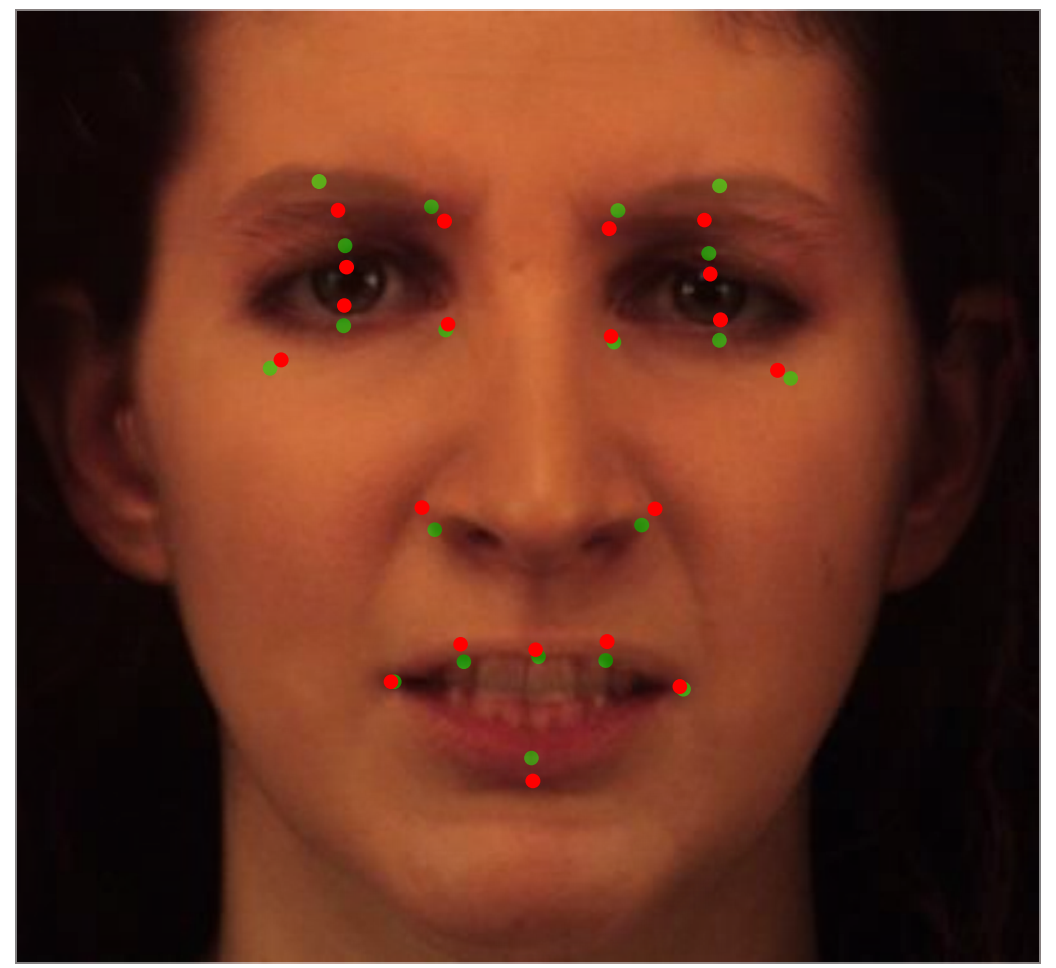

(c)

Fonte: Imagens da face retiradas da Base de dados KDEF (LUNDQVIST; FLYKT; ÖHMAN , 1988).

\subsubsection{Inferir Estado Emocional: Modelo 2}

O objetivo da segunda versão proposta para inferência do estado emocional do módulo afetivo é identificar emoções de valência negativa que representam dificuldade de utilização do sistema computacional pelo usuário ou aluno. As movimentações musculares faciais das 
expressões raiva, aversão, tristeza e medo são fortes indícios de dificuldades de utilização de um sistema computacional, aqui denominada insatisfação (I). Porém, observações feitas em experimentos de laboratório levaram a uma simplificação do modelo da tabela 6.2 , e a representação de insatisfação ou frustração do usuário/aluno passou a ser descrita por meio da identificação da movimentação dos pontos de referência e direções descritos na tabela 6.5.

Tabela 6.5 - Pontos de referência e respectivas direções para as expressões faciais de insatisfação (I).

\begin{tabular}{|c|c|c|c|c|c|c|c|c|}
\hline pts & $N$ & $N E$ & $E$ & $S E$ & $S$ & $S W$ & $\boldsymbol{W}$ & $N W$ \\
\hline $1 \mathrm{a}$ & I & & & I & & & & \\
\hline $1 b$ & I & & & & & I & & \\
\hline $2 \mathrm{a}$ & & I & & I & & & & \\
\hline $2 b$ & & & & & & I & & I \\
\hline $3 a$ & & & & & I & & & \\
\hline $3 b$ & & & & & I & & & \\
\hline $4 a$ & I & I & & & & & & \\
\hline $4 b$ & I & & & & & & & I \\
\hline $5 a$ & I & & & & & & & \\
\hline $5 b$ & I & & & & & & & \\
\hline $6 a$ & & I & & & & & & \\
\hline $6 b$ & & & & & & & & I \\
\hline $7 \mathrm{a}$ & I & & & & & & I & \\
\hline $7 b$ & I & & I & & & & & \\
\hline $8 \mathrm{a}$ & & & I & & & & I & I \\
\hline $8 b$ & & I & I & & & & I & \\
\hline $9 \mathrm{a}$ & & & & & I & & & \\
\hline $9 b$ & I & & & & I & & & \\
\hline $10 \mathrm{a}$ & & & & & & & & I \\
\hline $10 b$ & & I & & & & & & \\
\hline
\end{tabular}

Fonte: Elaboração própria.

Para os experimentos em laboratório, implementou-se cinco pranchas de comunicação digital com ícones no tamanho de $0.5 \mathrm{~cm}^{2}$ e distância 2 pixels entre eles. Perguntas realizadas aos usuários foram respondidas por meio do toque no ícone na tela, no menor intervalo de tempo possível. Os experimentos foram realizados com cinco usuários, utilizando o conceito de gamificação: quanto maior a quantidade de acerto em um menor intervalo de tempo, mais pontos o usuário adquiria.

Uma característica sobre as perguntas é que elas eram de conhecimento dos cinco usuários, isso fez que vencesse o "jogo" o usuário com maior destreza para selecionar ícones 
pequenos e próximos, em um pequeno intervalo de tempo. Quanto aos usuários, eles possuíam perfil de jogadores extremamente competitivos.

Após as 25 rodadas (5 pranchas versus 5 usuários), as informações das expressões faciais de dificuldade de seleção dos ícones e de frustração observadas por especialista foram utilizadas no ajuste da Tabela 6.2 para a Tabela 6.5. Porém, notou-se que os pontos mais representativos na insatisfação foram os pontos da região superior do rosto.

Mapeado o estado emocional insatisfeito e realizados os testes com pessoas não deficientes, o passo seguinte foi realizar os testes com deficientes, aqui denominados alunos.

Ao iniciar os testes com os alunos, notou-se que alguns possuem tiques refletidos na mímica da face. Ocorre que o tique se difere de aluno para aluno. Enquanto alguns apresentam tique na região próxima ao nariz, outros possuem tique de fechar fortemente, e de forma mais prolongada, os olhos. Tais tiques podem apresentar-se em outras regiões da face.

Devido às alterações musculares faciais causadas pelos tiques, o sistema tal qual testado com os usuários sem deficiências não foi capaz de detectar a insatisfação (ou dificuldade) durante a utilização da prancha de comunicação pelos alunos que apresentavam o tique.

Assim, propõe-se neste estudo realizar uma subdivisão entre os sinais faciais rápidos que representam mudanças na atividade física neuromuscular levando a alterações visualmente detectáveis na aparência facial entre sinais de linha base e sinais emocionais.

Por meio de observações de especialista durante os testes, notou-se que cada aluno apresenta um tique (sinal de linha base) bem definido. Desta forma, por meio da implementação de um algoritmo que analisa a mímica da face do aluno, antes do início dos testes foi possível diferenciar os sinais de linha base e os sinais emocionais, tratando os sinais de linha base como um ruído a ser eliminado antes da inferência do estado emocional.

Notou-se, também, que durante a interação com a prancha alguns alunos repetiam a pergunta realizada, antes de iniciar a seleção do ícone, como uma forma de certificar-se que haviam entendido o que lhe era pedido. Após cada acerto, a maioria deles também expressava um sorriso. Ocorre que tais movimentações na região da boca tratavam-se de ruído nos sinais emocionais. Assim, nos testes com os alunos, os pontos da região da boca foram desligados.

\subsection{Módulo de Tomada de Decisão}

O módulo de tomada de decisão recebe a saída do Modelo 2 do Módulo Afetivo e, com base nas informações contidas em um arquivo EML (Emotion Markup Language), altera 
as configurações iniciais da prancha de comunicação ao identificar dificuldade de utilização representada pelo estado emocional insatisfação.

Quando a prancha está com o sistema de varredura habilitado, o módulo de tomada de decisão pode realizar alterações na velocidade de varredura ou lateralidade. Para pranchas sem o sistema de varredura habilitado, o módulo de tomada de decisão pode alterar o tamanho do ícone ou a sensibilidade do toque na tela.

A lateralidade é inicializada conforme configuração inicial da prancha e pode assumir os sentidos horizontal ou vertical. A velocidade de varredura é inicializada conforme configuração inicial da prancha e pode assumir os sentidos mais rápido ou mais devagar. $\mathrm{O}$ tamanho do ícone é inicializado conforme configuração inicial da prancha e pode assumir os sentidos maior e menor. A sensibilidade de toque inicializa-se com o valor padrão de configuração do dispositivo, e pode ser alterada em relação à quantidade de pixels (maior ou menor) de arraste que são convertidos em cliques.

Antes de iniciar o uso da prancha com o modulo de tomada de decisão acionado, as seguintes informações devem ser configuradas: parâmetro a ser ajustado, quantidade de insatisfações aceitáveis dada uma janela de tempo, tamanho da janela de tempo, sentido inicial da alteração e porcentagem da alteração (exceto para a lateralidade, que é invertida).

Durante as interações, o módulo de tomada de decisão analisa se o sentido da alteração do parâmetro de configuração está correto. Isso é feito comparando-se a quantidade de insatisfações das janelas de tempo atual e passadas. Caso se verifique que a quantidade de insatisfação aumenta, à medida que as alterações ocorrem o algoritmo inverte o sentido da alteração. Por exemplo, supondo que uma prancha esteja com o sistema de varredura habilitado, e o valor de configuração de tempo de varredura inicial esteja demasiadamente lento para aquele usuário, a hipótese é que ao longo da utilização ele demonstre insatisfação por ter que esperar tanto tempo até que o sistema foque o ícone desejado. Supondo, ainda, que o sentido inicial de ajuste do módulo afetivo seja configurado como mais lento em $10 \%$, ocorrerá que o módulo afetivo tornará a velocidade ainda mais lenta, o que causará mais insatisfação ao usuário. A tendência é que, neste caso, a quantidade de insatisfação aumente nas janelas de tempo analisadas pelo algoritmo, possibilitando ao módulo de tomada de decisão identificar que o sentido da alteração está errado e invertê-lo. 


\subsection{Testes}

A seguir são descritos os procedimentos dos testes realizados nesta pesquisa, cujos resultados são apresentados no capítulo 7 .

Objetivando comparar os resultados obtidos nesta pesquisa, entrou-se em contato com outros autores que pesquisam e fornecem soluções de computação afetiva.

A empresa nViso oferece uma versão de demonstração de seu sistema de reconhecimento de emoções. Após preencher um formulário de cadastro, o site da empresa dá acesso a um painel de controle por meio do qual é possível realizar testes com imagens estáticas ou sequências de imagens. Ao criar um projeto no painel de controle, várias tentativas foram realizadas no sentido de testar o sistema, sem nenhum tipo de êxito.

As empresas Emotient, Kairos e RealEyes ofereceram versões de demonstração apenas para testes em tempo real, inviabilizando os testes com a base de dados própria gerada com emoções espontâneas. Nos três casos, a análise é feita em tempo real, enquanto o espectador assiste a um vídeo em seu navegador web. Os relatórios são disponibilizados, posteriormente, no painel de controle. $\mathrm{O}$ fato de não ser possível realizar a análise de vídeos pré-gravados inviabiliza a comparação de resultados.

A empresa Noldus forneceu uma versão de testes do FaceReader, limitada a 5 vídeos de 120 segundos cada. Optou-se por não testar o FaceReader devido a amostra ser muito pequena.

O software Intraface é oferecido em forma de código aberto, mas está passando por uma reformulação. $\mathrm{O}$ site informa que uma nova versão será disponibilizada em 01 de fevereiro de 2016.

A empresa Affectiva oferece um SDK de demonstração do software Affdex. Mas, por questões de facilidade de testes, optou-se por realizar testes de comparação com uma ferramenta on-line, disponibilizada pela empresa Sightcorp. Comparou-se os resultados obtidos com a metodologia proposta para as emoções simuladas, usando as bases de dados KDEF (The Karolinska Directed Emotional Faces) e CK+ (Cohn-Kanade Dataset).

Outros resultados, publicados pelos demais autores, também são apresentados e discutidos em relação aos resultados da metodologia proposta. 


\subsubsection{Algoritmo Face Neutra}

O algoritmo da face neutra foi testado com 136 sequências de vídeos, retiradas da base de dados descrita no tópico 6.5.3.2 deste texto. Os vídeos possuem taxas de 30 quadros por segundo. Considerando todo o processo de detecção da face, extração de características, classificação da expressão e inferência do estado emocional, a taxa média é de 27 interações por segundo.

\subsubsection{Algoritmo Linha Base}

Realizou-se quatro estudos de caso para testar o algoritmo de linha base, sendo dois com pessoas sem deficiência e dois com pessoas deficientes.

Em todos os casos, gerou-se uma sequência de três minutos de vídeo na qual durante os primeiros 60 segundos a pessoa foi orientada a olhar para um ponto fixo da tela; nos minutos seguintes, as pessoas sem deficiência navegaram por suas redes sociais e as com deficiência usaram uma prancha de comunicação.

Nenhuma pessoa sabia que fora selecionada para esses testes por possuir um tique, pois essa informação poderia incentivá-la a demonstrar ainda mais o tique ou, o oposto, a tentar escondê-lo.

Estudo de caso 1: homem de 44 anos, não deficiente, que possui tique facial na região dos olhos e não participou de nenhum outro teste do sistema.

Estudo de caso 2: mulher de 64 anos, não deficiente, que possui tique facial na região dos olhos e não participou de nenhum outro teste do sistema.

Estudo de caso 3: homem de 32 anos, com deficiência intelectual, que possui tique facial na região do nariz e participou dos testes do módulo de tomada de decisão. Nos testes com o módulo de tomada de decisão, essa pessoa está caracterizada como aluno 06 no estudo de caso 09.

Estudo de caso 4: mulher de 29 anos, com Síndrome de Down, que possui tique facial na região dos olhos e participou dos testes do módulo de tomada de decisão. Nos testes com o módulo de tomada de decisão, essa pessoa está caracterizada como aluno 02 no estudo de caso 05 .

O algoritmo da linha base foi testado em duas edições das sequências de vídeo geradas: Primeira edição da sequência: 15 segundos da pessoa olhando fixo para a tela +120 
segundos de utilização do computador (redes sociais ou prancha); segunda edição da sequência: 120 segundos de utilização do computador.

\subsubsection{Módulo Afetivo - Modelo 1}

\subsubsection{Emoções Simuladas}

Para avaliar a eficiência do módulo afetivo em relação à classificação das emoções básicas raiva, aversão, tristeza, medo, surpresa e felicidade de forma simulada foram utilizadas as bases de dados Cohn-Kanade Dataset (CK+) (LUCEY et al., 2010) e The Karolinska Directed Emotional Faces (KDEF) (LUNDQVIST; FLYKT; ÖHMAN, 1988).

A base KDEF é composta por 4.900 imagens de expressões faciais humanas de 70 pessoas (35 do sexo feminino e 35 do sexo masculino) posando para as expressões neutro, felicidade, raiva, medo, aversão, tristeza e surpresa, em cinco ângulos diferentes. Cada pessoa realizou duas sessões de poses.

Neste estudo utilizou-se as 980 imagens de posição frontal, e a inferência do estado emocional pelo modelo proposto foi realizado considerando a face neutra como primeiro quadro de um vídeo e a face com a expressão como segundo quadro do vídeo. Assim, analisou-se 840 expressões, sendo 140 de cada emoção.

Já a base $\mathrm{CK}+$ é composta por 10.558 imagens divididas em 123 diretórios. Cada um dos 123 diretórios possui subdivisões que são variáveis tanto em quantidade de diretórios quanto em quantidade de imagens por diretório. Cada subdiretório contém uma sequência de imagens que vai de uma face neutra a uma face com unidades de ação ativadas. Nem todas as sequências são rotuladas em termos de estado emocional.

Nos testes, utilizou-se apenas as sequências que estavam rotuladas com estados emocionais, sendo 45 sequências rotuladas como raiva, 57 como aversão, 25 como medo, 69 como felicidade, 27 como tristeza e 83 como surpresa, totalizando 306 sequências de imagens utilizadas nos testes.

Os resultados obtidos foram comparados com os de uma ferramenta on-line de testes fornecida pela empresa Sightcorp, utilizando-se as mesmas bases de dados nas sessões de testes. Além disso, os resultados são comparados e discutidos com os publicados por outros autores.

Como o algoritmo da Sightcorp realiza a inferência do estado emocional em imagens estáticas, e a base de dados $\mathrm{CK}+$ traz uma sequência de imagens que vão da face neutra até a 
ativação máxima de um estado emocional, os testes foram realizados em duas etapas. $\mathrm{Na}$ primeira, utilizou-se a última imagem da sequência, ou seja, aquela com ativação máxima de uma emoção (décimo sexto quadro da Figura 6.9, por exemplo). Na segunda, utilizou-se uma imagem com ativação média da emoção. Por exemplo, em uma sequência composta por dezesseis quadros na qual o primeiro traz a face neutra e o décimo sexto uma face com ativação máxima de um estado emocional, na segunda etapa dos testes foi utilizado o nono quadro da sequência.

Figura 6.9 - Exemplo de sequência de imagens da base de dados CK+. O primeiro quadro da segunda linha representa uma emoção com intensidade média, e o último quadro da última linha representa uma emoção com intensidade máxima.
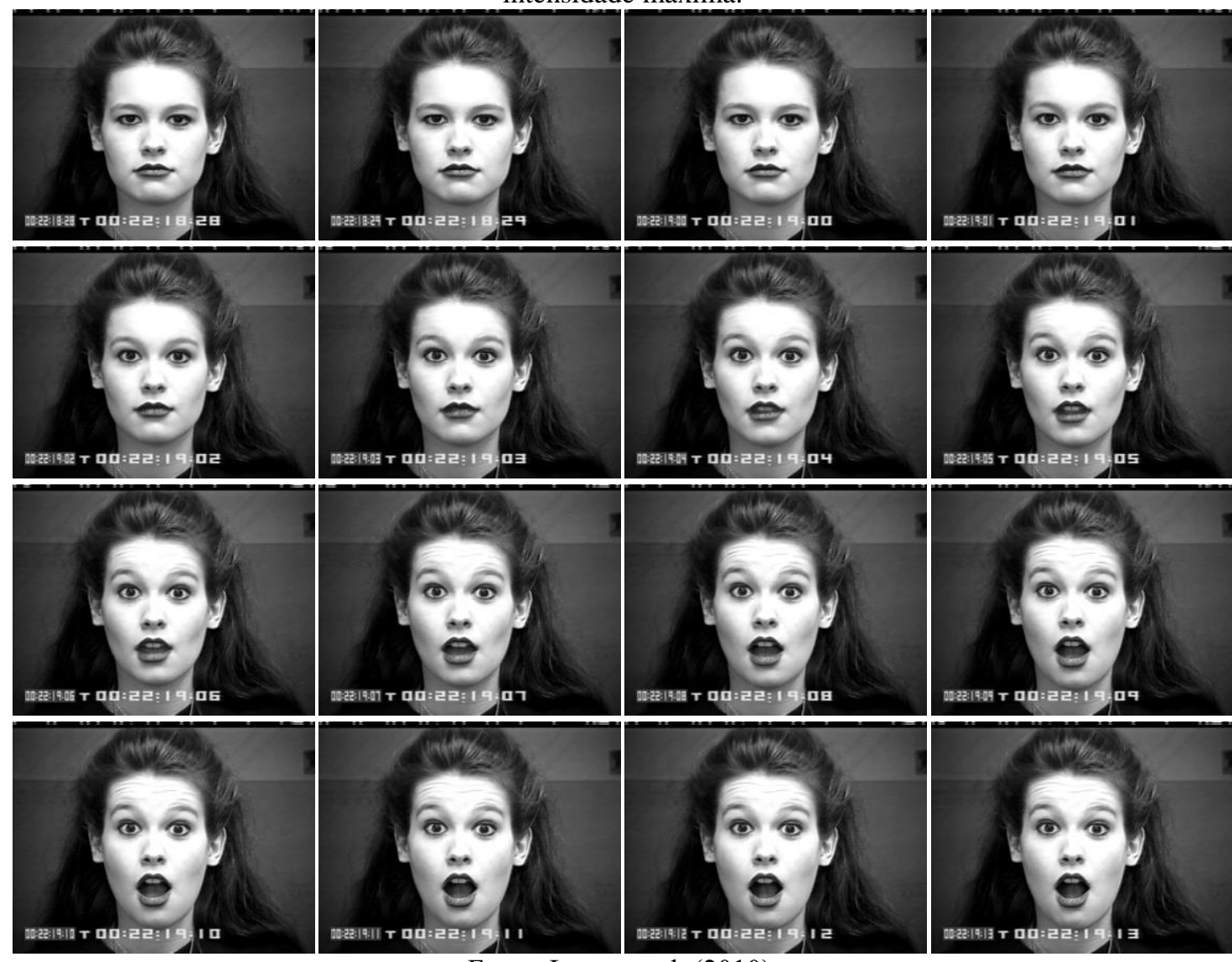

Fonte: Lucey et al. (2010).

Nos testes com emoções simuladas, não se utilizou os algoritmos de linha base nem de face neutra, uma vez que todas as sequências se iniciam com a face neutra e nenhuma contém imagens com expressões de tiques, apenas expressões emocionais. 


\subsubsection{Emoções Espontâneas}

Para avaliar emoções espontâneas, gerou-se uma base de dados de imagens de vídeo própria a partir da coleta de dados de 95 espectadores.

Considerando um cálculo amostral de uma população infinita, um erro de $10 \%$ e um nível de confiança de 90\% com um valor crítico de 1,645, selecionou-se 68 vídeos de espectadores com idade entre 18 e 63 anos para os testes de acordo com a equação abaixo:

$$
\begin{aligned}
& n=\frac{[1,645]^{2} \cdot 0,25}{0.10^{2}} \\
& n=68 \text { pessoas }
\end{aligned}
$$

Durantes os testes, os espectadores assistiram a um vídeo que, inicialmente, passa instruções de quais emoções o usuário deve simular (raiva, aversão, tristeza, medo surpresa e felicidade), depois, o mesmo vídeo explica que a partir de determinado momento o objetivo é captar emoções espontâneas e apresentava duas sequências de vídeos, uma com cenas engraçadas e outra com cenas violentas. Posteriormente, uma nova sequência foi adicionada com o objetivo de dar um susto no espectador. Enquanto assistiam ao vídeo na tela do computador, as imagens da face dos espectadores foram captadas para compor a base de dados de imagens de vídeos.

Após assistir ao vídeo de instrução, cada espectador respondeu a um questionário sobre como se sentiu ao assistir à sequência engraçada, a sequência violenta e, no final, se havia se assustado com a última sequência. Não foi fornecida nenhuma lista de opções aos espectadores, porém, o fato de eles terem sido orientados a simular emoções como felicidade, raiva e aversão fez que essas emoções figurassem entre as respostas de como os mesmos se sentiram ao assistir às sequências engraçada e violenta.

Devido à grande quantidade de espectadores que não conseguiram expressar de forma adequada as emoções simuladas - conforme ilustrado na Figura 6.10 -, gerando a necessidade de rotular cada expressão por meio de especialista antes de submeter ao módulo afetivo trabalho que seria demasiadamente custoso -, optou-se por não utilizar os trechos do vídeo com as emoções simuladas e, em vez disso, utilizou-se as bases de dados KDEF e CK+ para este fim. Além de as bases de dados trazerem os rótulos das expressões faciais de interesse anotados por especialistas, elas também são utilizadas como forma de avaliação da eficiência 
de expressões faciais e estados emocionais por diversos autores, o que facilita uma comparação em relação à eficiência de classificação com os trabalhos de outros autores.

A última sequência dos vídeos dos espectadores, cujo objetivo era capturar a expressão de surpresa, também não surtiu o efeito desejado. Na maioria dos casos, o espectador manteve a face neutra, sorriu, ou apenas movimentou a cabeça para trás. Assim, este trecho do vídeo também foi desconsiderado para os testes.

Dessa forma, apenas duas faixas dos vídeos gerados das expressões faciais dos espectadores foram submetidos ao módulo afetivo: uma faixa de 14 segundos, na qual o espectador estava assistindo aos vídeos engraçados, e outra faixa de 24 segundos, na qual o espectador assistia aos vídeos violentos.

Figura 6.10 - Imagens nas quais esperava-se a expressão de aversão.
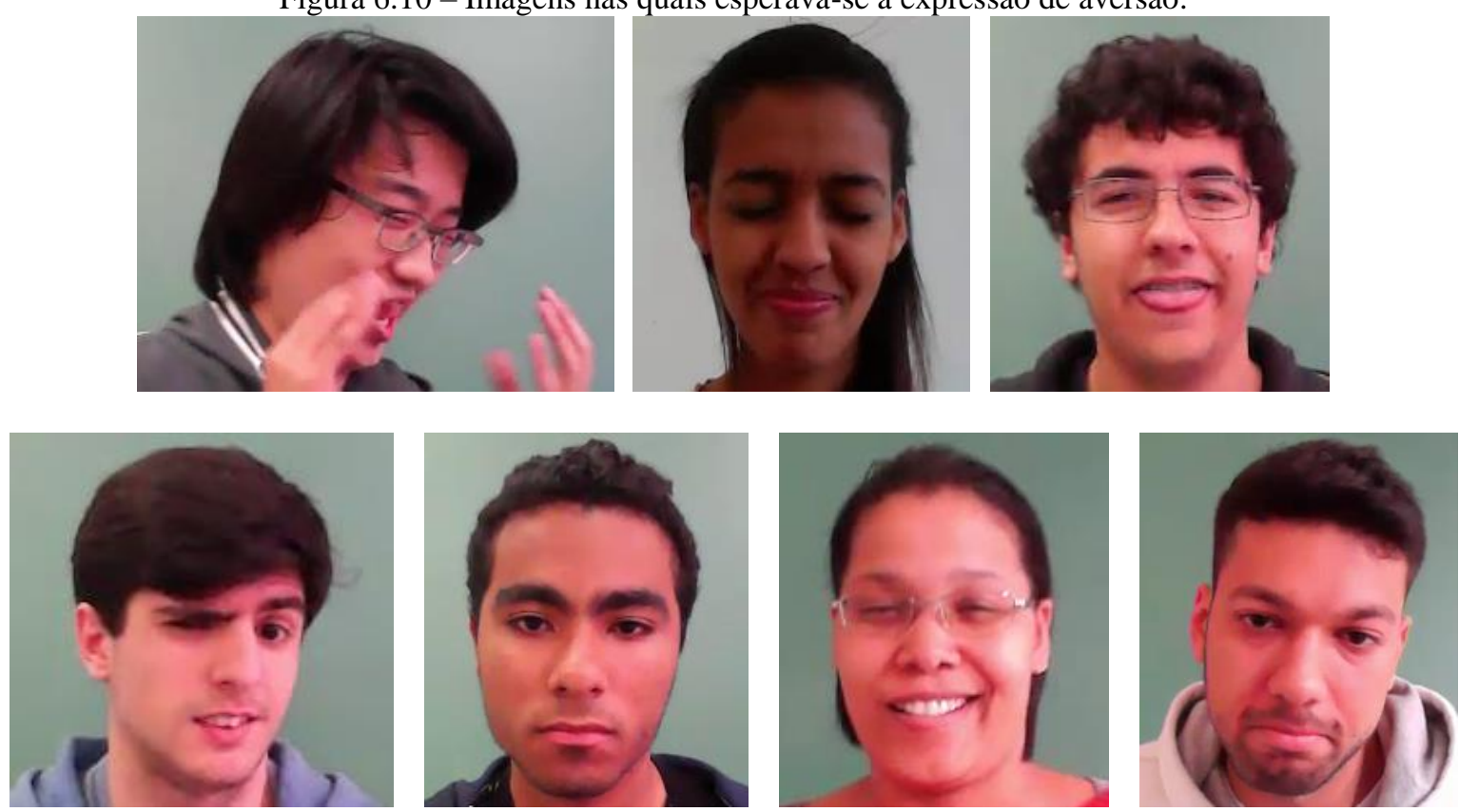

Fonte: Elaboração própria.

Todos os espectadores receberam a orientação de que a participação se daria de forma voluntária, leram e assinaram um termo de autorização de uso de imagem (ANEXO II), conforme previsto na Resolução 196/96, do Conselho Nacional de Saúde (BRASIL, 1996), que garante o direito de usos das imagens para fins de uso acadêmico.

A base de dados com os 95 vídeos gerados e as 136 sequências dos 68 vídeos selecionados, assim como o vídeo de instruções assistido pelos espectadores, podem ser solicitados a partir do endereço http://goo.gl/forms/t8MzAIcGJu.

Diferentemente das bases de dados $\mathrm{KDEF}$ e $\mathrm{CK}+$, cujos estados emocionais já vêm rotulados, foi necessário identificar e rotular os estados emocionais nos vídeos gerados. Após 
a edição do vídeo em duas sequências (as de cenas engraçadas e as de cenas violentas), os vídeos foram assistidos por 3 observadores que não tiveram acesso à natureza do vídeo de instrução, ou seja, não sabiam que na primeira sequência os espectadores assistiam aos vídeos engraçados e que na segunda sequência os espectadores estavam assistindo vídeos violentos. Os observadores foram convidados a rotular os estados emocionais identificados nos espectadores separadamente. Posteriormente, os três observadores compararam seus resultados. Quando dois ou mais atribuíram o mesmo estado emocional, manteve-se o mesmo. Em 21 sequências, cada observador rotulou um estado emocional diferente, assim, os mesmos assistiram novamente essas 21 sequências e determinaram, em conjunto, qual estado emocional deveria ser aferido como predominante.

Sorci et al. (2010) citam em seu trabalho um estudo semelhante, porém, quando o observador era questionado sobre quais emoções conseguia identificar, era oferecida uma lista com as opções felicidade, surpresa, medo, aversão, tristeza, raiva, neutro, outro e desconhecido aos observadores. Isso pode induzir o observador, em um primeiro momento, a tentar enquadrar as emoções nas classes felicidade, surpresa, medo, aversão, tristeza, raiva e neutro, e somente depois classificar expressões demasiadamente ambíguas como outro ou desconhecido.

Neste trabalho, não foi fornecida uma lista de emoções aos observadores, apenas os vídeos e uma planilha na qual o observador deveria anotar as emoções detectadas e, na opinião do observador, qual era predominante. Os resultados obtidos na classificação do módulo afetivo foram comparados às opiniões dos espectadores e dos observadores.

A comparação entre a emoção inferida pelo sistema e a emoção relatada pelo espectador determina a capacidade do modelo proposto para identificar o estado emocional de uma pessoa, ou seja, como ela se sente. Já a comparação entre a emoção inferida pelo sistema e a emoção relatada pelo observador determina a capacidade do modelo proposto para identificar o estado emocional de uma pessoa, tal qual outra pessoa faz durante uma interação.

Para determinar a emoção inferida pelo Módulo Afetivo, anotou-se a ocorrência de todas as emoções e determinou-se aquela com maior ocorrência, exceto a neutro que só foi classificada quando o módulo afetivo não identificou nenhum outro estado emocional.

Nos testes com as emoções espontâneas, utilizou-se o algoritmo de face neutra, uma vez que nem todas as sequências iniciam-se com a face neutra, e não se utilizou o algoritmo de linha base, uma vez que os vídeos não continham expressões de tiques. 


\subsubsection{Módulo de Tomada de Decisão}

Os testes realizados com o Módulo de Tomada de Decisão foram realizados com o Modelo 2 do Módulo Afetivo acoplado à Prancha de Comunicação, com o objetivo de analisar como as informações extraídas da mímica da face podem influenciar no processo de ajuste automático de parâmetros do sistema, melhorando a experiência do usuário.

Os testes do Módulo de Tomada de Decisão foram divididos em duas etapas: na primeira etapa, foram realizados estudos de caso com pessoas sem deficiência, já a segunda etapa é composta por estudos de casos de pessoas deficientes.

Os procedimentos utilizados em cada uma das etapas estão descritos nos próximos tópicos, e os resultados são apresentados no capítulo 7.

O algoritmo de face neutra estava habilitado durante os testes do módulo de tomada de decisão, e o algoritmo de linha base estava habilitado apenas nos testes dos usuários com tiques.

\subsubsection{Testes com usuários (pessoas sem deficiências)}

Os testes realizados com usuários são compostos por 3 estudos de caso. Os usuários que participaram dos estudos de caso não participaram dos experimentos da modelagem do sistema descritos no tópico 6.3.4.2, e nenhum deles possui tique.

De forma semelhante ao procedimento utilizado na modelagem, os usuários foram submetidos a perguntas respondidas por meio das pranchas de comunicação digital. A única forma de selecionar uma resposta era tocando sobre o ícone na tela. Porém, desta vez, o módulo afetivo estava captando a movimentação dos pontos de referência na face descritos na Tabela 6.5, e o módulo de tomada de decisão fazendo alterações em tempo real sobre o tamanho dos ícones.

A prancha selecionada para os estudos de caso possuía 12 ícones de $0.5 \mathrm{~cm}^{2} \mathrm{e}$ distância de 2 pixels entre cada (Figura 6.11), e os valores descritos na Tabela 6.6 foram configurados inicialmente no Módulo de Tomada de Decisão. 
Tabela 6.6 - Parâmetros de configuração inicial do módulo afetivo. P: parâmetro a ser alterado; Q: quantidade de insatisfações aceitáveis; T: janela de tempo;VP: valor padrão S: sentido da alteração e \% porcentagem da

\begin{tabular}{ccccccc}
\hline Est. Caso & $\mathbf{P}$ & $\mathbf{Q}$ & $\mathbf{T}$ & $\mathbf{V P}$ & $\mathbf{S}$ & $\mathbf{\%}$ \\
\hline 1 & tam_ico & 1 & 5 & $0.5 \mathrm{~cm}$ & + & $20 \%$ \\
\hline 2 & tam_ico & 2 & 5 & $0.5 \mathrm{~cm}$ & + & $20 \%$ \\
\hline 3 & tam_ico & 1 & 5 & $0.5 \mathrm{~cm}$ & - & $20 \%$ \\
\hline \multicolumn{7}{c}{ Fonte: Elaboração própria. }
\end{tabular}

Figura 6.11 - Prancha utilizada nos testes com usuários sem deficiência.

\begin{tabular}{|c|c|}
\hline$\sqrt{\text { [1 19_vestimentas_ND.httml }} \times \square$ & Ana Garolina $-a x$ \\
\hline 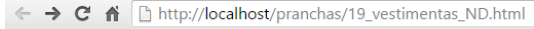 & \% 目目 \\
\hline
\end{tabular}

Fonte: Elaboração própria.

Durante as sessões de teste dos estudos de caso, foram realizadas as seguintes solicitações aos usuários: 1) Selecione o sapato feminino; 2) Selecione o sapato masculino; 3) Selecione o tênis; 4) Selecione a meia; 5) Selecione o vestido; 6) Selecione um item de inverno; 7) Selecione um item de verão; 8) Selecione um item de usar nos pés; 9) Selecione um item de usar na cabeça; 10) Selecione um item de usar nas mãos; 11) Selecione a luva; 12) Selecione o vestido; 13) Selecione o cachecol; 14) Selecione a camiseta; 15) Selecione a saia.

\subsubsection{Testes com alunos (pessoas deficientes)}

Para viabilizar os testes com os alunos, foi firmado um Termo de Autorização Institucional com a APAE de Presidente Prudente (ANEXO III). A coordenadora da APAE, em conjunto com uma equipe multidisciplinar, fez a seleção de 21 alunos que também apresentam dificuldade na fala como deficiência. 
Dos 21 alunos selecionados pela coordenação da APAE, dois não foi possível realizar contato com as famílias para autorização dos testes, três não foram autorizados pela família, dois os testes não foram realizados por motivos de faltas, três tinham menos de seis anos e não aceitaram ficar sem a presença da professora, um possuía dificuldade motora severa, sendo inclusive cadeirante, e não conseguiu tocar na tela do computador - tentou-se a utilização do mouse e de uma ponteira própria para deficientes, sem sucesso. Uma aluna movimentava-se para frente e para trás o tempo todo, e a câmera não conseguiu captar corretamente sua face já que a mesma saía do enquadramento. Uma câmera presa à cabeça dela resolveria o problema, mas não foi possível providenciar o equipamento a tempo para os testes.

Houve ainda um aluno autista que, por ser extremamente agitado, não parou em frente à câmera do computador, além disso, sua experiência com tecnologias e seu alto nível de inteligência fizeram que ele não apresentasse nenhum tipo de dificuldade na utilização das pranchas. Outros dois alunos autistas não aceitaram a presença de estranhos, mesmo após 2 semanas de permanência no ambiente com eles.

Dos seis alunos que participaram dos testes, os responsáveis legais concordaram com a participação nos testes como uma atividade dentre as demais que os alunos desenvolvem na APAE, porém apenas um responsável autorizou o uso das imagens do aluno, segundo documento elaborado descrito no Anexo IV.

Por meio de entrevistas aos professores, foram implementadas 29 pranchas de comunicação digital com atividades do cotidiano dos alunos (ANEXO V).

A Tabela 6.7 apresenta a caracterização dos alunos que participaram dos testes, e a tabela 6.8 a caracterização das pranchas utilizadas.

Tabela 6.7- Alunos voluntários da APAE.

\begin{tabular}{ccccc}
\hline Identificação & Sexo & Idade & Deficiência & Tique \\
\hline Aluno 01 & masculino & 47 & Intelectual & não \\
\hline Aluno 02 & feminino & 29 & Síndrome de Down & sim \\
\hline Aluno 03 & masculino & 33 & Intelectual & não \\
\hline Aluno 04 & masculino & 32 & Intelectual & não \\
\hline Aluno 05 & masculino & 13 & X-Frágil & não \\
\hline Aluno 06 & masculino & 37 & Intelectual & sim \\
\hline & & Fonte: Elaboração própria. &
\end{tabular}


Tabela 6.8 - Caracterização das pranchas utilizadas nos testes com os alunos.

\begin{tabular}{|c|c|c|c|}
\hline Categoria & Prancha & Qtd ícones & Descrição \\
\hline \multirow{7}{*}{ Simples } & 01 & 2 & Time de Futebol \\
\hline & 02 & 2 & Desenho Animado \\
\hline & 03 & 3 & Animais Domésticos \\
\hline & 04 & 3 & Brinquedos \\
\hline & 05 & 3 & Histórias Infantis \\
\hline & 06 & 3 & Salada \\
\hline & 07 & 4 & Frutas \\
\hline \multirow{11}{*}{ Intermediária } & 08 & 2 & Textura \\
\hline & 09 & 2 & Comportamento \\
\hline & 10 & 3 & Festas \\
\hline & 11 & 3 & Talheres \\
\hline & 12 & 3 & Tempo (clima) \\
\hline & 13 & 4 & Material escolar \\
\hline & 14 & 4 & Ambientes Domésticos \\
\hline & 15 & 4 & Emoções \\
\hline & 16 & 5 & Higiene Pessoal \\
\hline & 17 & 6 & Materiais de trabalho na horta \\
\hline & 18 & 6 & Materiais de limpeza \\
\hline \multirow{9}{*}{ Avançada } & 19 & 12 & Vestimentas e calçados \\
\hline & 20 & 2 & Localização (dentro/fora) \\
\hline & 21 & 2 & Localização (perto/longe) \\
\hline & 22 & 2 & Quantidade (mais/menos) \\
\hline & 23 & 2 & Tamanho (grande/pequeno) \\
\hline & 24 & 6 & Cores \\
\hline & 25 & 2 & Quebra-cabeça \\
\hline & 27 & 4 & Números \\
\hline & 28 & 5 & Vogais \\
\hline
\end{tabular}

Fonte: Elaboração própria.

Para determinar o tipo de dificuldade de cada aluno, inicialmente foi realizada uma sessão de testes apenas com a utilização da prancha, sem o módulo afetivo e sem o módulo de tomada de decisão atuando. Identificado o tipo de dificuldade, um ou mais testes foram realizados com o módulo afetivo, identificando as expressões faciais de insatisfação e o módulo de tomada de decisão atuando de acordo com os parâmetros configurados.

Durante os testes, alunos que já tinham contato com o computador tentaram usar o teclado. Alguns queriam acessar programas diversos e, irritados com a negativa, batiam, mordiam ou lançavam o computador. Assim, produziu-se uma capa acrílica (Figura 6.12) para proteger a máquina e impedir o acesso ao teclado. Além disso, o teclado foi coberto com uma folha branca, para não criar no aluno a ansiedade de acessá-lo. 
Figura 6.12 - Capa acrílica desenvolvida para os testes com alunos da APAE.
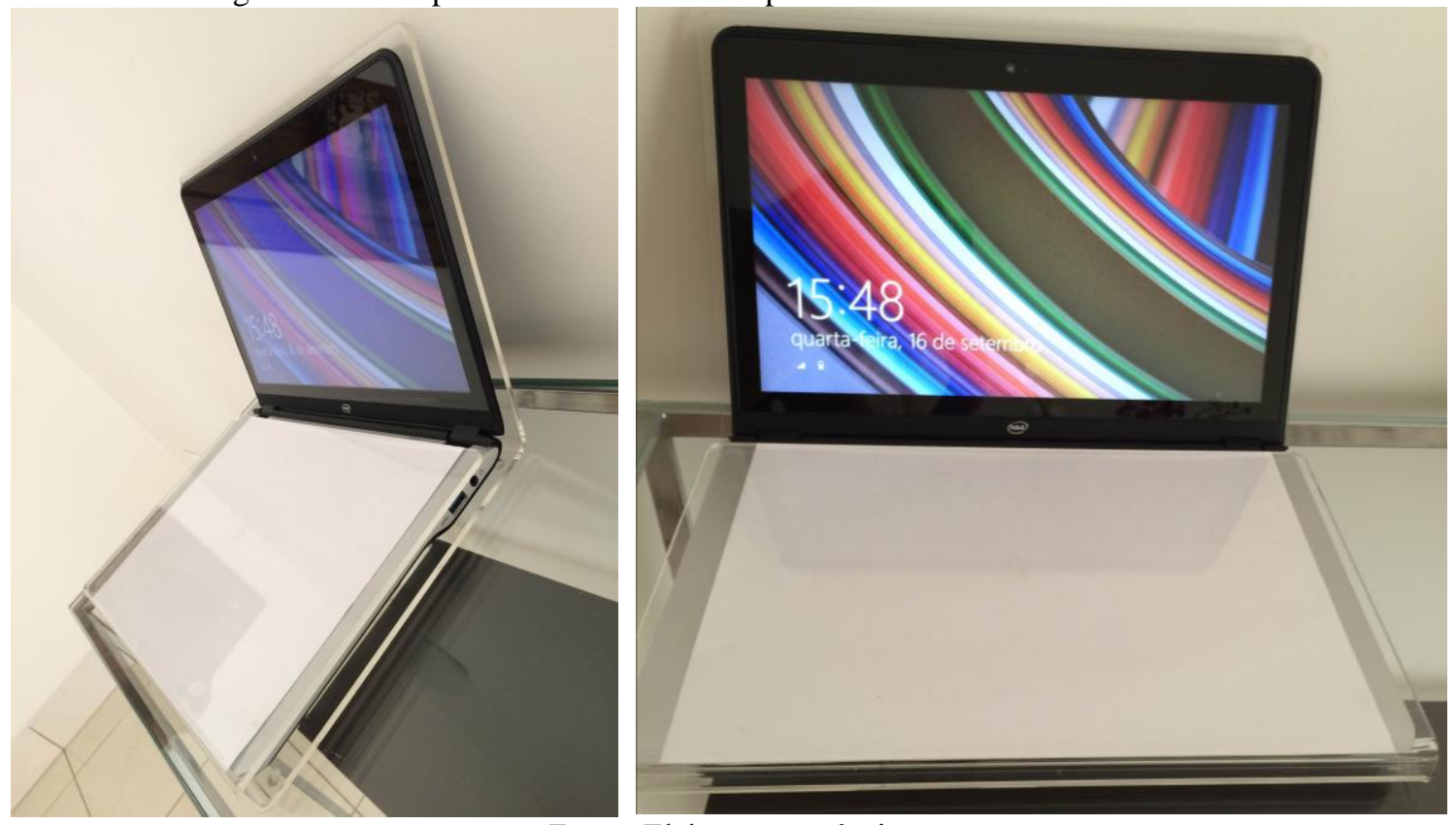

Fonte: Elaboração própria.

Estudo de Caso 04: O aluno apresentou dificuldades na seleção do ícone, pois arrastava o dedo na tela em vez de tocar e soltar quando desejava selecionar o objeto solicitado. Esse aluno desenvolve atividades na horta da APAE e, segundo relatos da família, ele não tem acesso a equipamentos eletrônicos em casa. Durante os testes, notou-se que o aluno não possui entendimento de cores e vogais. Nas perguntas feitas sobre os demais assuntos das pranchas de comunicação, o aluno demonstrou entendimento e respondeu corretamente às questões por meio da prancha de comunicação. Todas as pranchas foram testadas, e os testes foram realizados na seguinte ordem pelo número da prancha segundo a Tabela 6.8: 03,04,14, 09, 24, 20, 02, 21, 15, 10, 07, 16, 05, 17, 06, 18, 13, 26, 22, 25, 11, 23, 12, 08, 01, 19, 27.

Aluno: Aluno 01;

Dificuldade: Com o toque na tela;

Parâmetro a ser configurado: Converter arraste em clique;

Quantidade de Insatisfações aceitáveis: 1

Janela de tempo: 5 segundos

Valor inicial: $0,5 \mathrm{~cm}$

Sentido: +

Porcentagem de alteração: $20 \%$

Estudo de Caso 05: A aluna não apresentou dificuldades na seleção dos ícones. Teve facilidade para utilizar a prancha com o toque na tela e com o mouse. Além disso demonstrou 
habilidades com o teclado, sendo capaz de digitar seu próprio nome. Essa aluna desenvolve atividades na casa modelo da APAE e também frequenta as aulas de educação física. Segundo relatos da família, ela tem acesso a equipamentos eletrônicos em casa. Durante os testes, notou-se que a aluna não possui entendimento de cores, ferramentas utilizadas na horta e vogais. Nas perguntas feitas sobre os demais assuntos das pranchas de comunicação, a aluna demonstrou entendimento e respondeu corretamente às questões por meio da prancha de comunicação. Todas as pranchas foram testadas, e os testes foram realizados na seguinte ordem pelo número da prancha segundo a Tabela 6.8: 03,04,14, 09, 24, 20, 02, 21, 15, 10, 07 , 16, 05, 17, 06, 18, 13, 26, 22, 25, 11, 23, 12, 08, 01, 19, 27.

Uma vez que a aluna não apresentou dificuldade de utilização da prancha, para fins de teste configurou-se o tamanho dos ícones com $0,5 \mathrm{~cm}^{2}$ e 2 pixels de distância entre os mesmos, a fim de adicionar dificuldade de utilização nas pranchas para avaliar o módulo afetivo atuando com a aluna que possui tique na região dos olhos. Inicialmente, solicitou-se que a aluna olhasse para a tela do computador por 10 segundos, enquanto o algoritmo da linha base estava atuando, e só após esse tempo o teste teve início.

Aluno: Aluno 02;

Dificuldade: Nenhuma (adicionada tamanho do ícone);

Parâmetro a ser configurado: Tamanho do ícone;

Quantidade de Insatisfações aceitáveis: 1

Janela de tempo: 5 segundos

Valor inicial: $0,5 \mathrm{~cm}$

Sentido: +

Porcentagem de alteração: $20 \%$

Em data posterior ao primeiro teste, foi realizado um novo teste com os parâmetros tal qual o Módulo de Tomada de Decisão havia configurado no final do primeiro teste. Os demais parâmetros, cujo Módulo de Tomada de Decisão não altera, foram mantidos os mesmos.

\section{Valor inicial: $5 \mathrm{~cm}$}

Sentido: +

Estudo de Caso 06: O aluno não apresentou dificuldades na seleção dos ícones. Teve facilidade para utilizar a prancha com o toque na tela e com o mouse. Esse aluno desenvolve atividades na horta da APAE e também frequenta as aulas de educação física. Segundo relatos da família, ele não tem acesso a equipamentos eletrônicos em casa. Durante os testes, notouse que o aluno não possui entendimento de cores, emoções e vogais. Nas perguntas feitas 
sobre os demais assuntos das pranchas de comunicação, o aluno demonstrou entendimento e respondeu corretamente às questões por meio da prancha de comunicação. Todas as pranchas foram testadas, e os testes foram realizados na seguinte ordem pelo número da prancha segundo a Tabela 6.8: 03,04,14, 09, 24, 20, 02, 21, 15, 10, 07, 16, 05, 17, 06, 18, 13, 26, 22, 25, 11, 23, 12, 08, 01, 19, 27.

Uma vez que o aluno não apresentou dificuldade de utilização da prancha, para fins de teste configurou-se o tamanho dos ícones com $0,5 \mathrm{~cm}^{2}$ e 2 pixels de distância entre os mesmos, a fim de adicionar dificuldade de utilização nas pranchas.

Aluno: Aluno 03;

Dificuldade: Nenhuma (adicionada tamanho do ícone);

Parâmetro a ser configurado: Tamanho do ícone;

Quantidade de Insatisfações aceitáveis: 1

Janela de tempo: 5 segundos

Valor inicial: $0,5 \mathrm{~cm}$

Sentido: +

Porcentagem de alteração: $20 \%$

Um segundo teste também foi realizado com esse aluno. Os resultados obtidos são apresentados e discutidos no capítulo 7 deste trabalho.

Estudo de Caso 07: O aluno apresentou dificuldades na seleção dos ícones, pois, além de deficiência intelectual e da fala, também apresenta deficiência motora. Este aluno desenvolve atividades em umas das salas de aula APAE. Também frequenta aulas de música e o laboratório de informática. Segundo relatos da família, ele não tem acesso a equipamentos eletrônicos em casa. Durante os testes, notou-se que o aluno não possui entendimento de números e vogais. Nas perguntas feitas sobre os demais assuntos das pranchas de comunicação, o aluno demonstrou entendimento e respondeu corretamente às questões. Todas as pranchas foram testadas, e os testes foram realizados na seguinte ordem pelo número da prancha segundo a Tabela 6.8: 03,04,14, 09, 24, 20, 02, 21, 15, 10, 07, 16, 05, 17, 06, 18, 13, 26, 22, 25, 11, 23, 12, 08, 01, 19, 27.

Aluno: Aluno 04;

Dificuldade: Motora que dificulta a seleção dos ícones;

Parâmetro a ser configurado: Velocidade de varredura;

Quantidade de Insatisfações aceitáveis: 1

Janela de tempo: 5 segundos

Valor inicial: 1 segundo 


\section{Sentido: +}

Porcentagem de alteração: $10 \%$

Inicialmente, foram realizados dois testes: o primeiro com os parâmetros listados acima, e o segundo usando como valor inicial do tempo de varredura o valor de saída do primeiro teste (0,9 segundos). Nos dois primeiros testes, o parâmetro a ser ajustado pelo Módulo de tomada de Decisão foi o tempo de varredura.

Durante os dois primeiros testes, notou-se que, além da dificuldade em selecionar um ícone pela deficiência motora, o aluno também arrasta o dedo na tela em vez de clicar. Assim, um terceiro teste foi realizado, mantendo o tempo de varredura fixo em 1 segundo (valor de saída do segundo teste) e habilitando o Módulo de Tomada de Decisão para converter o arraste em clique, segundo os parâmetros descritos abaixo:

Aluno: Aluno 04;

Dificuldade: Com o toque na tela;

Parâmetro a ser configurado: Converter arraste em clique;

Quantidade de Insatisfações aceitáveis: 1

Janela de tempo: 5 segundos

Valor inicial: $0,5 \mathrm{~cm}$

Sentido: +

Porcentagem de alteração: $20 \%$

Estudo de Caso 08: O aluno apresentou dificuldades na seleção do ícone, pois arrastava o dedo na tela em vez de tocar e soltar quando desejava selecionar o objeto solicitado. Esse aluno desenvolve atividades na sala de aula APAE e também atividades de música, educação física e informática. Segundo relatos da família, ele tem acesso a equipamentos eletrônicos em casa. Durante os testes, notou-se que o aluno não possui entendimento de cores, dentro e fora, distância, emoções, datas comemorativas, personagens das histórias apresentadas, números, quebra-cabeça, tamanho, textura, time de futebol e vogais. Nas perguntas feitas sobre os demais assuntos das pranchas de comunicação, o aluno demonstrou entendimento e respondeu corretamente às questões por meio da prancha de comunicação. Todas as pranchas foram testadas, e os testes foram realizados na seguinte ordem pelo número da prancha segundo a Tabela 6.8: 03,04,14, 09, 24, 20, 02, 21, 15, 10, 07, 16, 05, 17, 06, 18, 13, 26, 22, 25, 11, 23, 12, 08, 01, 19, 27.

Aluno: Aluno 05;

Dificuldade: Com o toque na tela;

Parâmetro a ser configurado: Converter arraste em clique; 
Quantidade de Insatisfações aceitáveis: 1

Janela de tempo: 5 segundos

Valor inicial: $0,5 \mathrm{~cm}$

Sentido: +

Porcentagem de alteração: $20 \%$

Foram realizadas duas sequências de testes com esse aluno, sendo que na segunda o tamanho do arraste convertido em clique estava ajustado segundo o resultado do Módulo de Tomada de Decisão do primeiro teste em 1,4 cm. Entre a data de um teste e outro, a família solicitou a instalação das pranchas no computador da casa do aluno. Em casa, o aluno operou as pranchas com o mouse, e arrastes de até $1,4 \mathrm{~cm}$ foram convertidos em cliques de igual forma aos testes com a tela touch.

Os resultados dos testes são apresentados e discutidos no capítulo 7.

Estudo de Caso 09: O aluno não apresentou dificuldades na seleção dos ícones. Teve facilidade para utilizar a prancha com o toque na tela e com o mouse, além de demonstrar habilidades com o teclado. Esse aluno desenvolve atividades em sala de aula da APAE e também frequenta as aulas de educação física, música e informática. Segundo relatos da família, ele tem acesso a equipamentos eletrônicos em casa. Durante os testes, notou-se que o aluno possui entendimento de todos os assuntos tratados nas pranchas respondendo corretamente todas às questões. Todas as pranchas foram testadas, e os testes foram realizados na seguinte ordem pelo número da prancha segundo a Tabela 6.8: 03,04,14, 09, 24, 20, 02, 21, 15, 10, 07, 16, 05, 17, 06, 18, 13, 26, 22, 25, 11, 23, 12, 08, 01, 19, 27.

Uma vez que o aluno não apresentou dificuldade de utilização da prancha, para fins de teste configurou-se o tamanho dos ícones com $0,5 \mathrm{~cm}^{2}$ e 2 pixels de distância entre os mesmos, a fim de adicionar dificuldade de utilização nas pranchas para avaliar o módulo afetivo atuando com o aluno que possui tique na região do nariz. Inicialmente, solicitou-se que o aluno olhasse para a tela do computador por 10 segundos, enquanto o algoritmo da linha base estava atuando e só após esse tempo o teste teve início.

Aluno: Aluno 06;

Dificuldade: Nenhuma (adicionada tamanho do ícone);

Parâmetro a ser configurado: Tamanho do ícone;

Quantidade de Insatisfações aceitáveis: 1

Janela de tempo: 5 segundos

Valor inicial: $0,5 \mathrm{~cm}$

Sentido: + 
Porcentagem de alteração: $20 \%$

Em data posterior ao primeiro teste, foi realizado um novo teste com os parâmetros tal qual o Módulo de Tomada de Decisão havia configurado no final do primeiro teste. Os demais parâmetros, cujo Módulo de Tomada de Decisão não altera, foram mantidos os mesmos.

Valor inicial: $6 \mathrm{~cm}$

Sentido: +

\subsection{Considerações Finais}

Este capítulo apresentou os materiais utilizados nesta pesquisa e descreveu, em detalhes, os três módulos implementados: Prancha de Comunicação, Módulo Afetivo e Módulo de Tomada de Decisão.

A metodologia dos testes foi descrita, e os resultados obtidos serão apresentados e discutidos no próximo capítulo. 


\section{Capítulo}

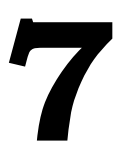

\section{Resultados e Conclusões}

Este capítulo apresenta os resultados e discussões sobre as metodologias descritas no capítulo anterior. Além disso, apresentam-se as conclusões sobre os estudos realizados e pontua-se trabalhos futuros.

\subsection{Algoritmo Face Neutra}

Das 136 sequências de vídeos utilizadas nos testes para identificar emoções espontâneas, 44 foram inicializadas com alguma expressão. Dentre essas 44 sequências analisadas em relação ao algoritmo da face neutra, apresentaram-se as seguintes situações:

Situação A: após algumas interações, o vetor da face neutra estava estabilizado. A quantidade média de interações para estabilizar o vetor foi de 130.

Situação B: o vetor da face neutra não se estabilizou, porque a emoção expressa na inicialização manteve-se durante toda a duração do vídeo. Porém, o sistema inferiu corretamente o estado emocional, devido ao fato de a intensidade da emoção demonstrada na inicialização ter sido menor que em determinados momentos do vídeo. 
Situação C: o vetor da face neutra não se estabilizou, e o sistema não conseguiu inferir corretamente o estado emocional.

A Tabela 7.1 apresenta a quantidade de ocorrência das situações A, B e C.

Tabela 7.1 - Dados das situações descritas para as 48 sequências de vídeo cuja emoção inicial não era neutra.

\begin{tabular}{ccc}
\hline Situação A & Situação B & Situação C \\
\hline 30 & 7 & 7 \\
\hline $62,5 \%$ & $14,58 \%$ & $14,58 \%$ \\
\hline
\end{tabular}

Fonte: Elaboração própria.

\subsection{Algoritmo Linha Base}

Os resultados obtidos nos estudos de caso demonstraram que o software foi capaz de separar os sinais faciais rápidos entre sinais de linha base e sinais emocionais apenas quando o usuário permanece por certo tempo sem interagir com o sistema.

\section{Estudo de caso 1:}

Durante os três minutos de teste, a pessoa não demonstrou nenhuma vez o tique, e o teste não pôde ser utilizado para verificar a eficiência do algoritmo da linha base. Notou-se que, ao finalizar o teste e iniciar um diálogo, o tique passou a ser demonstrado. Em conversas face a face, por telefone e por computador com recursos de áudio e vídeo, a pessoa apresenta o tique. Na interação com a máquina, sem um interlocutor humano, a pessoa não apresenta o tique. A hipótese é de que o tique esteja relacionado a questões associadas à fala.

\section{Estudos de caso 2, 3 e 4:}

A Tabela 7.2 apresenta os resultados dos testes realizados na primeira edição da sequência, contendo os 60 segundos da pessoa olhando fixo para a tela +120 segundos de utilização do computador.

Tabela 7.2 - Testes realizados na primeira edição da sequência dos vídeos dos estudos de caso 2, 3 e 4 .

\begin{tabular}{ccc}
\hline Estudo de Caso & Emoções identificadas por especialista & Emoções identificadas pelo software \\
\hline 2 & Nenhuma Insatisfação & Nenhuma Insatisfação \\
\hline 3 & Nenhuma Insatisfação & Nenhuma Insatisfação \\
\hline \multirow{3}{*}{4} & $00: 00: 15-$ Insatisfação & $00: 00: 15$ - Insatisfação \\
\cline { 2 - 3 } & $00: 00: 47$ - Insatisfação & $00: 00: 47-$ Insatisfação \\
\cline { 2 - 3 } & $00: 01: 31$ - Insatisfação & $00: 01: 31-$ Neutro
\end{tabular}

Fonte: Elaboração própria.

Como era esperado, sem os 60 segundos de treinamento do algoritmo da linha base, necessários para identificar os tiques antes de iniciar a classificação a insatisfação não houve 
convergência de resultados nos testes realizados na segunda edição da sequência contendo 120 segundos de utilização do computador.

\subsection{Módulo Afetivo - Modelo 1}

Os próximos tópicos apresentam os resultados dos testes realizados com o Modelo 1 do Módulo Afetivo, cujo objetivo é avaliar a eficiência do modelo proposto na inferência do estado emocional em situações simuladas e espontâneas. Os resultados obtidos serão apresentados, discutidos e comparados aos trabalhos de outros autores.

\subsubsection{Emoções Simuladas}

A Figura 7.1 apresenta o gráfico dos resultados obtidos na inferência do estado emocional pelo Modelo 1 do Módulo Afetivo proposto neste estudo, utilizando imagens da base de dados KDEF (LUNDQVIST; FLYKT; ÖHMAN, 1988). Abaixo do gráfico, são descritos os valores em forma de matriz de confusão na qual a diagonal principal representa a taxa de acerto dos demais valores de uma linha onde o sistema errou. A taxa de acerto médio em relação à precisão de inferência do estado emocional foi de 85,7\%. 
Figura 7.1 - Resultados dos testes do modelo proposto usando a base de dados KDEF.

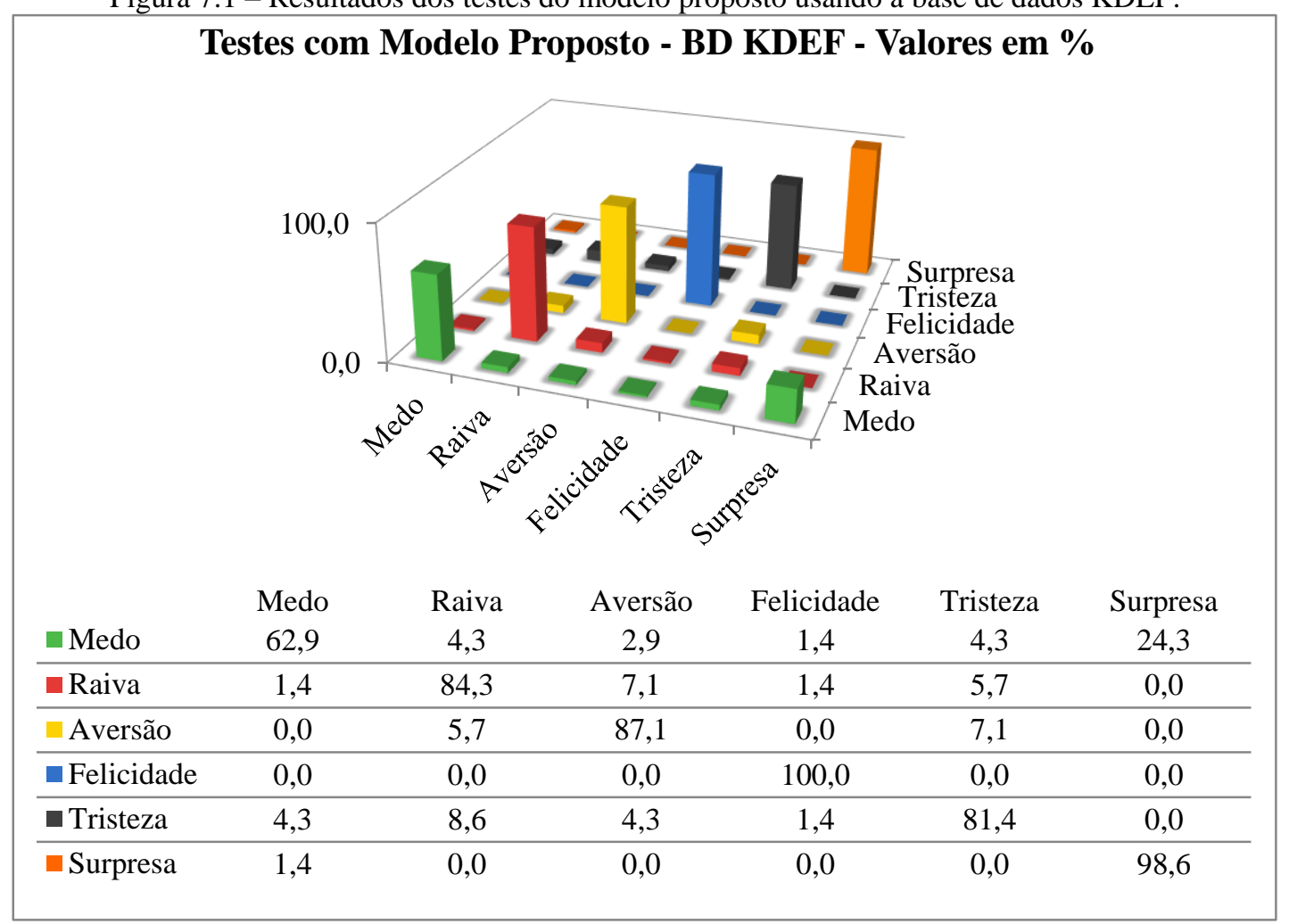

Fonte: Elaboração própria.

A Figura 7.2 apresenta o gráfico dos resultados obtidos na inferência do estado emocional pelo algoritmo da Sightcorp, utilizando imagens da base de dados KDEF. Abaixo do gráfico, são descritos os valores em forma de matriz de confusão. A taxa de acerto médio foi de $72 \%$. 
Figura 7.2 - Resultados dos testes do algoritmo da Sightcorp usando a base de dados KDEF.

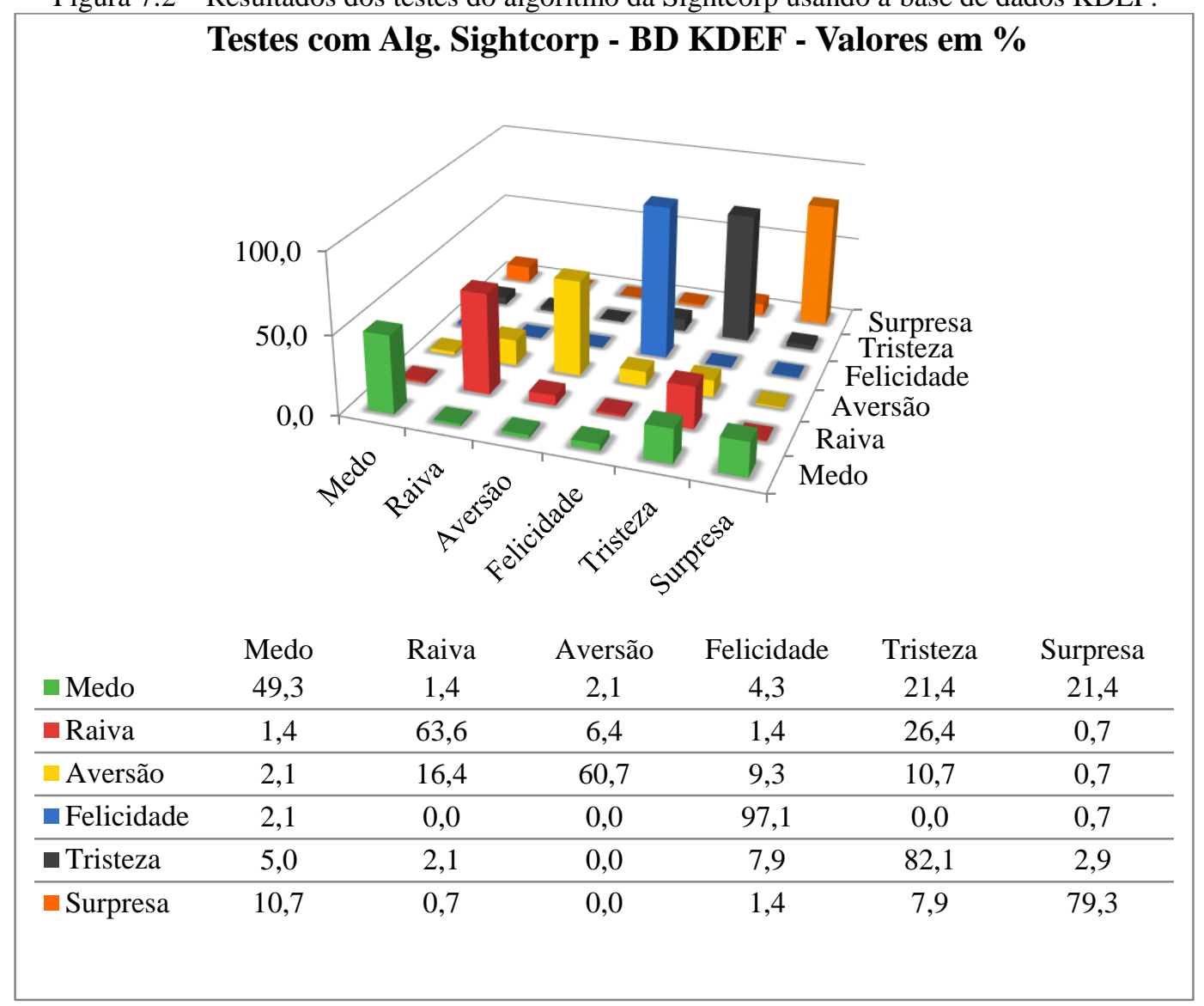

Fonte: Elaboração própria.

A Figura 7.3 apresenta o gráfico da comparação entre o modelo proposto e o algoritmo da Sightcorp, utilizando imagens da base de dados KDEF.

Figura 7.3 - Comparação dos testes do modelo proposto versus algoritmo da Sightcorp com a BD KDEF.

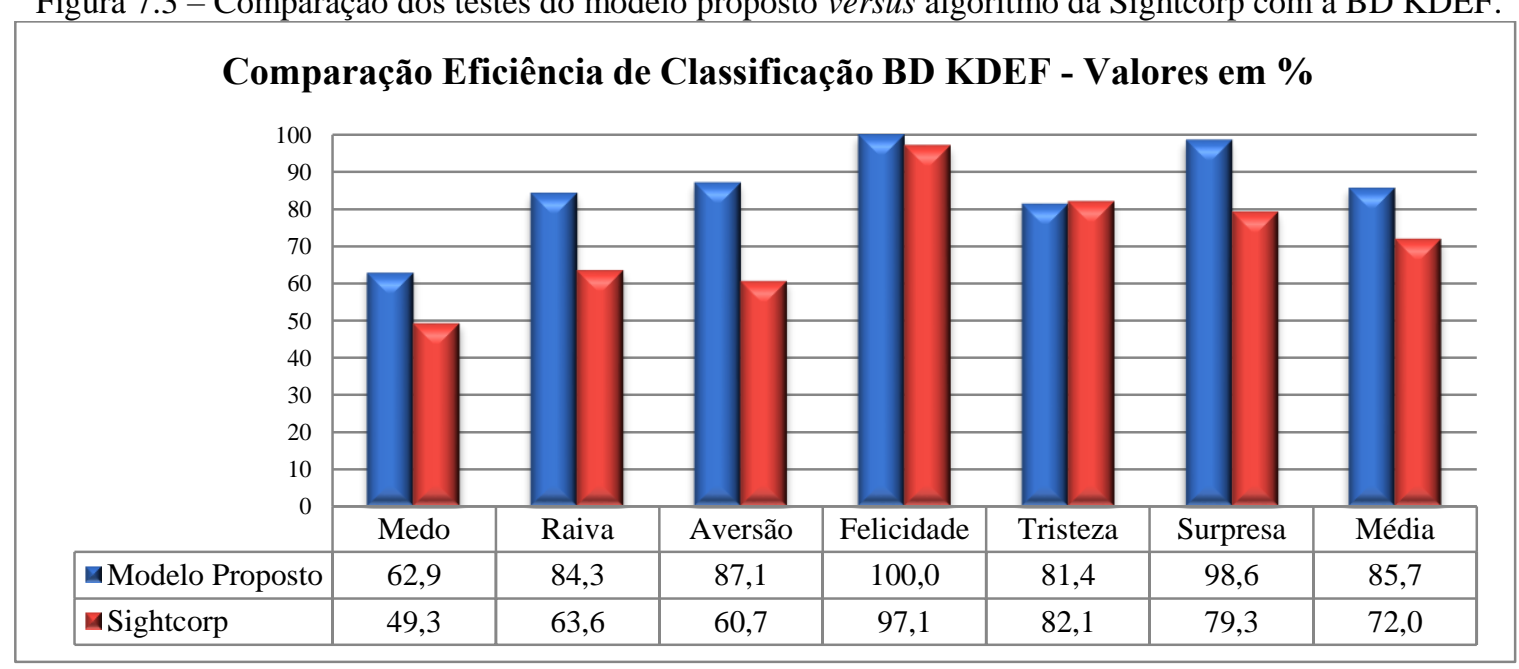

Fonte: Elaboração própria.

A Figura 7.4 apresenta o gráfico dos resultados obtidos na inferência do estado emocional pelo Modelo 1 do Módulo Afetivo proposto neste estudo, utilizando imagens da 
base de dados CK+ (LUCEY et al., 2010). Abaixo do gráfico, são descritos os valores em forma de matriz de confusão. A taxa de acerto médio foi de $91,2 \%$.

Figura 7.4 - Resultados dos testes do modelo proposto usando a base de dados CK+.

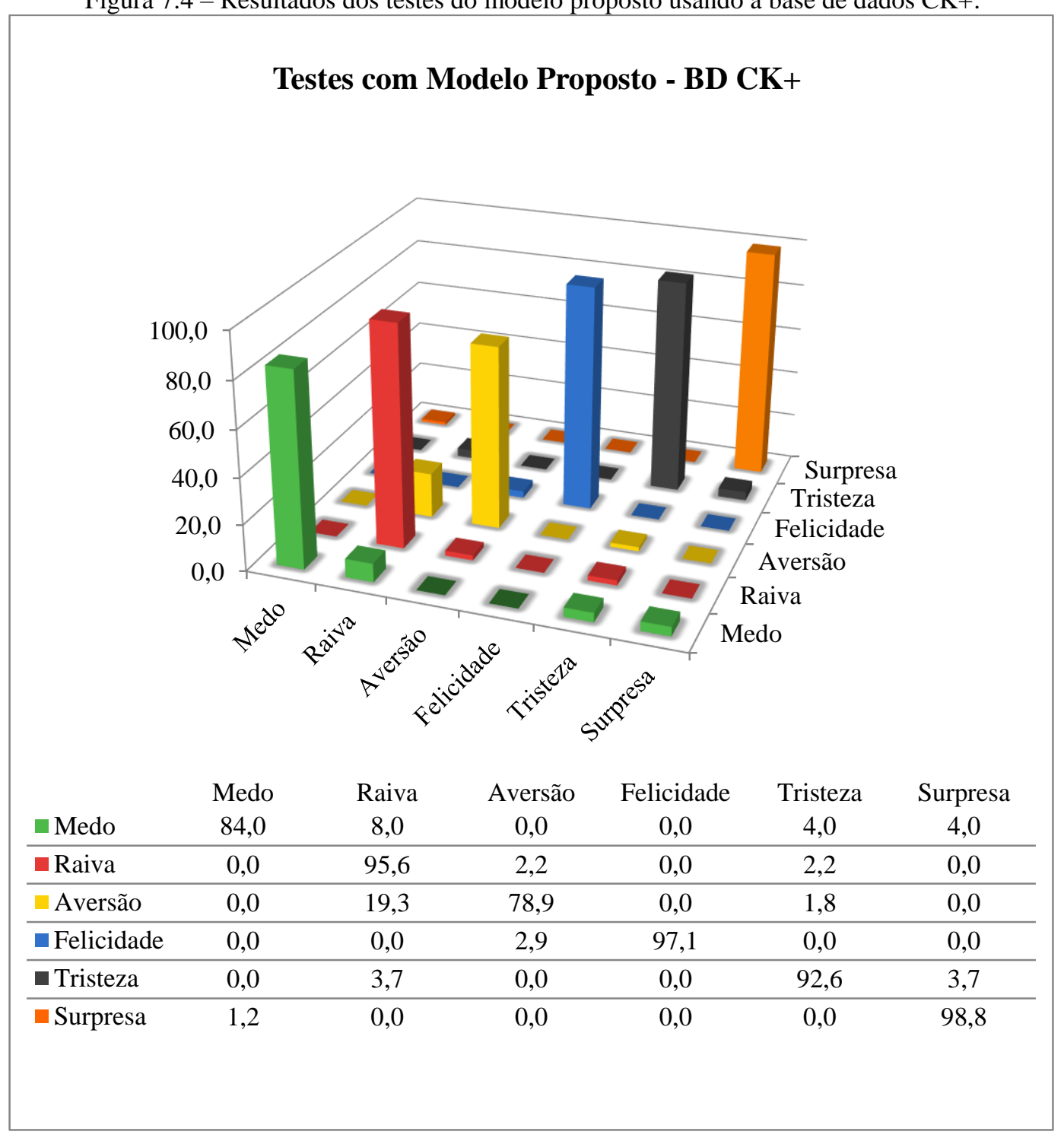

Fonte: Elaboração própria.

A Figura 7.5 apresenta o gráfico dos resultados obtidos na inferência do estado emocional pelo algoritmo da Sightcorp, utilizando imagens da base de dados $\mathrm{CK}+$ com ativação máxima. Abaixo do gráfico, são descritos os valores em forma de matriz de confusão. A taxa de acerto foi de 100\%. 
Figura 7.5 - Resultados dos testes do algoritmo da Sightcorp usando a base de dados CK+ ativação máxima.

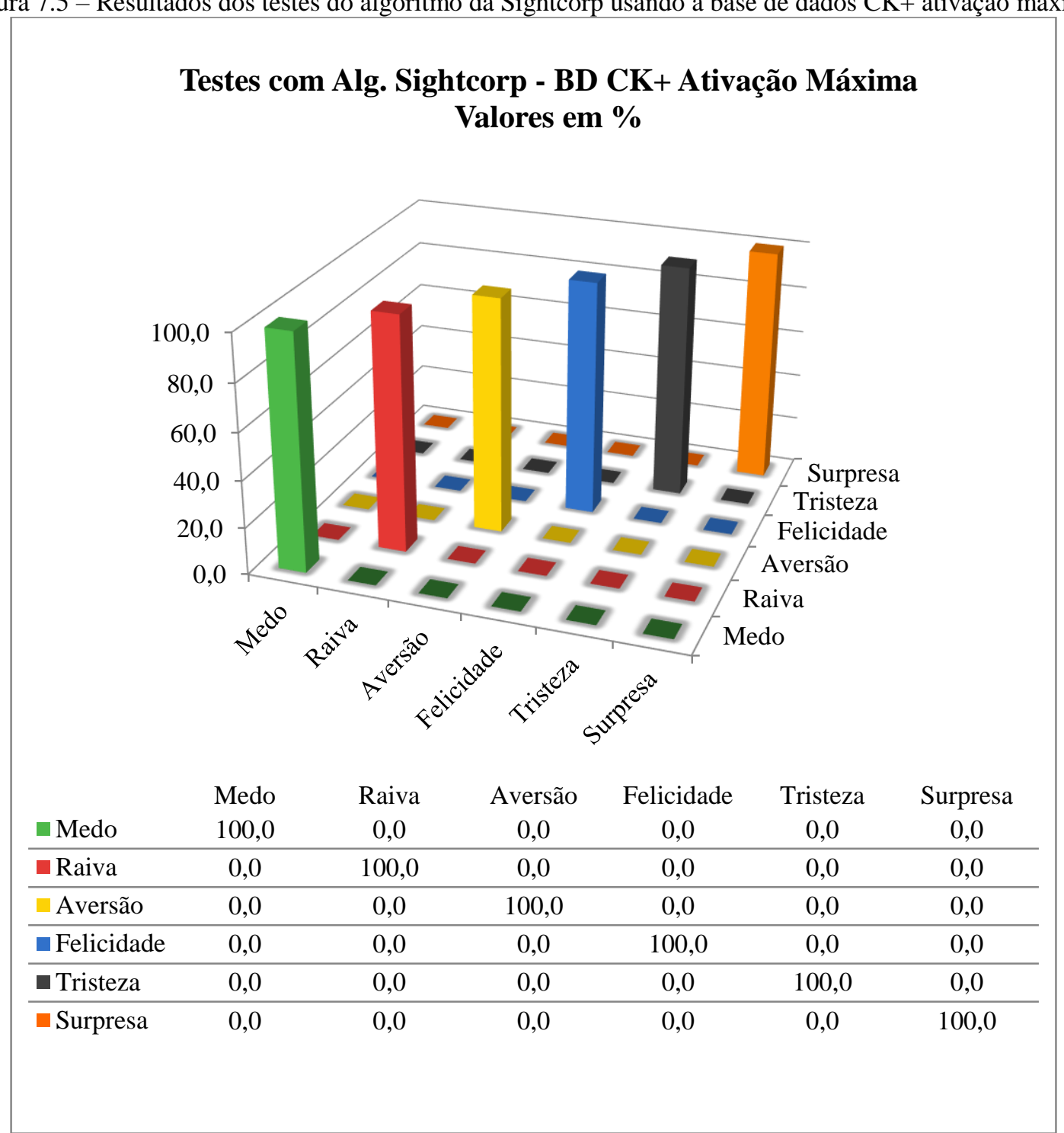

Fonte: Elaboração própria.

A Figura 7.6 apresenta o gráfico dos resultados obtidos na inferência do estado emocional pelo algoritmo da Sightcorp, utilizando imagens da base de dados $\mathrm{CK}+$ com ativação média. Abaixo do gráfico, são descritos os valores em forma de matriz de confusão. A taxa de acerto médio foi de $77,6 \%$. 
Figura 7.6 - Resultados dos testes do algoritmo da Sightcorp usando a base de dados CK+ ativação média.

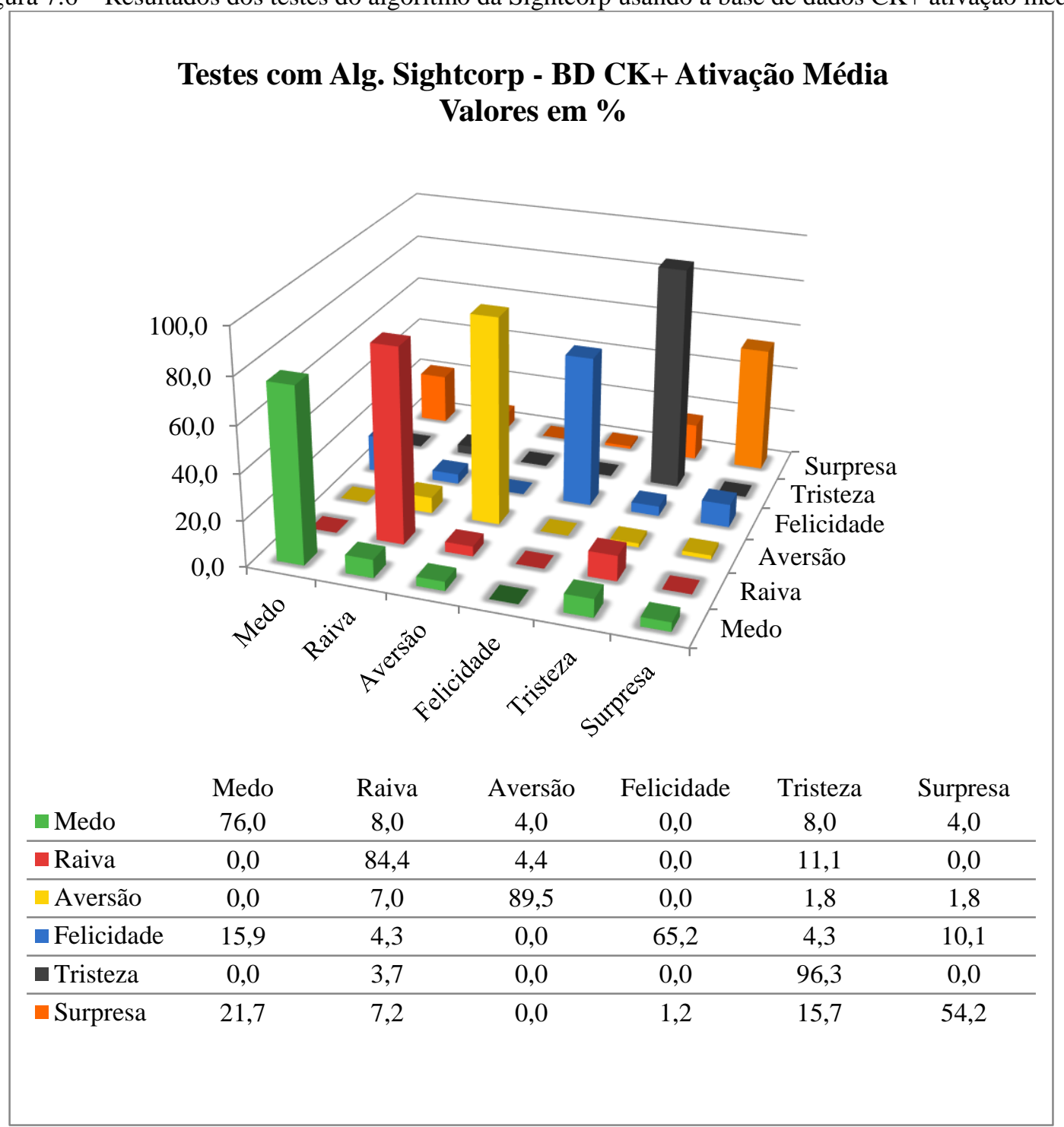

Fonte: Elaboração própria.

A Figura 7.7 apresenta o gráfico da comparação entre o modelo proposto e o algoritmo da Sightcorp, utilizando imagens da base de dados CK+. 
Figura 7.7 - Comparação dos testes do modelo proposto versus algoritmo da Sightcorp com a BD CK+.

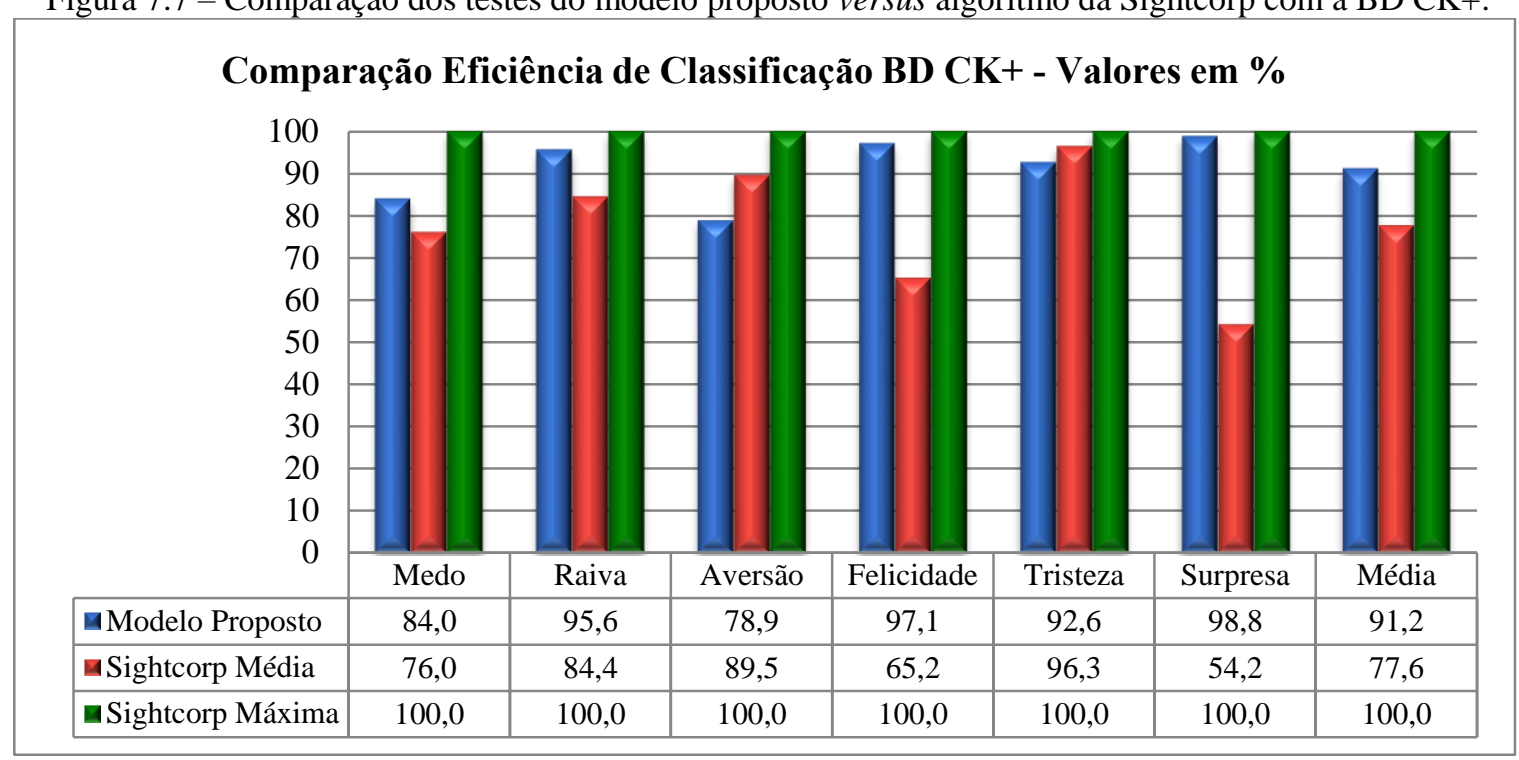

Fonte: Elaboração própria.

Em relação aos testes realizados com a base de dados KDEF, segundo Lewinski, Uyl e Butler (2014), a precisão do software FaceReader 6.0 é de $86 \%$. Este resultado é bastante próximo aos obtidos no modelo proposto, que foi de 86,7\%. O algoritmo da Sightcorp obteve uma média de precisão de recuperação de $72 \%$.

Já nos testes com a base de dados $\mathrm{CK}+$, o software da Sightcorp obteve taxa de acerto de $100 \%$, valor acima dos obtidos com o algoritmo proposto que foi de 91,2\%. Porém, quando o software da Sightcorp foi testado com imagens contendo ativação média da emoção, esse índice cai para $77,6 \%$.

A diferença entre os resultados obtidos com a ativação média e a máxima da emoção pode estar no fato de que, ao selecionar uma imagem no meio da sequência de imagens, algumas vezes, de fato, ainda não havia nela nenhuma emoção expressa, ou seja, considerando uma sequência de 15 quadros, no quadro 8 a expressão ainda poderia ser neutra ou estar com ativação muito baixa. Porém, o resultado de 100\% de acerto também não reflete a eficácia do algoritmo da Sightcorp, já que, ao ser testado com outra base de dados, o índice de acerto foi de $72 \%$. Isso se explica devido à base de dados de treinamento da Sightcorp ser a $\mathrm{CK}+$. Utilizando-se a mesma base de dados para treinamento e para testes, os resultados ficam inflados. Já ao testar outra base, obtêm-se resultados mais próximos da eficiência real do sistema.

O FaceReader, por exemplo, testado com a base de dados KDEF foi treinado com outras duas bases de dados diferentes, e os resultados publicados por Lewinski, Uyl e Butler (2014) relatam um índice de precisão de $86 \%$. Ao se utilizar o método leave-one-out nos 
testes, usando-se a mesma base de dados para testes e treinamento, os resultados obtidos não são generalizáveis a outras bases de dados.

Segundo De La Torre et al. (2015), a precisão do software IntraFace para inferência do estado emocional nos testes realizados com a base de dados CK+ é de 96,4\%. Porém, utilizase a mesma base para treinamento e inferência do estado emocional por meio do método leave-one-out. Mesmo usando tal técnica, obtém resultados médios de 86,5\% quando testa seu algoritmo com a base de dados FERA (VALSTAR et al., 2012 apud DE LA TORRE et al., 2015).

Considerando que os resultados de De La Torre et al. (2015) podem estar inflados pelo uso da técnica leave-one-out, a diferença de precisão de recuperação entre a base de dados $\mathrm{CK}+$ e a FERA explica-se pelos mesmos motivos do algoritmo proposto também ter obtido melhores resultados com a base de dados $\mathrm{CK}+$ do que com a base de dados KDEF.

Ocorre que para cada uma das emoções não há variação nos movimentos realizados pelas pessoas filmadas nos testes. O termo de consentimento de uso da base $\mathrm{CK}+$ permite a divulgação das imagens de apenas 11 pessoas, porém, percorrendo visualmente todas as 123 sequências rotuladas com emoções, nota-se que a mímica da face é sempre a mesma para uma emoção. Conforme já discutido nos capítulos anteriores, e ilustrado nas figuras 6.7 e 6.10 , nem sempre uma mesma emoção é representada pela mesma mímica facial, assim, os sistemas modelados de acordo com o FACS apresentam resultados significativos com a base $\mathrm{CK}+$, que foi gerada com base nas Unidades de Ação do FACS e rotulada segundo o FACSAID em termos de estados emocionais.

Jeni et al. (2011) descrevem a implementação do software RealEyes e apresentam uma precisão média de inferência do estado emocional de $86,8 \%$ para a base de dados $\mathrm{CK}+$ utilizada no treinamento e na classificação por meio do método leave-one-out. Outro teste do mesmo autor, no qual a base $\mathrm{CK}+$ é usada no treinamento, e uma outra base é usada na classificação, os resultados são inferiores (Figura 7.8). Porém, não é possível dizer a média exata, uma vez que as informações foram disponibilizadas apenas em forma de gráfico, sem rótulos de valores nas sequências, e a média do teste em questão não é mencionada no artigo. Os autores apenas citam que há uma discrepância entre as emoções das duas bases de dados. 
Figura 7.8 - Matriz de confusão dos testes realizados por Jeni et al. (2011) utilizando a base de dados CK+ para treinamento e outra base de dados para teste.

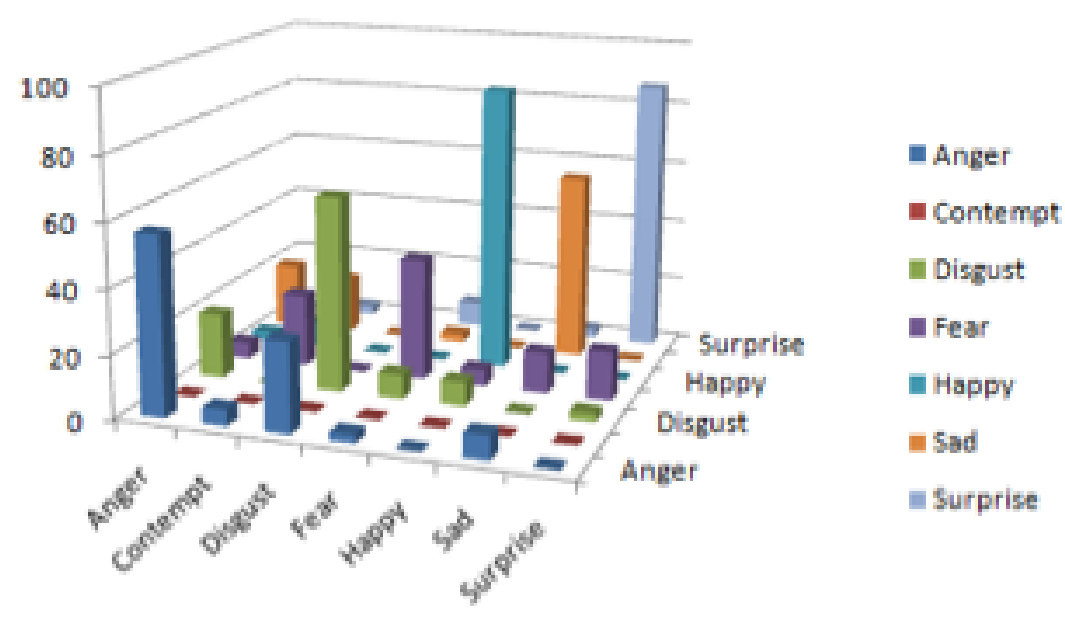

Fonte: Jeni et al. (2011).

Bansal, Chaudhary e Roy (2013) apresentam uma metodologia semelhante à deste trabalho. Após detectar a face e identificar 37 pontos de referência, os autores realizam a inferência do estado emocional por meio da análise do fluxo óptico com o algoritmo de Lucas Kanade. A principal diferença é que as movimentações dos pontos são analisadas apenas em duas direções (vertical e horizontal). Isso impede uma melhor diferenciação entre as classes emocionais. Considerando, por exemplo, a movimentação mais comum da sobrancelha para surpresa, raiva e tristeza, a partir de uma face neutra (Figura 7.9 a), tem-se para cima (Figura 7.9 b), medial para dentro e para baixo (Figura 7.9 c), e medial para dentro e para cima (Figura 7.9 d), respectivamente. O modelo proposto por Bansal, Chaudhary e Roy (2013) só considera a movimentação horizontal dos pontos marcados na Figura 7.9, não conseguindo, por meio destes, separar a surpresa da raiva e da tristeza com esta ROI tão representativa nas expressões faciais. Os resultados obtidos pelos autores nos testes com a base $\mathrm{CK}+$ foram de $80,7 \%$ de precisão de recuperação contra $91,6 \%$ do modelo proposto neste estudo, utilizandose a mesma base. 
Figura 7.9 - Representação da movimentação da sobrancelha. (a) Expressão neutra. (b) Expressão de surpresa. (c) Expressão de raiva. (d) Expressão de tristeza.

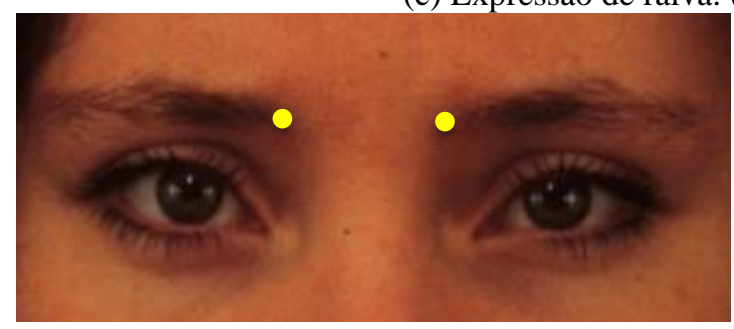

(a)

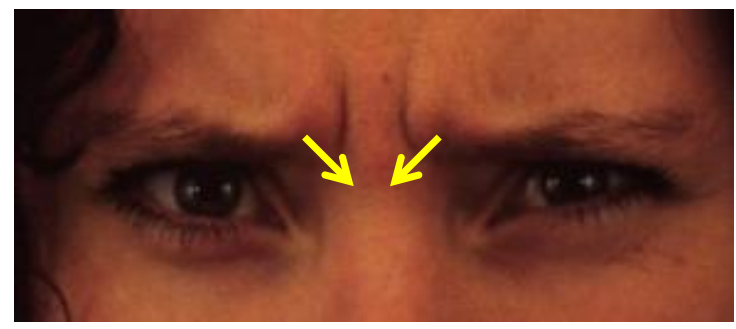

(c)

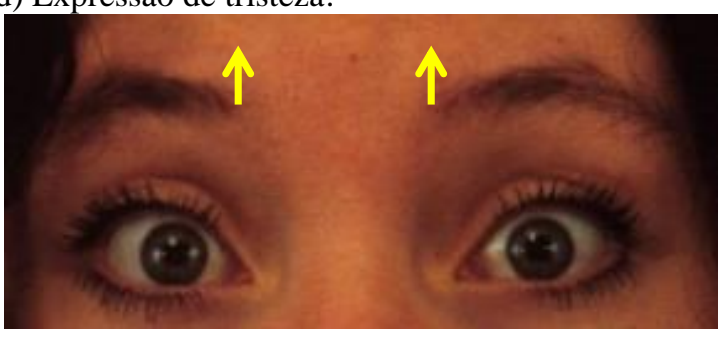

(b)

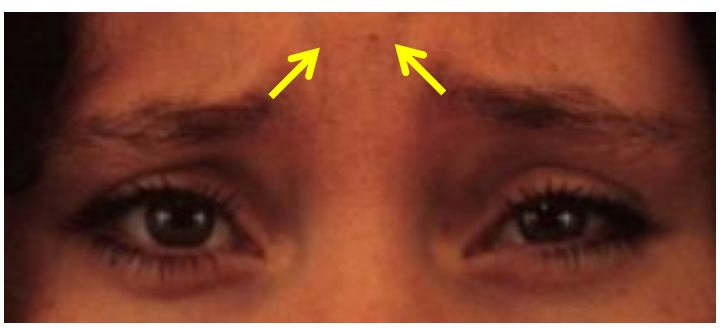

(d)

Fonte: Adaptado de Lundqvist, Flykt e Öhman (1988).

\subsubsection{Emoções espontâneas}

A Tabela 7.3 apresenta a categorização das emoções descritas pelos espectadores após assistirem às sequências de vídeos engraçados e de vídeos violentos.

Tabela 7.3 - Categorização das emoções descritas pelos espectadores.

\begin{tabular}{|c|c|c|c|c|c|c|c|}
\hline Felicidade & Neutro & Surpresa & Raiva & Aversão & Tristeza & Medo & Outro \\
\hline Alegre & Nada & Assustada & Brava & Com Aversão & Triste & Com Medo & Aflição \\
\hline Contente & Normal & Assustado & Bravo & Com Nojo & & & Aflito \\
\hline \multirow[t]{8}{*}{ Feliz } & & Espantado & Com Raiva & Nojo & & & Angustiado \\
\hline & & Pasma & Muito Bravo & Repulsa & & & Com Aflição \\
\hline & & Surpreso & Nervoso & & & & Com dó \\
\hline & & & & & & & Desconfortável \\
\hline & & & & & & & Incomodado \\
\hline & & & & & & & Indignado \\
\hline & & & & & & & Mal \\
\hline & & & & & & & Muito Mal \\
\hline
\end{tabular}

Fonte: Elaboração própria.

A Tabela 7.4 apresenta a matriz de confusão em valores absolutos, e a Tabela $7.5 \mathrm{em}$ porcentagem entre os resultados obtidos com Modelo 1 do Módulo Afetivo versus a opinião dos espectadores, segundo a categorização da Tabela 7.3. As emoções descritas na linha 
“outro" são detalhadas na Tabela 7.6, onde a primeira linha representa a emoção inferida pelo Módulo Afetivo e as demais linhas o estado emocional relatado pelo espectador.

Tabela 7.4 - Matriz de confusão dos testes o modelo proposto versus a opinião dos espectadores.

Resultados Testes Emoções Espontâneas - Valores Absolutos

\begin{tabular}{ccccccccc}
\hline & Medo & Raiva & Aversão & Felicidade & Tristeza & Surpresa & Neutro & Total \\
\hline Medo & 0 & 0 & 0 & 0 & 0 & 0 & 1 & 1 \\
\hline Raiva & 0 & 19 & 0 & 0 & 1 & 0 & 2 & 22 \\
\hline Aversão & 0 & 1 & 2 & 0 & 0 & 0 & 3 & 6 \\
\hline Felicidade & 1 & 1 & 0 & 52 & 1 & 2 & 2 & 59 \\
\hline Tristeza & 1 & 1 & 0 & 0 & 5 & 0 & 3 & 10 \\
\hline Surpresa & 0 & 1 & 0 & 0 & 0 & 8 & 1 & 10 \\
\hline Neutro & 0 & 1 & 0 & 0 & 0 & 0 & 7 & 8 \\
\hline Outro & 1 & 3 & 3 & 4 & 3 & 2 & 4 & 20 \\
\hline
\end{tabular}

Fonte: Elaboração própria.

Tabela 7.5 - Matriz de confusão dos testes o modelo proposto versus a opinião dos espectadores.

\begin{tabular}{ccccccccc}
\hline \multicolumn{7}{c}{ Resultados Testes Emoções Espontâneas - Valores em Porcentagem } \\
\hline & Medo & Raiva & Aversão & Felicidade & Tristeza & Surpresa & Neutro & Total \\
\hline Medo & 0,0 & 0,0 & 0,0 & 0,0 & 0,0 & 0,0 & 100,0 & 100,0 \\
\hline Raiva & 0,0 & 86,4 & 0,0 & 0,0 & 4,5 & 0,0 & 9,1 & 100,0 \\
\hline Aversão & 0,0 & 16,7 & 33,3 & 0,0 & 0,0 & 0,0 & 50,0 & 100,0 \\
\hline Felicidade & 1,7 & 1,7 & 0,0 & 88,1 & 1,7 & 3,4 & 3,4 & 100,0 \\
\hline Tristeza & 10,0 & 10,0 & 0,0 & 0,0 & 50,0 & 0,0 & 30,0 & 100,0 \\
\hline Surpresa & 0,0 & 10,0 & 0,0 & 0,0 & 0,0 & 80,0 & 10,0 & 100,0 \\
\hline Neutro & 0,0 & 12,5 & 0,0 & 0,0 & 0,0 & 0,0 & 87,5 & 100,0 \\
\hline Outro & 5,0 & 15,0 & 15,0 & 20,0 & 15,0 & 10,0 & 20,0 & 100,0 \\
\hline
\end{tabular}

Fonte: Elaboração própria.

Tabela 7.6 - Detalhamento dos estados emocionais classificados na linha "outro" da Tabela 7.4.

\begin{tabular}{ccccccc}
\hline Medo & Raiva & Aversão & Felicidade & Tristeza & Surpresa & Neutro \\
\hline Indignado & Aflito & Aflição & Desconfortável & Com Aflição & Desconfortável & Angustiado \\
\hline & Com dó & Aflição & Dó & Incomodado & Incomodado & Com dó \\
\hline Mal & Muito Mal & Mal & Mal & & Desconfortável \\
\hline
\end{tabular}

Fonte: Elaboração própria.

Desconsiderando as sequências cuja emoção relatada pelo espectador não figurava entre as descritas no modelo proposto, a taxa de acerto médio entre o estado emocional inferido pelo sistema e o relatado pelo espectador foi de $60,8 \%$. Porém, analisando-se apenas os resultados das sequências de vídeos engraçados, também desconsiderando a emoção “outro", a taxa de acerto médio foi de 94,1\%, conforme se pode observar nas Tabelas 7.7 e 
7.8, que apresentam as matrizes de confusão dos testes da inferência do estado emocional pelo modelo proposto versus a emoção relatada pelo espectador nas sequências de vídeos engraçados em valores absolutos e porcentagem, respectivamente.

Tabela 7.7 - Matriz de confusão dos testes do modelo proposto versus a opinião dos espectadores para sequências de vídeos engraçados.

\begin{tabular}{ccccccccc}
\hline \multicolumn{6}{c}{ Resultados Testes Emoções Espontâneas Sequência de Vídeos Engraçados - Valores Absolutos } \\
\hline & Medo & Raiva & Aversão & Felicidade & Tristeza & Surpresa & Neutro & Total \\
\hline Medo & 0 & 0 & 0 & 0 & 0 & 0 & 0 & 0 \\
\hline Raiva & 0 & 1 & 0 & 0 & 0 & 0 & 0 & 1 \\
\hline Aversão & 0 & 0 & 1 & 0 & 0 & 0 & 0 & 1 \\
\hline Felicidade & 1 & 0 & 0 & 51 & 1 & 2 & 2 & 57 \\
\hline Tristeza & 0 & 0 & 0 & 0 & 1 & 0 & 0 & 1 \\
\hline Surpresa & 0 & 0 & 0 & 0 & 0 & 1 & 0 & 1 \\
\hline Neutro & 0 & 1 & 0 & 0 & 0 & 0 & 3 & 4 \\
\hline Outro & 0 & 1 & 0 & 2 & 0 & 0 & 0 & 3 \\
\hline
\end{tabular}

Fonte: Elaboração própria.

Tabela 7.8 - Matriz de confusão dos testes do modelo proposto versus a opinião dos espectadores para sequências de vídeos engraçados.

\begin{tabular}{ccccccccc}
\hline \multicolumn{7}{c}{ Resultados Testes Emoções Espontâneas Sequência de Vídeos Engraçados - Valores em Porcentagem } \\
\hline & Medo & Raiva & Aversão & Felicidade & Tristeza & Surpresa & Neutro & Total \\
\hline Medo & - & - & - & - & - & - & - & - \\
\hline Raiva & 0,0 & 100,0 & 0,0 & 0,0 & 0,0 & 0,0 & 0,0 & 100,0 \\
\hline Aversão & 0,0 & 0,0 & 100,0 & 0,0 & 0,0 & 0,0 & 0,0 & 100,0 \\
\hline Felicidade & 1,8 & 0,0 & 0,0 & 89,5 & 1,8 & 3,5 & 3,5 & 100,0 \\
\hline Tristeza & 0,0 & 0,0 & 0,0 & 0,0 & 100,0 & 0,0 & 0,0 & 100,0 \\
\hline Surpresa & 0,0 & 0,0 & 0,0 & 0,0 & 0,0 & 100,0 & 0,0 & 100,0 \\
\hline Neutro & 0,0 & 25,0 & 0,0 & 0,0 & 0,0 & 0,0 & 75,0 & 100,0 \\
\hline Outro & 0,0 & 33,3 & 0,0 & 66,7 & 0,0 & 0,0 & 0,0 & 100,0 \\
\hline
\end{tabular}

Fonte: Elaboração própria.

Ao se analisar somente as sequências de cenas violentas, espera-se que emoções de valência negativa diversas sejam relatadas pelos espectadores. Neste trabalho, os vídeos não foram rotulados por especialista, porém, constatou-se, por amostragem de dez vídeos, que emoções inferidas pelo sistema, diferentes daquelas relatadas pelo usuário, estavam presentes em um ou mais momentos de 8 vídeos. Assim, fez-se uma nova análise da classificação dos vídeos contendo cenas violentas, agrupando as emoções entre valência positiva, negativa e neutra, segundo descrito na Tabela 7.9. As Tabelas 7.10 e 7.11 apresentam as Matrizes de 
Confusão dos resultados absolutos e em porcentagem, respectivamente. Desconsiderando as emoções positivas, devido ao baixo espaço amostral, o índice de acerto foi de 80,1\%.

Tabela 7.9 - Classificação de Emoções de Valência Positiva, Neutra e Negativa.

\begin{tabular}{ccccc}
\hline Positiva & Neutra & & Negativa & \\
\hline Alegre & Assustada & Aflição & Com Medo & Muito Mal \\
\hline Contente & Assustado & Aflito & Com Nojo & Nervoso \\
\hline Felicidade & Espantado & Angustiado & Com Raiva & Nojo \\
\hline Feliz & Nada & Aversão & Desconfortável & Raiva \\
\hline & Neutro & Brava & Incomodado & Repulsa \\
\hline Normal & Bravo & Indignado & Triste \\
\hline & Pasma & Com Aflição & Mal & Tristeza \\
\hline
\end{tabular}

Fonte: Elaboração própria.

Tabela 7.10 - Testes da classificação do modelo proposto versus relato do espectador considerando-se a valência das emoções segundo classificação da Tabela 7.9.

\begin{tabular}{ccccc}
\hline \multicolumn{5}{c}{ Testes Sequência de Vídeos Violentos - Valores Absolutos } \\
\hline & Positiva & Negativa & Neutro & Total \\
\hline Positiva & 1 & 1 & 0 & 2 \\
\hline Negativa & 2 & 36 & 15 & 53 \\
\hline Neutro & 0 & 1 & 12 & 13 \\
\hline \multicolumn{5}{c}{ Fonte: Elaboração própria. }
\end{tabular}

Tabela 7.11 - Testes da classificação do modelo proposto versus relato do espectador considerando-se a valência das emoções segundo classificação da Tabela 7.9.

\begin{tabular}{ccccc}
\hline \multicolumn{4}{c}{ Testes Sequência de Vídeos Violentos - Valores Em Porcentagem } \\
\hline & Positiva & Negativa & Neutro & Total \\
\hline Positiva & 50,0 & 50,0 & 0,0 & 100 \\
\hline Negativa & 3,8 & 67,9 & 28,3 & 100 \\
\hline Neutro & 0,0 & 7,7 & 92,3 & 100 \\
\hline
\end{tabular}

Fonte: Elaboração própria.

Ainda, considerando-se que nos 10 vídeos analisados por amostragem, 9 usuários demonstraram surpresa na parte da cena em que crianças colocam fogo em um animal doméstico, pode-se considerar que essa também seja uma emoção de valência negativa dentro do contexto deste estudo. Assim, a taxa de acerto passa a ser de $86,7 \%$, desconsiderando-se a valência positiva, segundo demonstra a matriz de confusão da Tabela 7.12. 
Tabela 7.12 - Testes da classificação do modelo proposto versus relato do espectador considerando-se a valência das emoções incluindo surpresa como emoção de valência negativa.

\begin{tabular}{ccccc}
\hline \multicolumn{5}{c}{ Testes Sequência de Vídeos Violentos - Valores Em Porcentagem } \\
\hline & Positiva & Negativa & Neutro & Total \\
\hline Positiva & 50,0 & 50,0 & 0,0 & 100 \\
\hline Negativa & 3,3 & 73,3 & 23,3 & 100 \\
\hline Neutro & 0,0 & 0,0 & 100,0 & 100 \\
\hline
\end{tabular}

Fonte: Elaboração própria.

A Tabela 7.13 apresenta a categorização das emoções descritas pelos observadores após assistirem as 136 sequências de vídeos, de acordo com a valência, e as Tabelas 7.14 e 7.15 apresentam as matrizes de confusão da comparação da inferência do estado emocional pelo Módulo Afetivo versus pelo Observador em valores absolutos e em porcentagem, respectivamente. A taxa de acerto média foi de $74,88 \%$.

Tabela 7.13 - Classificação de Emoções de Valência Positiva, Neutra e Negativa.

\begin{tabular}{ccccc}
\hline Positiva & Neutra & \multicolumn{3}{c}{ Negativa } \\
\hline Descontraído & Atento & Abismado & Horrorizada & Surpresa \\
\hline Felicidade & Indiferença & Aflição & Inconformismo & Surpresa \\
\hline Graça & Inexpressividade & Apreensão & Incredulidade & Susto \\
\hline Riso Contido & Neutro & Aversão & Indignação & Tensão \\
\hline & Observadora & Com Dó & Medo & Triste \\
\hline & Sem Reação & Desaprovação & Pavor & Tristeza \\
\hline & & Dó & Raiva & Apatia \\
\hline
\end{tabular}

Fonte: Elaboração própria.

Tabela 7.14 - Testes da classificação do modelo proposto versus relato dos observadores considerando-se a valência das emoções segundo classificação da Tabela 7.13.

\begin{tabular}{|c|c|c|c|c|}
\hline \multicolumn{5}{|c|}{ Testes Sequência de Vídeos - Valores Em Valores Absolutos } \\
\hline & Positiva & Negativa & Neutro & Total \\
\hline Positiva & 50 & 7 & 1 & 58 \\
\hline Negativa & 6 & 41 & 7 & 54 \\
\hline Neutro & 0 & 9 & 15 & 24 \\
\hline
\end{tabular}

Tabela 7.15 - Testes da classificação do modelo proposto versus relato dos observadores considerando-se a valência das emoções segundo classificação da Tabela 7.13.

\begin{tabular}{ccccc}
\hline \multicolumn{5}{c}{ valência das emoções segundo classificação da Tabela 7.13. } \\
\hline \multicolumn{5}{c}{ Testes Sequência de Vídeos - Valores Em Porcentagem } \\
\hline Positiva & Negativa & Neutro & Total \\
\hline Positiva & 86,21 & 12,07 & 1,72 & 100 \\
\hline Negativa & 11,11 & 75,93 & 12,96 & 100 \\
\hline Neutro & 0,00 & 37,50 & 62,50 & 100 \\
\hline \multicolumn{5}{c}{ Fonte· Elaboração própria }
\end{tabular}

Fonte: Elaboração própria. 
A Tabela 7.16 apresenta a categorização geral das emoções descritas pelos espectadores e observadores após assistirem as 136 sequências de vídeos, de acordo com a valência, e as Tabelas 7.17 e 7.18 apresentam as matrizes de confusão da comparação da inferência do estado emocional pelo Espectador versus pelo Observador em valores absolutos e em porcentagem, respectivamente. A taxa de acerto média foi de $66,85 \%$.

Tabela 7.16 - Classificação de emoções de valência Positiva, Neutra e Negativa.

\begin{tabular}{ccccc}
\hline Positiva & Neutra & & Negativa & Com Nojo \\
\hline Alegre & Atento & Abismado & Com Raiva & Nervoso \\
\hline Contente & Indiferença & Aflição & Desaprovação & Nojo \\
\hline Descontraído & Inexpressividade & Aflito & Desconfortável & Pasma \\
\hline Felicidade & Nada & Angustiado & Dó & Pavor \\
\hline Feliz & Neutro & Apatia & Espantado & Raiva \\
\hline Graça & Normal & Apreensão & Espanto & Repulsa \\
\hline Riso Contido & Observadora & Assustada & Horrorizada & Surpresa \\
\hline & Sem Reação & Assustado & Incomodado & Surpreso \\
\hline & & Aversão & Inconformismo & Susto \\
\hline & & Bravo & Incredulidade & Tensão \\
\hline & & Com Aflição & Indignação & Triste \\
\hline & & Com Aversão & Indignado & Tristeza \\
\hline & & Com Dó & Mal & Medo \\
\hline
\end{tabular}

Fonte: Elaboração própria.

Tabela 7.17 - Testes da classificação relato do espectador versus relato dos observadores considerando-se a valência das emoções segundo classificação da Tabela 7.16.

\begin{tabular}{|c|c|c|c|c|}
\hline \multicolumn{5}{|c|}{ Testes Sequência de Vídeos - Valores Em Valores Absolutos } \\
\hline & Positiva & Negativa & Neutro & Total \\
\hline Positiva & 50 & 8 & 0 & 58 \\
\hline Negativa & 8 & 46 & 0 & 54 \\
\hline Neutro & 2 & 15 & 7 & 24 \\
\hline
\end{tabular}

Fonte: Elaboração própria.

Tabela 7.18 - Testes da classificação do relato do espectador versus relato dos observadores considerando-se a valência das emoções segundo classificação da Tabela 7.16.

\begin{tabular}{ccccc}
\hline \multicolumn{5}{c}{ Testes Sequência de Vídeos - Valores Em Porcentagem } \\
\hline & Positiva & Negativa & Neutro & Total \\
\hline Positiva & 86,21 & 13,79 & 0,00 & 100 \\
\hline Negativa & 14,81 & 85,19 & 0,00 & 100 \\
\hline Neutro & 8,33 & 62,50 & 29,17 & 100 \\
\hline
\end{tabular}

Fonte: Elaboração própria. 
A comparação entre a classificação algorítmica e a opinião do espectador reflete o quanto o algoritmo foi capaz de interpretar aquilo que de fato a pessoa estava sentindo. $\mathrm{O}$ Sistema acertou 90,4\%, considerando-se a média dos resultados das 136 sequências de vídeos.

Já a comparação entre a classificação algorítmica e a opinião do observador reflete a capacidade do software em interpretar as emoções de uma pessoa segundo a interpretação de outrem. A taxa de acerto foi de $74,88 \%$, sendo que o que chama mais a atenção para esse resultado foi a quantidade de vídeos com expressões negativas, classificadas como neutro pelo observador. A hipótese é que essa diferença tenha se dado porque no sistema de inferência do estado emocional pelo módulo afetivo a expressão foi classificada de acordo com a que teve maior ocorrência, exceto neutro, sendo classificada como neutro apenas quando nenhuma outra emoção foi identificada. Já ao observador, pediu-se para anotar qual emoção para ele era predominante na sequência de vídeos. É possível que os observadores tenham notado as emoções de valência negativa, mas optaram por classificá-las como neutro devido à predominância da face neutra.

A comparação mais ambígua foi aquela entre o estado emocional relatado pelo espectador e o relatado pelo observador, cuja taxa de acerto média foi de $66,85 \%$. Os índices de acertos para as emoções de valência positiva e negativa aproximam-se dos $85 \%$, relatados na literatura como taxa de acerto média para seres humanos (LEWINSKI; UYL; BUTLER, 2014). Já a diferença entre a quantidade de espectadores que relatou emoções de valência negativa, classificadas como neutra pelo observador, pode ser explicada em parte motivo relatado no parágrafo anterior e em parte porque em alguns vídeos o expectador, de fato, manteve-se com a face neutra, mas depois relatou que sentiu emoções de valência negativa. Porém, somente uma análise mais detalhada de todas as sequências, realizada por especialista, poderia quantificar esses casos.

\subsection{Módulo Tomada de Decisão}

Os próximos tópicos apresentam os resultados obtidos com estudos de caso que avaliam a influência da emoção na tomada de decisão de sistemas computacionais. Os estudos de caso foram realizados com o Módulo de Decisão, alterando em tempo real parâmetros da Prancha de Comunicação, com base em informações obtidas do Modelo 2 do Módulo Afetivo. 


\subsubsection{Testes com usuários (pessoas não deficientes)}

Estudo de Caso 1: o teste teve duração de 45,20 segundos, durante os quais o Modelo 2 do Módulo Afetivo identificou insatisfação em 6 momentos diferentes. No final, o ícone estava ajustado pelo Módulo de Tomada de Decisão com o tamanho de 1,4 cm, e nos 22,28 segundos finais do teste o Módulo Afetivo não identificou insatisfação do usuário.

Estudo de Caso 2: o teste teve duração de 55,62 segundos, durante os quais o Modelo 2 do Módulo Afetivo identificou insatisfação em 10 momentos diferentes. No final, o ícone estava ajustado pelo Módulo de Tomada de Decisão com o tamanho de 1,7 cm, e nos 22,19 segundos finais do teste o Módulo Afetivo não identificou insatisfação do usuário.

Estudo de Caso 3: o teste teve duração de 46,05 segundos, durante os quais o Modelo 2 do Módulo Afetivo identificou insatisfação em 10 momentos diferentes. No final, o ícone estava ajustado pelo Módulo de Tomada de Decisão com o tamanho de 1,4 cm, e nos 24,27 segundos finais do teste o Módulo Afetivo não identificou insatisfação do usuário.

No primeiro estudo de caso, a quantidade de insatisfações identificadas pelo Módulo Afetivo, dada a janela de tempo definida, foi sempre igual ou menor que a janela de tempo anterior, até que o Módulo de Tomada de Decisão chegasse no tamanho de ícone adequado ao usuário e o mesmo não demonstrasse mais insatisfação.

Já no segundo estudo de caso, mesmo o sentido tendo sido iniciado com o valor + (mais), ou seja, deveria aumentar o tamanho do ícone, na faixa dos 14,10 segundos de teste o Módulo Afetivo identificou uma quantidade maior de insatisfação do usuário, mesmo o ícone já estando em $1 \mathrm{~cm}$ de tamanho. Assim, o Módulo Afetivo inverteu o sentido de ajuste do ícone e diminuiu seu tamanho para $0,8 \mathrm{~cm}$. A quantidade de insatisfação identificada novamente aumentou, e o sentido reajustado seguiu aumentando o tamanho do ícone até atingir um tamanho ajustado àquele usuário.

No terceiro estudo de caso, o sentido de alteração foi propositalmente iniciado com o valor - (menos), mesmo sabendo-se que $0,5 \mathrm{~cm}$ já era um tamanho que traria dificuldades de utilização para o usuário, que deveria fazer a seleção do ícone por meio de uma tela touch. Após o quarto retorno do Módulo Afetivo, o Módulo de Tomada de decisão já estava ajustado no sentido correto + (mais) e passou a aumentar o tamanho do ícone até que o mesmo atingisse $1,4 \mathrm{~cm}$, tamanho que deixou o usuário confortável para as seleções.

Nos três estudos de caso realizados com pessoas sem deficiência, o Módulo de tomada de decisão conseguiu atuar corretamente até que o usuário passasse a não mais demonstrar insatisfação. Os arquivos EML dos testes constam no Anexo VI deste trabalho. 
A Tabela 7.19 apresenta o resumo dos estudos de caso realizados com pessoas sem deficiência.

Tabela 7.19 - Resumo dos estudos de caso realizados com pessoas sem deficiência.

\begin{tabular}{|c|c|c|c|c|c|c|c|}
\hline $\begin{array}{l}\text { Estudo de } \\
\text { Caso }\end{array}$ & $\begin{array}{l}\text { Duração } \\
\text { (ss,ms) }\end{array}$ & $\begin{array}{c}\text { Qtd. de } \\
\text { Insatisfação }\end{array}$ & $\begin{array}{l}\text { Parâmetro a } \\
\text { ser ajustado }\end{array}$ & $\begin{array}{l}\text { Valor } \\
\text { inicial }\end{array}$ & $\begin{array}{l}\text { Valor } \\
\text { Final }\end{array}$ & $\begin{array}{l}\text { Tempo médio de } \\
\text { Insatisfação }\end{array}$ & $\begin{array}{l}\text { Tempo final sem } \\
\text { Insatisfação }\end{array}$ \\
\hline 1 & 45,20 & 6 & tam. ícone & $0,5 \mathrm{~cm}$ & $1,4 \mathrm{~cm}$ & $4,58 \mathrm{~s}$ & $22,28 \mathrm{~s}$ \\
\hline 2 & 55,62 & 10 & tam. ícone & $0,5 \mathrm{~cm}$ & $1,7 \mathrm{~cm}$ & $3,34 \mathrm{~s}$ & $22,19 \mathrm{~s}$ \\
\hline 3 & 46,05 & 10 & tam. ícone & $0,5 \mathrm{~cm}$ & $1,4 \mathrm{~cm}$ & $2,17 \mathrm{~s}$ & $24,27 \mathrm{~s}$ \\
\hline
\end{tabular}

\subsubsection{Testes com alunos (pessoas deficientes)}

\section{Estudo de Caso 04:}

O teste teve duração de 08:22,10 minutos, durante os quais o Modelo 2 do Módulo Afetivo identificou insatisfação em 13 momentos diferentes. No final, o arraste convertido em clique estava ajustado pelo Módulo de Tomada de Decisão com o tamanho de $5 \mathrm{~cm}$, e nos 03:11,99 minutos finais do teste o Módulo Afetivo não identificou insatisfação do usuário. $\mathrm{O}$ Gráfico da Figura 7.10 ilustra a linha do tempo dos ajustes realizados pelo Módulo Afetivo, sem uma proporcionalidade de tempo no eixo horizontal do Estudo de Caso 04.

Figura 7.10 - Gráfico com linha do tempo do Estudo de Caso 04.

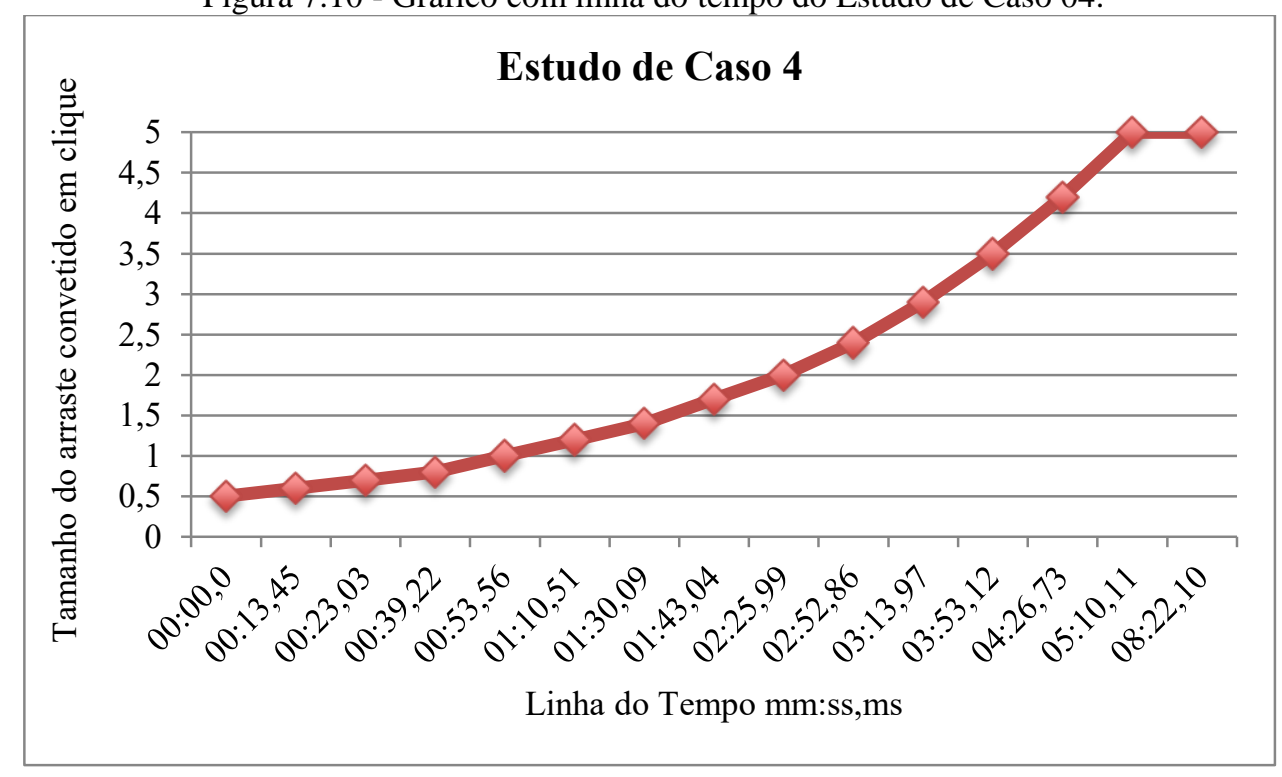

Fonte: Elaboração própria. 


\section{Estudo de Caso 05:}

O primeiro teste teve duração de 06:16,51 minutos, durante os quais o Modelo 2 do Módulo Afetivo identificou insatisfação em 19 momentos diferentes. Durante os primeiros 10 segundos, o algoritmo da linha base estava se justando. Ao iniciar o teste, o Módulo de Tomada de Decisão ficou aumentando e diminuindo o tamanho do ícone por 00:07,15 segundos, e só então conseguiu identificar o sentido correto de ajuste do ícone. No final, os tamanhos dos ícones estavam ajustados pelo Módulo de Tomada de Decisão $5 \mathrm{~cm}$, e nos 03:08,23 minutos finais do teste o Módulo Afetivo não identificou insatisfação do usuário.

O segundo teste teve duração de 07:14,08 minutos, durante os quais o Modelo 2 do Módulo Afetivo identificou insatisfação em 2 momentos diferentes. Durante os primeiros 10 segundos, o algoritmo da linha base estava se ajustando. No final, os tamanhos dos ícones estavam ajustados pelo Módulo de Tomada de Decisão 7,2 cm, e nos 02:30,21 minutos finais do teste o Módulo Afetivo não identificou insatisfação do usuário.

Os Gráficos das Figuras 7.11 e 7.12 ilustram as linhas do tempo dos ajustes realizados pelo Módulo Afetivo no primeiro e segundo testes, respectivamente.

Figura 7.11 - Gráfico com linha do tempo do Estudo de Caso 05, primeiro teste.

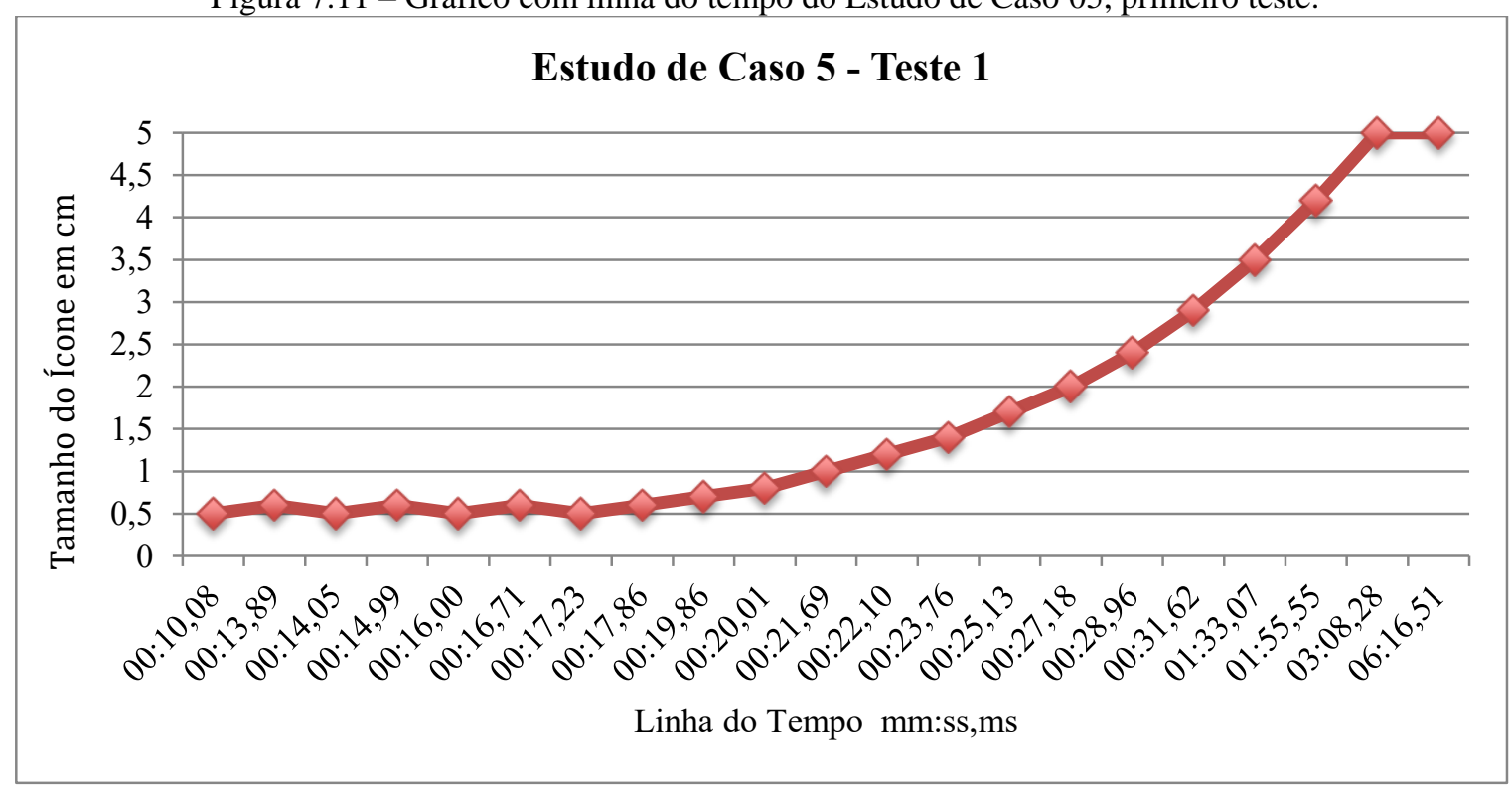

Fonte: Elaboração própria. 
Figura 7.12 - Gráfico com linha do tempo do Estudo de Caso 05, segundo teste.

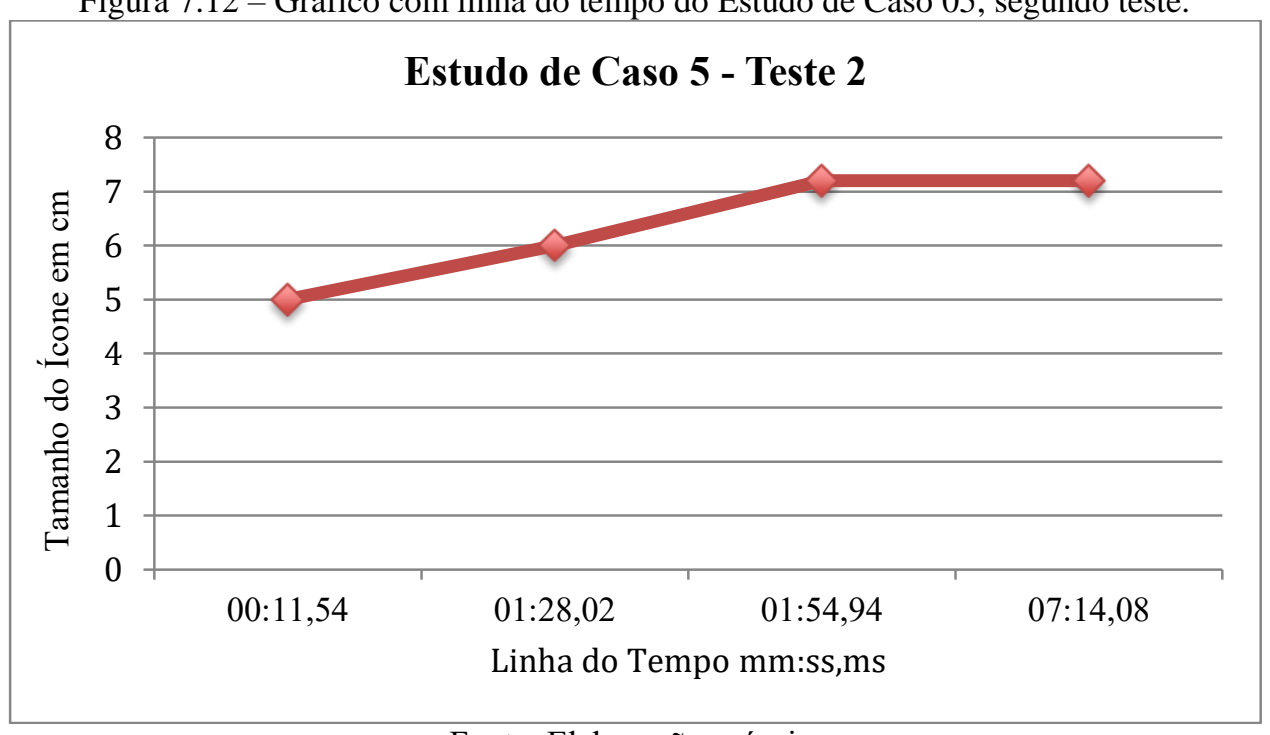

Fonte: Elaboração própria.

\section{Estudo de Caso 06:}

O primeiro teste teve duração de 07:06,12 minutos, durante os quais o Modelo 2 do Módulo Afetivo não identificou insatisfação em nenhum momento. $\mathrm{O}$ aluno tinha visível dificuldade de seleção dos ícones, até mesmo de identificar o conteúdo das figuras. Ele aproximava a face de tela para identificar a imagem do ícone e clicava várias vezes até conseguir selecionar o correto, mas não demonstrava insatisfação com a mímica da face. Toda vez que ele errava, fazia movimento de não com a cabeça; e toda vez que acertava, fazia movimento de sim com a cabeça. Na terceira prancha, o tamanho dos ícones foi alterado manualmente (usando a ferramenta de zoom) para $4 \mathrm{~cm}$. O aluno passou a ter menos dificuldade de seleção, mas continuou a não expressar suas dificuldades pela mímica da face.

O segundo teste teve duração de 05:12,76 minutos, e os ícones já foram inicializados com tamanho de $4 \mathrm{~cm}$ para impedir que o aluno ficasse aproximando sua face da tela do computador. Novamente, o Modelo 2 do Módulo Afetivo não identificou insatisfação em nenhum momento, mesmo sendo possível observar as dificuldades sendo expressas pelo movimento de não com a cabeça.

No final dos testes, solicitou-se ao aluno que fizesse algumas expressões a fim de verificar se ele tinha dificuldade de movimentação dos músculos faciais. Foi possível notar movimentações normais na região da boca e nariz. Já na região das sobrancelhas, ele conseguiu fazer o movimento para cima, mas não conseguiu reproduzir o movimento medial para baixo. 


\section{Estudo de Caso 07:}

O primeiro teste teve duração de 09:18,07 minutos, durante os quais o Modelo 2 do Módulo Afetivo identificou insatisfação em 42 momentos diferentes. No final, o tempo de varredura estava ajustado pelo Módulo de Tomada de Decisão para 0,9 segundos, e o Módulo Afetivo identificou insatisfação até os momentos finais do teste. De fato, os valores do tempo de varredura ficaram variando em torno de 1 segundo, o dobro do que havia sido configurado inicialmente.

O segundo teste teve duração de 10:57,19 minutos, durante os quais o Modelo 2 do Módulo Afetivo identificou insatisfação em 67 momentos diferentes. No final, o tempo de varredura estava ajustado pelo Módulo de Tomada de Decisão para 1 segundo, e o Módulo Afetivo identificou insatisfação até os momentos finais do teste. Novamente, os valores do tempo de varredura ficaram variando em torno de 1 segundo, sendo que desta vez o teste havia sido inicializado com 0,9 segundos para o tempo de varredura.

O terceiro teste teve duração de 05:50,81 minutos, durante os quais o Modelo 2 do Módulo Afetivo identificou insatisfação em 18 momentos diferentes. No final, o tamanho do arraste convertido para clique foi ajustado pelo Módulo de Tomada de Decisão para $6 \mathrm{~cm}$, e o Módulo Afetivo não identificou insatisfação nos últimos 1:54,49 minutos do teste.

Os Gráficos das Figuras 7.13, 7.14 e 7.15 ilustram as linhas do tempo dos ajustes realizados pelo Módulo Afetivo nos testes.

Figura 7.13 - Gráfico com linha do tempo do Estudo de Caso 07, primeiro teste.

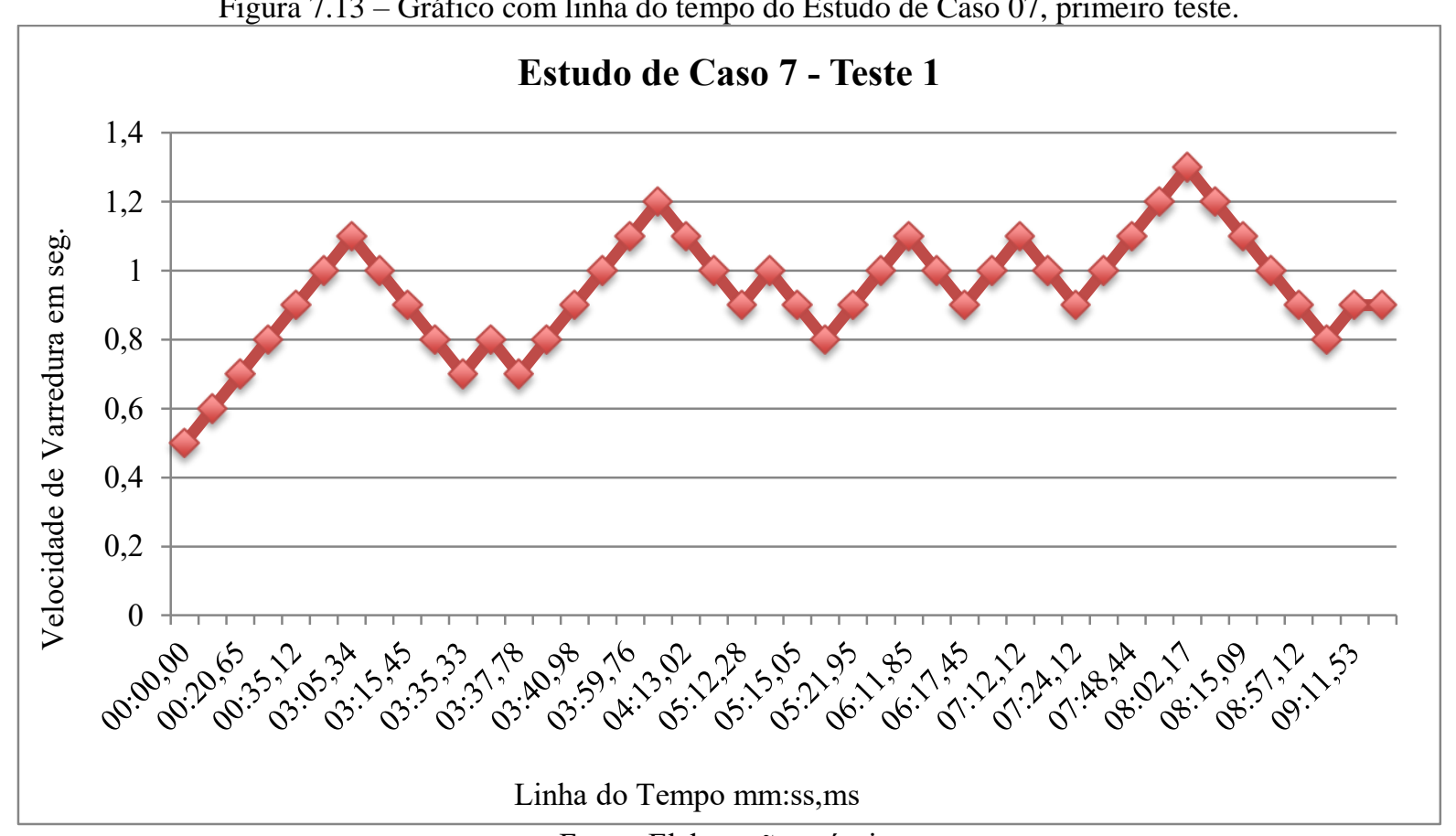

Fonte: Elaboração própria. 
Figura 7.14 - Gráfico com Linha do tempo do Estudo de Caso 07, segundo teste.

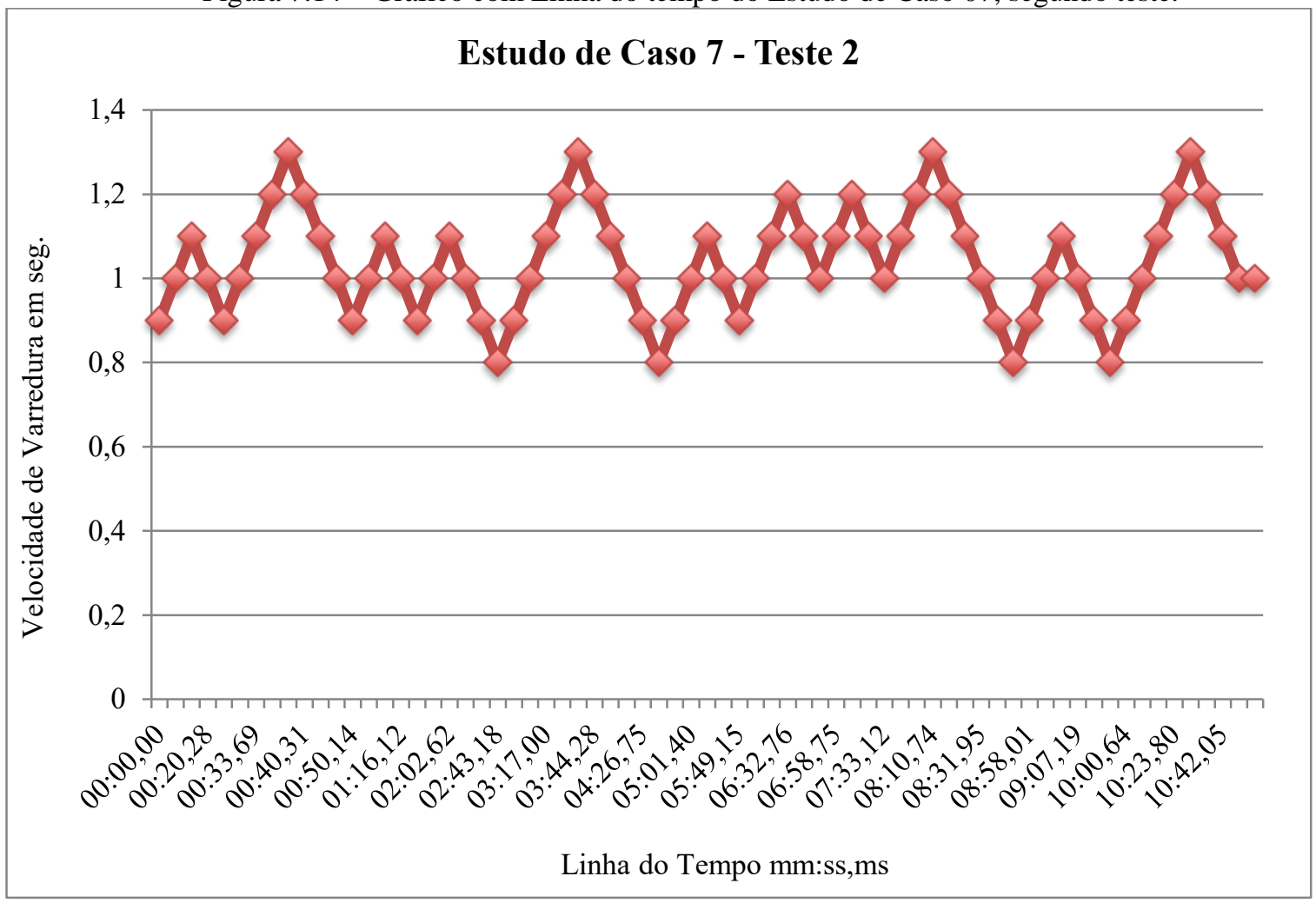

Fonte: Elaboração própria.

Figura 7.15 - Gráfico com linha do tempo do Estudo de Caso 07, terceiro teste.

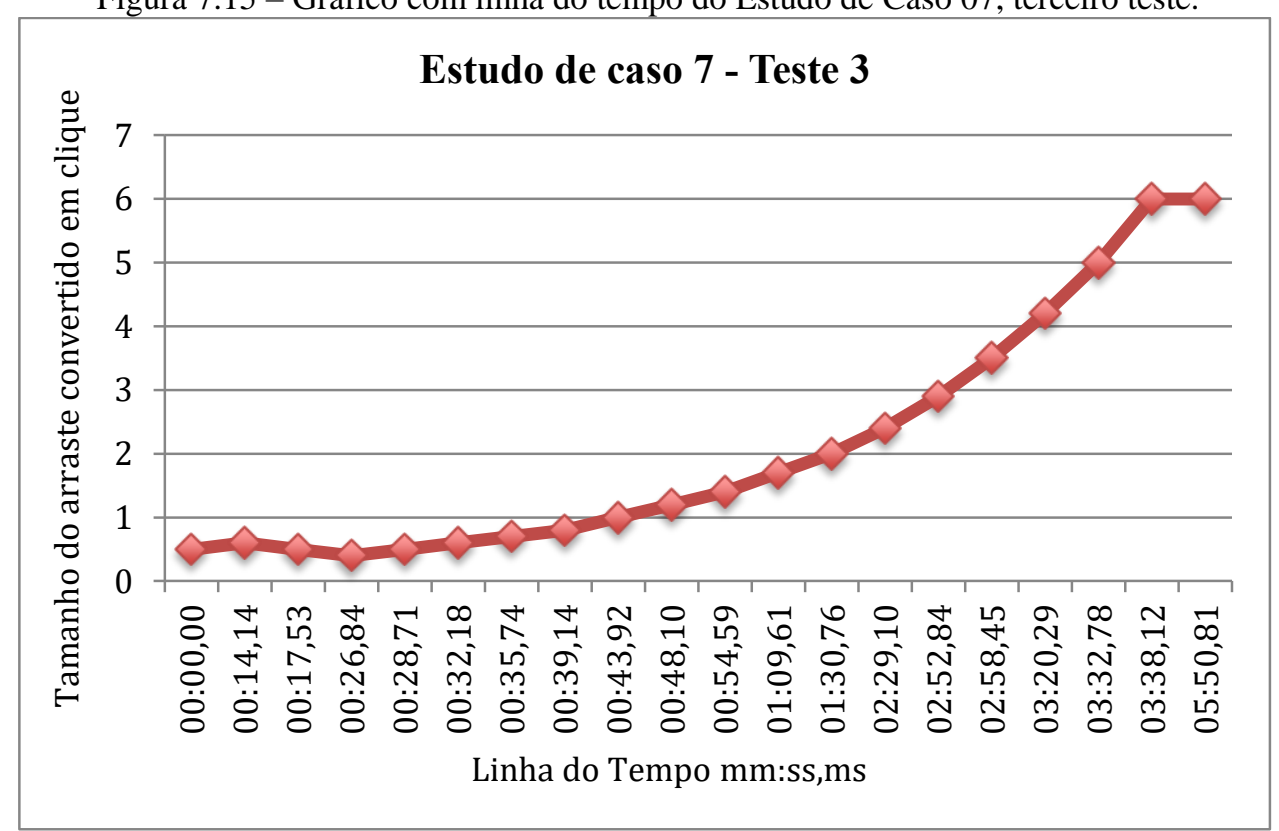

Fonte: Elaboração própria.

\section{Estudo de Caso 08:}

O primeiro teste teve duração de 08:55,12 minutos, durante os quais o Modelo 2 do Módulo Afetivo identificou insatisfação em 12 momentos diferentes. No final, o arraste convertido em clique estava ajustado pelo Módulo de Tomada de Decisão com o tamanho de 
$1,4 \mathrm{~cm}$, e a última insatisfação foi identificada pelo módulo afetivo 08,77 segundos antes do final do teste. Porém, notou-se que após 5:51,56 minutos de teste, quando o arraste convertido em clique estava configurado em $1,2 \mathrm{~cm}$, o aluno passou a demonstrar insatisfação com as perguntas e não com a prancha, ou seja, no início, ele franzia a testa quando tentava selecionar um ícone e não conseguia. No final, o aluno só franzia a testa quando eram feitas perguntas sobre coisas que não eram de seu cotidiano.

O segundo teste teve duração de 08:43,71 minutos, durante os quais o Modelo 2 do Módulo Afetivo identificou insatisfação em 7 momentos diferentes. Como o teste iniciou-se com o tamanho do arraste já ajustado ao teste anterior, pôde-se observar que as primeiras mímicas de insatisfação eram em relação ao entendimento das perguntas, porém, o algoritmo se confundiu e inverteu a ordem da alteração do tamanho do arraste convertido em clique. Quando o tamanho do arraste chegou a $1 \mathrm{~cm}$, o aluno também passou a demonstrar insatisfação durante as tentativas frustradas de tocar na tela, o algoritmo conseguiu se reajustar e novamente mudou o sentido, aumentando o tamanho do arraste convertido em clique. Após 03:30,26 minutos de teste, o tamanho do ícone estava em 1,2 cm, e as franzidas de testa finais foram em relação ao entendimento das perguntas. No final do teste, o arraste convertido em clique estava configurado em $1,7 \mathrm{~cm}$, e nos $02: 43,51$ minutos finais do teste o módulo afetivo não identificou insatisfação.

Os Gráficos das Figuras 7.16 e 7.17 ilustram as linhas do tempo dos ajustes realizados pelo Módulo Afetivo nos testes do Estudo de Caso 08.

Figura 7.16 - - Gráfico com linha do tempo do Estudo de Caso 08, primeiro teste.

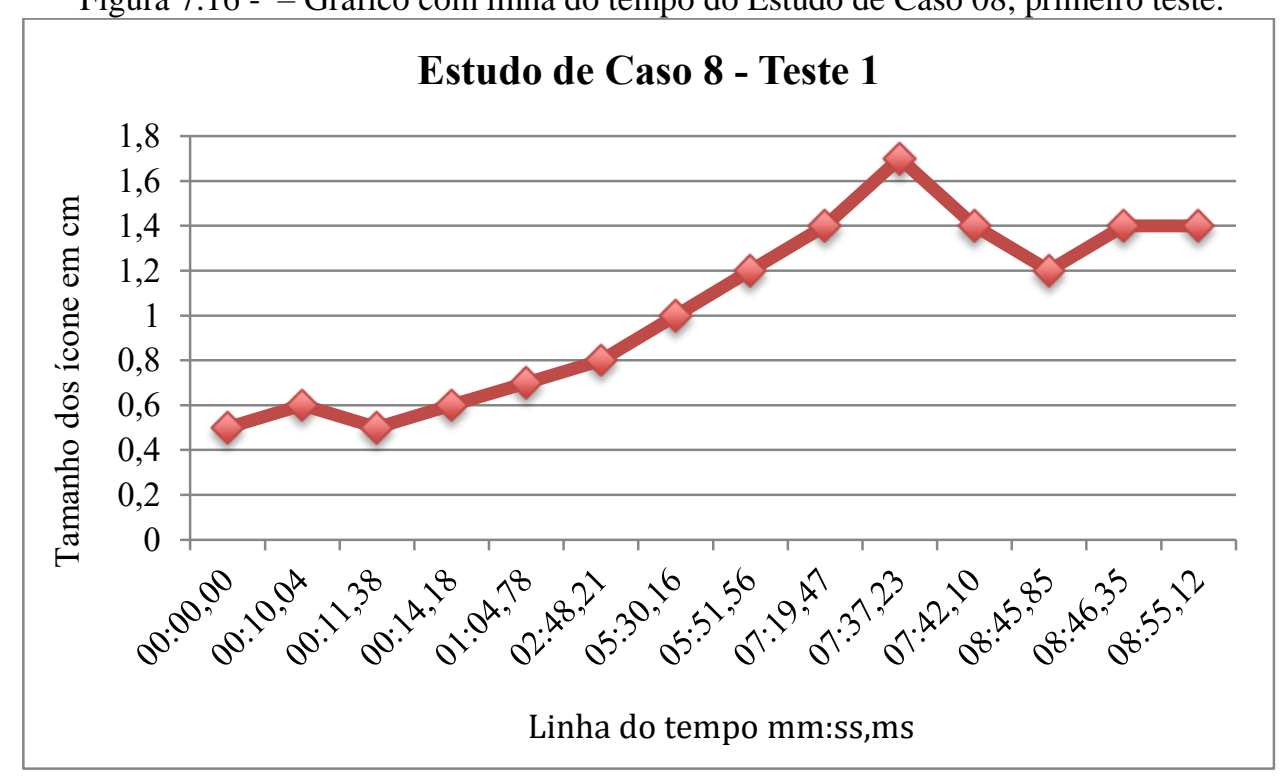

Fonte: Elaboração própria. 
Figura 7.17 - Gráfico com linha do tempo do estudo de Caso 07, segundo teste.

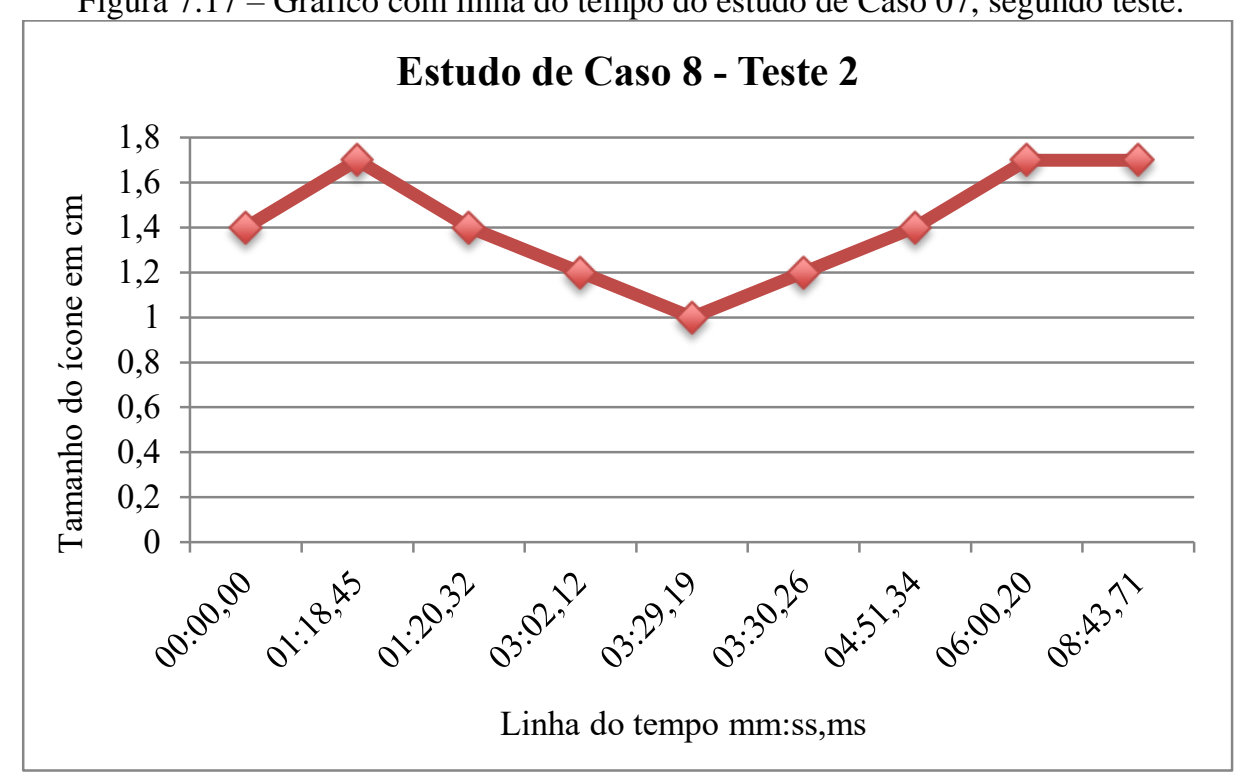

Fonte: Elaboração própria.

\section{Estudo de Caso 09:}

O primeiro teste teve duração de 14:01,19 minutos, durante os quais o Modelo 2 do Módulo Afetivo identificou insatisfação em 24 momentos diferentes. Durante os primeiros 10 segundos, o algoritmo da linha base estava se ajustando. No final, os tamanhos dos ícones estavam ajustados pelo Módulo de Tomada de Decisão $6 \mathrm{~cm}$, e nos 04:40,01 minutos finais do teste o Módulo Afetivo não identificou insatisfação do usuário.

O segundo teste teve duração de 09:03,12 minutos, durante os quais o Modelo 2 do Módulo Afetivo identificou insatisfação em 3 momentos diferentes. Durante os primeiros 10 segundos, o algoritmo da linha base estava se ajustando. No final, os tamanhos dos ícones estavam ajustados pelo Módulo de Tomada de Decisão 7,2 cm, e nos 06:50,38 minutos finais do teste o Módulo Afetivo não identificou insatisfação do usuário.

Os Gráficos das Figuras 7.19 e 7.20 ilustram as linhas do tempo dos ajustes realizados pelo Módulo Afetivo nos testes do Estudo de Caso 09. 
Figura 7.18 - Gráfico com linha do tempo do Estudo de Caso 09, primeiro teste.

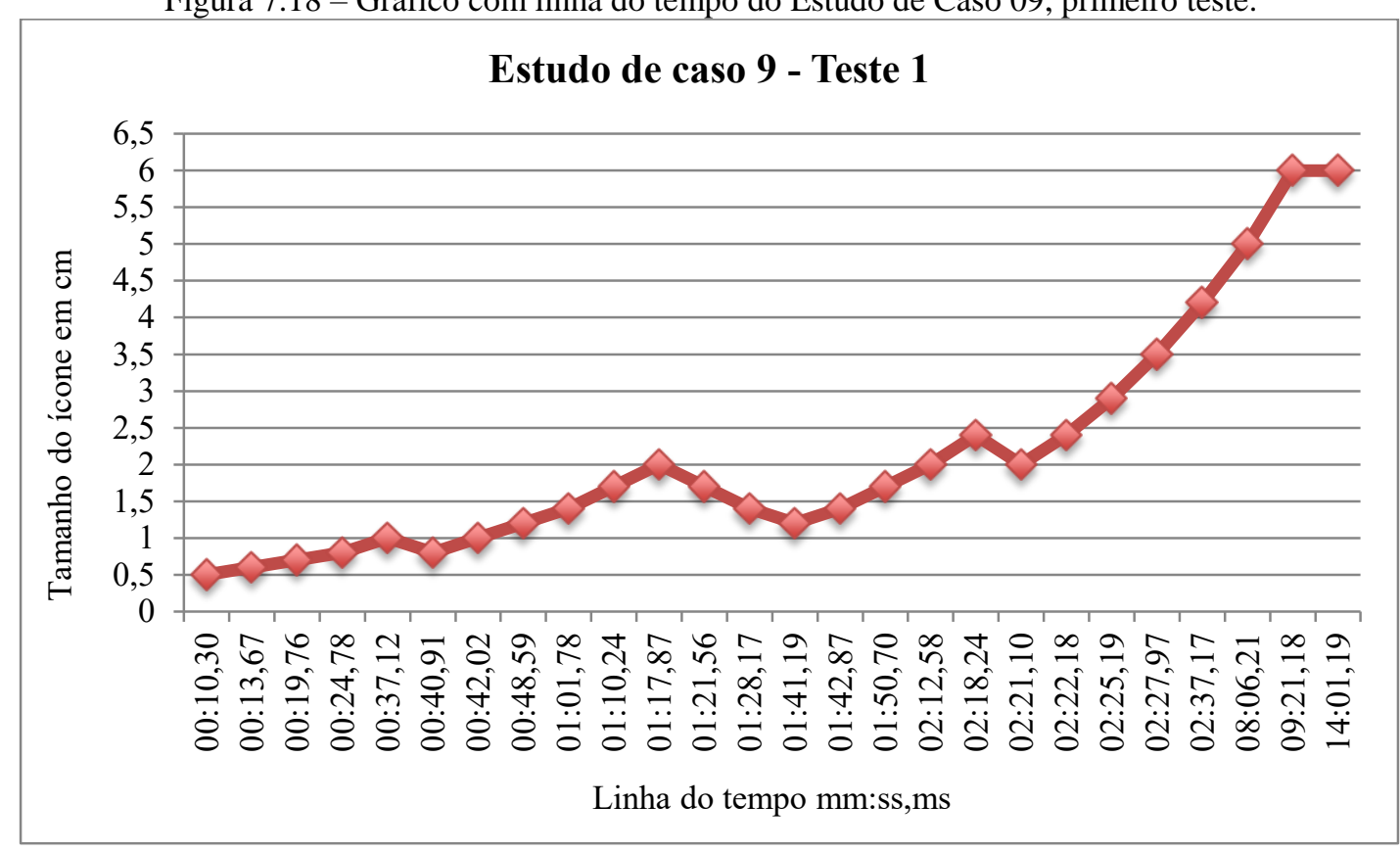

Fonte: Elaboração própria.

Figura 7. 19 - Gráfico com linha do tempo do Estudo de Caso 09, segundo teste.

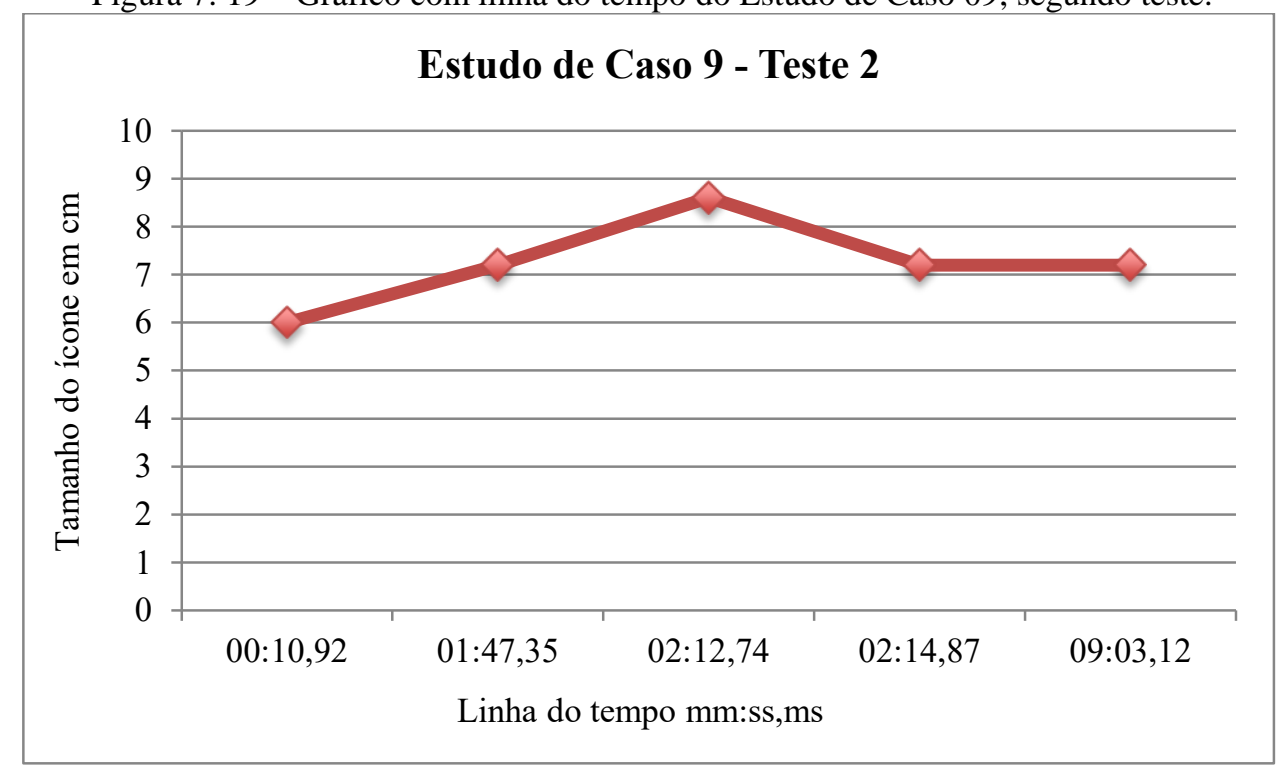

Fonte: Elaboração própria.

A Tabela 7.20 apresenta o resumo dos estudos de caso realizados com deficientes. No caso 7.3, o valor da velocidade de varredura foi fixado, e o Módulo de Tomada de Decisão ajustou o parâmetro arraste convertido em clique. Nos casos 8.1 e 8.2, a primeira linha representa os cálculos de tempo para insatisfações observadas em relação à dificuldade do arraste, e a segunda linha representa todas as insatisfações identificadas (pelo arraste e pela incompreensão das perguntas). 
Tabela 7.20 - Resumo dos estudos de caso realizados com pessoas com deficiência.

\begin{tabular}{|c|c|c|c|c|c|c|c|}
\hline $\begin{array}{l}\text { Estudo de } \\
\text { Caso }\end{array}$ & $\begin{array}{c}\text { Duração } \\
\text { (mm:ss,ms) }\end{array}$ & $\begin{array}{c}\text { Qtd. de } \\
\text { Insatisfação }\end{array}$ & $\begin{array}{l}\text { Parâmetro a } \\
\text { ser ajustado }\end{array}$ & $\begin{array}{l}\text { Valor } \\
\text { inicial }\end{array}$ & $\begin{array}{l}\text { Valor } \\
\text { Final }\end{array}$ & $\begin{array}{l}\text { Tempo médio de } \\
\text { Insatisfação } \\
\text { (mm:ss,ms) }\end{array}$ & $\begin{array}{l}\text { Tempo final sem } \\
\text { Insatisfação } \\
\text { (mm:ss,ms) }\end{array}$ \\
\hline 4 & $08: 22,10$ & 13 & arraste & $0,5 \mathrm{~cm}$ & $5 \mathrm{~cm}$ & $02: 11,98$ & $03: 11,99$ \\
\hline 5.1 & $06: 16,51$ & 19 & tam. ícone & $0,5 \mathrm{~cm}$ & $5 \mathrm{~cm}$ & $00: 38,31$ & $03: 08,23$ \\
\hline 5.1 & $07: 14,08$ & 2 & tam. ícone & $5 \mathrm{~cm}$ & $7,2 \mathrm{~cm}$ & $01: 41,48$ & $05: 19,14$ \\
\hline 6.1 & $07: 06,12$ & - & tam. ícone & $0,5 \mathrm{~cm}$ & $0,5 \mathrm{~cm}$ & - & - \\
\hline 6.2 & $05: 12,76$ & - & tam. ícone & $4 \mathrm{~cm}$ & $4 \mathrm{~cm}$ & - & - \\
\hline 7.1 & $09: 18,07$ & 42 & vel. varredura & $0,5 \mathrm{seg}$ & $0,9 \mathrm{seg}$ & $05: 10,13$ & $00: 06,54$ \\
\hline 7.2 & $10: 57,19$ & 67 & vel. varredura & $0,9 \mathrm{seg}$ & $1,0 \mathrm{sem}$ & $05: 16,38$ & $00: 06,88$ \\
\hline 7.3 & $05: 50,81$ & 18 & $\begin{array}{l}\text { vel. varredura } \\
\text { arraste }\end{array}$ & $\begin{array}{l}0,9 \mathrm{seg} \\
0,5 \mathrm{~cm}\end{array}$ & $\begin{array}{c}\text { fixa } \\
6,0 \mathrm{~cm}\end{array}$ & $01: 30,71$ & $02: 12,69$ \\
\hline 8.1 & $08: 55,12$ & 12 & arraste & $0,5 \mathrm{~cm}$ & $1,4 \mathrm{~cm}$ & $\begin{array}{l}02: 15,76 \\
04: 40,11\end{array}$ & $\begin{array}{c}03: 03,56 \\
- \\
\end{array}$ \\
\hline 8.2 & $08: 43,71$ & 7 & arraste & $1,4 \mathrm{~cm}$ & $1,7 \mathrm{~cm}$ & $\begin{array}{l}02: 32,07 \\
03: 21,70\end{array}$ & $\begin{array}{l}05: 13,45 \\
02: 43,51\end{array}$ \\
\hline 9.1 & $14: 01,19$ & 24 & tam. ícone & $0,5 \mathrm{~cm}$ & $6,0 \mathrm{~cm}$ & $02: 03,88$ & $04: 40,01$ \\
\hline 9.2 & 09:03,12 & 2 & tam. ícone & $6,0 \mathrm{~cm}$ & $8,6 \mathrm{~cm}$ & $02: 00,05$ & $06: 50,38$ \\
\hline
\end{tabular}

\subsection{Conclusões}

Os resultados obtidos com os testes do algoritmo da face neutra, descritos na Situação B do tópico 7.1 deste texto, contrariam os resultados dos estudos de Ekman (1978) no que se refere à afirmação de que as alterações musculares faciais rápidas raramente ultrapassam o tempo de 5 segundos, exceto em casos de crise ou patológicas. Considerando os vídeos, 44 não inicializados com a face neutra, em 14,58\% dos casos testados constatou-se expressões faciais emocionais demonstradas por tempos acima de 5 segundos. Na maioria dos casos, as expressões duraram toda a sequência do vídeo, apenas se alterando em intensidade.

Em alguns casos, o algoritmo da face neutra - implementado por não haver nenhum tipo de treinamento para inferência do estado emocional - atrapalhou a classificação da emoção quando ela era expressa por mais tempo do que a expressão neutra. Isso não interferiu nos resultados dos testes com as emoções espontâneas, pois para inferir qual emoção o sistema identificou analisou-se a com maior ocorrência, exceto neutro. Porém, se o objetivo fosse determinar exatamente quanto tempo cada emoção durou em uma linha do tempo, o algoritmo da face neutra teria prejudicado os resultados finais. Em especial nos vídeos de cenas engraçadas, muitas pessoas permaneceram por mais tempo sorrindo do que com a face neutra, e a partir de certo ponto a expressão de felicidade passou a ser classificada como neutra.

Uma forma de resolver esse problema é utilizar algoritmos de treinamento para inferência do estado emocional, porém, tais algoritmos tendem a identificar bem o estado 
emocional de imagens da base de dados utilizadas no treinamento, mas esses resultados nem sempre são generalizáveis, como demonstrado nos testes feitos com o algoritmo da Sightcorp. O método de inferência do estado emocional apresentado neste trabalho baseia-se na forma como o ser humano classifica emoções, por meio de informações de especialistas, dispensando a fase de treinamento na inferência do estado emocional. O problema dessa técnica é a questão da inicialização do sistema com uma imagem contendo expressão facial diferente de neutro, já que toda classificação é realizada com base na face neutra. Uma solução a ser investigada é criar um algoritmo híbrido, que considere informações médias de uma face neutra por meio de treinamento, mas que também considere informações específicas de um indivíduo, por meio do cálculo da média do vetor da face neutra durante as interações do mesmo com o sistema, segundo implementado neste trabalho. Aplicando-se uma linha de corte entre a distância do vetor da face neutra obtida no treinamento e os vetores obtidos durante as interações, evitaria que expressões fossem computadas na média da face neutra.

Quanto ao algoritmo de linha base, os resultados obtidos demonstraram que o mesmo foi capaz de separar os sinais faciais rápidos entre sinais de linha base e sinais emocionais, após uma etapa de treinamento que consiste em o usuário permanecer por certo tempo sem interagir com o sistema, ou seja, demonstrando apenas os sinais faciais de linha base sem a presença de sinais emocionais. Não faz parte do escopo deste trabalho estudar tiques faciais, porém, notou-se que mesmo havendo tiques diferentes não é improvável que seja possível categorizá-los, por meio de treinamento de bases de dados de imagens de vídeos só de pessoas com tiques, e realizar um treinamento prévio do sistema, a fim de filtrá-los sem a necessidade de o usuário permanecer alguns segundos sem apresentar sinais emocionais.

Testou-se Modelo 1 do Módulo Afetivo tanto com emoções simuladas usando as bases de dados KDEF e $\mathrm{CK}+$ quanto com emoções espontâneas por meio de base de dados própria.

Os testes com as emoções simuladas demonstram que o modelo proposto, diferentemente dos modelos que necessitam de treinamento para a etapa de inferência do estado emocional, é generalizável a bases de dados diferentes. Além disso, quando comparado com o trabalho de Bansal, Chaudhary e Roy (2013), que utilizam uma metodologia semelhante, também sem a fase de treinamento para inferência do estado emocional, demonstrou resultados $10,9 \%$ melhores.

Os testes com emoções espontâneas apresentaram vários desafios. Dentre eles, figuram a questão já discutida da inicialização sem a face neutra, e o fato de a emoção ser expressa por mais tempo que o previsto, de acordo com o levantado na literatura. Além disso, mesmo sem a análise e a classificação das imagens por especialista, é possível constatar que 
nem sempre o sentimento relatado pelo espectador é condizente com sua expressão facial. Mesmo assim, o modelo proposto obteve uma taxa de conformidade entre o estado emocional relatado pelo espectador e o inferido pelo sistema de $94,1 \%$ para sequências de vídeos engraçados. Já a conformidade entre o estado emocional inferido pelo sistema e o relatado pelo usuário foi de $86,7 \%$, agrupando as emoções por valência, desconsiderando dois casos de valência positiva e incluindo surpresa como valência negativa.

A taxa de conformidade entre a inferência do estado emocional do modelo proposto e do observador foi de $74,88 \%$, e a taxa de conformidade entre o estado emocional relatado pelo espectador e o identificado pelo observador foi de 66,85\%. Em ambas situações, o problema encontra-se na classificação da emoção neutra. Apenas a análise e a rotulação das sequências por especialista poderiam explicar o motivo de tantas emoções relatadas como de valência negativa pelo espectador terem sido classificadas como neutro, tanto pelo sistema quando pelo observador.

Os estudos de caso realizados com o Módulo de Tomada de Decisão demonstraram que foi possível melhorar a interação entre o ser humano e o computador, configurando parâmetros automaticamente, dada uma informação sobre o estado emocional do usuário extraída pela mímica da face.

Nos três primeiros casos de testes realizados com pessoas sem deficiência, o Módulo de Tomada de Decisão ajustou o tamanho do ícone em 14,66\% do tempo médio total dos testes.

Já nos testes com deficientes, em um dos seis casos estudados, o Módulo Afetivo foi incapaz de identificar a insatisfação do usuário, já que a mesma não era expressa pela mímica da face e sim por movimentos do tronco do aluno para frente e para trás. Além disso, em outro dos seis casos, o ajuste de um único parâmetro não foi suficiente para tornar a prancha adequada àquele aluno. Foi necessário que o Módulo de Tomada de Decisão ajustasse um parâmetro (tempo de varredura) e, depois do mesmo ser fixado manualmente, um segundo parâmetro (arraste convertido em clique) fosse ajustado pelo Módulo de Tomada de Decisão. Porém, os testes demonstraram que é possível melhorar a experiência de pessoas com deficiência na interação com recursos computacionais, realizando ajustes em sistemas assistivos, considerando a emoção expressa por meio da mímica da face.

Este estudo demonstrou como a emoção expressa pela mímica da face de deficientes foi eficiente no ajuste de parâmetros de um sistema de comunicação alternativa e ampliada. Também, demonstrou que um sistema comercial que se proponha a usar o estado afetivo do deficiente para melhorar sua usabilidade deve considerar outras variáveis tais como: 
Uso de câmeras fixadas na cabeça da pessoa, para aqueles deficientes que não conseguem se manter parados em frente ao dispositivo;

Uso de sensores de movimento, para pessoas que demonstram suas emoções com movimentos corporais mais do que com movimentos faciais;

Implementação de um sistema que identifique automaticamente qual é a dificuldade de utilização por meio da análise do uso do recurso computacional e seja capaz de ajustar diversos parâmetros simultaneamente.

\subsection{Principais Contribuições}

Neste trabalho, demonstrou-se que é possível melhorar a HCI, considerando as emoções humanas expressas por meio da face na tomada de decisões de sistemas computacionais.

Apresentou-se uma abordagem de detecção de emoções baseada na forma como os seres humanos identificam as emoções. Tal abordagem é baseada no FACS, mas representa não só a ativação de uma Unidade de Ação, mas também a direção da mesma. Além disso, para inferência do estado emocional insatisfeito, propôs-se uma adaptação do FACS ao modelo de Tomkins, agrupando sinais faciais de valência negativa. Por meio de observações de especialista, filtrou-se apenas os sinais faciais presentes na insatisfação do usuário ao utilizar o computador.

Propôs-se o algoritmo da face neutra que minimizou o problema da inicialização da sequência de imagens contendo uma emoção.

Propôs-se uma subdivisão dos sinais faciais rápidos entre sinais de linha base e sinais emocionais.

Até onde estendeu-se o levantamento bibliográfico deste trabalho, este é o primeiro estudo de detecção de emoções pela mímica da face testado e modelado para pessoas com deficiência, além de ser o primeiro estudo que usou as emoções expressas pela mímica da face para tomada de decisão em sistemas assistivos.

Implementações computacionais que utilizam a mímica da face para inferência do estado emocional não são uma inovação em pesquisas acadêmicas, porém, este trabalho apresentou uma metodologia eficiente que se difere das demais pesquisas por sua simplicidade de implementação e pela facilidade utilização em outros tipos de aplicação, uma vez que utiliza a plataforma aberta da $W e b$. Os autores pesquisados não discutem tempo de processamento, o que dificulta uma comparação neste aspecto, porém, a metodologia 
apresentada necessita apenas de um Web Browser em um dispositivo com webcam para detectar a face, extrair características, identificar uma expressão e inferir o estado emocional com uma taxa média de 27 interações por segundo, o que a torna atrativa para implementações de sistemas de tempo real.

Apresenta-se como contribuição menos relevante na área científica, mas importante no âmbito social, o programa que gera pranchas de comunicação digital, distribuído em forma de software livre.

Outra contribuição social desta pesquisa foi o trabalho desenvolvido junto às pessoas deficientes. Algumas professoras da APAE relataram que o uso da prancha melhorou o desempenho dos alunos em sala de aula, uma vez que as atividades trabalhadas nas pranchas eram as mesmas que as trabalhadas em aula. Dois pais de deficientes identificaram melhoras em seus filhos após participarem do projeto. Um deles, pai de um autista, relatou que o filho estava mais disposto a obedecer em outras atividades para poder realizar atividades no computador. Já a mãe de uma portadora de retardo mental relatou melhora na comunicação entre ela e sua filha após ter sido fornecido e instalado o software da prancha no computador pessoal da deficiente.

\subsection{Publicações}

GRACIOSO, A. C. N. R.; SUAREZ, C. C. B.; BACHINI, C.; RAMIREZFERNANDEZ, F. J. Emotion Recognition System Using Open Web Platform. In: 47th International Carnahan Conference on Security Technology (ICCST), 2013, Medellín. Proceedings... Medellín, Antioquia, Colômbia: IEEE, 2013. p. 1-5.

Encontra-se em fase de submissão os resultados obtidos nos testes do Módulo de Tomada de Decisão em: http://informahealthcare.com/idt.

Encontra-se em fase de elaboração um artigo com os resultados do módulo afetivo a ser submetido em: http://www.journals.elsevier.com/signal-processing-image-communication.

\subsection{Trabalhos Futuros}

Pesquisar e desenvolver técnicas mais eficientes quanto à classificação de sequências de imagens de vídeo não inicializadas com a face no estado neutro. Uma solução possível é a implemantação de um algoritmo que realize uma etapa de treinamento, como por exemplo 
SVM, Rede Neural, Rede Bayesiana, ou outro, a fim de aprender quais são as características de uma face neutra.

Pesquisar e desenvolver técnicas mais eficientes para a subdivisão dos sinais faciais rápidos entre sinais de linha base e sinais emocionais, nas quais o usuário não necessite permanecer com a face neutra por um intervalo de tempo antes do início da inferência do estado emocional. A mesma solução proposta para resolver o problema da inicialização com uma face não neutra pode ser aplicada para resolver o problema da identificação dos sinais faciais de linha base e sinais emocionais. Porém, neste caso, o algoritmo deve aprender quais são os padrões e as frequência de linha base versus sinais emocionais, buscando uma distinção entre os mesmos que possa ser generalizável a diferentes usuários com diferentes sinais de linha base.

Pesquisar e desenvolver formas de identificar automaticamente qual é a dificuldade do usuário e de implementar sistemas capazes de ajustar diversos parâmetros simultaneamente. $\mathrm{O}$ próprio mecanismo já implementado para verificar se o sentido da alteração está correto pode ser implementado de forma recursiva, variando-se os parâmetros configuráveis da prancha de comunicação para identificar automaticamente qual(ais) é (são) a(s) necessidade(s) de ajuste(s) do usuário. Outra forma é identificar computacionalmente qual ação está sendo realizada pelo usuário no instante em que o módulo afetivo identifica dificuldade de utilização. Tal informação pode ser processada a fim de se identificar automaticamente qual parâmetro é passível de ajuste pelo módulo de tomada de decisão. 


\section{REFERÊNCIAS}

ABDAT, F.; MAAOUI, C.; PRUSKI, A. Human-computer interaction using emotion recognition from facial expression. In: UKSim 5th European Symposium on Computer Modeling and Simulation, 2011, Spain. Proceedings... Spain: EMS, 2011.

ABERTAY. Scotland. 2010.2 Disponível em: <http://www.abertay.ac.uk/about/news/newsarchive/2010/name,6983,en.html>. Acesso em: 22 ago. 2011.

ABERTAY. Scotland. Disponível em: <http://www.abertay.ac.uk/about/news/newsarchive/2014/name,19106,en.html>. Acesso em: 17 dez. 2014.

ABBOUD, D.; DAVOINE, F. Appearance factorization based facial expression recognition and synthesis. In: 17th International Conference on Pattern Recognition, 2004. Proceedings... San Francisco, CA: IEEE, 2004. p. 163-166.

AFFECTIVA. Waltham. Disponível em: <http://www.affectiva.com>. Acesso em: 18 ago. 2015a.

AFFECTIVA. Waltham. Disponível em: <http://developer.affectiva.com/accuracy/>. Acesso em: 18 ago. $2015 b$.

ALENCAR, G. A. R. O direito de comunicar, por que não? Comunicação alternativa aplicada a portadores de necessidades educativas especiais no contexto de sala de aulaIn: $25^{\mathrm{a}}$ Reunião Anual da ANPEd, 2002, Caxambu. Anais... Caxambu: ANPEd, 2002. p. 1-13.

ANDERSON, K.; MCOWAN, P. W. A real-time automated system for recognition of human facial expressions. IEEE Trans. Systems, Man, and Cybernetics, v. 36, n. 1, p. 96-105, 2006.

ANTONINI, G. et al. Discrete choice models for static facial expression recognition. LNCS, v. 4179, p. 710-721, 2006.

ARNOLD, M. B. Emotion and personality. New York: Columbia University Press, 1960

AVERILL, J. R. A constructivist view of emotion. In: PLUTCHIK, R.; KELLERMAN, H. (Eds.). Emotion: Theory, research, and experience. New York: Academic Press, 1980. p. 305-339.

BAKER, R. et al. Why Students Engage in 'Gaming the System' Behavior in Interactive Learning Environments. Journal of International Learning Research, n. 19, v. 2, p. 185224, 2008.

BANSAL, A.; CHAUDHARY, S.; ROY, S. D. A Novel LDA and HMM-Based Technique for Emotion Recognition from Facial Expressions. LNAI, v. 7742, MPRSS, p. 19-26, 2013. 
BARTLETT, M. S. et al. Classifying facial action. In: Advances in Neural Information Processing Systems 8, D. Touretzky, M. Mozer, and M. Hasselmo (Eds.), 1996. Proceedins... Cambridge, MA: MIT Press, 1996. p. 823-829.

BARTLETT, M. S. et al. Machine learning methods for fully automatic recognition of facial expressions and facial actions. In: IEEE International Conference on Systems, Man \& Cybernetics, 2004, The Hague. Proceedings... San Francisco, CA: IEEE, 2004, p. 592-597.

BARTLETT, M. S. et al. Recognizing facial expression: machine learning and application to spontaneous behavior. In: Computer Vision and Pattern Recognition, 2005. Proceedings... San Francisco, CA: IEEE, 2005. p. 568-573.

BARTLETT, M. S. et al. Automatic Recognition of Facial Actions in Spontaneous Expressions. Journal of Multimedia, n. 1, v. 6, p. 22-35, 2006 a.

BARTLETT, M. S. et al. Fully automatic facial action recognition in spontaneous behavior. In: FGR '06: Proceedings of the 7th International Conference on Automatic Face and Gesture Recognition, 2006, Washington. Proceedings... San Francisco, CA: IEEE, 2006 b. p. 223-230.

BARTLETT, M. S. et al. Data mining spontaneous facial behavior with automatic expression coding. Lecture Notes in Computer Science, n. 5042, 2008. p. 1-21.

BARTLETT, M. S. et al. Insights on spontaneous facial expressions from automatic expression measurement. In: GIESE, M.; CURIO, C.; BULTHOFF, H. (Eds.). Dynamic Faces: Insights from Experiments and Computation. Cambridge, MA: The MIT Press, 2010. p. 1-33, cap. II, part. 14.

BASSILI, J. N. Emotion recognition: the role of facial movement and the relative importance of upper and lower areas of the face. Journal of personality and social psychology, v. 37, n. 11, p. 2049-2058, 1979.

BELL, C. The anatomy and philosophy of expression as connected with the fine arts. London: Covent Garden, 1865.

BERSCHE, R.; TONOLLI, J. C. Introdução ao Conceito de Tecnologia Assistiva e Modelos de Abordagem da Deficiência. 2006. Disponível em: <http://www.bengalalegal.com/tecnologia-assistiva>. Acesso em: 14 dez. 2015.

BIANCHI, M. F. Extração de características de imagens de faces humanas através de wavelets, PCA e IMPCA. 2006. 139 p. Dissertação (Mestrado) - Escola de Engenharia de São Carlos, São Carlos, 2006.

BOUGUET, J.-Y. Pyramidal Implementation of the Lucas Kanade Feature Tracker Description of the algorithm. Intel Corporation Microprocessor Research Labs, 2000.

BRADSKI, G.; KAEHLER, A. Learning OpenCV: Computer Vision with the OpenCV Library. 1. ed. United States of America: O’Reilly Media, 2008. 
BRASIL. Conselho Nacional de Saúde. Resolução nº 196, de 10 de outubro de 1996. Aprova normas regulamentadoras de pesquisas envolvendo seres humanos. Brasília: Diário Oficial da União, 1996.

BRUCE, V.; YOUNG, A. In the eye of the beholder: the science of face perception. Oxford, England New York: Oxford University Press, 1998.

CALDER, A. J.; LAWRENCE, A. D.; YOUNG, A. W. Neuropsychology of fear and loathing. Nature Reviews Neuroscience, n. 2, p. 352-363, 2001.

CAMPBELL, C. kernel methods: A survey of current techniques. Neurocomputing, n. 48, p. 63-84, 2002.

CANNY, J. A. computational approach to edge detection. IEEE Trans. Pattern Anal. Mach. Intell, n. 8, v. 6, p. 679-698, 1986.

CASTELLANO, G. et al. It's all in the game: towards an affect sensitive and context aware game companion. In : 3rd International Conference on Affective Computing and Intelligent Interaction, 2009, Amsterdam. Proceedings... San Francisco, CA: IEEE, 2009. p.1-8.

CHANG, Y.; HU, C. TURK, M. Probabilistic expression analysis on manifolds. In: IEEE Computer Society Conference on Computer Vision and Pattern Recognition, CVPR 2004, 2., 2004. Proceedings... San Francisco, CA: IEEE, 2004. p. II-520-II-527.

CHANGBO, $\mathrm{H}$. et al. Manifold based analysis of facial expression. In: Conference on Computer Vision and Pattern Recognition Workshop (CVPRW '04), 2004. Proceedings... San Francisco, CA: IEEE, 2004. p. 81.

CHEN, M. et al. AIWAC: Affective interaction through wearable computing and cloud technology. In: IEEE Wireless Communications, 2015. Proceedings.... San Francisco, CA: IEEE, 2015, p. 20-27.

CHOI, J. Y.; PLATANIOTIS, K. N.; RO, Y. M. Using colour local binary pattern features for face recognition. In: IEEE 17th International Conference on Image Processing, 2010, Hong Kong. Proceedings... San Francisco, CA: IEEE, 2010. p. 26-29.

CHROME. Google Chrome Navigator. Disponível em: 〈https://www.google.com/chrome〉. Acesso em: $1^{\circ}$ mar. 2013.

CHU, W. S.; DE LA TORRE, F.; COHN, J. F. Selective Transfer Machine for Personalized Facial Action Unit Detection. In: IEEE Conference on Computer Vision and Pattern Recognition (CVPR), 2013, Portland. Proceedings... San Francisco, CA: IEEE, 2013. p.1-8.

CHUAN, Y. C. et al. Emotion recognition with consideration of facial expression and physiological signals. In: 6th Annual IEEE conference on Computational Intelligence in Bioinformatics and Computational Biology (CIBCB'09), 2006, USA. Proceedings... San Francisco, CA: IEEE, 2006. p. 278-283.

COHEN, I. et al. Facial expression recognition from video sequences: Temporal and static modeling. CVIU, v. 91, n. 1-2, p. 160-187, 2003. 
CONATI, C. Probabilistic Assessment of User's Emotions in Educational Games. Applied Artificial Intelligence, Philadelphia, v. 16, n. 7-8, p. 555-575, Aug. 2002.

COOK, A. M.; POLGAR, J. M. Cook \& Hussey's Assistive Technologies: Principles and Practice. Philadelphia: Mosby/Elsevier, 2008.

COOTES, T. F. et al. Active shape models - their training and application. Computer Vision and Image Understanding, v. 61, n. 1, p. 38-59, Jan. 1995.

COOTES, T. F.; EDWARDS, G. J.; TAYLOR, C. J. Active appearance models. IEEE Trans. Pattern Anal. Mach. Intell., v. 23, n. 6, p. 681-685, Jun. 2001.

COOTES, T. F.; TAYLOR, C. J. Active Shape Models - 'smart snakes'. In: David Hogg and Roger Boyle (Eds.), British Machine Conference, 1992. Proceedings... Springer-Verlag, September, 1992. p. 28.1-28.10.

CRISTINACCE, D.; COOTES, T. F. Feature detection and tracking with constrained local models. In: Proc. Brit. Mach. Vision Conf., 2006, pp. 929-938.

DALAL, N.; TRIGGS, B. Histograms of oriented gradients for human detection. In: IEEE Computer Society Conference on Computer Vision and Pattern Recognition, 1., 2005, San Diego. Proceedings... San Francisco, CA: IEEE, 2005. p. 886-893.

DALGLEISH, T. The emotional brain. Nature Reviews Neuroscience, v. 5, p. 582-589, 2004.

DARWIN, C. The Expression of the Emotions in Man and Animals. London: John Murray, 1872.

DARWIN, C. On the Origin of Species. 3. ed. London: John Murray, 1861.

DE LA TORRE et al. IntraFac. In: 11th IEEE International Conference and Workshops on Automatic Face and Gesture Recognition (FG), 1., 2015, Ljubljana. Proceedings... San Francisco, CA: IEEE, 2015. p. 1-8.

DONATO, G. et al. Classifying facial actions. IEEE Transactions on Pattern Analysis And Machine Intelligence, v. 21, n. 10, p. 974-989, 1999.

DU, S.; TAO, Y.; MARTINEZ, A. M. Compound facial expressions of emotion, Proc. of the National Academy of Sciences, v. 111, n. 15, p. E1454-E1462, 2014.

DUCHENNE (de Boulogne), G.-B. Mécanisme de la physionomie humaine. Atlas. 2. ed. Paris: J.-B. Bailliere et Fils. Essays, 1876. Disponível em: <http://vlp.mpiwgberlin.mpg.de/library/data/lit25060/index_html?pn=1\&ws=1.5>. Acesso em: 12 out. 2013.

ECMASCRIPT - The language of the Web. Disponível em: 〈http://www.ecmascript.org/>. Acesso em: 16 fev. 2015. 
EKMAN, P. Facial signs: Facts, fantasies, and possibilities. In: SEBEOK, T. Sight, sound and sense. Bloomington, Ind.: Indiana University Press, 1978. p. 125-156.

EKMAN, P. The Argument and Evidence About Universals: In: Handbook of Social Psychophysiology, Chichester, John Wiley, Ltd., p. 143-164, 1989. Facial Expression of Emotion.

EKMAN, P. All emotions are basic. In: EKMAN, P.; DAVIDSON, R. J. (Eds.). The nature of emotion: Fundamental questions. New York: Oxford University Press, 1994. p. 7-19.

EKMAN, P. et al. Final report to NSF of the planning workshop on facial expression understanding. Human Interaction Laboratory, University of California, San Francisco, v. 378, 1993.

EKMAN, P.; FRIESEN, W. Facial Action Coding System: A Technique for the Measurement of Facial Movement. Palo Alto: Consulting Psychologists Press, 1978.

EKMAN, P. ; OSTER, H. Facial Expressions of Emotion. Anual Review Psychology, v. 30, p. 527-554, 1979.

EKMAN, P.; ROSENBERG, E. L. What the Face Reveals: Basic and Applied Studies of Spontaneous Expression Using the Facial Action Coding System (FACS). 2. ed. New York: Oxford University Press, 2005.

EMOTIENT. Disponível em: <http://emotient.com>. Acesso em: 16 fev. 2015.

ESMAEILY, R.; HENDESSI, F. An affective ephemeral social network for vehicular scenarios. Journal Of Ambient Intelligence And Smart Environments, v. 7, n. 1, p. 21-36, Dec. 2014.

ESSA, I. A.; PENTLAND, A. P. A vision system for observing and extracting facial action parameters. In: Computer Vision and Pattern Recognition - CVPR'94., 1994, Seattle. Proceedings... San Francisco, CA: IEEE, 1994. p. 76-83.

ESSA, I. A.; PENTLAND, A. P. Coding, analysis, interpretation, and recognition of facial expressions. IEEE Transaction on Pattern Analysis and Machine Intelligence, v. 19, n. 7, p. 757-763, 1997.

FACSAID - Facial Action Coding System Affect Interpretation Dictionary. Disponível em: <http://face-and-emotion.com/dataface/facsaid/description.jsp>. Acesso em: 19 ago. 2011.

FIGUEIRA, E. Psicronicando: a prática da escrita como o divã! São Paulo: Edição do Autor/AgBok, 2011.

FRAGOPANAGOS, N.; TAYLOR, J. Emotion recognition in human-computer interaction. Neural Networks, v. 18, p. 389-405, 2005.

FRANTZIDIS, C.A. et al. On the Classification of Emotional Biosignals Evoked While Viewing Affective Pictures: An Integrated Data-Mining-Based Approach for Healthcare 
Applications. In: IEEE Transactions on Information Technology in Biomedicine, 2010. Proceedings... San Francisco, CA: IEEE, 2010. p. 309-318.

FREUND, Y.; SCHAPIRE, R. E. A decision-theoretic generalization of on-line learning and an application to boosting. Journal of Computer and System Sciences, v. 55, n. 1, p. 119139, 1997. Special issue.

FUKUNAGA, K.; HOSTETLER, L. D. The Estimation of the Gradient of a Density Function, with Applications in Pattern Recognition. IEEE Transactions On Information Theory, v. IT-21, n. 1, p. 32-40, Jan. 1975.

GIMENEZ, R. P. Análise retrospectiva das alterações da dinâmica facial após aplicações seriadas de toxina botulínica tipo A. 2006. 120 p. Dissertação (Mestrado) - Faculdade de Medicina da Universidade de São Paulo, São Paulo, 2006.

GLEITMAN, H.; REISBERG, D.; GROSS, J. Psicologia. Porto Alegre: Artmed, 2009.

GOCKLEY, R.; SIMMONS, R.; FORLIZZI, J. Modeling affect in socially interactive robots. In: 15th IEEE International Symposium on Robot and Human Interactive Communication, 2006, Hatfield. Proceedings... San Francisco, CA: IEEE, 2006. p. 558-563.

GOOGLE Inc. Hartwig Adam, Hartmut Neven, Johannes B. Steffens. Image based multibiometric system and method. US 7697735 B2, 13 abr. 2010. Disponível em: <http://www.google.com/patents/US7697735>. Acesso em: 16 fev. 2015.

GUNDUZ, A.; KRIM, H. Facial feature extraction using topological methods. In: International Conference on Image Processing (ICIP), 2003. Proceedings... San Francisco, CA: IEEE, 2003. p. I673-I676.

GRIFFITHS, P. E. Emotions. In: STICH, S. P.; WARFIELD, T. A. (Eds). The Blackwell Guide to Philosophy of Mind. Oxford: Blackwell Publishing, 2002.

HADID, A. The Local Binary Pattern Approach and its Applications to Face Analysis. In: Image Processing Theory, Tools \& Applications, 2008, Sousse. Proceedings... San Francisco, CA: IEEE, 2008. p. 1-9.

HAGER, J. C. DataFace: Facial Expressions, Emotion Expressions, Nonverbal Communication. Disponível em: <http://face-andemotion.com/dataface/general/homepage.jsp> Acesso em: 3 out. 2011.

HAGER, J. C.; EKMAN, P. The Inner and Outer Meanings of Facial Expressions. In: SOCIAL Psychophysiology, New York, Gilford Press, p. 287-306, 1983.

HU, C. et al. Manifold based analysis of facial expression. In: 2004 Conference on Computer Vision and Pattern Recognition Workshop (CVPRW'04), 5., 2004, Washington. Proceedings... San Francisco, CA: IEEE, 2004. p. 81.

HUANG, C. et. al. High-Performance Rotation Invariant Multiview Face Detection. IEEE Transactions On Pattern Analysis And Machine Intelligence, v. 29, n. 4, p. 671-686, Apr. 2007. 
IBGE - Instituto Brasileiro de Geografia e Estatística. Censo demográfico. Rio de Janeiro: IBGE, 2010.

ICHIM, A. E.; BOUAZIZ, S.; PAULY, M. Dynamic 3D avatar creation from hand-held video input. ACM Transactions on Graphics (TOG) - Proceedings of ACM SIGGRAPH 2015, v. 34, n. 4, Aug. 2015. p. 1-14. Article n. 45.

INTRAFACE. Pittsburgh. Disponível em: <http://www.humansensing.cs.cmu.edu/>. Acesso em: $1^{\circ}$ out. 2015.

JAMES, W. What is an emotion? Mind, v. 9, n. 34, p. 188-205, 1884.

JENI, L. A. et al. 3D Shape Estimation in Video Sequences Provides High Precision Evaluation of Facial Expressions. Journal Image and Vision Computing, Elsevier, v. 30, n. 10, p. 785-795, 2011.

JOHNSON, M. A Tobii Dynavox Company. Disponível em: <http://www.mayerjohnson.com/boardmaker-software>. Acesso em: 15 dez. 2015.

JOHO, H. et al. Exploiting Facial Expressions for Affective Video Summarisation. In: CIVR '09 - ACM International Conference on Image and Video Retrieval, 2009, Santorini. Proceedings... Santorini: CIVR, 2009.

JUNQUEIRA, V. T. S. Inclusão de alunos com necessidades educacionais especiais na rede regular de ensino (PDE). Cornélio Procópio: 2007. Disponível em: <http://www.diaadiaeducacao.pr.gov.br/portals/pde/arquivos/561-2.pdf>. Acesso em: $1^{\mathrm{o}}$ out. 2014.

KAIROS. Miami. Disponível em: 〈https://www.kairos.com/>. Acesso em: 1º out. 2015.

KALYAN, A. S. et al. International Journal of Signal Processing, Image Processing and Pattern Recognition, v. 4, n. 2, p. 19-30, Jun. 2011.

KARMAKAR, D.; MURTHY, C. A. Face Recognition using Face-Autocropping and Facial Feature Points Extraction. In: 2nd International Conference on Perception and Machine Intelligence, 2015, Kolkata. Proceedings... Kolkata, India: ACM, 2015. p. 116-122.

KHAN, J. A. Aesthetic Surgery: Diagnosing and Healing the Miscues of Human Facial Expression. Ophthalmic Plastic and Reconstructive Surgery, v. 17, n. 1, p. 4-6, 2001.

KIM, D. K., CHO, Y., PARK, K. S. Mediating individual affective experience through the emotional photo frame. Journal of Ambient Intelligence and Smart Environments Affect Aware Ubiquitous Computing, v. 7, n. 1, p. 99-113, Jan. 2015.

KOELSTRA, S.; PANTIC, M. Non-rigid registration using free-form deformations for recognition of facial actions and their temporal dynamics. In: 8th IEEE International Conference on Automatic Face \& Gesture Recognition (FG '08), 2008, Amsterdam. Proceedings... San Francisco, CA: IEEE, 2008. p. 1-8. 
KUILENBURG, H.; WIERING, M.; UYL, M. A Model Based Method for Automatic Facial Expression Recognition. LNAI, n. 3720, ECML, p. 194-205, 2005.

LACERDA, S. M. Interação entre familiares e usuários de comunicação alternativa: padrões de comunicação e efeitos de um programa de treinamento. 2000. 133 p. Dissertação (Mestrado) - Universidade do Estado do Rio de Janeiro, Rio de Janeiro, 2000.

LATECA. QUEM SOMOS?. Rio de Janeiro. Disponível em: < http://www.latecauerj.net/qsomos/apresentacao/>. Acesso em: $1^{\circ}$ out. 2015.

LEVI, K.; WEISS, Y. Learning Object Detection from a Small Number of Examples: the Importance of Good Features. In: 2004 IEEE Computer Society Conference on Computer Vision and Pattern Recognition (CVPR'04), 2., 2004. Proceedings... San Francisco, CA: IEEE, 2004. p. II53-II60.

LEWINSKI, P.; UYL, T. M.; BUTLER, C. Automated facial coding: validation of basic emotions and facs aus in FaceReader. Journal of Neuroscience, Psychology, and Economics, v. 7, n. 4, 227-236, 2014.

LI, S. Z. et al. Statistical Learning of Multi-view Face Detection. LNCS, v. 2353, ECCV '02 Proceedings of the 7th European Conference on Computer Vision-Part IV, p. 67-81, 2002.

LI, S.; ZHANG, Z. Floatboost learning and statistical face detection. IEEE Transactions Pattern Analysis and Machine Intelligence, v. 26, n. 9, p. 1112-1123, 2004.

LIEN, J. J. et al. Automated facial expression recognition based on FACS action units. In: Automatic Face and Gesture Recognition. Third IEEE International Conference, 1998, Nara. Proceedings... San Francisco, CA: IEEE, 1998. p. 390-395.

LIENHART, R.; MAYDT, J. An extended set of haar-like features for rapid object detection. ICIP, p. 900-903, 2002.

LITTLEWORT, G. et al. Dynamics of facial expression extracted automatically from video. In: IEEE Conference on Computer Vision and Pattern Recognition, Workshop on Face Processing in Video, 2004. Proceedings... San Francisco, CA: IEEE, 2004. p. 80.

LITTLEWORT, G. et al. Dynamics of facial expression extracted automatically from video. Image and Vision Computing, v. 24, n. 6, p. 615-625, 2006.

LUCAS, B. D.; KANADE, T. An iterative image registration technique with an application to stereo vision. Journal of Japanese Society for Artificial Intelligence, p. 121-130, 1981.

LUCEY, P. et al. The Extended Cohn-Kanade Dataset (CK+): A complete dataset for action unit and emotion-specified expression. In: EEE Computer Society Conference on Computer Vision and Pattern Recognition Workshops (CVPRW), 2010, San Francisco. Proceedings... San Francisco, CA: IEEE, 2010. p. 94-101.

LUNDALV, M. Blissymbolics Communication International. Sweden. Disponível em: <http://www.blissymbolics.org/>. Acesso em: 15 dez. 2015. 
LUNDQVIST, D., FLYKT, A.; ÖHMAN, A. The Karolinska Directed Emotional Faces KDEF. Sweden, Department of Clinical Neuroscience, Psychology section, Karolinska Institutet, 1998. 1 CD-ROM.

MAAOUI, C.; ABDAT, F.; PRUSKI, A. Physio-visual data fusion for emotion recognition. IRBM, v. 35, n. 3, p. 109-118, Jun. 2014.

MATSUMOTO, D.; WILLINGHAM, B. The Thrill of Victory and the Agony of Defeat: Spontaneous Expressions of Medal Winners of the 2004 Athens Olympic Games. Journal of Personality and Social Psychology, v. 91, n. 3, p. 568 -581, 2006.

MARTINEZ, A.; DU, S. A model of the perception of facial expressions of emotion by humans: Research overview and perspectives. Journal of Machine Learning Research, $n$. 13, p. 1589-1608, 2012.

MARTINS, J. M. A lógica das emoções: na ciência e na vida. Petrópolis: Vozes, 2004.

MCDUFF. D. et al. Predicting Ad Liking and Purchase Intent: Large-Scale Analysis of Facial Responses to Ads. IEEE Transactions on affective computing, v. 6, n. 3, p. 223-235, jul./sept. 2015.

MENA, A. P.; MAYORAL, M. B.; DÍAZ-LÓPEZ, E. Comparative Study of the Features Used by Algorithms Based on Viola and Jones Face Detection Algorithm. LNCS, n. 9108, IWINAC 2015, Parte III, p. 175-183, 2015.

MICROSOFT Corporation. Washington. Disponível em: <http://www.microsoft.com>. Acesso em: $1^{\circ}$ out. 2015.

MILBORROW, S.; MORKEL, J.; NICOLLS, S. The MUCT Landmarked Face Database. Pattern Recognition Association of South Africa, p. 1-6, 2010. Disponível em: <http://www.milbo.org/muct/>. Acesso em: $1^{\circ}$ fev. 2014.

MILLER, G. F. A mente seletiva: como a escolha sexual influenciou a evolução da natureza humana. Rio de Janeiro: Campus, 2000.

MITA, T.; KANEKO, T.; HORI, O. Joint Haar-like features for face detection. In: Tenth IEEE International Conference on Computer Vision (ICCV), 2., 2005, Beijing. Proceedings... Beijing: IEEE, 2005. p. 1619-1626.

MOORE, S.; ONG, E. J.; BOWDEN, R. Facial Expression Recognition Using Spatiotemporal Boosted Discriminatory Classifiers. LNCS, n. 6111, ICIAR 2010, Part I, p. 405-414, 2010.

MYSQL - The world's most popular open source database. Disponível em: <https://www.mysql.com/>. Acesso em 16 fev. 2015.

NEESE, R. M. Evolutionary explanations of emotions. Human Nature, n. 1, p. 261-289, 1990. 
NEISSER, U. The Imitation on Man by Machine: The view that machines will think as man does reveals misunderstanding os the nature of human thought. Science, v. 139, p. 193-197, 1963.

NOLDUS. FaceReader 6 - Technical specification. Noldus: Netherlands, [201?]a.

NOLDUS. The Observer XT 12.5: Technical specifications. Noldus: Netherlands, [201?]b.

NOLDUS. Netherlands. Disponível em: <http://www.noldus.com/> Acesso em: 16 dez. 2014.

NVISO. Switzerland. Disponível em: <http://www.nviso.ch/>. Acesso em: $1^{\circ}$ out. 2015.

NUNES, L. R. O. P.; NUNES, D. R. P. Um breve histórico da pesquisa em Comunicação Alternativa na UERJ. In: NUNES, L. R., PELOSI, M. B; GOMES, M. R. v. 1. Um retrato da comunicação alternativa no Brasil. Rio de Janeiro: Quatro Pontos, 2007. p. 19-32.

OATLEY, K.; JENKINS, J. M. Compreender as emoções. Lisboa: Instituto Piaget, 2002.

OJALA, T.; PIETIKAEINEN, M.; MAEENPAEA, T. Multiresolution Gray-Scale and Rotation Invariant Texture Classification with Local Binary Patterns. IEEE Transactions On Pattern Analysis And Machine Intelligence, v. 24, n. 7, Jul. 2002.

OMS - Organização Mundial da Saúde. Relatório Mundial sobre deficiência. São Paulo: Secretaria dos Direitos Humanos, 2011.

OMOTE, S. Atratividade Física Facial: Percepção e Efeitos sobre Julgamentos. 1992. 133 p. Tese (Livre Docência) - Faculdade de Filosofia e Ciências da Universidade Estadual Paulista, Marília, 1992.

ORTONY, A. On making believable emotional agents believable. In: Trappl, R.; Petta, P. (Eds.). Emotions in humans and artifacts. Cambridge: The MIT Press, 2001. p. 1-13.

ORTONY, A.; CLORE, G. L.; COLLINS, A. The cognitive structure of emotions. New York: Cambridge University Press, 1988.

ORTONY, A.; TURNER, T. J. What's basic about basic emotions?. Psychological review, v. 97, n. 3, p. 315, 1990.

OYGARD, A. M. CLMTRACKR - Javascript library for precise tracking of facial features via Constrained Local Models. Disponível em: <https://github.com/auduno/clmtrackr>. Acesso em: 16 dez. 2014.

PADGETT, C.; COTTRELL, G. W. A simple neural network models categorical perception of facial expressions. In: Proceedings of the Twentieth Annual Cognitive Science Conference, 1998. Proceedings... Erlbaum, 1998. p. 806-807.

PAISITKRIANGKRAI, S.; SHEN, C.; ZHANG, J. Face Detection with Effective Feature Extraction. LNCS, n. 6494, Computer Vision - ACCV, p. 460-470, 2010. 
PANTIC, M.; PATRAS, I. Dynamics of facial expression: recognition of facial actions and their temporal segments from face profile image sequences. IEEE Transactions on Systems, Man, and Cybernetics, v. 36, n. 2, Part B, p. 433-449, 2006.

PANTIC, M.; ROTHKRANTZ, L. J. M. Expert system for automatic analysis of facial expression. Image and Vision Computing, n. 18, p. 881-905, 2000.

PHP: Hypertext Preprocessor. Disponível em: <https://www.php.net/>. Acesso em: 16 fev. 2015.

PICARD, R. W. Affective Computing. M. I. T. - Media Laboratory Perceptual Computing Section Technical Report, Cambridge, n. 321, p. 1-6, 1995.

PLUTCHIK, R. The Nature of Emotions. American Scientist, v. 89, n. 4, p. 344-350, Jul. 2001.

PORTAL BRASIL. Brasília. Disponível em: <http://www.brasil.gov.br/>. Acesso em: 16 fev. 2015.

PU, X. et al. Facial expression recognition from image sequences using twofold random forest classifier. Neurocomputing, v. 168, p. 1173-1180, 2015.

QUE FALA! Disponível em: <http://www.quefala.com.br/>. Acesso em: 15 dez. 2013.

RAKESH, R. R.; CHAUDHURI, P.; MURTHY, C. A. Thresholding in Edge Detection: A Statistical Approach. IEEE Transactions On Image Processing, v. 13, n. 7, p. 927-936, Jul. 2004.

RATNER, C. A social constructionist critique of naturalistic theories of emotion. Journal of Mind and Behavior, v. 10, p. 211-230, 1989.

REALEYESIT Disponível em: <https://www.realeyesit.com> Acesso em: 01 out. 2015.

RUS, G. G. 3.8.5. Rebus. Instituto Superior de Formación y Recursos en Red para el Profesorado. Disponível em: <http://ares.cnice.mec.es/informes/18/contenidos/95.htm\#up>. Acesso em: 15 dez. 2015.

RUSSELL, J. A. A circumplex model of affect. Journal of Personality and Social Psychology, n. 39, p. 1161-1178, 1980.

SANCHEZ, J. A. et al. An extensible platform for seamless integration and management of applications for emotion sensing and interpretation. Journal Of Ambient Intelligence And Smart Environments, v. 7, n. 1, p. 5-19, 2015a.

SANCHEZ, W. et al. Inferring loneliness levels in older adults from smartphones. Journal of Ambient Intelligence and Smart Environments - Affect Aware Ubiquitous Computing archive, v. 7, n. 1, p. 85-98, jan. 2015b. 
SARAGIH, J. M.; LUCEY, S.; COHN, J, F. Deformable Model Fitting by Regularized Landmark Mean-Shift. International Journal of Computer Vision, v. 91, n. 2, p. 200-215, jan. 2011.

SARTORETTO; M. L.; BERSCH, R. O que é tecnologia assistiva?. 2014a. Disponível em: <http://www.assistiva.com.br/tassistiva.html>. Acesso em 15 dez. 2015.

SARTORETTO; M. L.; BERSCH, R. O que é a comunicação alternativa?. 2014b. Disponível em: <http://www.assistiva.com.br/ca.html>. Acesso em 15 dez. 2015.

SATO, W.; YOSHIKAWA, S. Emotional elicitation by dynamic facial expression. In: 4th IEEE International Conference on Development and Learning, 2005, Osaka. Proceedings... Osaka: IEEE, 2005. p. 170-174.

SAWANGSRI, T.; PATANAVIJIT, V.; JITAPUNKUL, S. Face segmentation using novel skin-color map and morphological technique. World Academy of Science, Engineering and Technology, v. 2, p. 534-537, 2007.

SCHERER, K. R. On the nature and function of emotion: A component process approach. In: SCHERER, K. R.; EKMAN, P. (Eds.). Approaches to emotion. Hillsdale, NJ: Erlbaum, 1984a. p. 293-317.

SCHERER, K. R. Emotion as a multi-component process: A model and some cross-cultural data. In: Shaver, P. Review of personality and social psychology. Emotions, relationships and health. v. 5. Beverly Hills, CA: Sage, 1984b. p.37-63.

SCHERER, K. R. Toward a dynamic theory of emotion: The component process model of affective states. Geneva Studies in Emotion and Communication, v. 1, 1-98, 1987.

SCHIRMER, C. R. et al. Atendimento Educacional Especializado para Alunos com Deficiência Física. Brasília: Moderna, 2007.

SCHOOL OF COMPUTER SCIENCE. Disponível em: <http://www2.cs.cmu.edu/afs/cs/project/face/www/facs.htm>. Acesso em: $28 \mathrm{dez} .2011$.

SCREENCASTIFY. Disponível em: <https://www.screencastify.com>. Acesso em: 3 fev. 2015.

SEBE, N. et. al. Emotion Recognition Based on Joint Visual and Audio Cues. In: 18th International Conference on Pattern Recognition (ICPR'06), 2006, Hong-Kong. Proceedings... San Francisco, CA: IEEE, 2006. p. 1136-1139.

SECONDLIFE. Disponível em: <http://secondlife.com>. Acesso em: 22 ago. 2011.

SIGHTCORP. Amsterdam. Disponível em: <http://sightcorp.com/>. Acesso em: $1^{\circ}$ out. 2015.

SIMÕES, E. A. Q; TIEDEMANN, K. Psicologia da Percepção. São Paulo: EPU, 1985. 1 v.

SIMON, H. A. Motivational and Emotional Controls os Cognition. Psychological Review, v. 74, n. 1, p. 29-39, 1967. 
SIVIERO, E. K. O papel da ginástica terapêutica chinesa lian gong em 18 terapias no comportamento psicomotor e cotidiano de praticantes adultos. 2004. 254 p. Dissertação (Mestrado) - Universidade Estadual Paulista, Rio Claro, 2004.

SMITH, P.; LOBO, N. V.; SHAH, M. Temporalboost for event recognition. In: Tenth IEEE International Conference on Computer Vision (ICCV), 1., 2005, Washington. Proceedings... San Francisco, CA: IEEE, 2005. p. 733-740.

SORCI, M. et al. Modelling human perception of static facial expressions. Image and Vision Computing, v. 28, p. 790-806, 2010.

SORCI, M. et al. Modelling human perception of static facial expressions. In: 8th IEEE International Conference on Automatic Face \& Gesture Recognition (FG '08), 2008, Amsterdam. Proceedings... San Francisco, CA: IEEE, 2008. p. 1-8.

SORCI, M. et al. Modelling human perception of static facial expressions. Image and Vision Computing, v. 28, p. 790-806, 2010.

STAROSTENKO, O. et. al. Unobtrusive emotion sensing and interpretation in smart environment. Journal of Ambient Intelligence and Smart Environments - Affect Aware Ubiquitous Computing archive, v. 7, n. 1, p. 59-83, Jan. 2015.

SYMBOLWORLD. Carol for Christmas. Disponível em: <http://symbolworld.org/articles/2378-Carol-for-Christmas>. Acesso em: 15 dez. 2015.

SUN, Y. et al. Authentic Emotion Detection in Real-Time Video. Computer Vision in Human-Computer Interaction, HCI/ECCV, p. 94-104, 2004.

TANVEER, I. Eigenface based Facial Expression Classification. Disponível em: $<$ http://www.mathworks.com/matlabcentral/fileexchange/33325-eigenface-based-facialexpression-classification>. Acesso em: 17 mar. 2011.

TAO, H.; HUANG, T. Connected vibrations: A modal analysis approach to non-rigid motion tracking. In: IEEE Computer Society Conference on Computer Vision and Pattern Recognition, 1998, Santa Barbara. Proceedings... San Francisco, CA: IEEE, 1998. p. 735-740.

TIAN, Y. KANADE, T. COHN, J. F. Recognizing Action Units for Facial Expression Analisis. IEEE Transactions on Pattern Analysis and Machine Intelligence, v. 23 n. 2, p. 97-115, 2001.

TIAN, Y.; KANADE, T.; COHN, J. F. Evaluation of gabor-wavelet-based facial action unit recognition in image sequences of increasing complexity. In: Fifth IEEE International Conference on Automatic Face and Gesture Recognition, 2002, Washington. Proceedings... San Francisco, CA: IEEE, 2002. p. 229-234.

TOMKINS, S. S. Affect Imagery Consciousness. Volume I - The Positive Affects. New York: Edward Brothers, 2008. 
TOOBY, J.; COSMIDES, L. The past explains the present: Emotional adaptations and the structure of ancestral environments. Ethology and Sociobiology, v. 11, p. 407-424, 1990.

TORRES, L.; REUTTER, J. Y.; LORENTE, L. The importance of the color information in face recognition. In: IEEE International Conference on Image Processing (ICIP'99), 1999, Kobe. Proceedings... San Francisco, CA: IEEE, 1999. p.627-631, v. 3.

TOVEE, M. J. Is face Processing Special? Neuron, v. 21, p. 1239-1242, 1998.

TURK, M. A.; PENTLAND, A. P. Eigenfaces for Recognition. Journal of cognitive neuroscience, v. 3, n. 1, p. 71-86, 1991.

VAPNIK, V. Statistical Learning Theory. New York: John Wiley and Sons, 1998.

VALSTAR, M.; PANTIC, M. Fully automatic facial action unit detection and temporal analysis. In: Conference on Computer Vision and Pattern Recognition Workshop (CVPRW’06), 2006. Proceedings... San Francisco, CA: IEEE, 2006. p. 149.

VALSTAR, M.F.; PANTIC, M. COMBINED support vector machines and hidden markov models for modeling facial action temporal dynamics. LNCS, n. 4796, ICCV-HCI, p. 118$127,2007$.

VERZONI, L. D. N. Bliss e PCS: Sistemas Alternativos de Comunicação. Bengala Legal. 2011. Disponível em: <http://www.bengalalegal.com/bliss-e-pcs>. Acesso em: 15 dez. 2015.

VICARVISION. Disponível em: <http://www.vicarvision.nl/>. Acesso em: $1^{\text {o }}$ out. 2015.

VIOLA, P.; JONES, M. Rapid Object Detection Using aBoosted Cascade of Simple Features. In: Conference on Computer Vision and Pattern Recognition, 2001, United States. Proceedings... San Francisco, CA: IEEE, 2001. p . 511-518.

VIOLA, P.; JONES, M.; SNOW D. Detecting Pedestrians Using Patterns of Motion and Appearance. In: Ninth IEEE International Conference on Computer Vision, 2003, Nice, France. Proceedings... San Francisco, CA: IEEE, 2003. p.1-8.

VISUAL RECOGNITION. Amsterdam. Disponível em: <http://www.visual-recognition.nl>. Acesso em: 22 ago. 2011.

VYGOTSKY, L. S. Thought and Language. Cambridge, MA: MIT Press, 1962.

W3C. HTML5 - A vocabulary and associated APIs for HTML and XHTML. Disponível em: <http://www.w3.org/TR/html5/> Acesso em: 16 fev. 2015a.

W3C. Emotion Markup Language (EmotionML) 1.0. Disponível em: <http://www.w3.org/TR/emotionml/>. Acesso em: 16 fev. 2015b.

W3C. Cascading Style Sheets Level 2 Revision 1 (CSS 2.1) Specification. Disponível em: <http://www.w3.org/TR/CSS2/>. Acesso em: 16 fev. 2015c. 
W3C. Web Speech API Specification. Disponível em: <https://dvcs.w3.org/hg/speechapi/raw-file/tip/speechapi.html>. Acesso em: 16 fev. 2015d.

WIKIMEDIA

COMMONS.

Disponível

em: <https://commons.wikimedia.org/wiki/File:Guillaume_Duchenne_de_Boulogne_performing_ facial_electrostimulus_experiments_(3).jpg>. Acesso em: 15 dez. 2014.

WU, T., BARTLETT, M. S.; MOVELLAN, J. Facial expression recognition using gabor motion energy filters. In: IEEE Conference on Computer Vision and Pattern Recognition Workshops, 2010. San Francisco. Proceedings... San Francisco, CA: IEEE, 2010. p. 42-47.

XIONG, X.; DE LA TORRE, F. Supervised Descent Method and Its Applications to Face Alignment. In IEEE Conference on Computer Vision and Pattern Recognition (CVPR), 2013, Portland. Proceedings... San Francisco, CA: IEEE, 2013. p. 532-539.

YE, J.; ZHAN, Y.; SONG, S. Facial expression features extraction based on gabor wavelet transformation. In: IEEE International Conference on Systems, Man and Cybernetics, 2004. Proceedings... San Francisco, CA: IEEE, 2004. p. 2215- 2219, vol.3.

YOKOYAMA, T.; WU, H.; YACHIDA, M. Automatic detection of facial feature points and contours. In: IEEE international Workshop on Robot and Human

Communication, 1996, Tsukuba. Proceedings... San Francisco, CA: IEEE, 1996. p. 335- 340.

YUCE, A., SORCI, M. THIRAN, J.-P. Improved local binary pattern based action unit detection using morphological and bilateral filters. In: 10th IEEE International Conference and Workshops on Automatic Face and Gesture Recognition (FG), 2013, Shanghai. Proceedings... San Francisco, CA: IEEE, 2013. p. 1-7.

ZAFEIRIOU, S.; ZHANG, C.; ZHANG, Z. A Survey on Face Detection in the wild: past, present and future. Computer Vision and Image Understanding, v. 138, p. 1-24, Sep. 2015.

ZATEPYAKIN, E. JSFeat - JavaScript Computer Vision library. Disponível em: <https://github.com/inspirit/jsfeat>. Acesso em: 16 dez. 2014.

ZENG, Z. et al. A Survey of Affect Recognition Methods: Audio, Visual, and Spontaneous Expressions. IEEE Trans. Pattern Analysis and Machine Intelligence, v. 31, n. 1, p. 39-58, Jan. 2009.

ZHANG, F.; GAO, Y. BAKOS, J. D. Lucas-Kanade Optical Flow Estimation on the TI C66x Digital Signal Processor. In: IEEE High Performance Extreme Computing Confererece (HPEC), 2014, Waltham. Proceedings... San Francisco, CA: IEEE, 2014. p. 1-6

ZHANG, Y.; JI, Q. Active and dynamic information fusion for facial expression understanding from image sequences. IEEE Transactions on Pattern Analysis and Machine Intelligence, v. 27, n. 5, p. 699-714, 2005.

ZHANG, Z. et al. Comparison between geometry- based and gabor-wavelets-based facial expression recognition using multi-layer perceptron. In: 3rd International Conference on Face \& Gesture Recognition (FG'98), 1998, Nara. Proceedings... San Francisco, CA: IEEE, 1998. p. 454-459. 
ZHAO, K. et al. Joint Patch and Multi-label Learning for Facial Action Unit Detection. In: IEEE Conference on Computer Vision and Pattern Recognition (CVPR), 2015, Boston. Proceedings... San Francisco, CA: IEEE, 2015. p. 2207-2216. 
Apêndice A

Tabela de AUs

Tabela A.1 - Unidades de Ação (AUs - Action Units) individuais.

\begin{tabular}{|l|l|l|l|}
\hline AU & Músculo & Ação Principal & Imagem de Exemplo \\
\hline 0 & & Face Neutra. & \\
\hline 1 & Frontal (parte interna). & Levantar a parte interna da sobrancelha. & \\
\hline
\end{tabular}




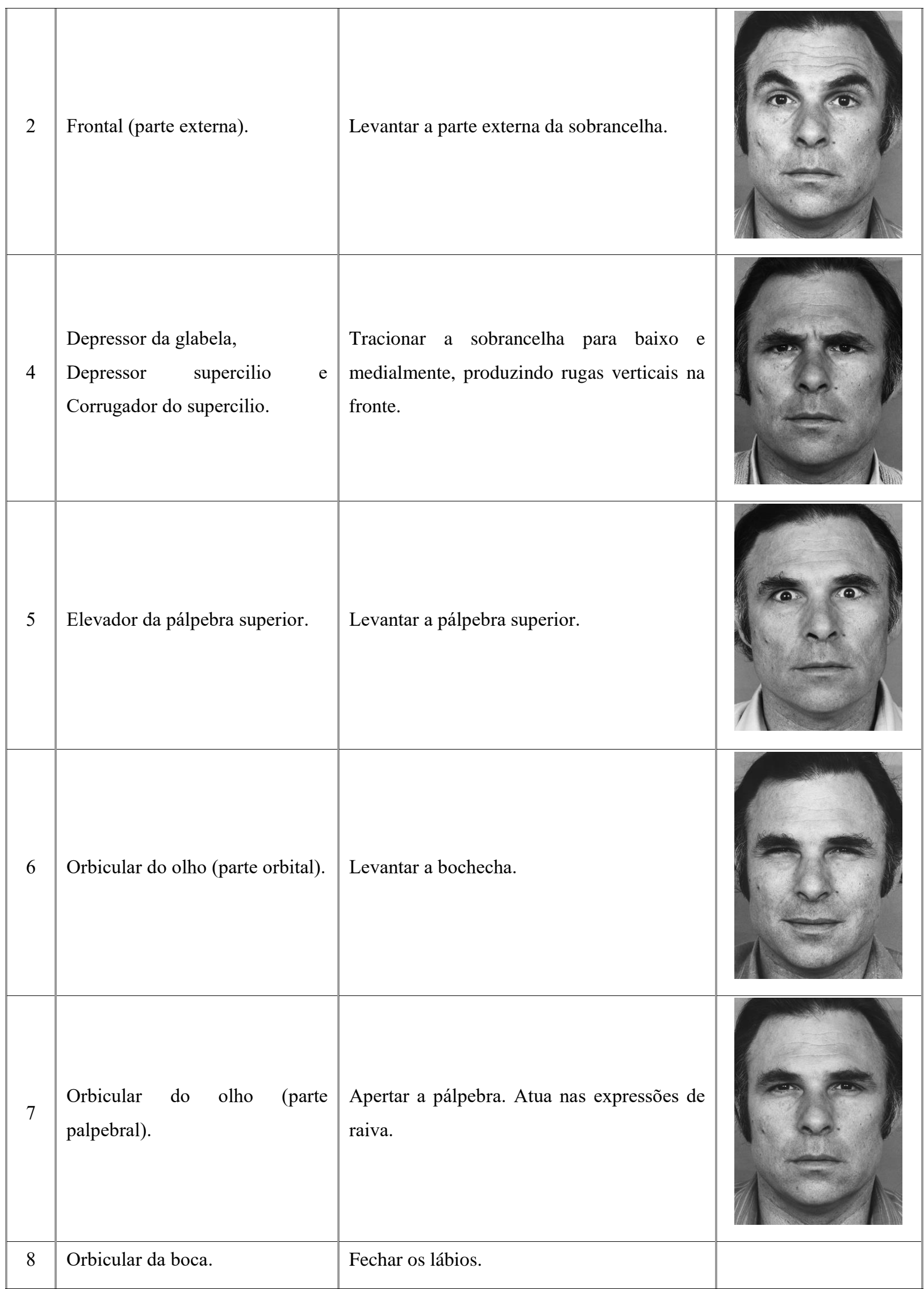




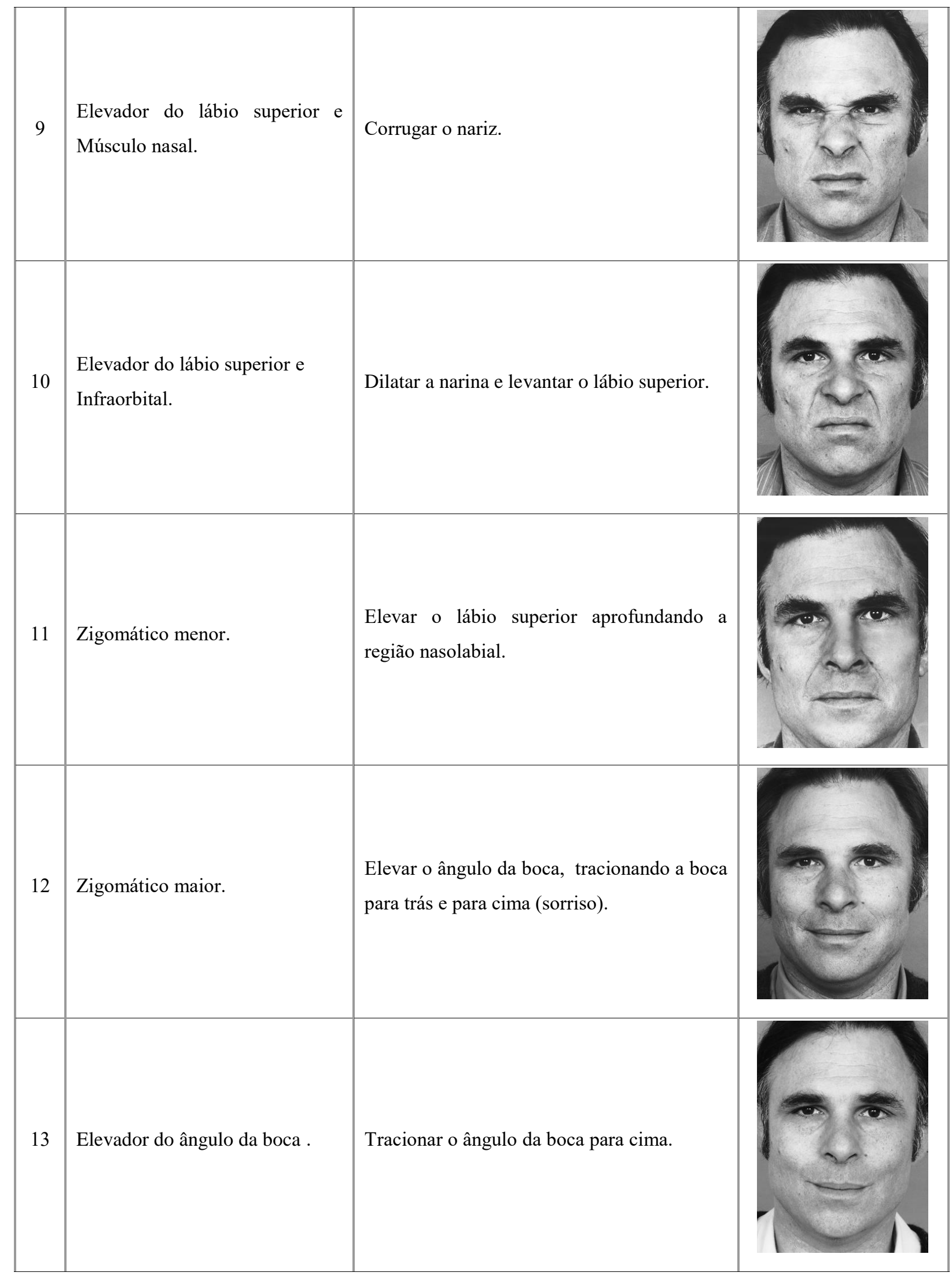




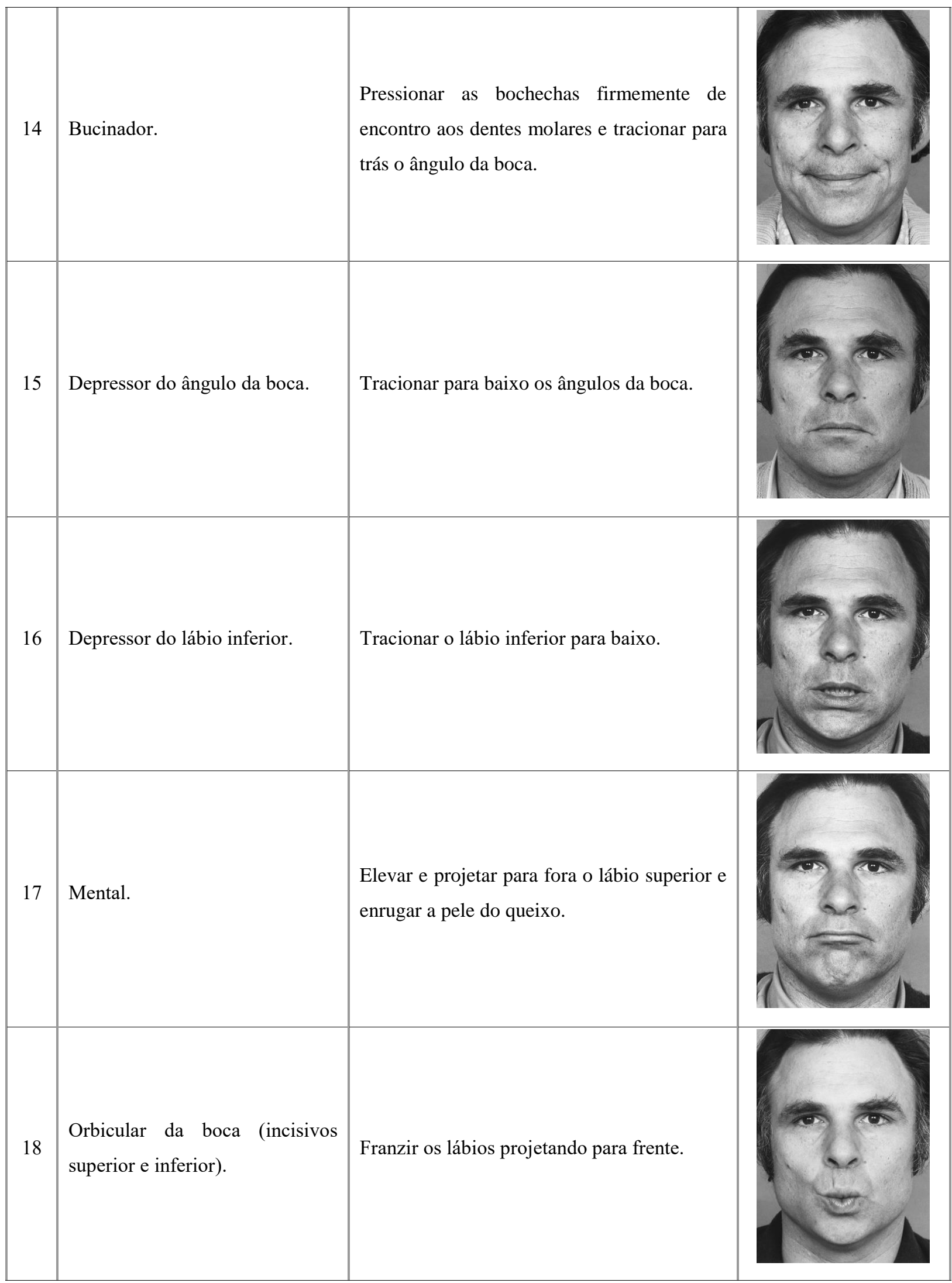




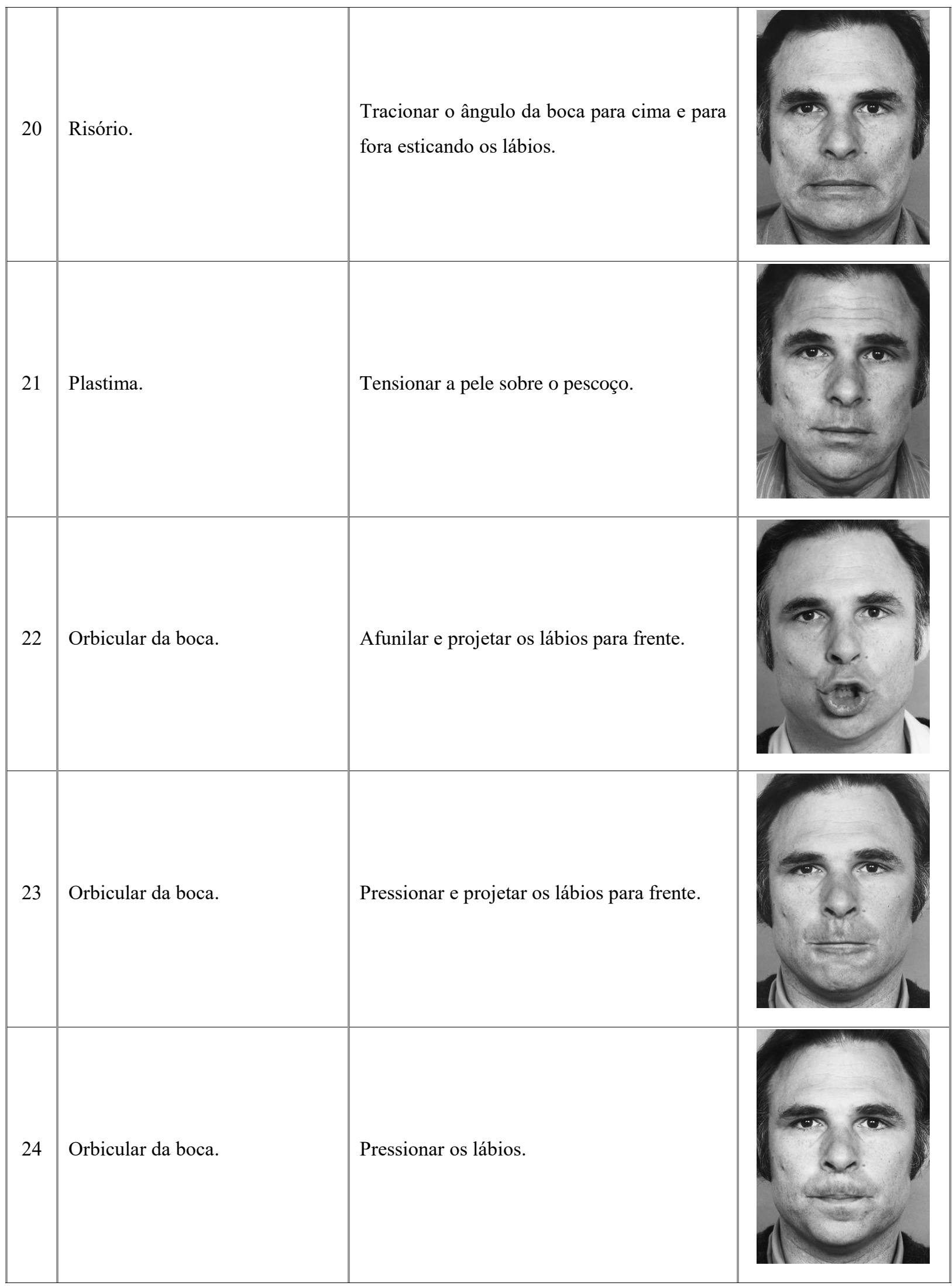




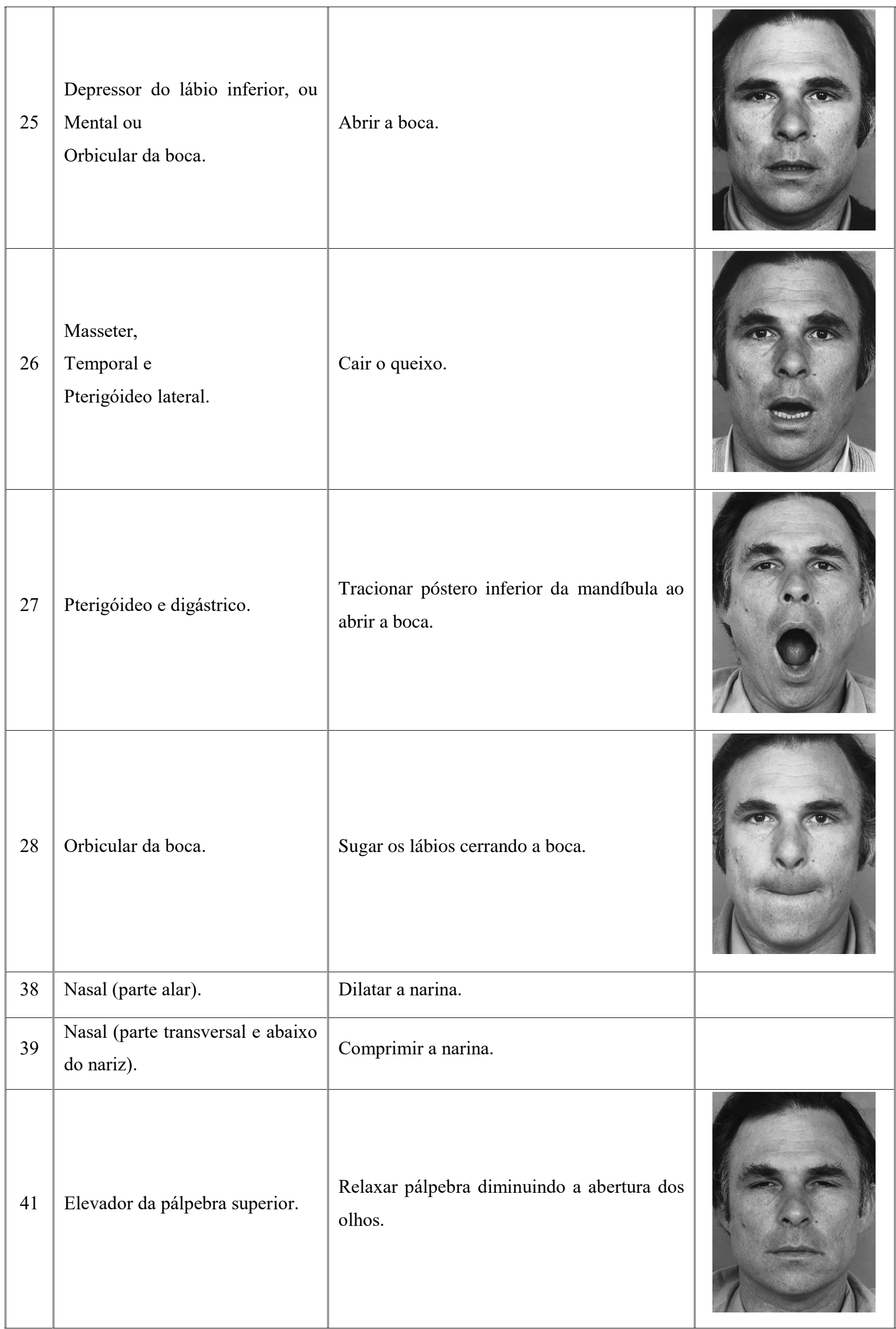




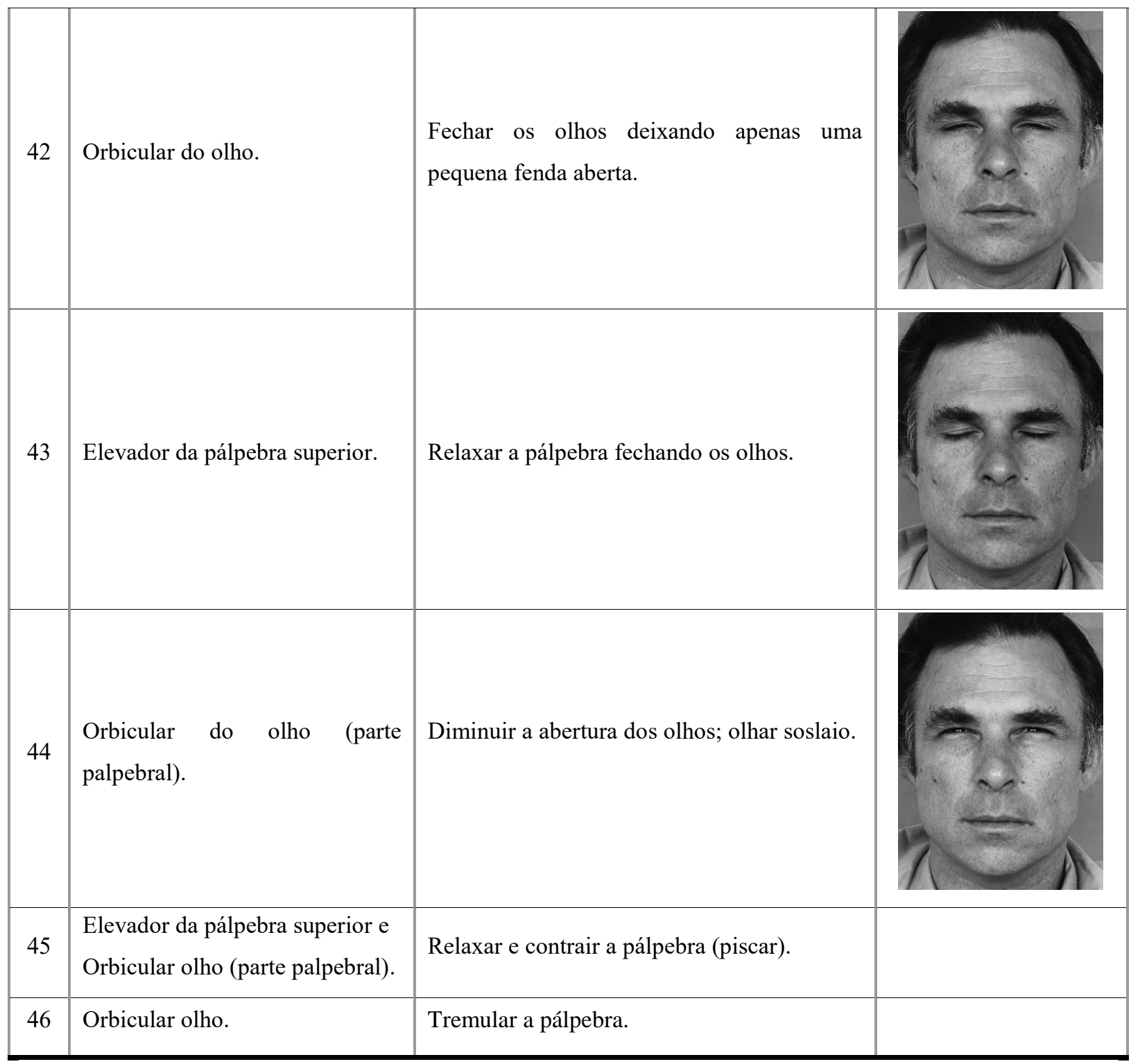

Fonte: Adaptado de Ekman e Friesen (1978).

Tabela A.2 - Outras Unidades de Ação (AUs - Action Units).

\begin{tabular}{|l|l|l|}
\hline AU & Ação Principal & Imagem de Exemplo \\
\hline 19 & Mostrar a língua. & \\
\hline 21 & Tensionar o pescoço & \\
\hline 29 & Projetar a mandíbula para frente. & \\
\hline & & \\
\hline & & \\
\hline
\end{tabular}




\begin{tabular}{|l|l|l|}
\hline 31 & Apertar a mandíbula. & \\
\hline 32 & {$[$ Lábios] Morder. } & \\
\hline 33 & {$[$ Bochecha] Espirar. } & \\
\hline 34 & {$[$ Bochecha] Espirar e Inspirar rapidamente. } & \\
\hline 35 & [Bochecha] Sugar. & \\
\hline 36 & & \\
\hline 37 & Esfregar os lábios. & \\
\hline
\end{tabular}

Fonte: Adaptado de Ekman e Friesen (1978).

Tabela A.3 - Unidades de Ação (AUs - Action Units) referentes ao posicionamento da cabeça e olhos.

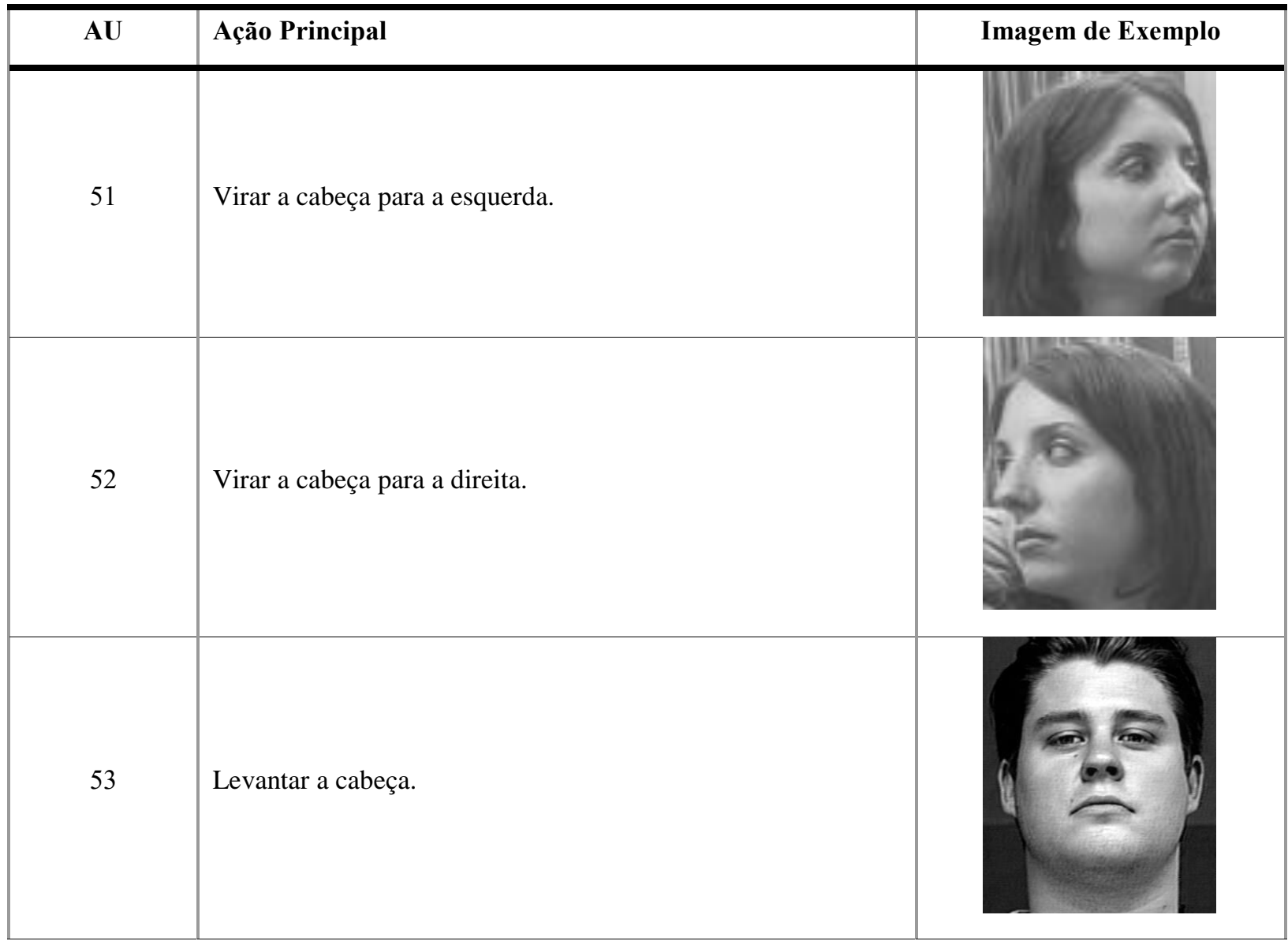




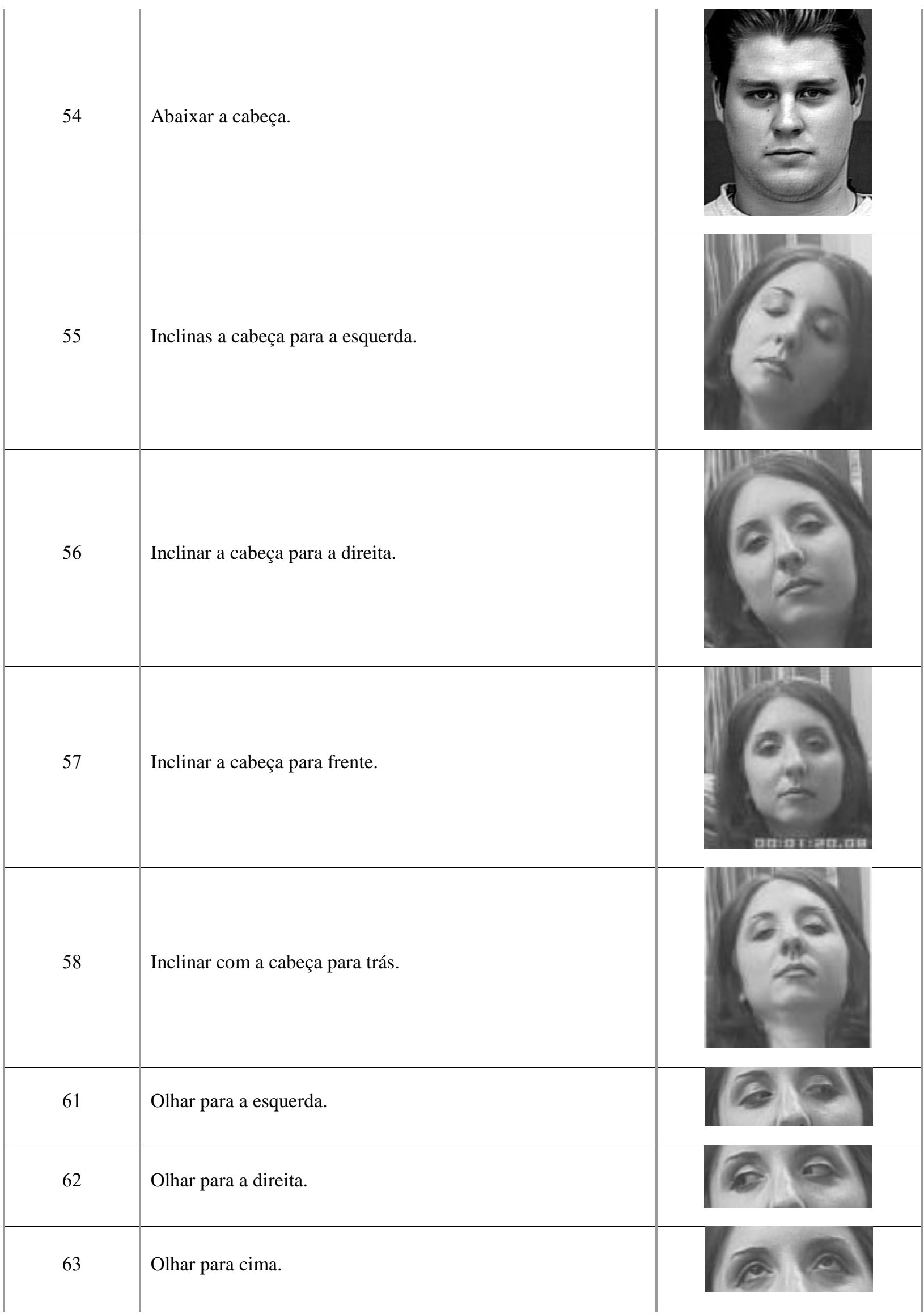




\begin{tabular}{|l|l|l|}
\hline 64 & Olhar para baixo. & \\
\hline
\end{tabular}

Fonte: Adaptado de Ekman e Friesen (1978) e School of Computer Science (2011). 
Anexo

I

\section{Wireframes e Detalhamento das Páginas da Prancha}

Tela: Home (Figura I.1).

Descrição: Esta tela disponibiliza três funcionalidades:

- Logar: Permite que os usuários cadastrados acessem a área restrita do site, sendo eles os administradores das pranchas de comunicação.

\section{Campos:}

- E-mail: recebe o e-mail de acesso do usuário.

- Senha: recebe a senha de acesso do usuário.

- Cadastrar: Permite o cadastramento de novos usuários administradores de pranchas de comunicação.

Campos:

- Nome Completo: recebe o nome completo do usuário.

- E-mail: recebe o e-mail do usuário.

- CPF: recebe um CPF válido.

- Senha: recebe a senha que o usuário deseja utilizar.

- Confirmar Senha: recebe a mesma senha do campo acima.

- Telefone: recebe o telefone residencial ou empresarial do usuário.

- Celular: recebe o celular do usuário.

- Esqueci Minha Senha: Permite recuperar a senha de um determinado usuário. 
Figura I.1 - Tela da Home Page.

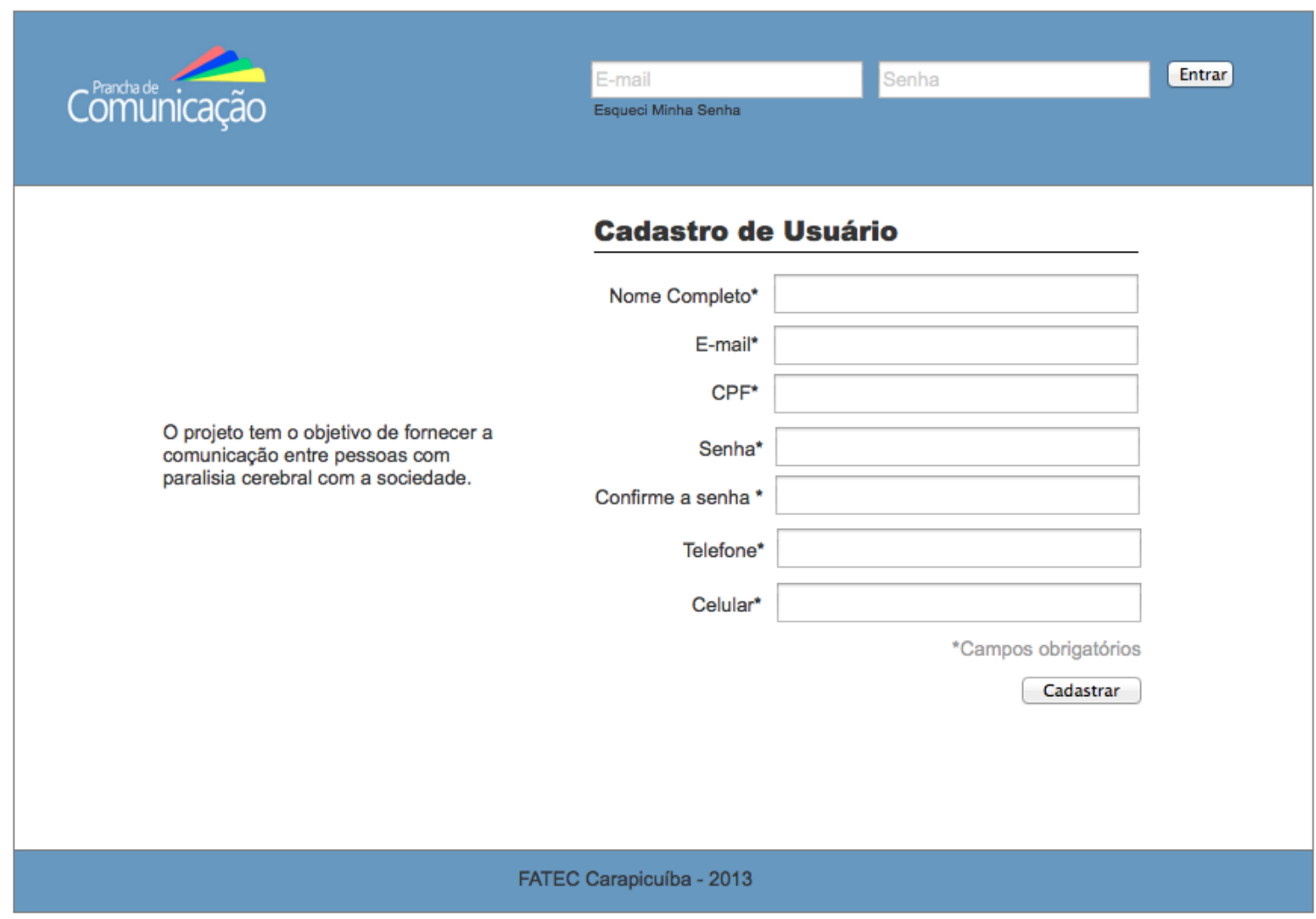

Fonte: Elaboração própria. 
Tela: Esqueci Minha Senha (Figura I.2).

Descrição: Fornece ao usuário a opção de recuperar a senha de acesso.

\section{Campos:}

- E-mail: recebe o e-mail de acesso ao site.

- Botão Enviar: aciona o envido de email de recuperação de senha.

- Botão Voltar: redireciona o usuário para a tela de login.

Figura I.2 - Esqueci minha senha.

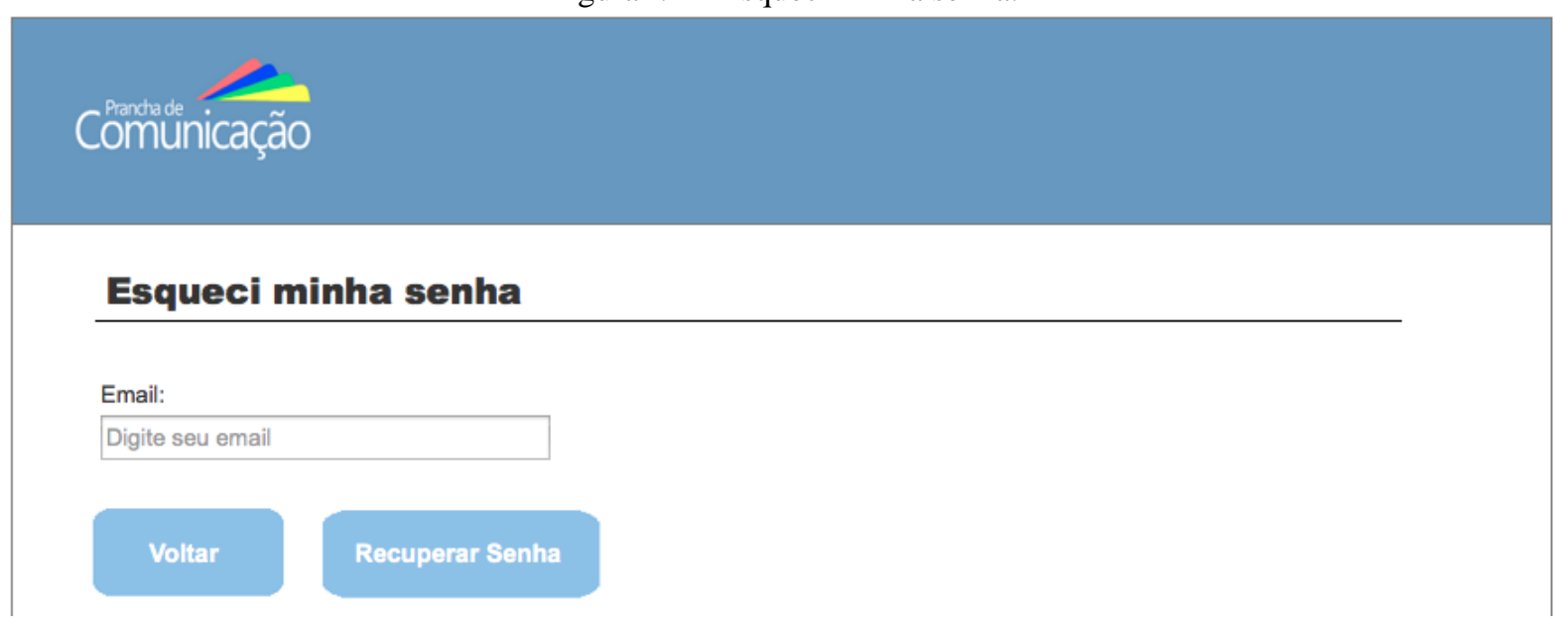

Fonte: Elaboração própria. 
Tela: Menu (Figura I.3).

Descrição: a tela de menu de acesso para usuários logados.

\section{Campos:}

- Botão Criar Pranchas: redireciona o usuário para a tela de criar nova prancha, onde pode ser criada uma prancha, organizada as imagens pré-definidas no sistema e realizado upload de novas imagens.

- Botão Minhas Pranchas: redireciona o usuário para a tela de minhas pranchas, nela haverá todas as pranchas criadas pelo usuário.

- Botão Cadastro de paciente: redireciona o usuário para tela de cadastro de paciente.

- Botão Meus Pacientes: redireciona o usuário para a tela de meus pacientes, onde encontra-se a lista de todos os pacientes cadastrados pelo usuário.

- Botão Tutoriais: redireciona o usuário para a tela de tutoriais.

Figura I.3 - Menu de usuários logados.

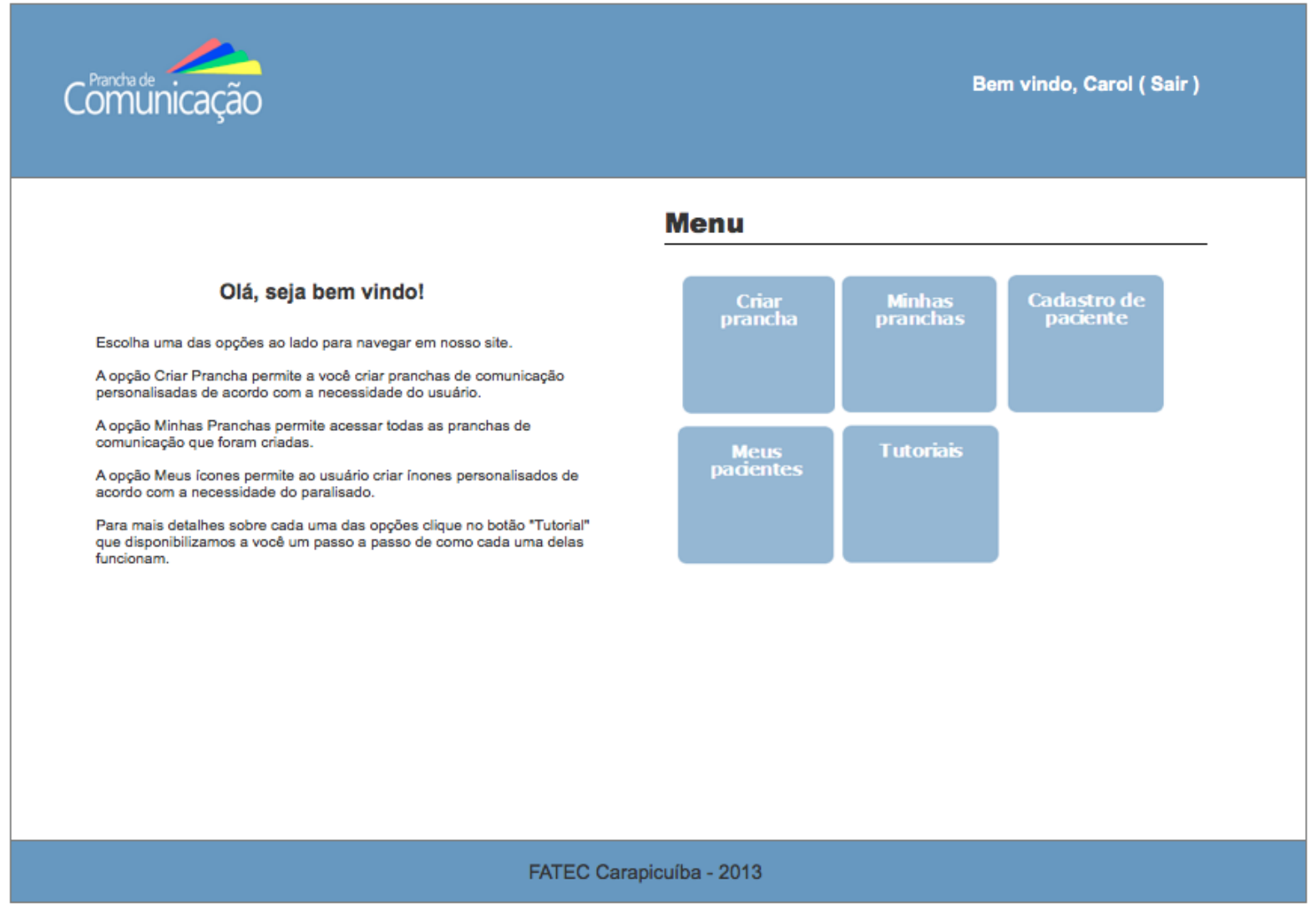

Fonte: Elaboração própria. 
Tela: Criar Prancha - Configurações (Figura I.4).

Descrição: permite criar novas pranchas para pacientes já cadastrados.

\section{Campos:}

- Nome da Prancha: recebe o nome da prancha.

- Paciente: permite a seleção do paciente para o qual está se criando uma prancha.

- Varredura: permite a seleção do tipo de varredura do sistema: vertical, horizontal e nenhuma.

- Velocidade da Varredura: permite configurar a velocidade da varredura caso a varredura esteja habilitada.

Figura I.4 - Criar prancha - Configurações.

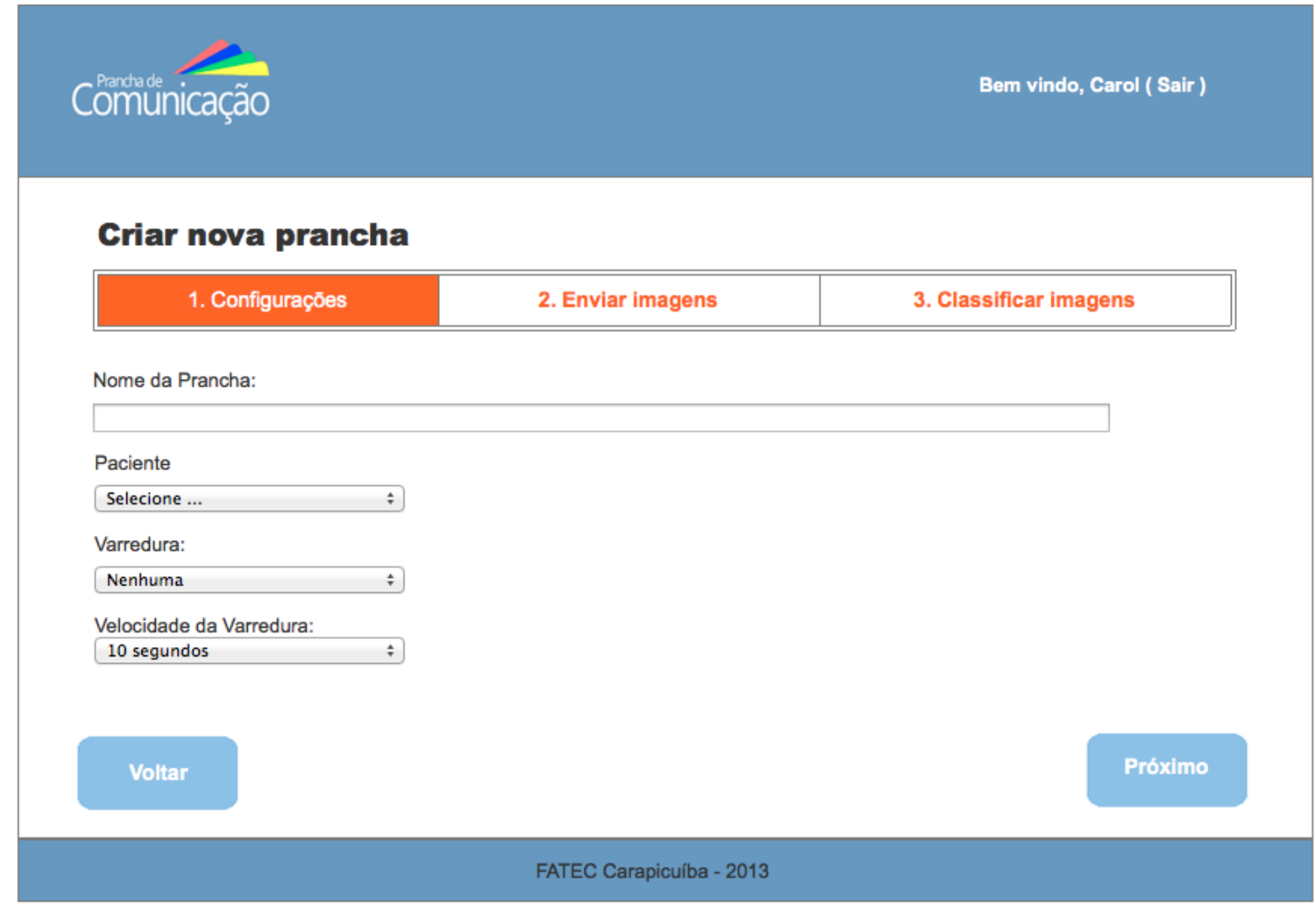

Fonte: Elaboração própria. 
Tela: Criar Prancha - Enviar Imagens (Figura I.5).

Descrição: permite o envio de imagens personalizadas para a prancha.

\section{Campos:}

- Botão procurar imagens: permite o upload de imagens do computador do usuário para o servidor web.

- Botão próximo: permite ao usuário continuar criando a prancha.

- Botão anterior: permite que ao usuário retorna para o passo "Configurações".

Figura I.5 - Criar prancha - Enviar imagens.

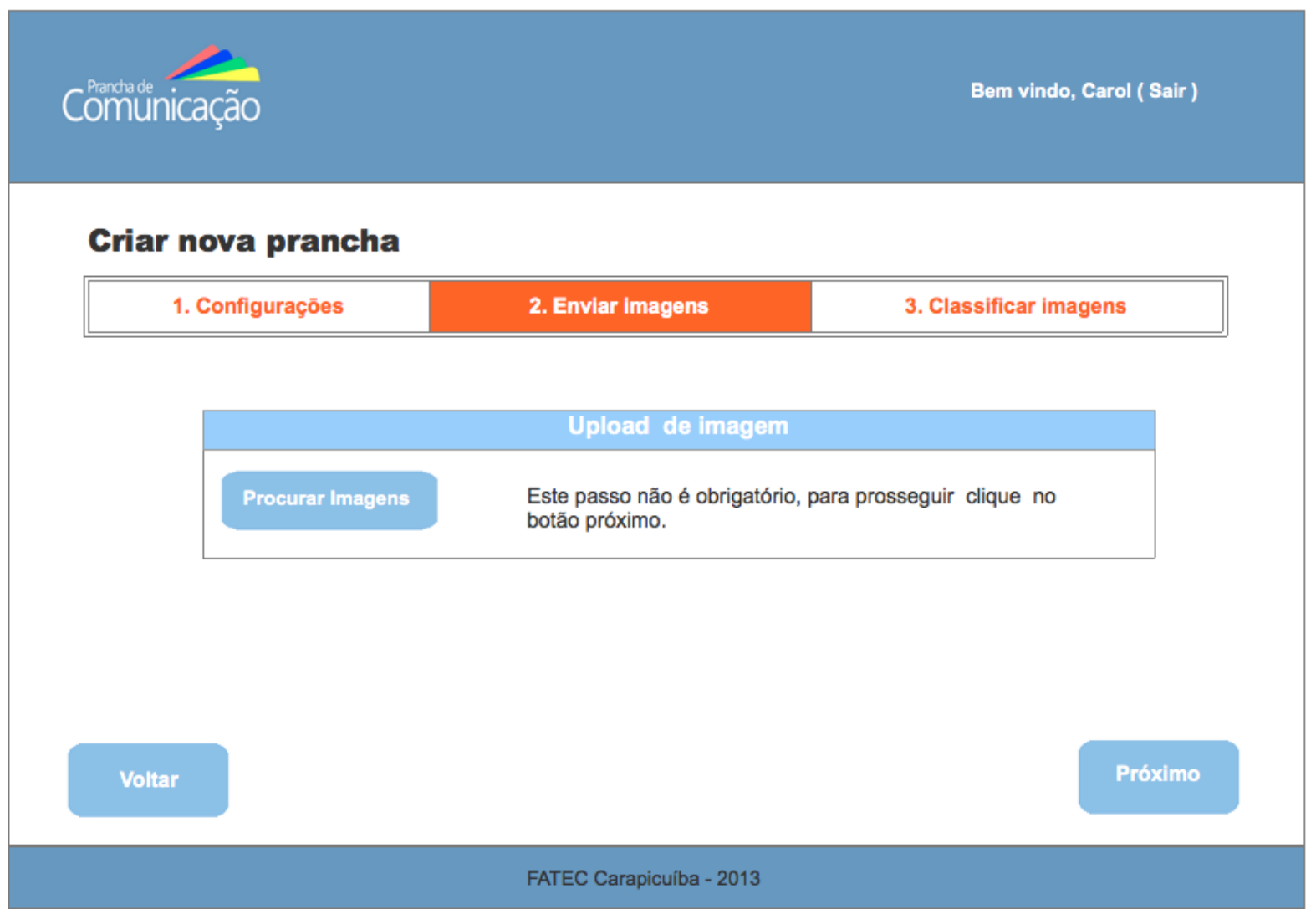

Fonte: Elaboração própria. 
Tela: Criar Prancha - Inserir imagem (Figura I.6).

Descrição: possibilita a adição de informações nas imagens do usuário, quando o mesmo fez o uso do recurso upload de imagens.

\section{Campos:}

- Upload de Imagem: campo para indicar o caminho da imagem.

- Nome do ícone: campo para informar o nome do ícone.

- Descrição: campo para informar a descrição da imagem.

- Recortar imagem: possibilita o ajuste da imagem.

- Botão enviar ícone para a prancha: realiza o envio da imagem personalizada para a área "Classificar imagens", próximo passo da criação da prancha.

- Botão próximo: permite ao usuário continuar a criação da prancha.

- Botão anterior : permite ao usuário retorna para as configurações.

Figura I.6 - Nova prancha: Inserir imagem.

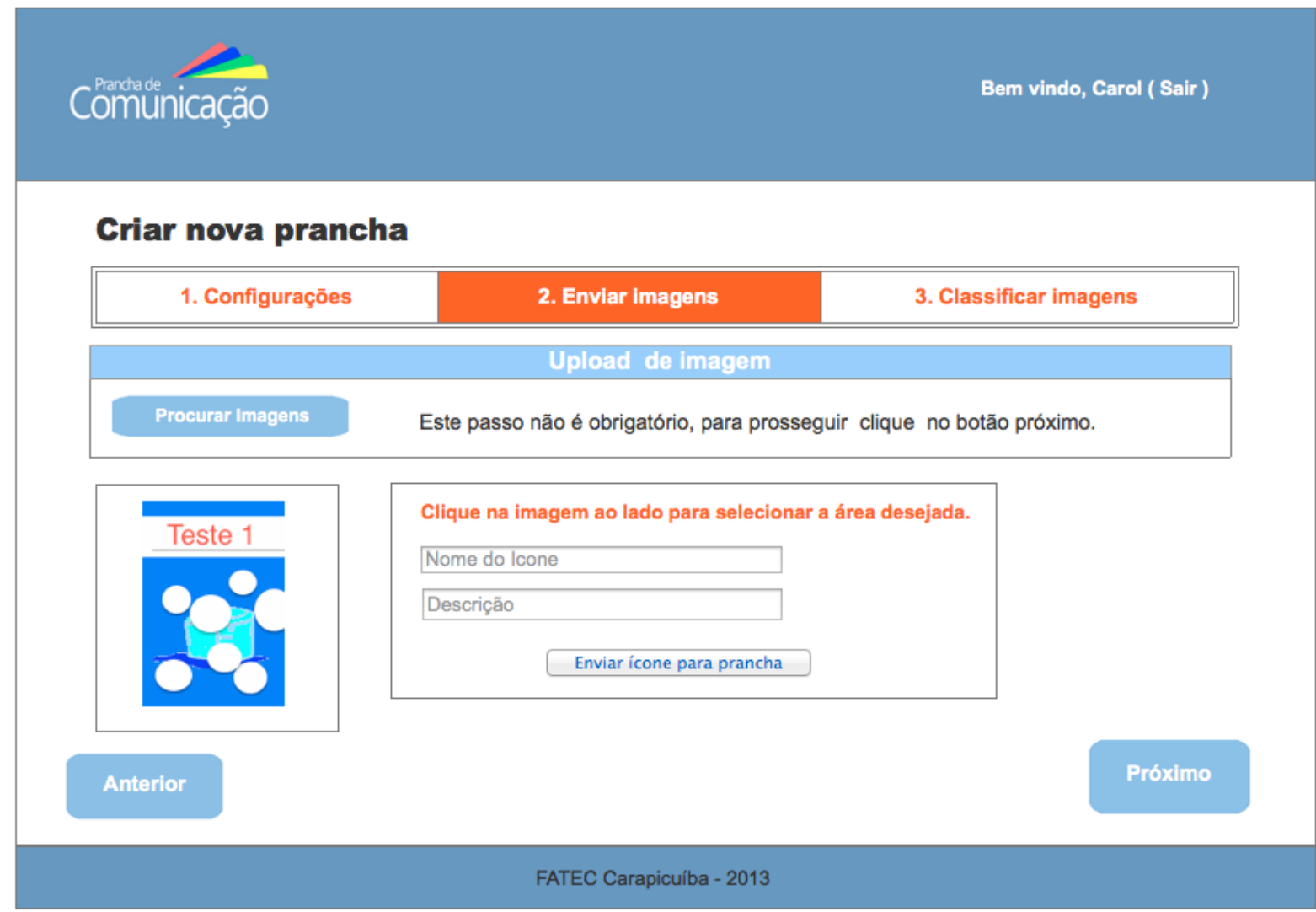

Fonte: Elaboração própria. 
Tela: Criar Prancha - Classificar imagens (Figura I.7).

Descrição: Permite ao usuário classificar as imagens que fez upload.

\section{Campos:}

- Não Classificados: local das imagens fornecidas pelo usuário (upload).

- Campos de Classificação: fornece 6 categorias: 'Adjetivos', 'Conjunções', 'Expressões', 'Pronomes', 'Substantivos', 'Verbos'. Cada uma possui as imagens padrões do sistema e podem ser acrescidas das imagens fornecidas pelo usuário.

- Botão Anterior: permite ao usuário retornar para a tela de "Enviar imagens".

- Botão finalizar: permite ao usuário salvar a prancha.

- Botão visualizar ${ }^{\oplus}$ : permite ao usuário visualizar a imagem do ícone.

- Botão deletar 亩 : permite ao usuário deletar um ícone da prancha.

- Botão Classificar : permite ao usuário classificar suas imagens personalizadas.

Figura I.7 - Criar prancha: Classificar imagens.

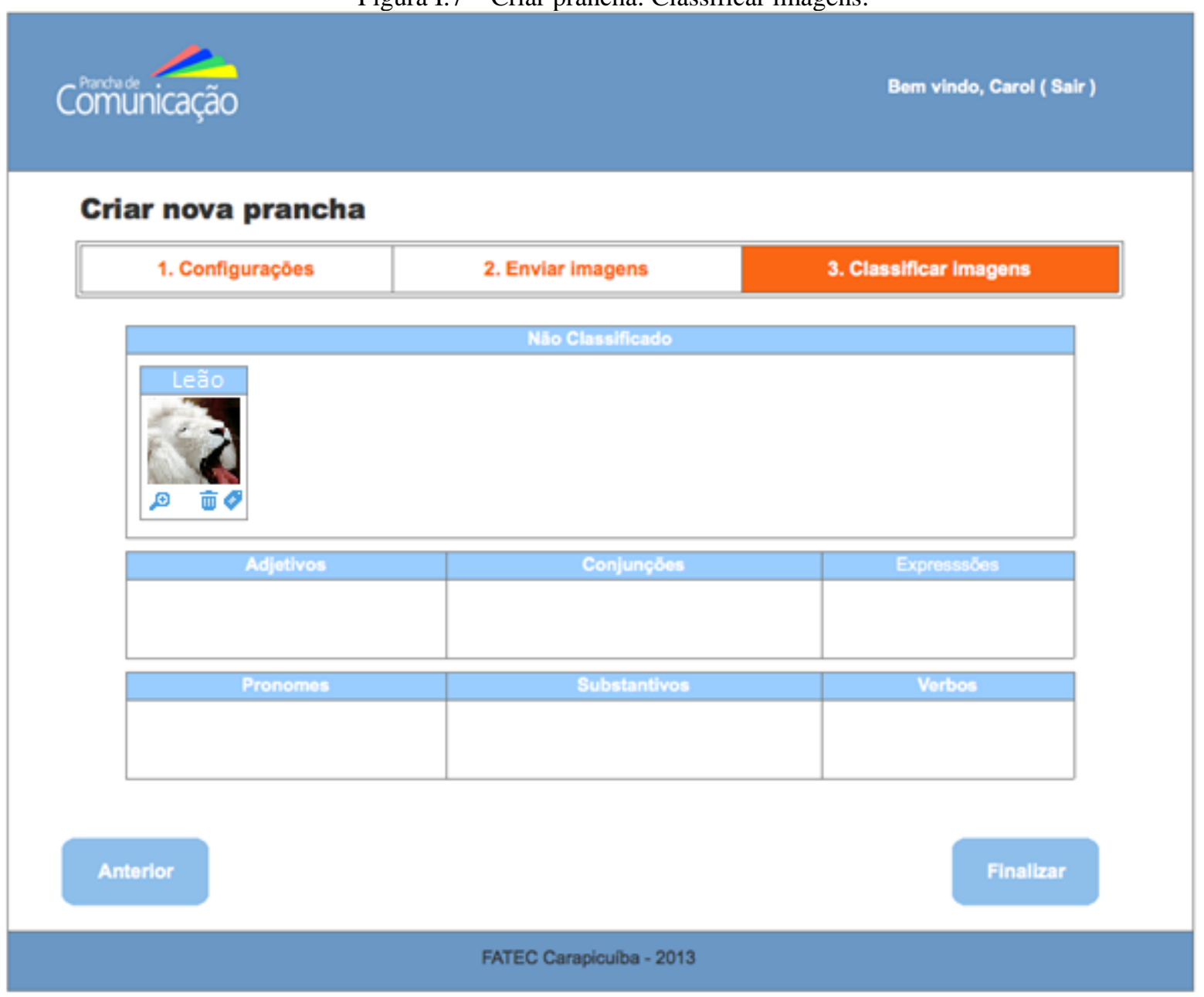

Fonte: Elaboração própria. 
Tela: Minhas pranchas (Figura I.8).

Descrição: exibe todas as pranchas de um usuário, possibilitando o gerenciamento das mesmas ou criar nova prancha.

\section{Campos:}

- Grid de pranchas: contém as colunas: 'nome', 'varredura', 'velocidade', 'URL' e 'Criado em'. Possibilita ao usuário buscar uma determinada prancha por meio de filtros e ordenações.

- Botão Editar: permite a edição de uma prancha.

- Botão Excluir: permite a exclusão de uma prancha.

- Botão Nova Prancha: permite criar nova prancha

- Botão Voltar: permite o usuário voltar ao menu.

Figura I.8 - Minhas pranchas.

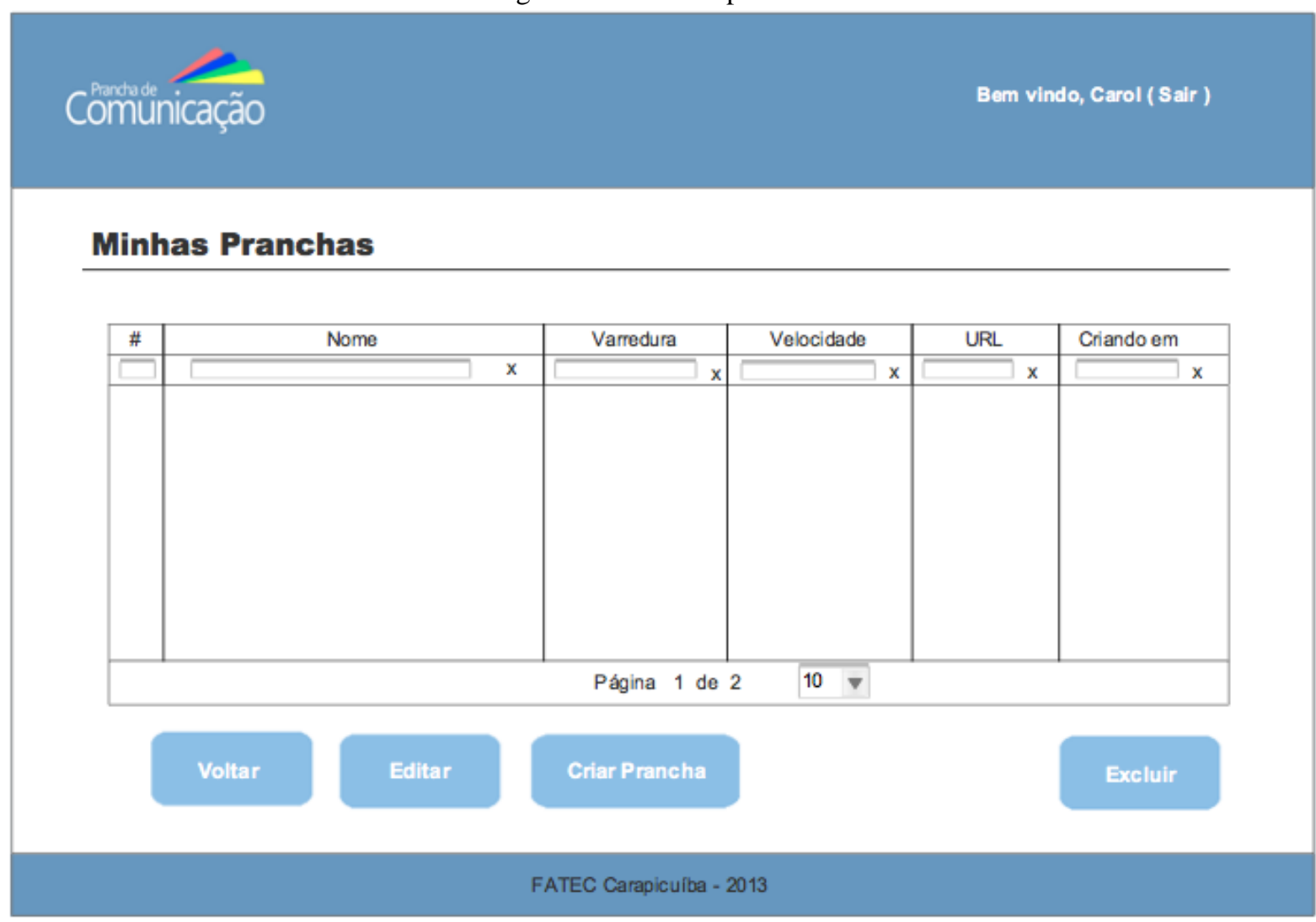

Fonte: Elaboração própria. 
Tela: Cadastro de Paciente (Figura I.9).

Descrição: permite ao usuário realizar o cadastro de pacientes no sistema.

\section{Campos:}

- Nome: recebe o nome do paciente.

- Grau de instrução: recebe o grau de instrução do paciente.

- Data de nascimento: recebe a data de nascimento do paciente.

- Botão Criar prancha: redireciona para a tela "Criar prancha" com o paciente cadastrado selecionado.

Figura I.9 - Cadastro de paciente.

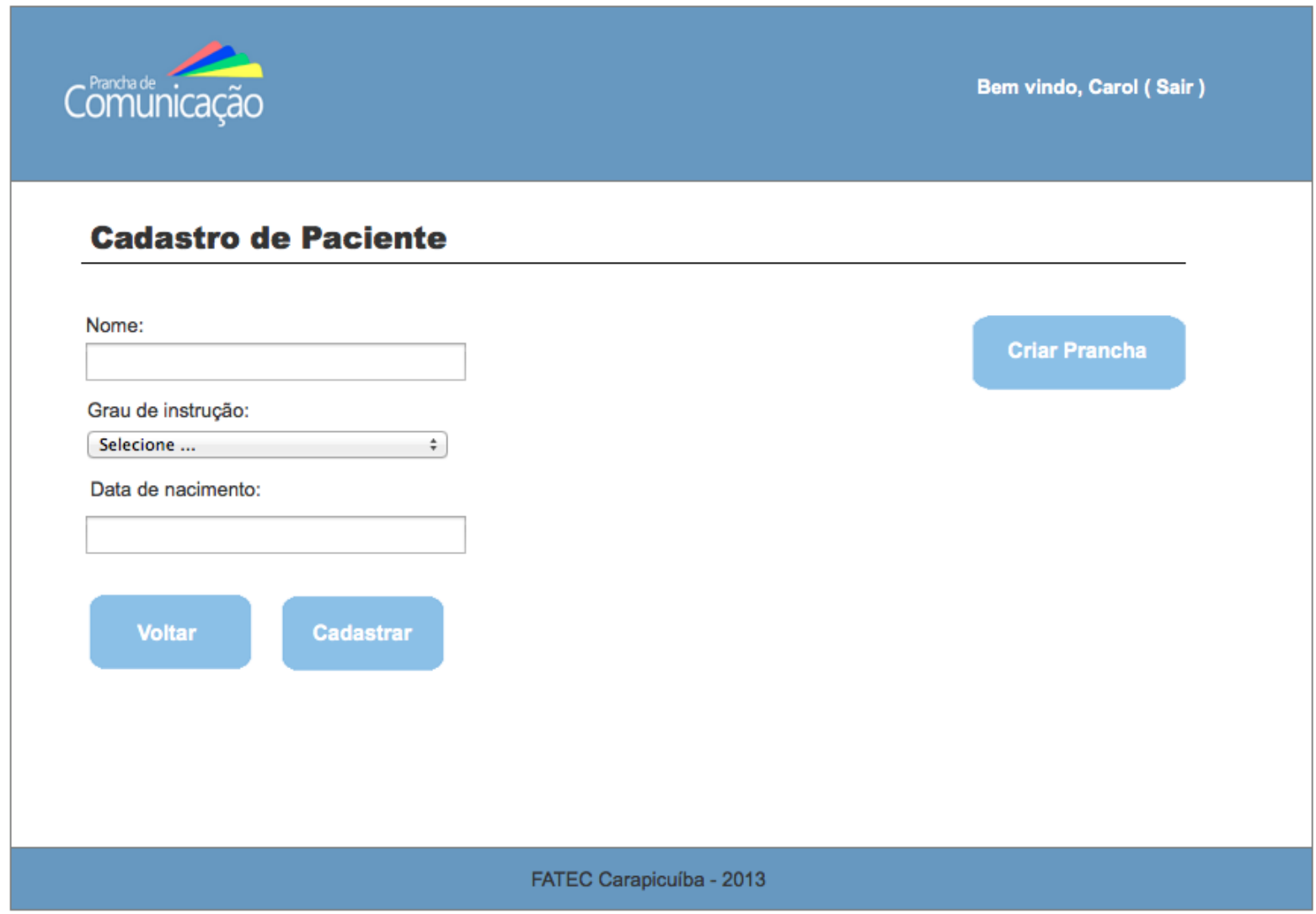

Fonte: Elaboração própria. 
Tela: Meus Pacientes (Figura I.10).

Descrição: exibe uma tabela contendo todos os pacientes que o usuário possui, permitindo o gerenciamento desses pacientes e o cadastro de novos.

\section{Campos:}

- Botão Editar: permite ao usuário a edição dos dados do paciente.

- Botão Excluir: permite ao usuário a exclusão do paciente.

- Botão Nova Prancha: permite ao usuário gerar nova prancha para o paciente

- Botão Voltar: permite ao usuário voltar para o menu.

Figura I.10 - Meus pacientes.

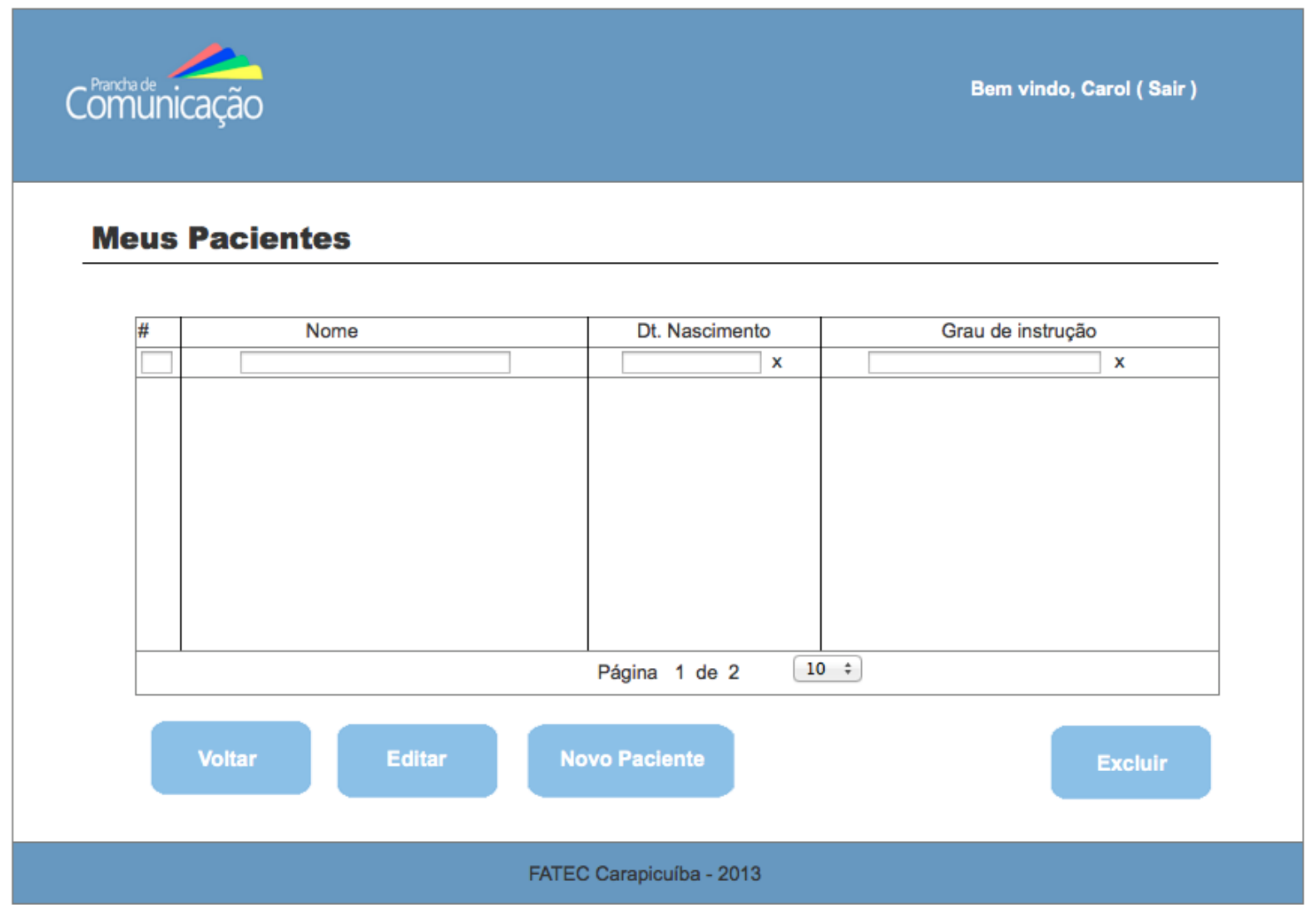

Fonte: Elaboração própria. 
Tela: Tutorial (Figura I.11).

Descrição: fornece ao usuário acesso a tutoriais do sistema.

\section{Campos:}

- Link - Criando uma prancha: fornece ao usuário informações de como criar uma prancha.

- Link - Acessando minhas pranchas: fornece ao usuário informações de como acessar pranchas existentes.

- Botão Voltar: permite ao usuário retornar para o menu de acesso.

Figura I.11 - Tutorial.

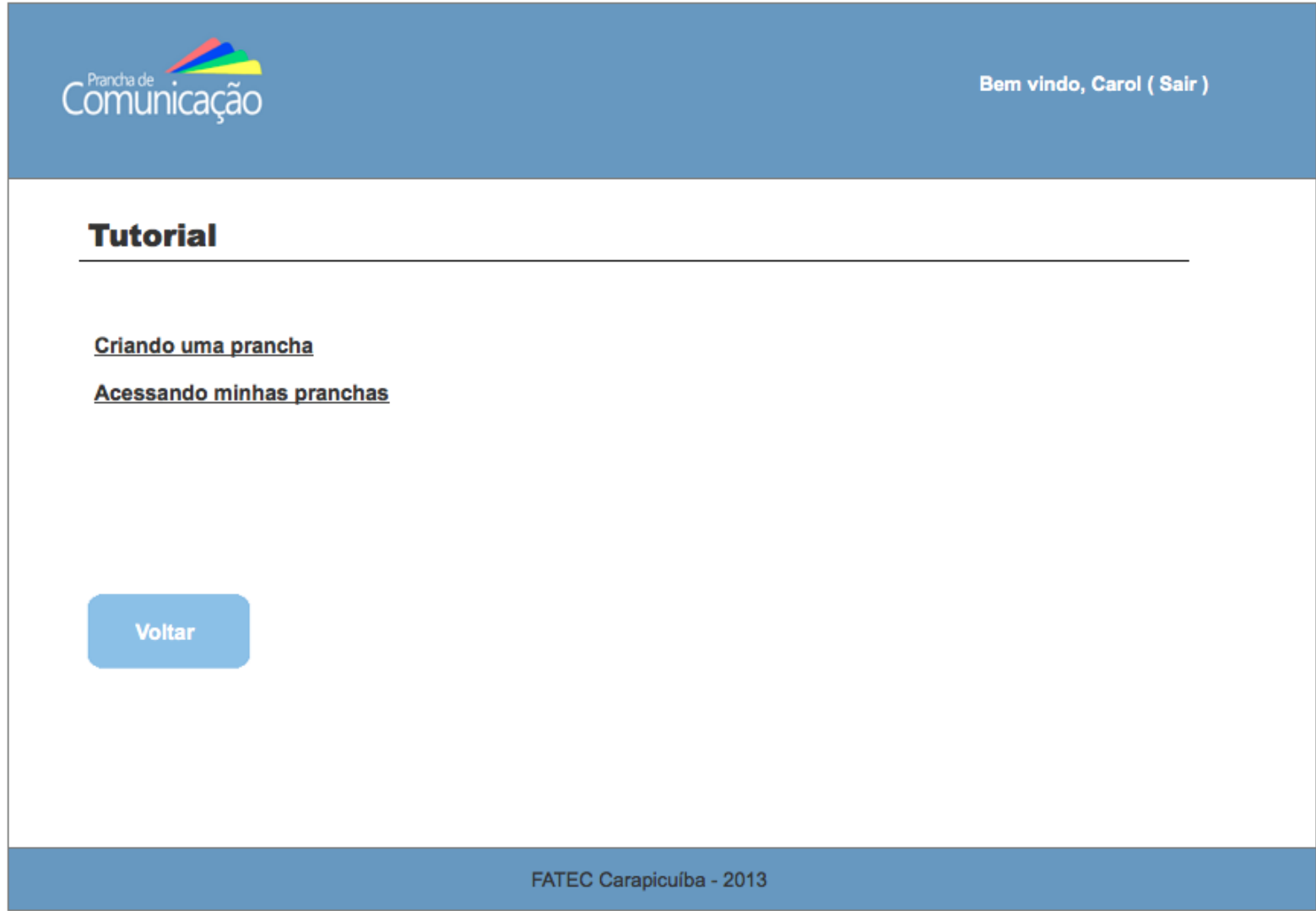

Fonte: Elaboração própria. 


\section{Anexo}

\section{Termo de Autorização de Uso de Imagem}

TERMO DE AUTORIZAÇÃO DE USO DE IMAGEM

Nome:

Nacionalidade:

E-mail:

Data de nascimento:

RG: CPF:

AUTORIZO o uso de minha imagem e/ou voz e/ou video para ser utilizada em uma pesquisa realizada de fins acadẻmicos, que servirá de estudo para o teste de uma aplicação web de reconhecimento das emoçōes expressas através da face. Sejam essas destinadas à divulgaçăo ao público em geral, desde que nảo haja desvirtuamento da sua finalidade. A presente autorizaçăo é concedida a título gratuito, abrangendo o uso da imagem e/ou voz e/ou video acima mencionado em todo território nacional e no exterior, em todas as suas modalidades e sem limite de tempo ou número de utilizaçōes. Por esta ser a expressäo da minha vontade declaro que autorizo o uso acima descrito sem que nada haja a ser reclamado a título de direitos conexos à minha imagem ou a qualquer outro, e assino a presente autorizaçäo em 2 (duas) vias de igual teor e forma. 


\section{Anexo}

\section{Termo de Autorização Institucional}

ESCOLA POLITÉCNICA DA UNIVERSIDADE DE SÃO PAULO

Departamento de Engenharia de Sistemas Eletrônicos

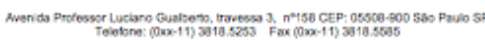

TERMO DE AUTORIZAÇÃO INSTITUCIONAL

Presidente Prudente, 16 de abril de 2015.

llustrissimo (a) Senhor (a)

EU, ANA CAROLINA NICOLOSI DA ROCHA GRACIOSO, aluna do programa de pós graduaçăo em Engenharia Elétrica da Escola Politécnica da USP em nivel de doutorado, venho pelo presente, solicitar vossa autorizaçăo para realizar na Associaçẫo de Pais e Amigos dos Excepcionais APAE de Presidente Prudente, estudos de campo para o trabalho de pesquisa inttuluado Avaliação das Emoçōes Humanas na Tomada de Decisão de Sistemas Computacionais Assistivos, orientado pelo Professor Dr. Francisco Javier Jamirez Fernandez.

O objetivo deste projeto de pesquisa é avaliar como as emoç̄es demonstradas através da mímica da face durante a utilização de um sistema computacional assistivo podem ser utlizadas na autoconfiguraçäo deste sistema visando melhorar a experiência do usuário. Para isso, serão realizados testes de utilizaçāo em sistemas assistivos, captando vídeos da face dos alunos durante os testes. Esta atividade nāo apresenta riscos aos participantes e está prevista para o periodo de 4 semanas.

Espera-se com esta pesquisa gerar dados nas áreas de visẫo computacional, sistemas afetivos e sistemas assistivos que permitam melhorar a experiência de usuários de sistemas computacionais assistivos. Qualquer informaçăo adicional poderá ser obtida junto aos pesquisadores através dos e-mails e telefones: carol.gracioso@usp.br. (11)98511-7540 e jramirez@ime.usp.br, (11)3091-5310 Ramal: 301.

Os dados obtidos serão utilizados na publicação de artigos científicos. Nos comprometemos a não publicar qualquer dado pessoal dos participantes como nome e endereço, por exemplo. Os videos captados durante os testes poderão ser utilizados em apresentações de cunho cientifico em congressos e na defesa da tese mediante autorização expressa por escrito do responsável legal dos alunos.

A participaçāo será voluntária, nảo fornecemos por ela qualquer tipo de pagamento. 


\section{ESCOLA POLITÉCNICA DA UNIVERSIDADE DE SÃO PAULO}

Departamento de Engenharia de Sistemas Eletrônicos

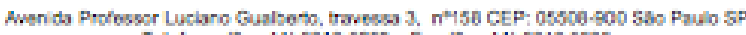

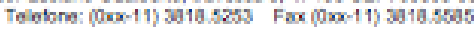

\section{Autorizaçāo Institucional}

Eu, UBIRATAN MARCHI FERNANDES presidente da Associação de Pais e Amigos dos Excepcionais APAE de Presidente Prudente declaro que fui informado dos objetivos da pesquisa acima, e concordo em autorizar a execuçāo da mesma nesta instituição. Caso necessário, a qualquer momento como instituiçāo CO-PARTICIPANTE desta pesquisa poderemos revogar esta autorizaçāo, se comprovada atividades que causem algum prejuizo à esta instituição ou aos alunos da mesma. Declaro também, que não recebemos qualquer pagamento por esta autorização bem como os participantes também não receberão qualquer tipo de pagamento.

Prof' Me. Ana Caroina N. da Rocha Graciose
(Pesquisadora)
(Pesquisadora)
Ubiratan Narchi Femandes (Responsavel pela Insthuigase)

Prot Dr. Francisco Javier Ramirez Fernandez

(Orientader) 


\section{Anexo}

\section{Termo de Consentimento para Uso de Imagem e Voz}

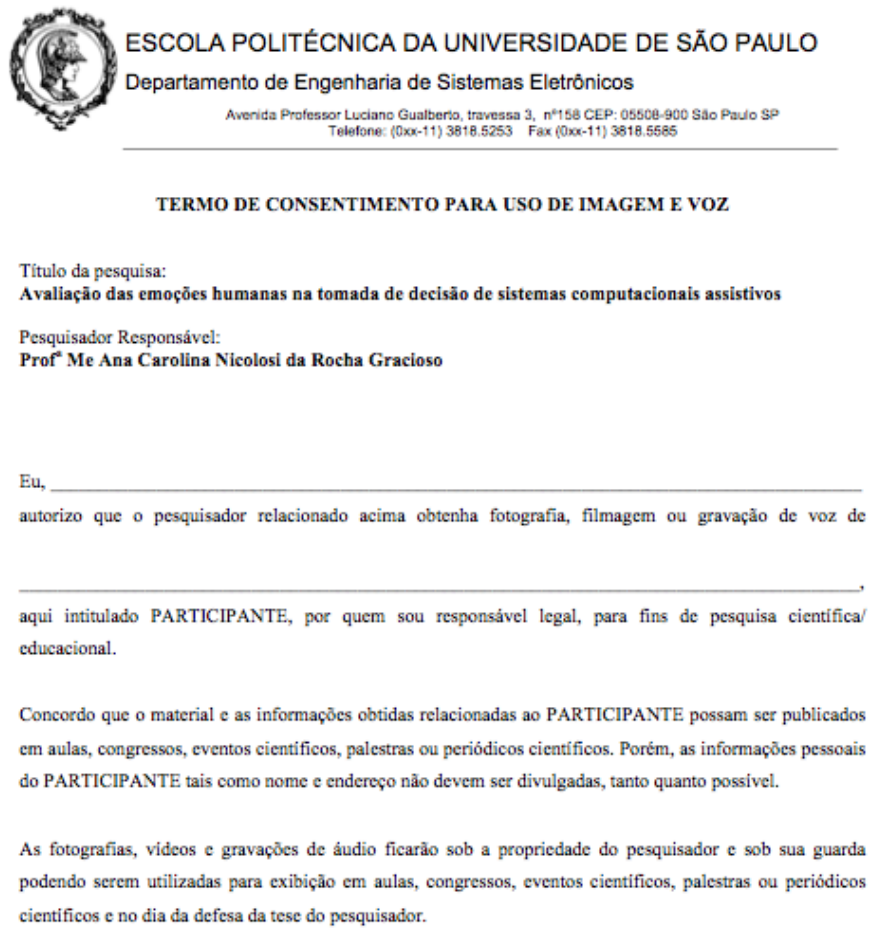

Presidente Prudente, de abril de 2015 . 


\section{Anexo}

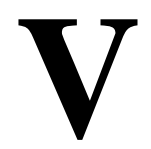

\section{Pranchas de Comunicação}

Prancha 01: Qual time você torce?

Figura V. 1 - Prancha 01: Time de Futebol.
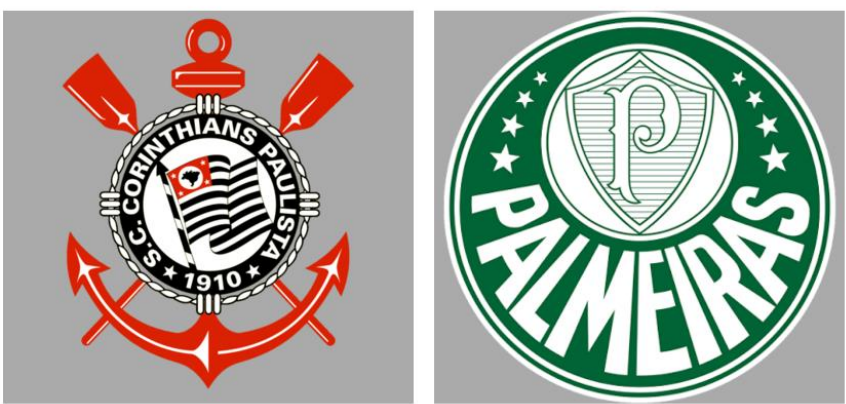

Fonte: Elaboração própria. 
Prancha 02: Qual é o desenho do Pato Donald/Mônica?

Figura V.2 - Prancha 02: Desenho Animado.

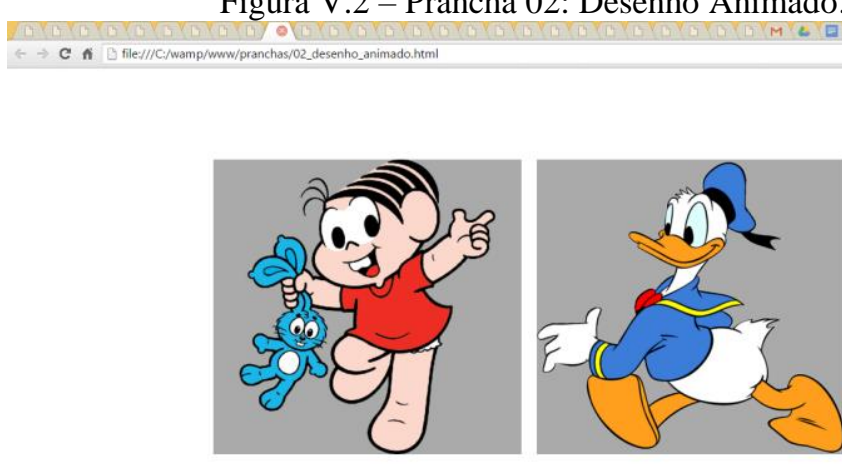

Fonte: Elaboração própria.

Prancha 03: Qual é o Cachorro/Gato/Pato?

Figura V.3 - Prancha 03: Animais Domésticos.
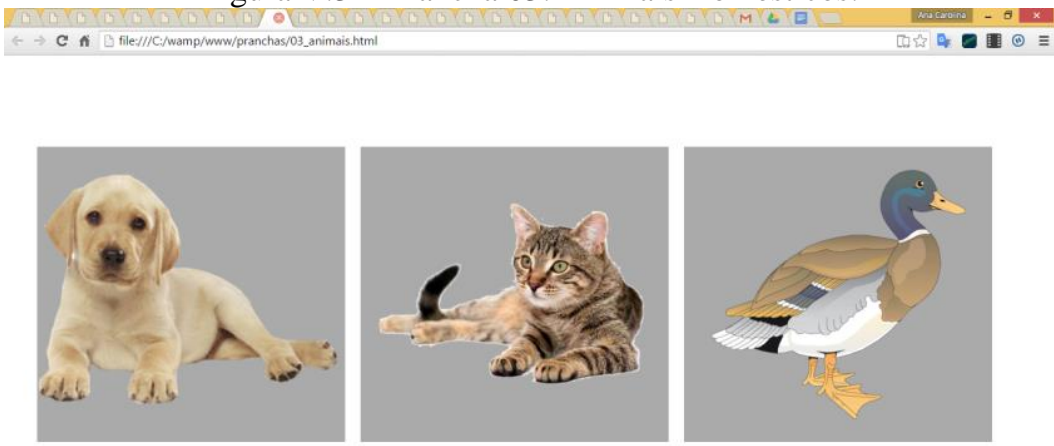

Fonte: Elaboração própria. 
04: Qual é o Carro/Boneca/Bola?

Figura V.4 - Prancha 04: Brinquedos.

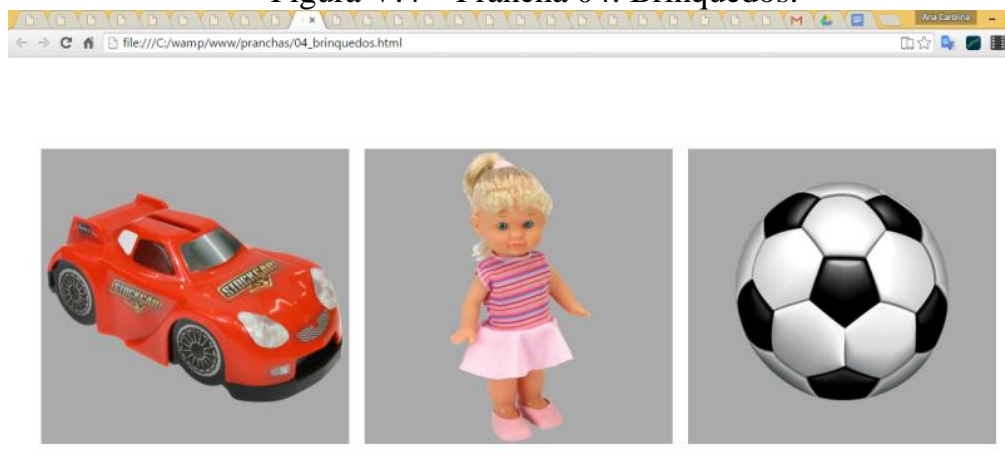

Fonte: Elaboração própria.

Prancha 05: Qual é a História da Cinderela/Branca de Neve/Patinho Feio?

Figura V.5 - Prancha 05: Histórias Infantis.
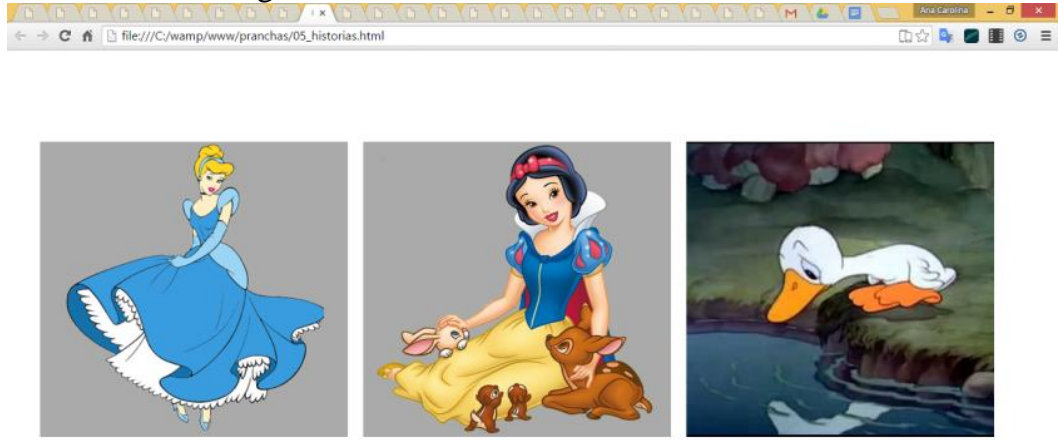

Fonte: Elaboração própria. 
Prancha 06: Qual é o Tomate/Alface/Cenoura?

Figura V.6 - Prancha 06: Salada.

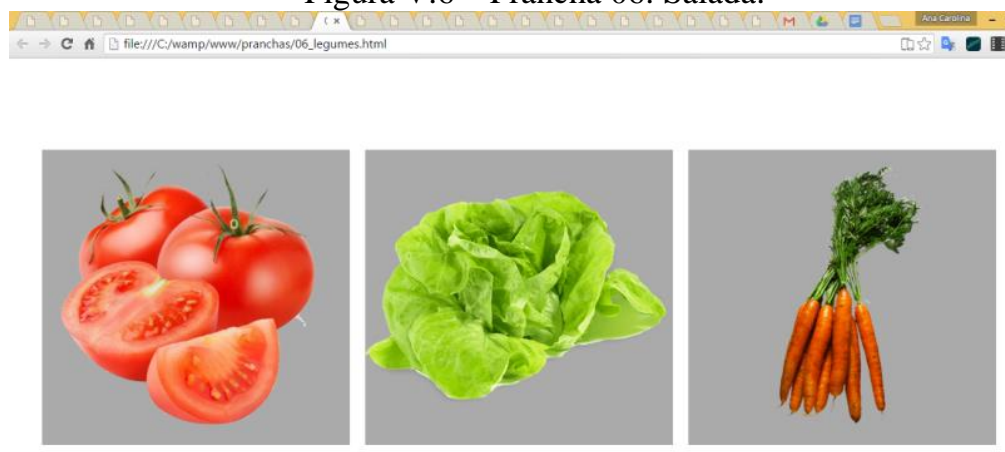

Fonte: Elaboração própria.

Prancha 07: Qual é a Banana/Maçã/Uva/Laranja?

Figura V.7 - Prancha 07: Frutas.

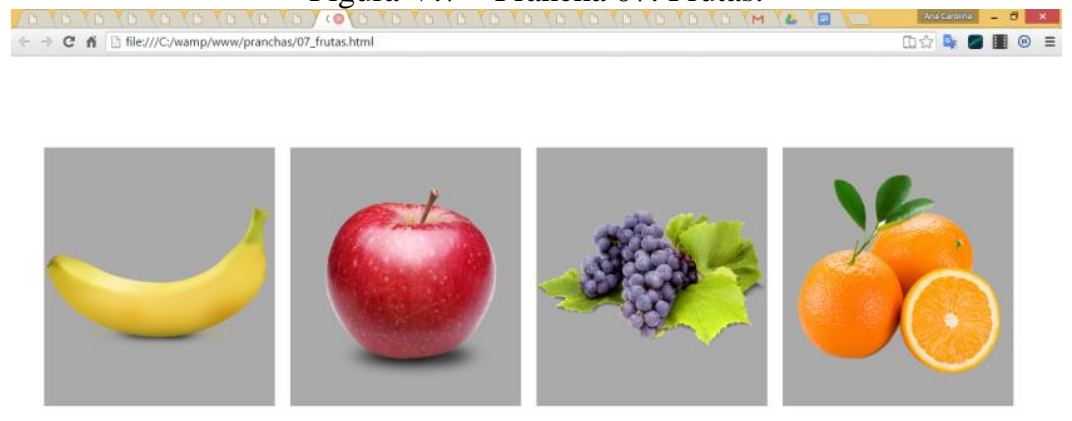

Fonte: Elaboração própria. 
Prancha 08: Qual é Macio/Áspero?

Figura V.8 - Prancha 08: Textura.

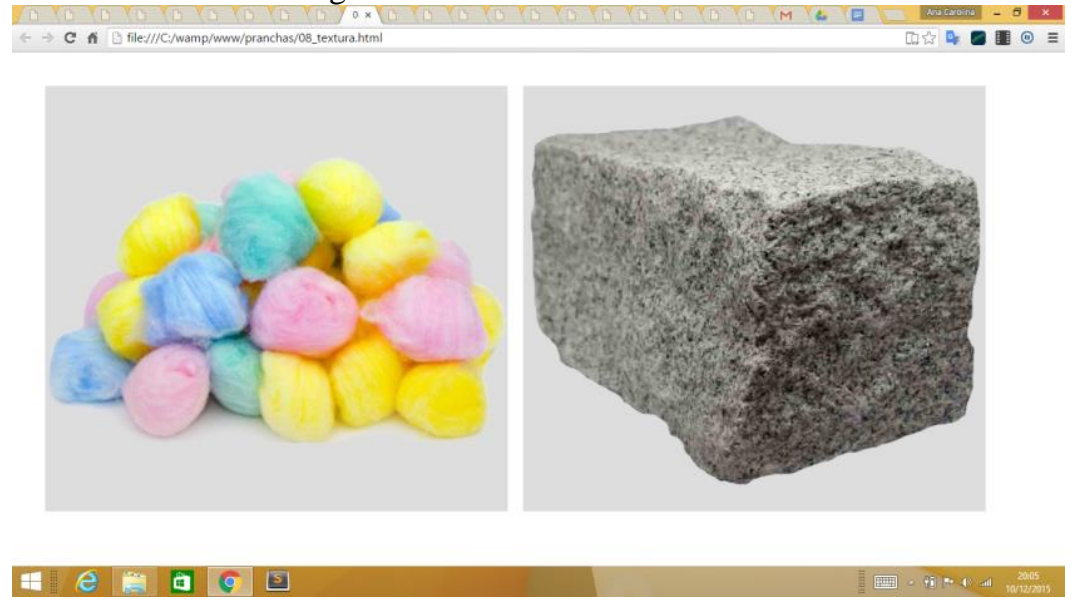

Fonte: Elaboração própria.

Prancha 09: Qual é o não Gritar/Bater?

Figura V.9 - Prancha 09: Comportamento.

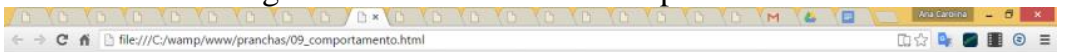

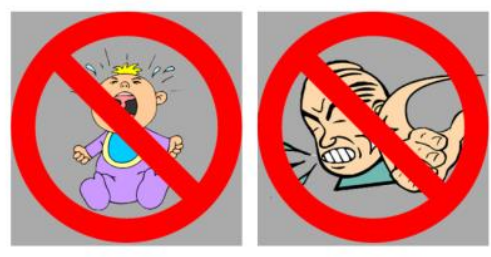

Fonte: Elaboração própria. 
Prancha 10: Qual representa a Páscoa/Carnaval/Índio?

Figura V. 10 - Prancha 10: Festas.

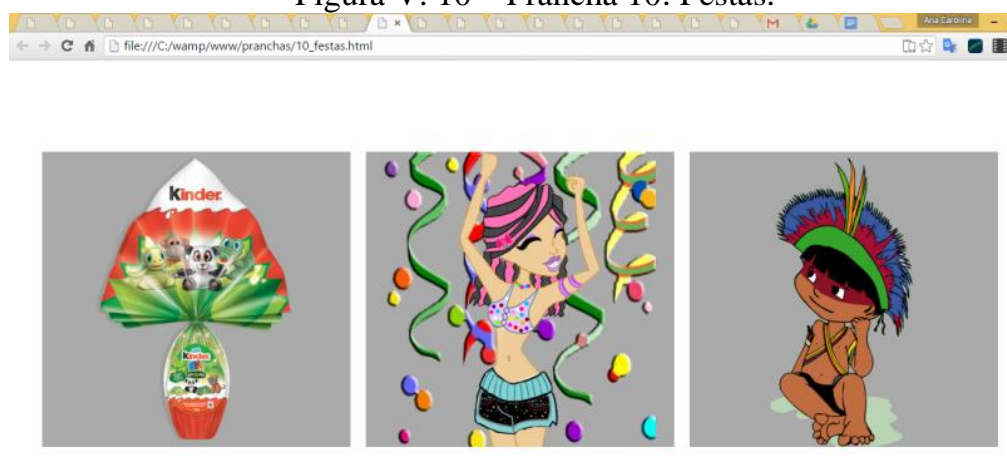

Fonte: Elaboração própria.

Prancha 11: Qual você usa para Cortar/Comer Salada/Tomar Sopa?

Figura V. 11 - Prancha 11: Talheres.

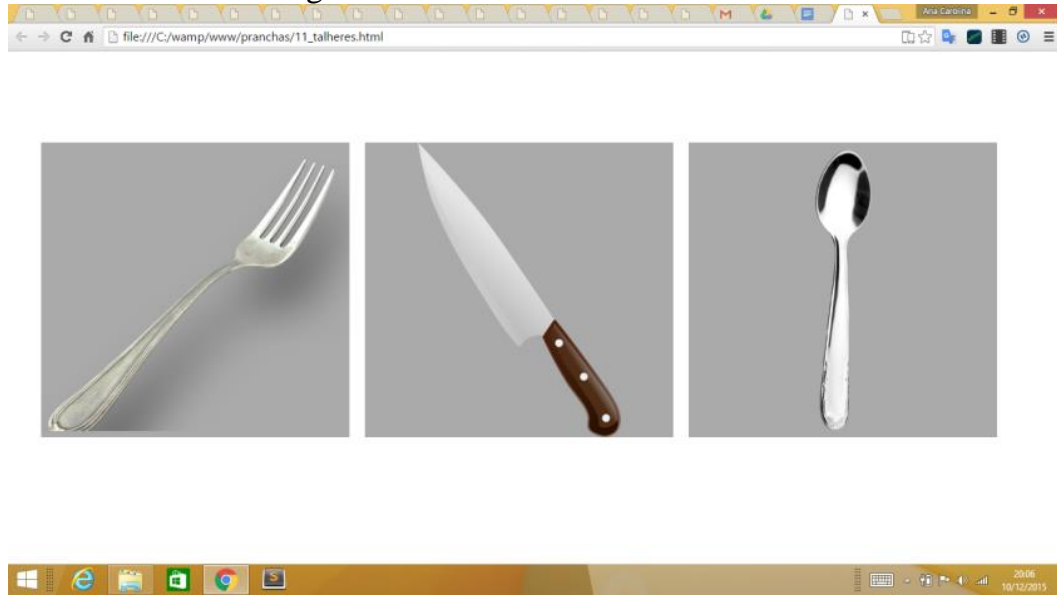

Fonte: Elaboração própria. 
Prancha 12: Onde está Frio/Calor/Chovendo?

Figura V.12 - Prancha 12: Tempo (clima).

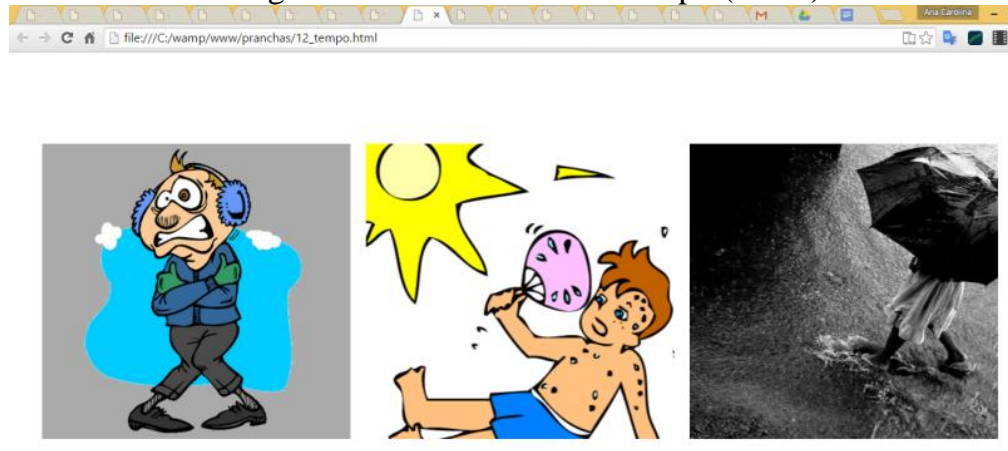

Fonte: Elaboração própria.

Prancha 13: Qual você usa para Escrever/Colar/Cortar/Colorir?

Figura V. 13 - Prancha 13: Material Escolar.

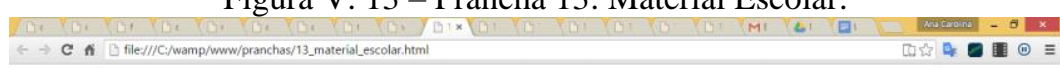
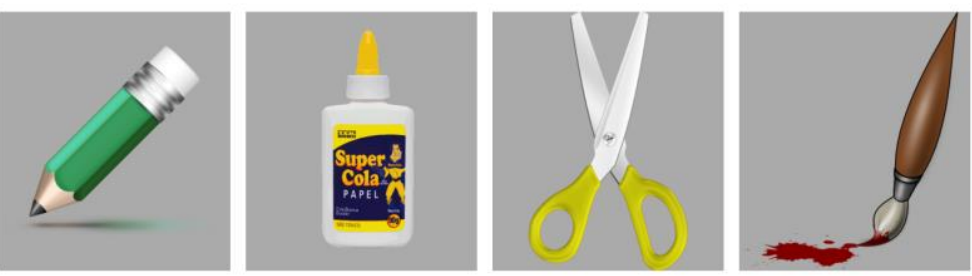

Fonte: Elaboração própria. 
Prancha 14: Qual ambiente está Bagunçado? Onde você toma banho?

Figura V.14 - Prancha 14: Ambientes Domésticos.

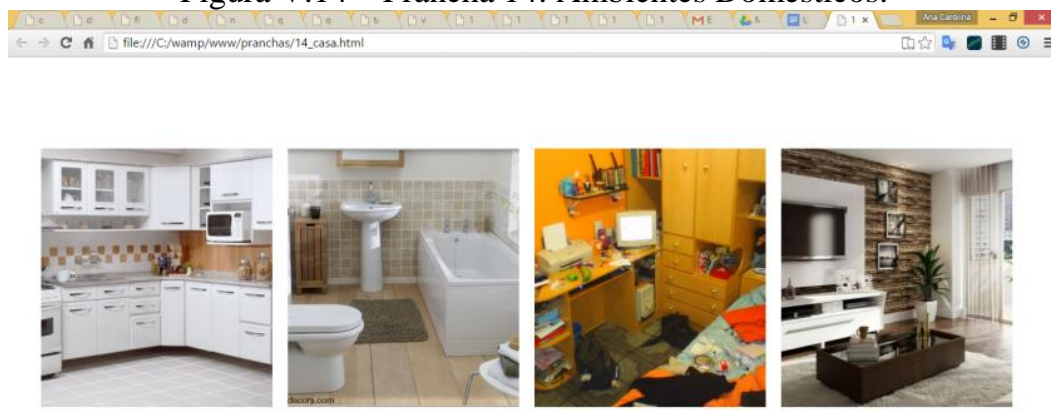

A 6 a

Fonte: Elaboração própria.

Prancha 15: Quem está Feliz/Triste/Com Medo/Com Raiva?

Figura V. 15 - Prancha 15: Emoções.

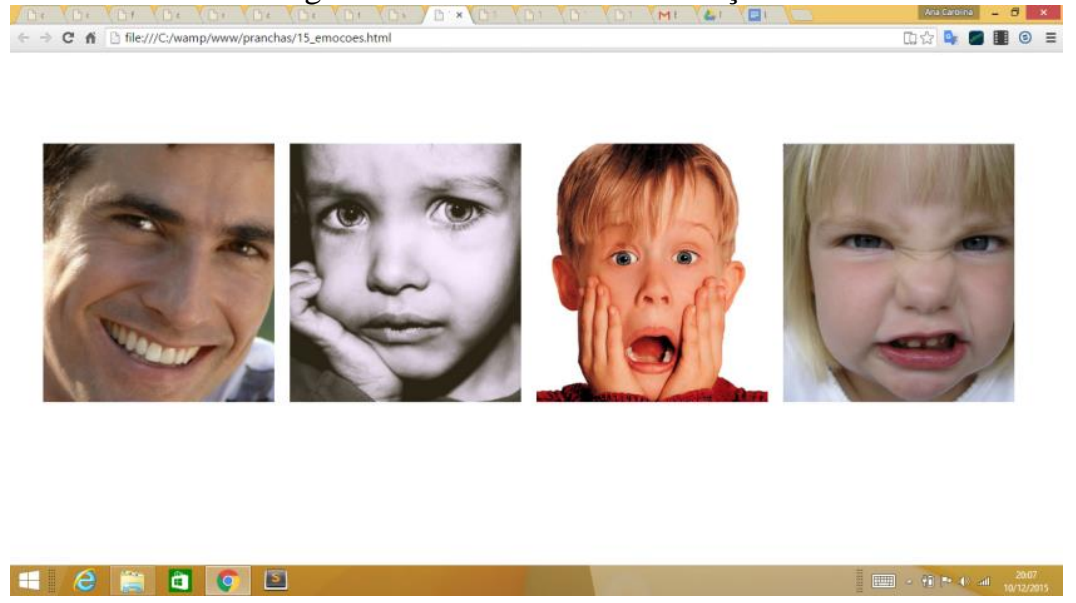

Fonte: Elaboração própria. 
Prancha 16: Quem está Lavando as Mãos/Escovando os Dentes/Tomando Banho/Penteando o Cabelo?

Figura V. 16 - Prancha 16: Higiene Pessoal.

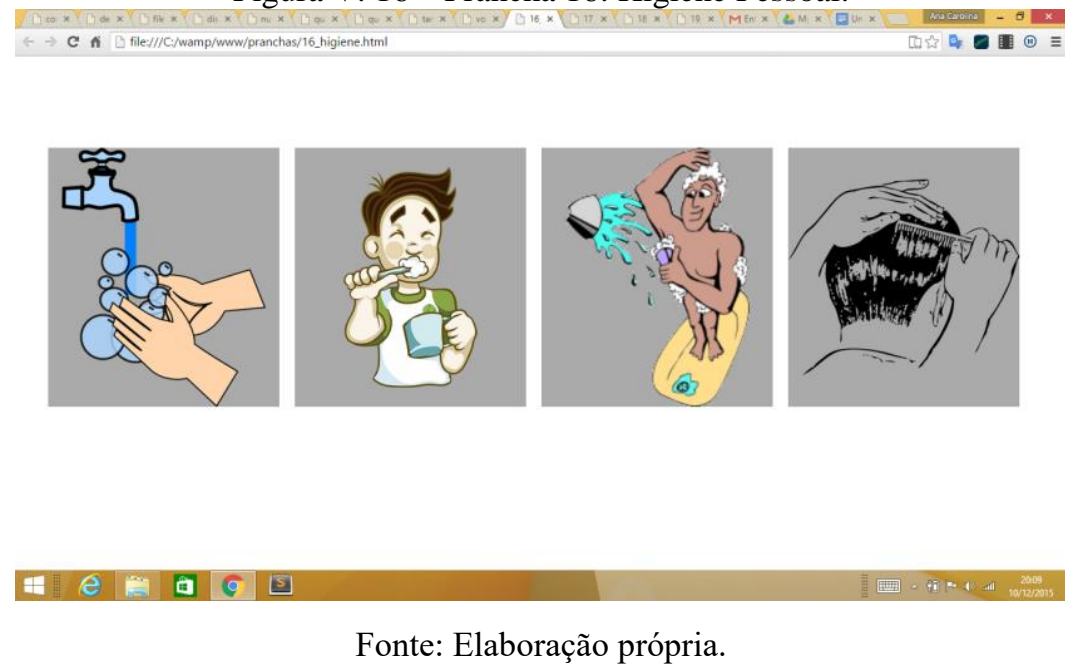

Prancha 17: Qual você usa para Transportar/Aguar Horta/Cavar/Rastelar/Aguar o Vaso/Tirar o Mato?

Figura V. 17 - Prancha 17: Materiais de Trabalho na Horta.

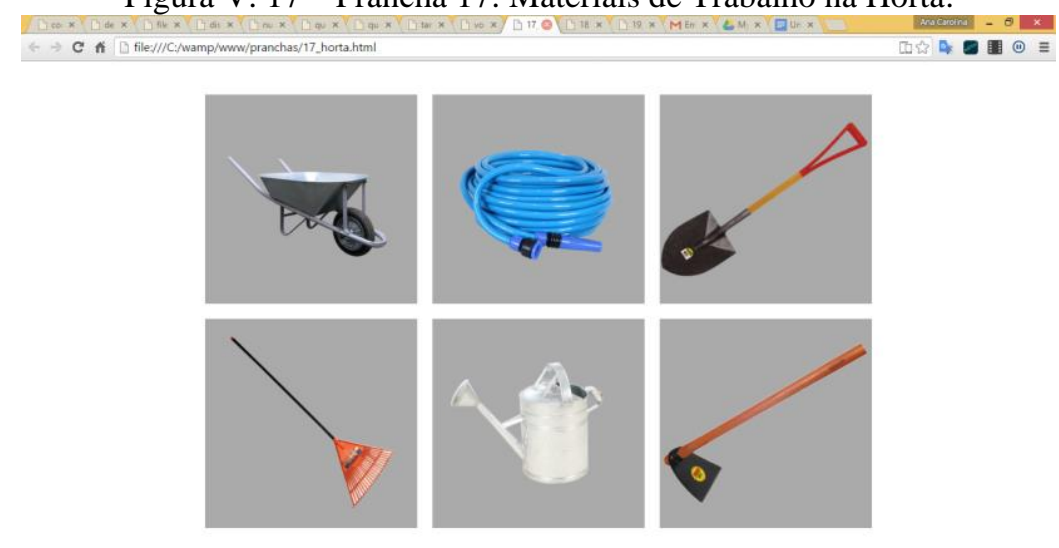

Fonte: Elaboração própria. 
Prancha 18: Qual você usa para Pegar Água/Lavar Roupa/Varrer/Rodar/Quais dois usa para Lavar Louça?

Figura V.18 - Prancha 18: Materiais de Limpeza.

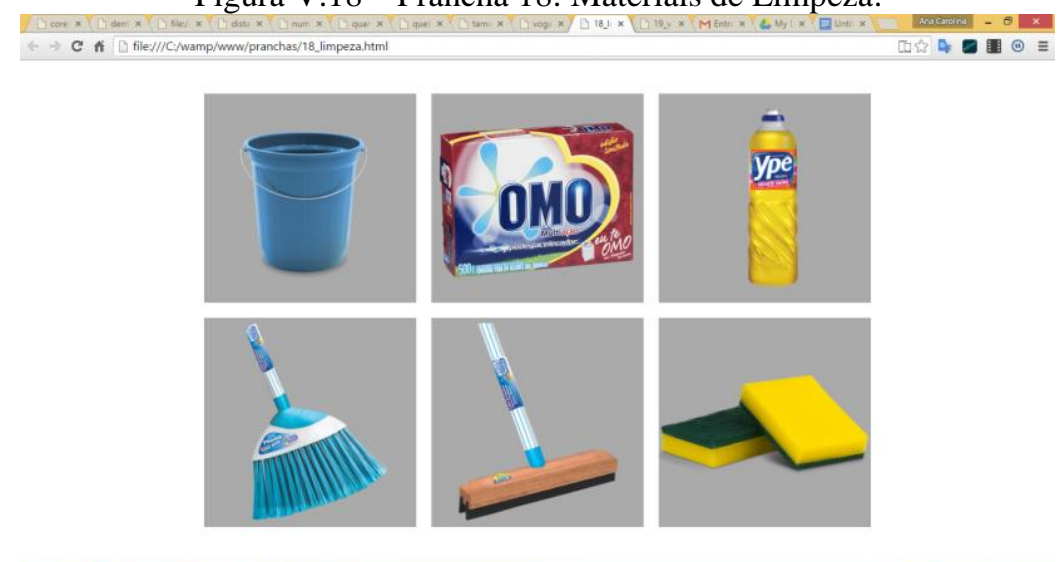

Fonte: Elaboração própria.

Prancha 19: Qual você usa no Frio/Calor? Qual você usa nos Pés/Mãos? Qual você usa na Praia? Quais são de Homem/Mulher?

Figura V.19 - Prancha 19: Vestimentas e Calçados.

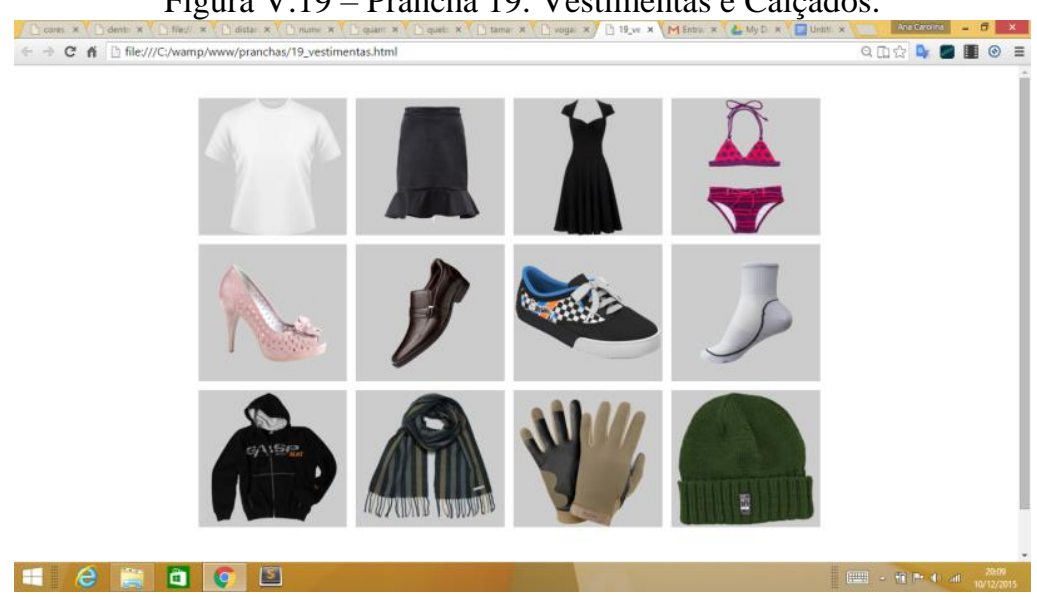

Fonte: Elaboração própria. 
Prancha 20: Qual cachorro está Dentro/Fora da casinha?

Figura V. 20 - Prancha 20: Localização (dentro e fora).

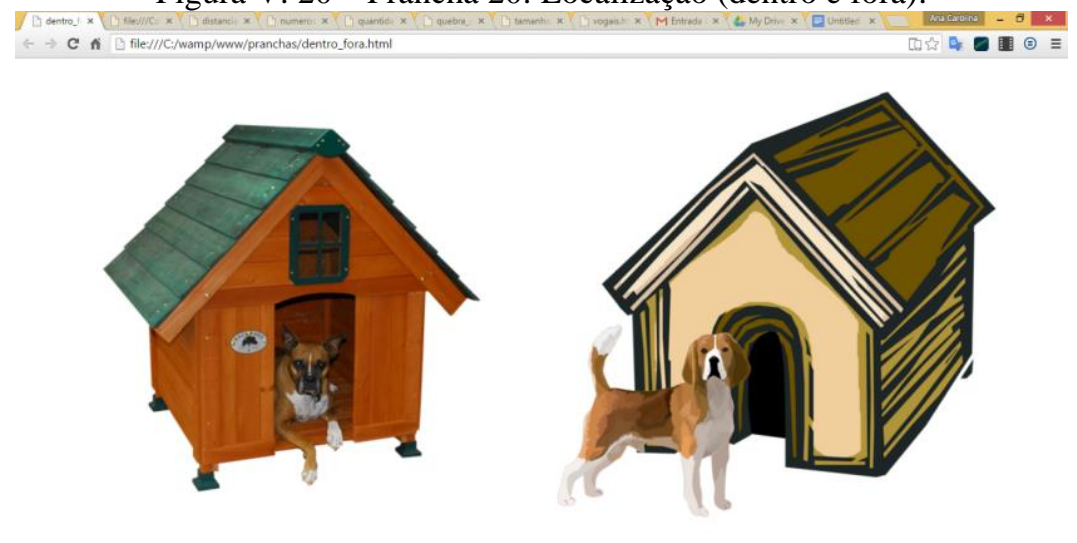

Fonte: Elaboração própria.

Prancha 21: Qual menino está com a bola Longe/Perto do pé?

Figura V.21 - Prancha 21: Localização (longe e perto).

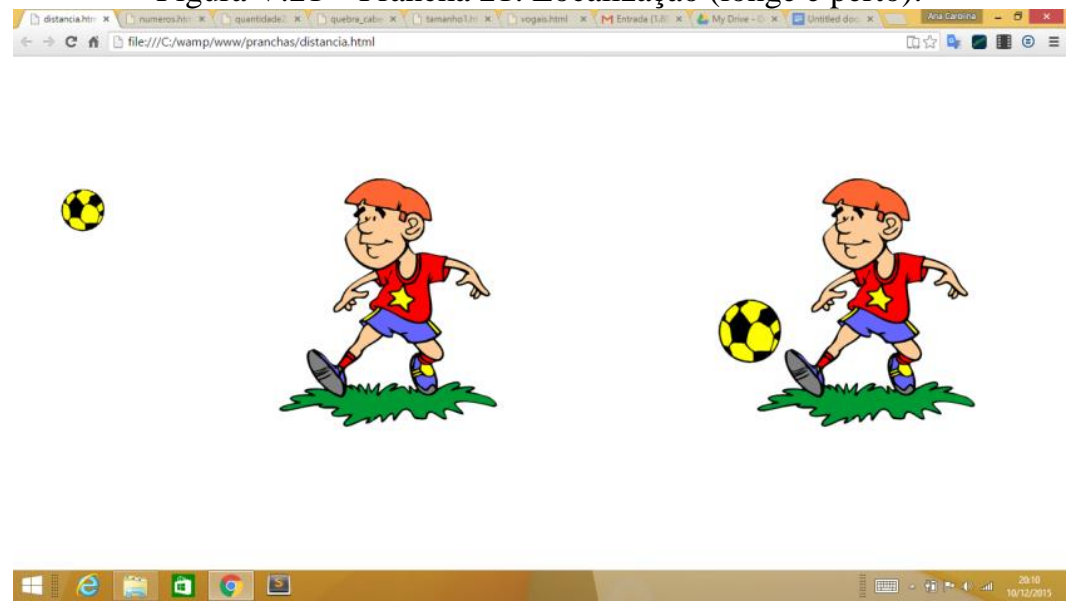

Fonte: Elaboração própria. 
Prancha 22: Qual onde tem Mais/Menos maçãs?

Figura V.22 - Prancha 22: Quantidade (mais/menos).

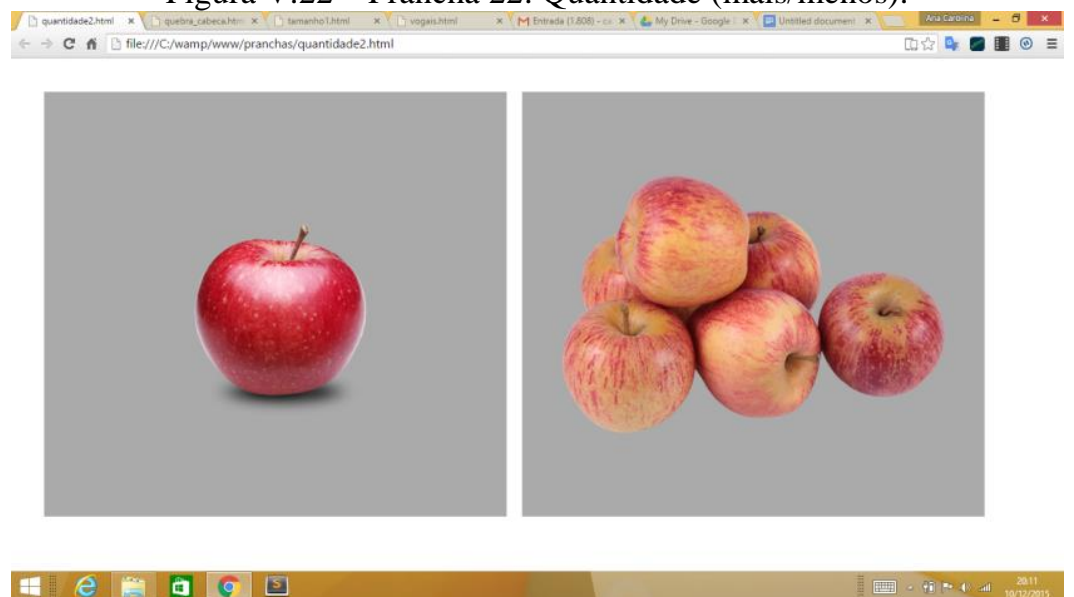

Fonte: Elaboração própria.

Prancha 23: Qual maçã é Maior/Menor?

Figura V.23 - Prancha 23: Tamanho (grande/pequeno).

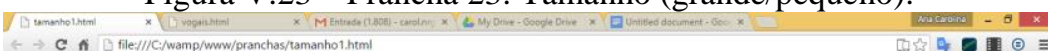

$x \rightarrow c$ ก

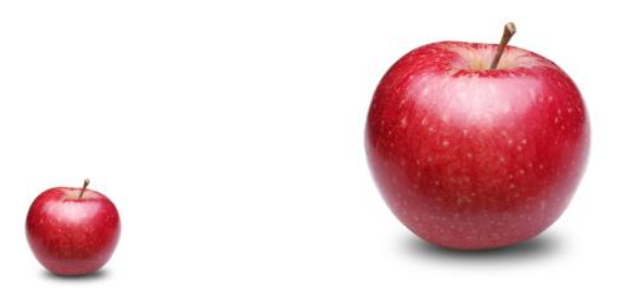

Fonte: Elaboração própria. 
Prancha 24: Qual é o Preto/Vermelho/Verde/Azul/Amarelo/Rosa?

Figura V.24 - Prancha 24: Cores.

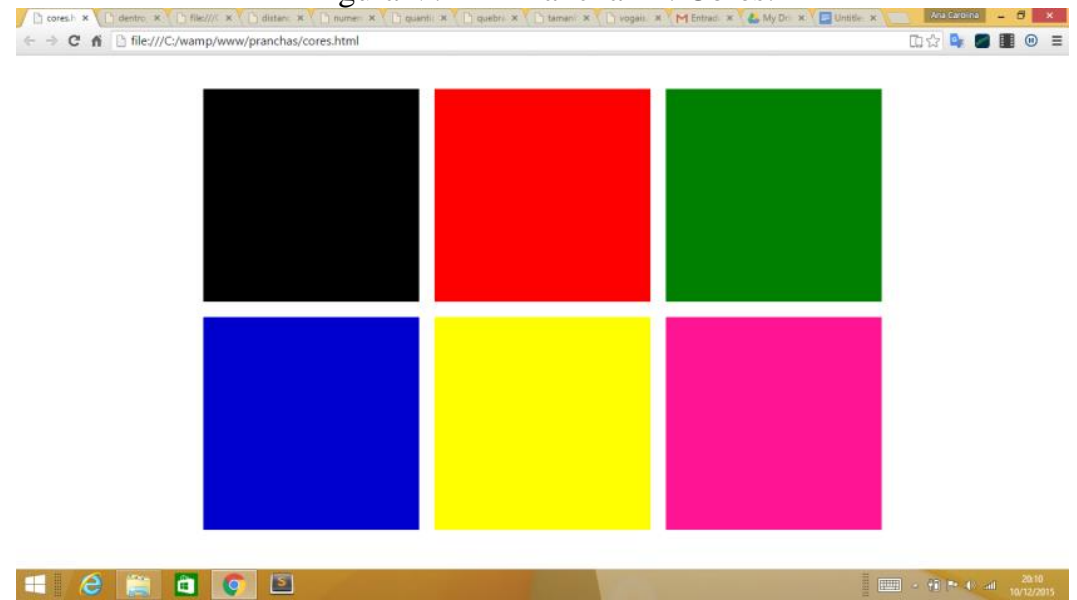

Fonte: Elaboração própria.

Prancha 25: Qual figura de baixo se encaixa na de cima?

Figura V.25 - Prancha 25: Quebra-cabeça.

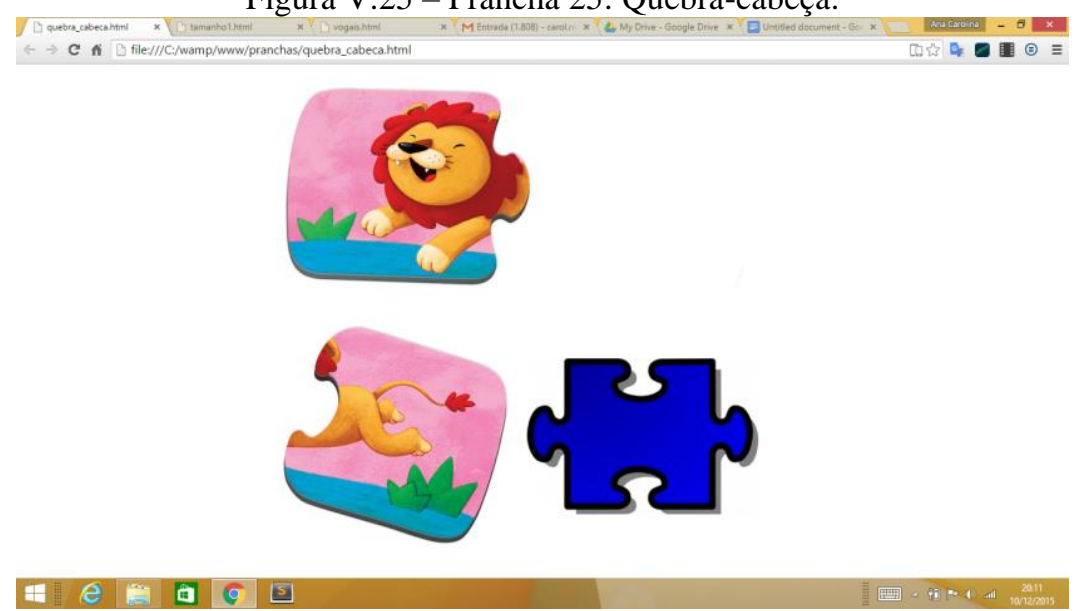

Fonte: Elaboração própria. 
Prancha 26: Qual é o número 1/2/3/4?

Figura V. 26 - Prancha 26: Números.

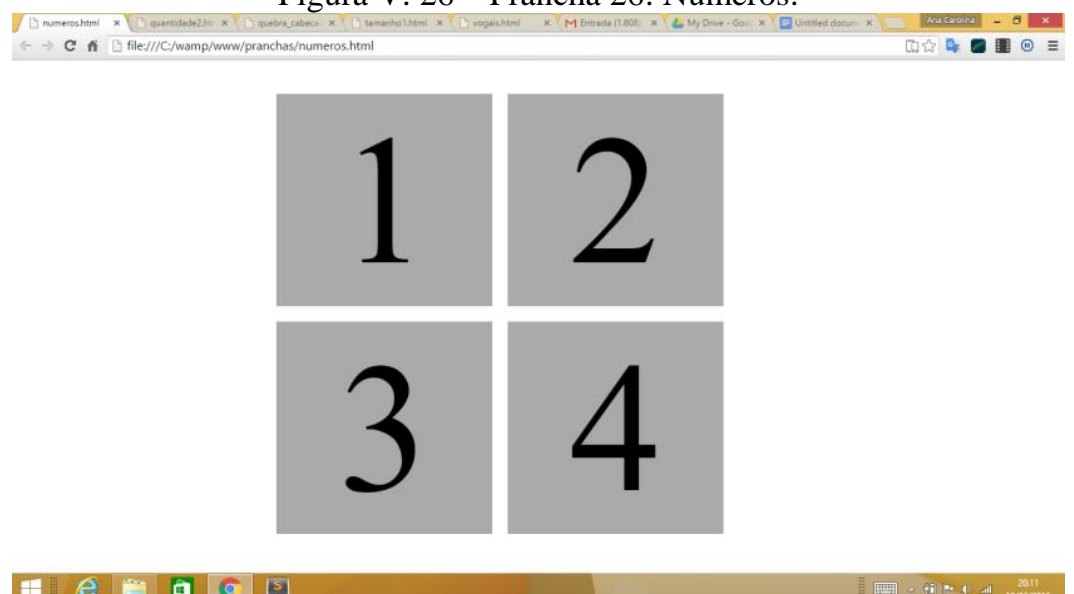

Fonte: Elaboração própria.

Prancha 27: Qual é a vogal A/E/I/O/U?

Figura V. 27 - Prancha 27: Vogais.

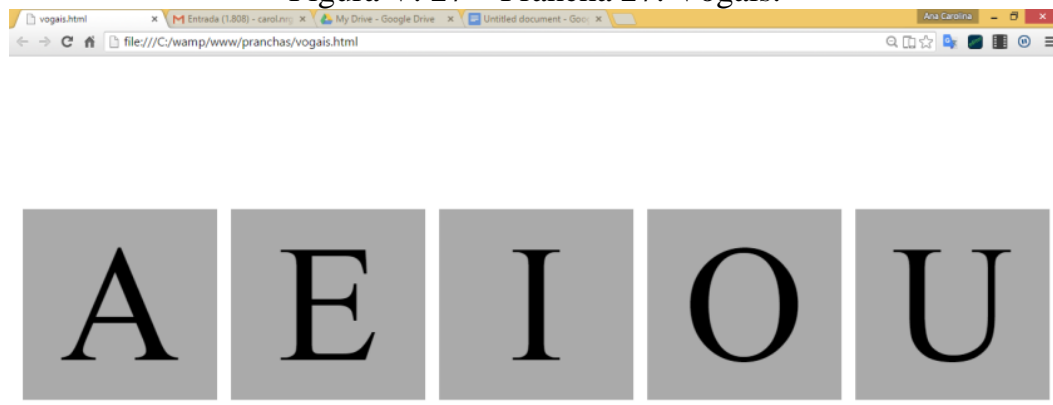

Fonte: Elaboração própria. 


\section{Anexo}

\section{Arquivos EML dos Estudos de Caso}

\section{Estudo de Caso 1:}

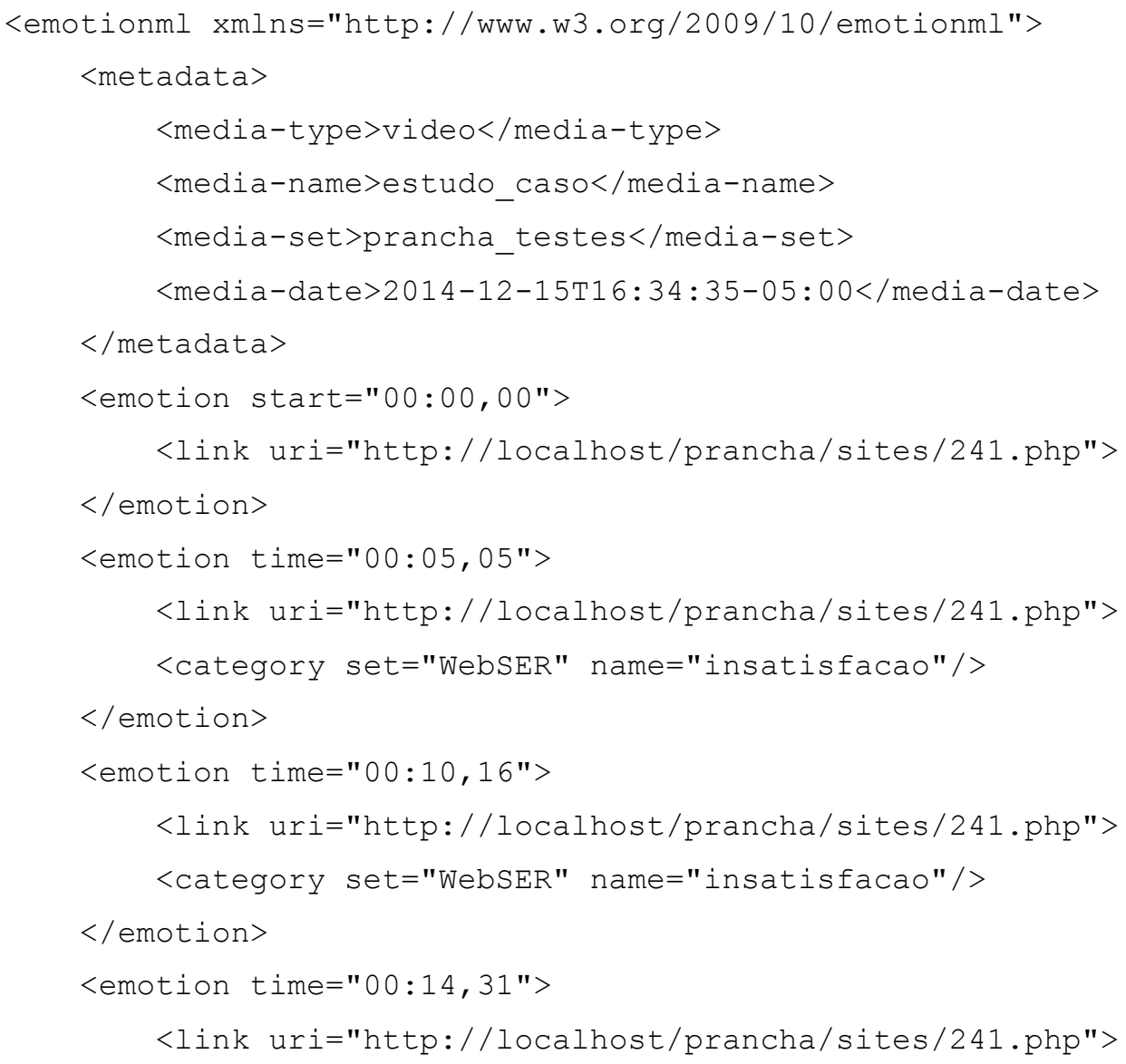




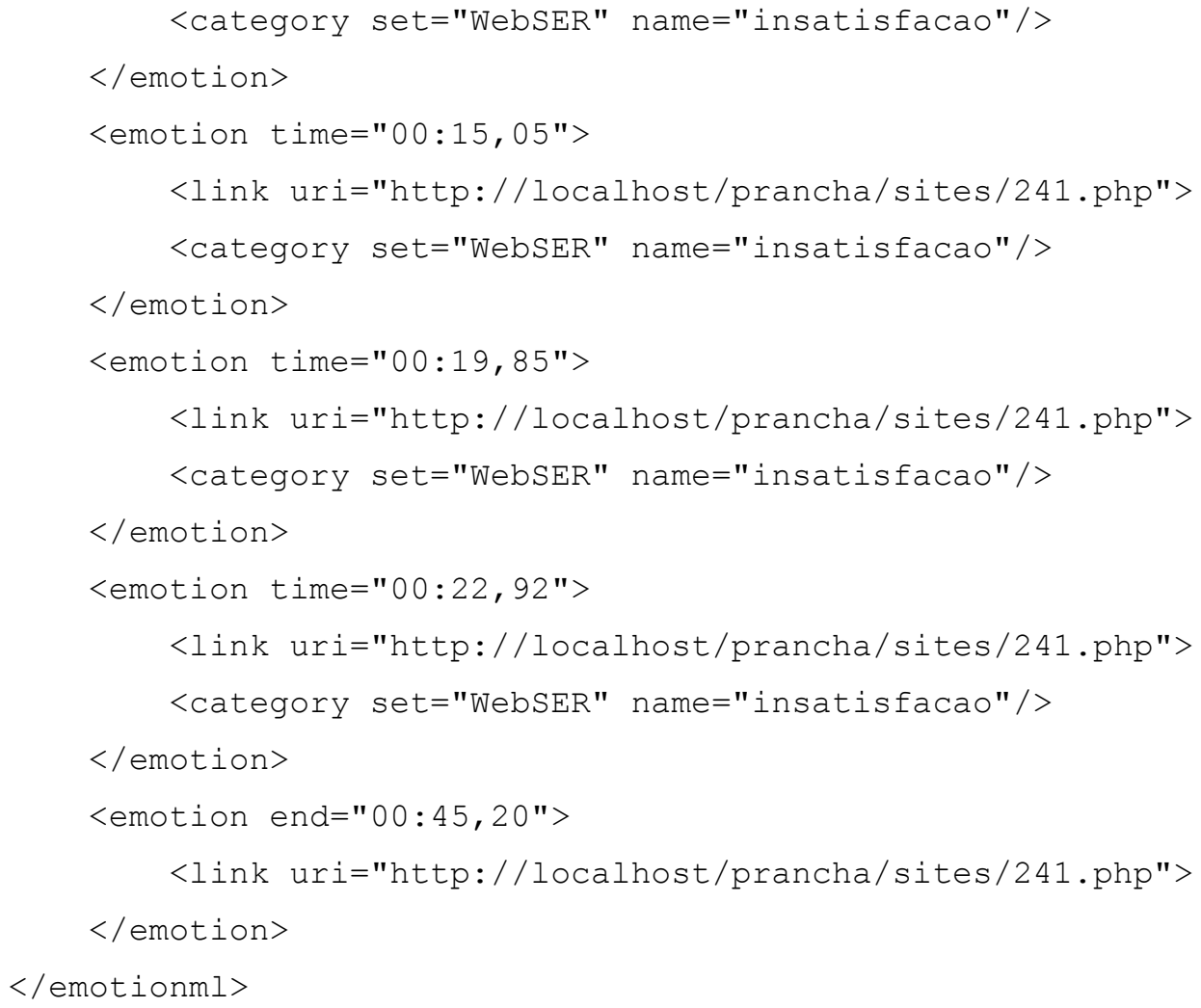

\section{Estudo de Caso 2:}

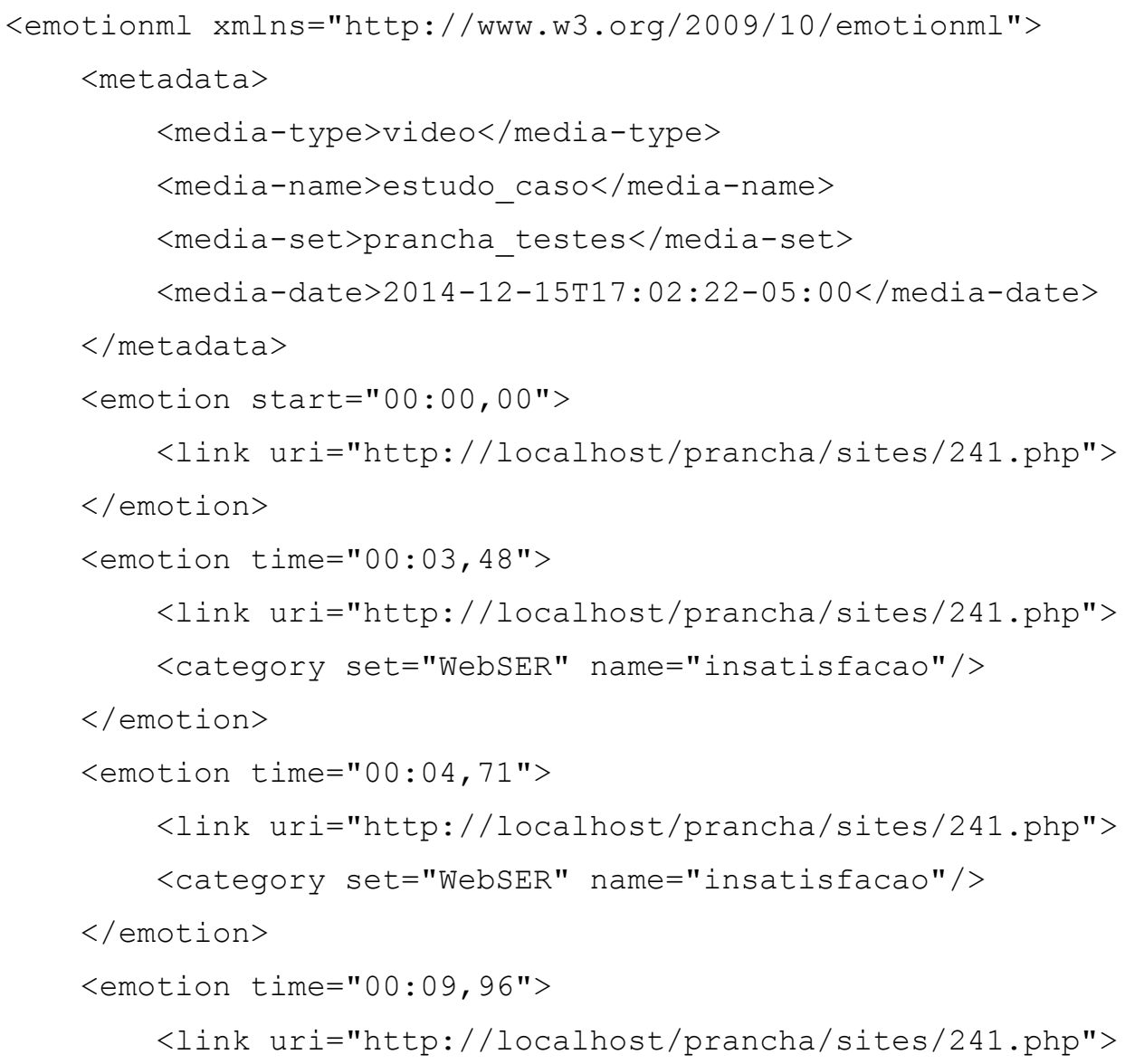




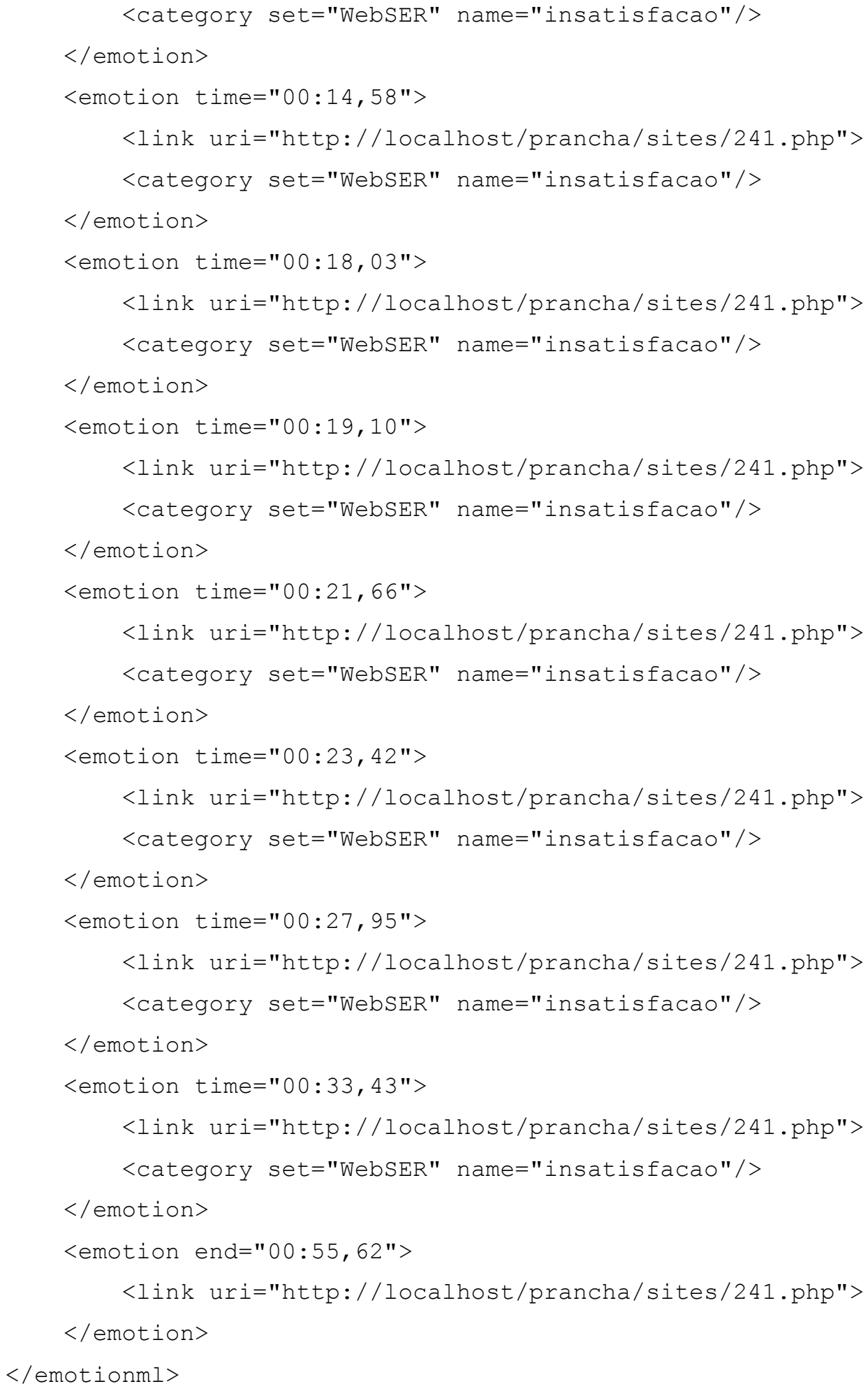

\section{Estudo de Caso 3:}

<emotionml xmlns="http://www.w3.org/2009/10/emotionml">

$<$ metadata $>$

$<$ media-type $>$ video $</$ media-type $>$

$<$ media-name>estudo_caso $</$ media-name $>$ 


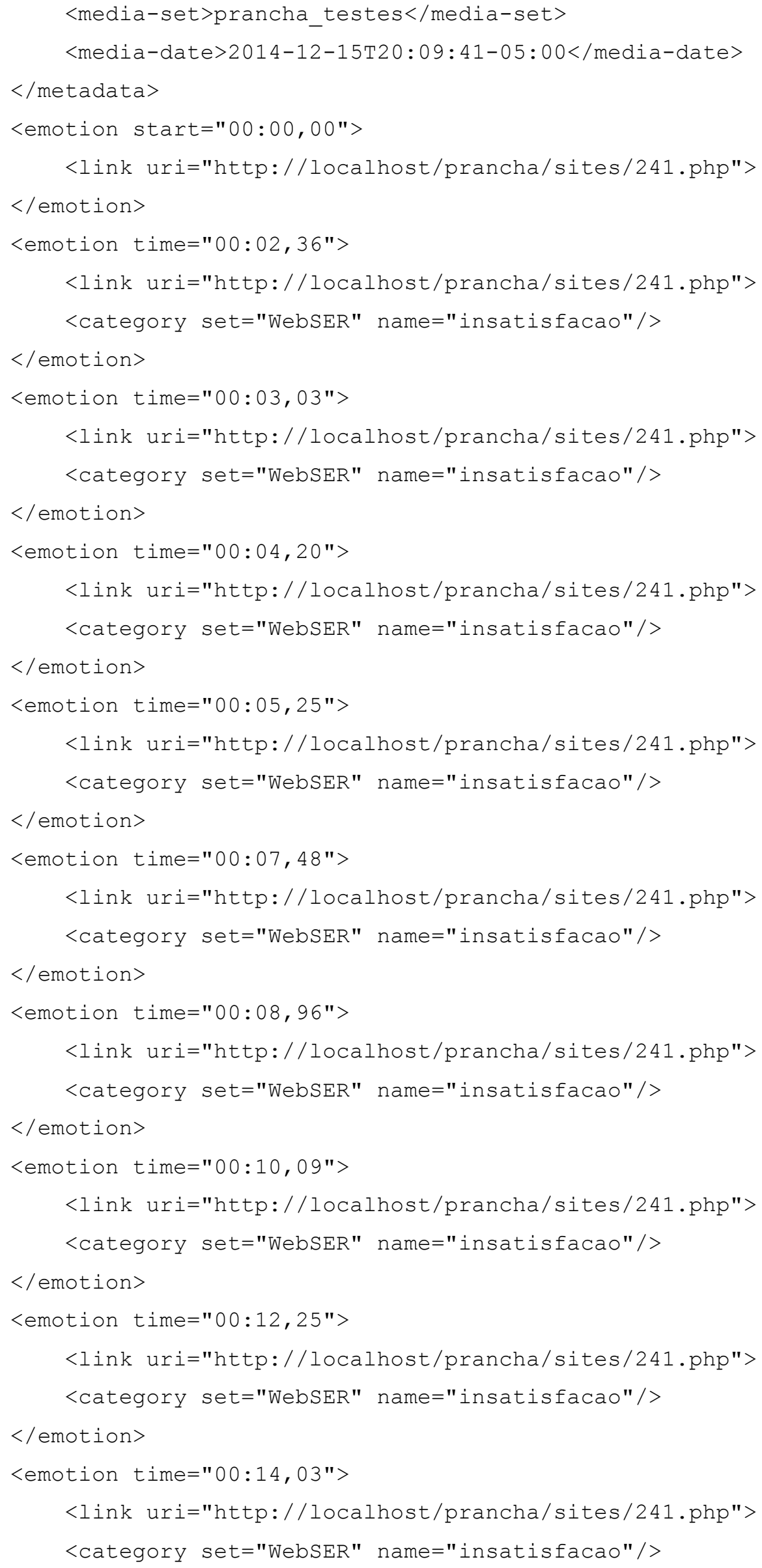


$</$ emotion $>$

<emotion time="00:21,78">

<link uri="http://localhost/prancha/sites/241.php">

<category set="WebSER" name="insatisfacao"/>

$</$ emotion $>$

<emotion end="00:46,05">

<link uri="http://localhost/prancha/sites/241.php">

$</$ emotion $>$

$</$ emotionml> 